\title{
CATALYTIC SYNTHESIS OF OXYGENATES: Mechanisms, Catalysts and Controlling Characteristics
}

\author{
Kamil Klier and Richard G. Herman \\ Department of Chemistry \\ 6 E. Packer Ave. \\ Lehigh University \\ Bethlehem, PA 18015 \\ Final Technical Progress Report \\ for \\ Research Project No. DE-FG02-01ER15181 \\ September 1, 2001-August 31, 2005 \\ to \\ U. S. Department of Energy \\ Chemical Sciences, Geosciences, and Biosciences Division \\ Office of Basic Energy Sciences
}

November 30, 2005 


\title{
CATALYTIC SYNTHESIS OF OXYGENATES: Mechanisms, Catalysts and Controlling Characteristics
}

\begin{abstract}
Acknowledgment
This material is based upon work supported by the U. S. Department of Energy under Award No. DE-FG02-01ER15181.
\end{abstract}

\section{Disclaimer}

This report was prepared as an account of work sponsored by an agency of the United States Government. Neither the United State Government nor any agency thereof, nor any of their employees, makes any warranty, express or implied, or assumes any legal liability or responsibility for the accuracy, completeness, or usefulness of any information, apparatus, product, or process disclosed, or represents that its use would not infringe privately owned rights. Reference herein to any specific commercial product, process, or service by trade name, trademark, manufacturer, or otherwise does not necessarily constitute or imply its endorsement, recommendation, or favoring by the United States Government or any agency thereof. Any opinions, findings, and conclusions or recommendations expressed in this material are those of the authors and do not necessarily reflect the views of the United States Department of Energy. 


\section{CATALYTIC SYNTHESIS OF OXYGENATES: Mechanisms, Catalysts and Controlling Characteristics}

\section{EXECUTIVE SUMMARY}

This research focused on catalytic synthesis of unsymmetrical ethers as a part of a larger program involving oxygenated products in general, including alcohols, ethers, esters, carboxylic acids and their derivatives that link together environmentally compliant fuels, monomers, and high-value chemicals. The catalysts studied here were solid acids possessing strong Brønsted acid functionalities. The design of these catalysts involved anchoring the acid groups onto inorganic oxides, e.g. surface-grafted acid groups on zirconia, and a new class of mesoporous solid acids, i.e. propylsulfonic acid-derivatized SBA-15. The former catalysts consisted of a high surface concentration of sulfate groups on stable zirconia catalysts. The latter catalyst consists of high surface area, large pore propylsulfonic acidderivatized silicas, specifically SBA-15. In both cases, the catalyst design and synthesis yielded high concentrations of acid sites in close proximity to one another. These materials have been well-characterization in terms of physical and chemical properties, as well as in regard to surface and bulk characteristics. Both types of catalysts were shown to exhibit high catalytic performance with respect to both activity and selectivity for the bifunctional coupling of alcohols to form ethers, which proceeds via an efficient $\mathrm{S}_{\mathrm{N}} 2$ reaction mechanism on the proximal acid sites. This commonality of the dual-site $\mathrm{S}_{\mathrm{N}} 2$ reaction mechanism over acid catalysts provides for maximum reaction rates and control of selectivity by reaction conditions, i.e. pressure, temperature, and reactant concentrations. This research provides the scientific groundwork for synthesis of ethers for energy applications. The synthesized environmentally acceptable ethers, in part derived from natural gas via alcohol intermediates, exhibit high cetane properties, e.g. methylisobutylether with cetane No. of 53 and dimethylether with cetane No. of 55-60, or high octane properties, e.g. diisopropylether with blending octane No. of 105 , and can replace aromatics in liquid fuels. 
Cover Page

Acknowledgment and Disclaimer

EXECUTIVE SUMMARY

Table of Contents

List of Tables

List of Figures

ABSTRACT

I. A Novel $(\mathrm{OH})_{3} \mathrm{ZrO}_{3} \mathrm{SO}-\mathrm{CH}_{2} \mathrm{CH}_{2}-\mathrm{OSO}_{3} \mathrm{Zr}(\mathrm{OH})_{3}$-Derived Catalyst for Ether Synthesis: Synthesis and Characterization of $\left[\mathrm{NaO}_{3} \mathrm{SO}-\mathrm{CH}_{2} \mathrm{CH}_{2}-\mathrm{OSO}_{3} \mathrm{Na}\right]$ and its Anchored Form, the Surface-grafted Acid Groups on Zirconium Hydroxide

1. Introduction 19

2. Experimental Section 20

2.1. Sample Preparation 20

2.1.1. Precursor 20

2.1.2. The Anchored Precursor 20

2.1.3. The Surface-Grafted Acid Groups 20

2.2. Characterization of Samples 20

2.2.1. Near-Infrared Diffuse Reflectance Spectroscopy $\quad 20$

2.2.2. High Resolution X-ray Photoelectron Spectroscopy 21

2.2.3. Quantitative Analysis of HR-XPS Data 21

2.2.4. ${ }^{1} \mathrm{H}$ NMR and ${ }^{13} \mathrm{C}$ Solid State MAS NMR Spectroscopies

2.2.5. Determination of Surface Area and Acid Exchange Capacities

3. Results and Discussion

3.1. ${ }^{1} \mathrm{H}$ NMR and ${ }^{13} \mathrm{C}$ Solid State MAS NMR Characterization of the Precursor and the Anchored Precursor 22

3.1.1. ${ }^{1} \mathrm{H}$ NMR Studies of the Precursor 22

3.1.2. ${ }^{13} \mathrm{C}$ MAS NMR Studies of the Precursor and the Anchored Precursor 
3.2. NIR-DRS Characterization of the Precursor and the Anchored Precursor, and MMFF Simulation of the $\mathrm{C}-\mathrm{H}$ Vibrations

3.3 HR-XPS Characterization of the Precursor and the Anchored Precursor

3.3.2. HR-XPS Analysis of the Anchored Precursor

4. Conclusions

5. References to Chapter I

II. Sulfonic Acid-Functionalized Mesoporous Silica: Synthesis, Characterization, and Catalytic Reaction of Alcohol Coupling to Ethers

1. Synthesis Technique 32

2. X-Ray Powder Diffraction 33

3. High resolution X-ray photoelectron spectroscopy 33

4. Surface Area and Surface Acid Concentration 34

5. Catalytic Testing 34

6. References to Chapter II 39

III. Sorption of Nitrogen Bases and X-Ray Photoelectron Spectroscopy Study of Mesoporous Solid Acid SBA-15

1. Introduction

2. Experimental Methods $\quad 42$

2.1. Synthesis 42

2.2. Characterization 42

2.3. Nitrogen Base Adsorption and Ammonium Exchange 43

3. Theoretical Methods 44

4. Results 45

4.1. Experimental Results 45

4.2. Theoretical Results 49

4.2.1. Models for SBA 49

4.2.2. Models for Hydrocarbon- vs Fluorocarbon -Sulfonic Acids 53

4.2.3. General Pattern of Nitrogen CLS a Comparison with Experiment 55

5. Discussion

5.1. Pure SBA-15 56

5.2. Sorption of Nitrogen Bases 57

6. Conclusions 59

7. References to Chapter III 59 
8. Appendix 1. Supporting Information

\section{Dehydrocondensation of Alcohols to Form Ethers over Highly Ordered Mesoporous SBA-15 Catalyst}

1. Introduction 69

2. Experimental Procedures 70

2.1. Catalyst Synthesis $\quad 70$

2.2. Determination of Activity and Selectivity 70

2.3. Kinetic Modelling 71

2.4. Surface Analysis 72

2.5. Electron Microscopy and X-Ray Powder Diffraction 72

2.6. Computational Modelling and Analysis 73

3. Results 74

3.1. Methano1/Isobutanol Reactions. 74

3.1.1. Pressure Dependence with $\mathrm{MeOH} / \mathrm{i}-\mathrm{BuOH}=1 / 1$

3.1.2. Temperature Dependence with $\mathrm{MeOH} / \mathrm{i}-\mathrm{BuOH}=1 / 1 \quad 75$

3.1.3. Pressure Dependence with $\mathrm{MeOH} / \mathrm{i}-\mathrm{BuOH}=2 / 1 \quad 76$

3.1.4. Temperature Dependence with $\mathrm{MeOH} / \mathrm{i}-\mathrm{BuOH}=2 / 177$

3.2. Catalyst Stability 77

3.3. Site Blocking by Pyridine 78

3.4. XPS Analysis of SBA-15 After Testing 80

3.5. Acidity and Textural Properties of the Tested Catalyst 81

3.6. Quantum Mechanical Modeling of the Reaction Pathways for the Principal Reactions: (I) $\rightarrow$ (II) for DME, (III) $\rightarrow$ (IV) for MIBE, and (V) $\rightarrow$ (VI) for Dehydration of i-BuOH to IB

4. Discussion

4.1. Ethers from Alcohols. 89

4.1.1. Ether Synthesis from $\mathrm{MeOH} / \mathrm{i}-\mathrm{BuOH}=1 / 1$ Reactants 89

4.1.2. Ether Synthesis from $\mathrm{MeOH} / \mathrm{i}-\mathrm{BuOH}=2 / 1$ Reactants 89

4.2. Deactivation of the SBA-15 Catalyst by Pyridine 90

4.3. XPS Analyses of the SBA-15 Catalyst 91

4.4. Textural Properties

4.5. Theory of Reactant Bonding, Pre-reaction Complexes,

Stationary Points on the Three Principal Reaction Pathway, and Reaction Mechanisms

4.5.1. Single Adsorbates and Multiple Adsorbates 92

4.5.2. Reaction Pathways 92

4.5.3. Poisoning by Pyridine 93

4.5.4. Relation to Kinetics 93

4.5.5. Some Theoretical Predictions for Catalyst Design 94

5. Conclusions 
6. References for Chapter IV 95

V. Synthesis of Ethers from Alcohols over a High Acidity, Defective SBA-15 Catalyst

1. Introduction 99

2. Experimental 100

2.1. Catalyst Synthesis, Characterization, and Determination of Activity and Selectivity 100

2.2. Computational Modelling and Analysis 100

3. Results And Discussion 101

3.1. Catalyst Properties 101

3.2. Catalytic Activity, Selectivity, Primary and Secondary Products 102

3.2.1. Activity with $\mathrm{MeOH} / \mathrm{i}-\mathrm{BuOH}=2 / 1$ Reactant 102

3.2.2. Pressure Dependence 102

3.2.3. Contact Time Dependence 102

3.3. Modeling and Analysis of the Catalytic Chemistry 104

4. References for Chapter V 108

VI. Ion Exchange, Core-Level Shifts, and Bond Strengths in Mesoporous Solid Acid SBA-15

1. Introduction 109

2. Experimental Methods 110

3. Theoretical Method 110

4. Results And Discussion 111

4.1. Experimental 111

4.2. Theoretical 113

5. Conclusions 117

6. References for Chapter VI 117

LIST OF RESULTANT SCIENTIFIC PUBLICATIONS 119 


\section{LIST OF TABLES}

\section{Chapter I}

Page No.

Table 1. The calculated and observed $\mathrm{C}-\mathrm{H}$ stretching frequencies of the $\mu_{2}-\mathrm{CH}_{2} \mathrm{CH}_{2}-$ group in the $\left[\mathrm{NaO}_{3} \mathrm{SO}-\mathrm{CH}_{2} \mathrm{CH}_{2}-\mathrm{OSO}_{3} \mathrm{Na}\right]$ molecule, the free precursor and the anchored precursor.

Table 2. XPS binding energies, peak intensities, and surface atomic ratios.

\section{Chapter II}

Table 1. Product space time yields ( $\mathrm{mol} / \mathrm{kg}$ cat $/ \mathrm{hr})$ in the reaction of $\mathrm{MeOH} / \mathrm{i}-\mathrm{BuOH}(1: 1)$ with flowrates of $3.44 \mathrm{~mol} / \mathrm{kg}$ cat $/ \mathrm{hr}$ alcohols and $16 \mathrm{~mol} / \mathrm{kg}$ cat $/ \mathrm{hr}$ carrier gas at $101.3 \mathrm{kPa}$ total pressure of carrier gas and alcohols over the extracted sulfonic acid-functionalized SBA-15 material.

\section{Chapter III}

Table 1. Stoichiometric Equivalences, Binding Energies ${ }^{\mathrm{a}}$, Peak Widths, and Chemical Shifts for the SBA-15 Material with Adsorbed Nitrogen Bases.

Table 2. Adsorption Energies of Nitrogen Bases on Propylsulfonic Acid Sites. Energies are given in $\mathrm{kJ} / \mathrm{mol}$ of adsorbate.

Table 3. The Kohn-Sham Orbital Energies of Propylsulfonic Acid Sites with Nitrogen Bases.

Table 4. Adsorption Energies of Pyridine, $\mathrm{E}_{\text {ads }}$, and Theoretical N1s, S2s, and S2p Core-Level Shifts in Molecular Adducts of Pyridine with Ethyl-Sulfonic Acid and Perfluoroethyl-Sulfonic Acid.

Table S1. Nitrogen-Containing Polymers and Molecular Models for Calculations of N1s Core Level Chemical Shifts

Table S2. N1s and C1s Experimental Binding Energies and Theoretical Core-Levels of Nitrogen-Containing Polymers and Corresponding Molecular Models (eV).

\section{Chapter IV}

Table 1. Formation rates of products $(\mathrm{mol} / \mathrm{kg}$ catal $/ \mathrm{h})$ as a function of Time on-stream at $404 \mathrm{~K}$ and $2.17 \mathrm{MPa}$ with $\mathrm{MeOH} / \mathrm{i}-\mathrm{BuOH} / \mathrm{N}_{2}=$ $10.4 / 5.2 / 184 \mathrm{~mol} / \mathrm{kg}$ catal $/ \mathrm{h}$. 
Table 2. Comparison of the space time yields ( $\mathrm{mol} / \mathrm{kg}$ catal $/ \mathrm{h}$ ) of the products before and after pyridine (Py) addition to the reactant stream consisting of $\mathrm{MeOH} / \mathrm{i}-\mathrm{BuOH} / \mathrm{N}_{2}=10.4 / 5.2 / 183-184 \mathrm{~mol} / \mathrm{kg}$ catal $/ \mathrm{h}$.

Table 3. Total energies of sorption complexes of reactants, products, and transition states for the dual-site catalyzed dehydrocondensation of methanol with $\mathrm{MeOH}$ to $\mathrm{DME}$, of $\mathrm{MeOH}$ with $\mathrm{i}-\mathrm{BuOH}$ to $\mathrm{MIBE}$, and dehydration of $\mathrm{i}-\mathrm{BuOH}$ to IB. The models, calculation method, and optimization protocol are given in Section 2.6.

Table 4. Imaginary vibrational frequencies at the transition states for the formation of dimethylether (DME), methylisobutyl ether (MIBE), and dehydration isobutene (IB). The models, calculation method and optimization protocol are given in Section 2.6.

Table 5. The calculated adsorption energies of reactants, products, and poisons onto single site $-\mathrm{SO}_{3} \mathrm{H}$ with an adjacent non-interacting - $\mathrm{SH}$ group on the SBA-15 surface modeled as $\mathrm{HS}\left(\mathrm{CH}_{2}\right)_{3}-\mathrm{Si}(\mathrm{H})_{2}-\mathrm{O}-\mathrm{Si}(\mathrm{H})_{2}-\left(\mathrm{CH}_{2}\right)_{3} \mathbf{S O}_{3} \mathbf{H}$. Comparison is made with the adsorption energies calculated with a dual reactive site modeled as $\mathbf{H O}_{3} \mathbf{S}\left(\mathrm{CH}_{2}\right)_{3}-\mathrm{Si}(\mathrm{H})_{2}-\mathrm{O}-\mathrm{Si}(\mathrm{H})_{2}-\left(\mathrm{CH}_{2}\right)_{3} \mathbf{S O}_{3} \mathbf{H}$. To simulate the rigidity of the silica wall, the seven atoms of the $-\mathrm{Si}-\mathrm{O}-\mathrm{Si}-$ backbone capped by four hydrogen atoms were kept frozen in all geometry optimizations in which all other atoms were allowed to move.

\section{Chapter V}

Table 1. Conversion of $\mathrm{MeOH}$ and $\mathrm{i}-\mathrm{PrOH}$ as a function of GHSV at $114^{\circ} \mathrm{C}$ over SBA catalyst.

Table 2. Activities, barriers, isotope effects, and frequencies of $\mathrm{MeOH}+\mathrm{i}-\mathrm{BuOH}$ and $\mathrm{MeOH}+\mathrm{i}-\mathrm{PrOH}$ reactions.

Table 3. Kinetic isotope effects in the dual SBA-acid site catalyzed $\mathrm{S}_{\mathrm{N}} 2$ reaction $2 \mathrm{i}-\mathrm{PrOH} \rightarrow \mathrm{DIPE}+\mathrm{H}_{2} \mathrm{O}$ and dehydration of i-PrOH to propene.

\section{Chapter VI}

Table 1. XPS Stoichiometric Equivalences, Binding Energies, ${ }^{\mathrm{a}}$ Peak Widths, and Chemical Shifts for the Ion-Exchanged SBA-15 Materials.

Table 2. The KS orbital energies of $-\mathrm{SO}_{3} \mathrm{H}$ sites with exchanged ions. 


\section{LIST OF FIGURES}

\section{Chapter II}

$\underline{\text { Page No. }}$

Figure 1. The S2p XPS spectrum of the extracted propanesulfonic acid-derivatized SBA-15 catalyst.

Figure 2. The rates of MIBE formation, $v_{\mathrm{MIBE}}(\mathbf{\square})$, DME formation, $v_{\mathrm{DME}}(\bullet)$, and isobutene (IB) formation, $v_{\mathrm{IB}}(\mathbf{A})$, in the reaction of $\mathrm{MeOH} / \mathrm{i}-\mathrm{BuOH}$ (2:1 molar ratio) with flowrates of $15.6 \mathrm{~mol} / \mathrm{kg}$ cat $/ \mathrm{hr}$ alcohols and 186 $\mathrm{mol} / \mathrm{kg}$ cat $/ \mathrm{hr}$ carrier gas at $388 \mathrm{~K}$ as a function of isobutanol partial pressure, $\mathrm{P}_{\mathrm{i}-\mathrm{BuOH}}$, are given as data points. The fitted kinetic laws (cf. Text) are shown as the curves, giving DME kinetic constant, $\mathrm{k}_{1}=0.59 \mathrm{~mol} / \mathrm{kg}$ cat $/ \mathrm{hr}$; isobutene kinetic constant, $\mathrm{k}_{3}=1.79 \mathrm{~mol} / \mathrm{kg}$ cat $/ \mathrm{hr} ;$ MIBE kinetic constant, $\mathrm{k}_{4}=1.12$ $\mathrm{mol} / \mathrm{kg}$ cat $/ \mathrm{hr}$; methanol adsorption equilibrium constant, $\mathrm{K}_{\mathrm{M}}=0.0092 \mathrm{kPa}^{-1}$; and isobutanol adsorption equilibrium constant $\mathrm{K}_{\mathrm{B}}=0.019 \mathrm{kPa}^{-1}$.

\section{Chapter III}

Figure 1. S2p regions of SBA-15 material with adsorbed nitrogen bases. Data are color coded and stacked additively. FFT filter smoothed line plots are shown with data points.

Figure 2. C1s regions of SBA-15 material with adsorbed nitrogen bases. Data are color coded and stacked additively. FFT filter smoothed line plots are shown with data points. The main peak of En-SBA is emission from the propyl-sulfonic groups and the shoulder at higher BE are the carbons of ethylene diamine.

Figure 3. N1s regions of SBA-15 material with adsorbed nitrogen bases. Data are color coded and stacked additively. FFT filter smoothed line plots are shown with data points.

Figure 4. Models for the propylsulfonic pendant groups in the SBA material: single site [formula (I)] and dual site [formula (II)]. The thiol group in the single site is inert and the distance $-\mathrm{SH} \ldots \mathrm{O}=\mathrm{S}$ is $0.25 \mathrm{~nm}$. The dotted lines in the dual site mark a weak double hydrogen bonding with distances $\mathrm{OH} . . \mathrm{O}=\mathrm{S}$ equal to $0.16 \mathrm{~nm}$.

Figure 5. Single site complexes with nitrogen bases: (a) ammonia, (b) pyridine, (c) ethylene diamine. The hydrogen bonding distances $-\mathrm{O}_{2} \mathrm{SO} \ldots \mathrm{H} \ldots \mathrm{N}$ are, in $\mathrm{nm},(\mathrm{a}) 0.108(\mathrm{O} \ldots \mathrm{H})$ and $0.152(\mathrm{H} \ldots \mathrm{N})$, (b) $0.110(\mathrm{O} \ldots \mathrm{H})$ and $0.148(\mathrm{H} \ldots \mathrm{N})$, and (c) $0.153(\mathrm{O} \ldots \mathrm{H})$ and $0.111(\mathrm{H} \ldots \mathrm{N})$. All the $-\mathrm{SH}$ groups are inert to the nitrogen base adsorption and far enough 
from the $\mathrm{SO}_{3} \mathrm{H}$ sites, $0.21-0.22 \mathrm{~nm}$, indicating an extremely weak, if any, hydrogen bonding $-\mathrm{SH} . . \mathrm{O}=\mathrm{SO}_{2} \mathrm{H}$.

Figure 6. S2p orbital energies (DFT/BP/DN**) in the single and dual sites, their complexes with nitrogen bases. Each sulfur atom-containing species has three S2p levels associated with the $2 p_{x}, 2 p_{y}$, and $2 p_{z}$ orbitals.

Figure 7. Pyridine complexes with (a) ethyl-sulfonic acid and (b) perfluoroethyl-sulfonic acid showing differences in the proton transfer from the $-\mathrm{SO}_{3} \mathrm{H}$ functionality to the nitrogen atom of pyridine due to substitution of aliphatic hydrogen by fluorine in the ethyl group. Calculations at the DFT/BP/DN** level with fully optimized geometries.

Figure S1. Correlation between the DFT N1s orbital energies (negative of the Kohn-Sham core-level energies) and the experimental N1s BEs of nitrogen-containing polymers. Identification of the models for polymer segments and data from Table S1.

\section{Chapter IV}

Figure 1. Rates of formation of dimethylether (DME), isobutene (IB), methyl isobutylether (MIBE), diisobutylether (DIBE), n-butenes (cis- and trans-2-butenes), methyl tertiarybutylether (MTBE), and tertiarybutylisobutylether (TBIBE) in the reaction of $\mathrm{MeOH} / \mathrm{i}-\mathrm{BuOH}$ (1/1 molar ratio) over the SBA-15 catalyst with flow rates of 3.44 $\mathrm{mol} / \mathrm{kg}$ catal $/ \mathrm{h}$ alcohols and $16.0 \mathrm{~mol} / \mathrm{kg}$ catal $/ \mathrm{h}$ of $\mathrm{N}_{2}$ at $404 \mathrm{~K}$ as a function of isobutanol partial pressure, $\mathrm{p}_{\mathrm{i}-\mathrm{BuOH}}$, are given as data points. The fitted kinetic laws for IB, MIBE, and DME syntheses are shown as solid curves for those three products.

Figure 2. Arrhenius plots for determination of the apparent activation energies of the ethers (right) and olefins (left) formed over the SBA-15 catalyst from the $\mathrm{MeOH} / \mathrm{i}-\mathrm{BuOH}=1 / 1$ reactant mixture at $101.3 \mathrm{kPa}$.

Figure 3. Rates of formation of DME, IB, and MIBE in the reaction of $\mathrm{MeOH} / \mathrm{i}-\mathrm{BuOH}(2 / 1$ molar ratio) over the SBA-15 catalyst with flow rates of $16.5 \mathrm{~mol} / \mathrm{kg}$ catal $/ \mathrm{h}$ alcohols and $184 \mathrm{~mol} / \mathrm{kg}$ catal $/ \mathrm{h}$ of $\mathrm{N}_{2}$ at $404 \mathrm{~K}$ as a function of isobutanol partial pressure, $\mathrm{p}_{\mathrm{i}-\mathrm{BuOH}}$, are given as data points. The open symbols represent a second test sequence of the catalyst after the first test (closed symbols) was completed and the catalyst was purged with nitrogen at ambient pressure before repressurizing to the higher range of pressures. The fitted kinetic laws are shown as solid curves. 
Figure 4. Arrhenius plots for the determination of the apparent activation energies of the products formed over the SBA-15 catalyst from the $\mathrm{MeOH} / \mathrm{i}-\mathrm{BuOH}=2 / 1$ reactant mixture at $2.17 \mathrm{MPa}$.

Figure 5. Deactivation of the SBA-15 catalyst at $404 \mathrm{~K}$ and $375 \mathrm{kPa}$ upon changing the reactant gas mixture from $\mathrm{MeOH} / \mathrm{i}-\mathrm{BuOH} / \mathrm{N}_{2}=$ $7.4 / 7.4 / 184 \mathrm{~mol} / \mathrm{kg}$ catal $/ \mathrm{h}$ to $\mathrm{MeOH} / \mathrm{i}-\mathrm{BuOH} / \mathrm{Py} / \mathrm{N}_{2}=10.4 / 5.2 / 1.04 / 183$ $\mathrm{mol} / \mathrm{kg}$ catal $/ \mathrm{h}$ with $\mathrm{GHSV}=4870 \mathrm{l} / \mathrm{kg}$ catal $/ \mathrm{h}$.

Figure 6. Transmission electron micrographs of the as-synthesized SBA-15 catalyst showing (A) the view perpendicular to the pore axes, (B) the close-packed hexagonal structure of parallel pores shown from the six-fold symmetry axis of view, and (C) the small-angle XRD pattern.

Figure 7. The optimized configuration (left) for the adsorption of two $\mathrm{MeOH}$ molecules on the dual sulfonic acid centers on the SBA-15 catalyst. The transition state for DME synthesis over SBA-15 is shown in the middle of the figure, where electron density is shown as a transparent isosurface to within 0.08 electrons/a.u. ${ }^{3}$. The optimized configuration of adsorbed DME and $\mathrm{H}_{2} \mathrm{O}$ product molecules on the dual sulfonic acid centers of the SBA-15 catalyst is shown on the right. Selected distances of importance to the adsorption and reaction are given in $\AA$.

Figure 8. The optimized configuration, left, of adsorbed $\mathrm{MeOH}$ and $\mathrm{i}-\mathrm{BuOH}$ molecules on the proximal sulfonic acid centers on the SBA-15 catalyst. The transition state for the reaction of $\mathrm{MeOH}$ with $\mathrm{i}-\mathrm{BuOH}$ to form MIBE over SBA-15 is shown in the middle, where electron density is shown as a transparent isosurface to within 0.08 electrons/a.u. ${ }^{3}$. The optimized configuration of adsorbed MIBE and $\mathrm{H}_{2} \mathrm{O}$ product molecules on proximal sulfonic acid centers of the SBA-15 catalyst is shown on the right. Selected distances of importance to the adsorption and reaction are given in $\AA$.

Figure 9. The optimized configuration, left, of an adsorbed i-BuOH molecule on a sulfonic acid center on the SBA-15 catalyst, also showing interaction with an adjacent unoccupied sulfonic acid group. The transition state for isobutanol dehydration over SBA-15 is shown in the middle of the figure, where electron density is shown as a transparent isosurface to within 0.08 electrons/a.u. ${ }^{3}$. The optimized configuration of the products of dehydration of isobutanol is shown on the right. Selected distances of importance to the adsorption and dehydration are given in $\AA$. 


\section{Chapter V}

Figure 1. A cluster of defective SBA particles. These particles have pore diameters of about $10 \mathrm{~nm}$, and the particles tend to be $500-1000 \mathrm{~nm}$ in length, appreciably shorter than particles of well-ordered SBA-15.

Figure 2. Rates of formation of PE, DME, MIPE, and DIPE in the reaction of $\mathrm{MeOH} / \mathrm{i}-\mathrm{PrOH}$ (2/1 molar ratio) over the SBA catalyst at $387 \mathrm{~K}$ as a function of $\mathrm{i}-\mathrm{PrOH}$ partial pressure.

Figure 3. Selectivity of i-PrOH conversion to the MIPE, PE, and DIPE products formed from $\mathrm{MeOH} / \mathrm{i}-\mathrm{PrOH}=2 / 1$ as a function of contact time at $114^{\circ} \mathrm{C}$ and $2.17 \mathrm{MPa}$.

Figure 4. The optimized configuration of two adsorbed i-PrOH molecules (left), along with the reaction transition state (TS) in the middle and the adsorbed products DIPE and $\mathrm{H}_{2} \mathrm{O}$ on the right.

\section{Chapter VI}

Figure 1. A cartoon of the potentially multifunctional SBA material with a TEM inset of a side (upper) and top (lower) view of the structure. Pore-to-pore distance is $14 \mathrm{~nm}$.

Figure 2. Models for potassium exchanged SBA material: (a) Single site with proton of the propylsulfonic group replaced by $\mathrm{K}^{+}$, (b) Dual site with protons of two neighboring propylsulfonic groups replaced by $\mathrm{K}^{+}$. Distances between the $\mathrm{K}^{+}$ions and nearest oxygens of the $-\mathrm{SO}_{3}{ }^{-}$counterions in $\mathrm{nm}$ show the multiple coordination of potassium, the non-equivalence of the two $\mathrm{K}^{+}$ions on the dual site, and the electrostatic repulsion between the two potassium cations on the dual site, as well as 'tying-up' of the proximal $-\mathrm{SO}_{3}{ }^{-}$groups of the dual site by one of the $\mathrm{K}^{+}$ions.

Figure 3. S2p orbital energies (DFT/GGA/BP/DN**) in the single and dual sites and protons exchanged with $\mathrm{K}^{+}$and binding as $-\mathrm{SO}_{3} \mathrm{H} . . . \mathrm{NH}_{3}$. Each sulfur-containing species has three $\mathrm{S} 2 \mathrm{p}$ levels associated with the $2 p_{x}, 2 p_{y}$, and $2 p_{z}$ orbitals. Interactions with other nitrogen bases, ethylenediamine (En) and pyridine (Py) are shown for comparison.

Figure 4. Average S2p core level shifts (CLS) referenced to Si2p. 


\title{
CATALYTIC SYNTHESIS OF OXYGENATES: Mechanisms, Catalysts and Controlling Characteristics
}

\begin{abstract}
This report is written with six chapters, each with a specific focus. Each chapter is fully self-contained with its own reference list.

Chapter I. A Novel (OH) $)_{3} \mathrm{ZrO}_{3} \mathrm{SO}-\mathrm{CH}_{2} \mathrm{CH}_{2}-\mathrm{OSO}_{3} \mathrm{Zr}(\mathrm{OH})_{3}$-Derived Catalyst for Ether Synthesis: Synthesis and Characterization of $\left[\mathrm{NaO}_{3} \mathrm{SO}-\mathrm{CH}_{2} \mathrm{CH}_{2}-\mathrm{OSO}_{3} \mathrm{Na}\right]$ and its Anchored Form, the Surface-grafted Acid Groups on Zirconium Hydroxide. Surface-grafted Acid Groups on Zirconium HydroxideA novel (HO) ${ }_{3} \mathrm{ZrO}_{3} \mathrm{SO}_{-} \mathrm{CH}_{2} \mathrm{CH}_{2}$ $\mathrm{OSO}_{3} \mathrm{Zr}(\mathrm{OH})_{3}$-derived catalyst was synthesized and tested for the coupling of methanol with isobutanol to form methylisobutylether (MIBE), and it was found that the catalyst had higher activity and selectivity for this reaction than typical sulfated zirconia catalysts. The catalyst has been characterized by high resolution X-ray photoelectron (XPS), near-infrared diffuse reflectance (NIR-DRS), ${ }^{1} \mathrm{H}$ nuclear magnetic resonance (NMR), and ${ }^{13} \mathrm{C}$ magic angle spinning (MAS) NMR spectroscopies to clarify the state of the catalyst during synthesis steps and to determine the dominant factor in producing the higher activity and selectivity. Coupled with MMFF simulation of the fundamental stretching vibrations in the $\mathrm{C}-\mathrm{H}$ region, the results provided evidence of the $\mu_{2}-\mathrm{CH}_{2} \mathrm{CH}_{2}$ - ligand bridged between two - $\mathrm{OSO}_{3}$ - groups in the precursor and the anchored precursor. The ethyl bridge was removed upon calcination at $773 \mathrm{~K}$ to yield surface-grafted acid groups on zirconia. This material had a surface area of $97 \mathrm{~m}^{2} / \mathrm{g}$ and an acid-exchange capacity of $0.70 \mathrm{meq}$ of $\mathrm{H}^{+} / \mathrm{g}$, corresponding to $7.2 \mu \mathrm{mol}$ acid sites $/ \mathrm{m}^{2}$, which was about $50 \%$ higher than that of sulfated zirconia prepared by standard methods of impregnation by sulfuric acid or ammonium sulfate. The XPS quantitative determination of the calcined sample yielded the ratios of 0.85 for $\mathrm{S} / \mathrm{Zr}$ and $\approx 4.0$ for $\mathrm{O} / \mathrm{S}$, where $\mathrm{O}$ was only the oxygen from the hydrogen sulfonic group. The results suggest that the surface-grafted acid groups correspond to the formula $2\left[\left(\mathrm{HSO}_{4}\right)_{0.85}^{-}-\mathrm{ZrO}_{2}\right]$ on the surface. Such $2\left[\left(\mathrm{HSO}_{4}\right)_{0.85}^{-}-\mathrm{ZrO}_{2}\right]$ groups grafted on the zirconia surface possessed proximal acid sites favoring high activity and selective catalysts for alcohol coupling to form ethers. Compared with a conventionally impregnated sulfated zirconia catalyst using sulfuric acid or ammonium sulfate, the new catalyst reported here exhibited a 78\% higher space time yield of MIBE formed by the alcohol coupling reaction. This work illustrates a new method for preparing anchored Brønsted acid functionalities on supports, which have utility for surface reactions that proceed by dual acid site mechanisms.
\end{abstract}

Chapter II. Sulfonic Acid-Functionalized Mesoporous Silica: Synthesis, Characterization, and Catalytic Reaction of Alcohol Coupling to Ethers. A propylsulfonic acid-derivatized mesoporous SBA-15 catalyst was synthesized, characterized in terms of surface properties, and shown to have high selectivities for alcohol coupling to ethers, specifically methanol and isobutanol coupling to form MIBE with no detectable formation of butenes at temperatures $<400 \mathrm{~K}$. Kinetic analysis was consistent with 
competitive adsorption of the two alcohols onto Brønsted acid sites, with isobutanol being more strongly adsorbed on the acid sites than the methanol. Specifically, the experimental data were satisfactorily fitted using the Langmuir-Hinshelwood kinetic laws. The rates of formation of MIBE and dimethylether (DME) obeyed kinetics, $v_{\mathrm{MIBE}}=\mathrm{k}_{4} \mathrm{~K}_{\mathrm{M}} \mathrm{p}_{\mathrm{M}} \mathrm{K}_{\mathrm{B}} \mathrm{p}_{\mathrm{B}} /(1+$ $\left.\mathrm{K}_{\mathrm{M}} \mathrm{p}_{\mathrm{M}}+\mathrm{K}_{\mathrm{B}} \mathrm{p}_{\mathrm{B}}\right)^{2}$ and $v_{\mathrm{DME}}=\mathrm{k}_{1} \mathrm{~K}_{\mathrm{M}}^{2} \mathrm{p}_{\mathrm{M}}^{2} /\left(1+\mathrm{K}_{\mathrm{M}} \mathrm{p}_{\mathrm{M}}+\mathrm{K}_{\mathrm{B}} \mathrm{p}_{\mathrm{B}}\right)^{2}$, where $\mathrm{p}$ is the partial pressure of methanol (M) or isobutanol (B). Here, $\mathrm{k}_{1}$ and $\mathrm{k}_{4}$ are the kinetic constants for DME and MIBE formation, and $\mathrm{K}_{\mathrm{M}}$ and $\mathrm{K}_{\mathrm{B}}$ denote the adsorption equilibrium constants for methanol and isobutanol. Values of $\mathrm{K}_{\mathrm{M}}=0.0092 \pm 0.001 \mathrm{kPa}^{-1}, \mathrm{~K}_{\mathrm{B}}=0.019 \pm 0.002 \mathrm{kPa}^{-1}, \mathrm{k}_{1}=0.59 \pm$ $0.01 \mathrm{~mol} / \mathrm{kg} \mathrm{cat} / \mathrm{hr}$ and $\mathrm{k}_{4}=1.12 \pm 0.01 \mathrm{~mol} / \mathrm{kg}$ cat $/ \mathrm{hr}$ were obtained. In addition, the rate of isobutene formation was found to obey the kinetic law $v_{I B}=k_{3} K_{B} p_{B} /\left(1+K_{M} p_{M}+K_{B} p_{B}\right)^{3}$, yielding $\mathrm{k}_{3}=1.79 \pm 0.02 \mathrm{~mol} / \mathrm{kg}$ cat $/ \mathrm{hr}$ with the same values of $\mathrm{K}_{\mathrm{M}}$ and $\mathrm{K}_{\mathrm{B}}$ previously determined from the DME and MIBE data.

It was shown that this well-crystallized sulfonic acid-functionalized silica catalyst possessed a mesoporous structure with pores $\approx 7.4 \mathrm{~nm}$ in diameter and a surface area of 674 $\mathrm{m}^{2} / \mathrm{g}$. The acid exchange capacity was $1.6 \mathrm{meq} \mathrm{H}^{+} / \mathrm{g}$ of $\mathrm{SiO}_{2}$, and the material exhibited excellent thermal stability. At elevated temperatures, the selectivities toward MIBE and DME increased with alcohol pressure, while butene selectivity dramatically decreased. Thus, this catalyst exhibited high ether selectivities while also showing higher catalytic activity for ether formation than other inorganic solid acid catalysts.

In a reaction of two molecules at a surface, we have found that a precursor state in which both are brought by the catalyst to proximity is effective in the formation of the transition state (TS) that lowers the TS barrier energy compared to a single-site catalyzed reaction. The TS of the reaction of methanol with isobutanol over Nafion-H catalyst was theoretically calculated using a model comprising two fluorosulfonic acid functionalities $\left(\mathrm{CF}_{3} \mathrm{SO}_{3} \mathrm{H}\right.$ sites). The results show convincingly that dissociation-reassociation of the $\mathrm{C}-\mathrm{O}$ bond in the adsorbed methanol subject to the "rear attack" onto its inverting methyl group is the dominant feature of the reaction pathway at the TS. Moreover, the overall barrier height and its connectivity with reactants and products is strongly influenced by the concerted motion of the "far away" atoms and the flexibility of the entire dual-site ensemble with the hydrogen-bonded adsorbates. The $\mathrm{S}_{\mathrm{N}} 2$ reaction is facilitated by a proton transfer between the neighboring sites that provides for charge balance on the reaction pathway and charge neutrality of the two catalyst sites at the conclusion of the reaction. Thus, a "dual-stite" mechanism is found to possess features that accelerate the dehydrocondensation of alcohols to ethers compared to "single-site" paths in solutions and zeolites.

\section{Chapter III. Sorption of Nitrogen Bases and X-Ray Photoelectron Spectroscopy} Study of Mesoporous Solid Acid SBA-15. A mesoporous SBA-15 material containing a high concentration of $\equiv \mathrm{Si}\left(\mathrm{CH}_{2}\right)_{3} \mathrm{SO}_{3} \mathrm{H}$ functionalities accessible to ion exchange and adsorption of nitrogen bases was studied by X-ray photoelectron spectroscopy (XPS). Highresolution XPS was used to determine stoichiometric equivalences between the $-\mathrm{SO}_{3}{ }^{-}$groups and $\mathrm{NH}_{4}{ }^{+}$cations exchanged for the $-\mathrm{SO}_{3} \mathrm{H}$ protons, as well as between the $-\mathrm{SO}_{3} \mathrm{H}$ groups 
and adsorbed pyridine and ethylenediamine. XPS core-level shifts (CLS) of S2p photoemission to lower binding energies (BEs) identify the $-\mathrm{SO}_{3} \mathrm{H}$ groups as sites for cation exchange and donor hydrogen bonding to the adsorbed nitrogen bases. The N1s CLS to higher BEs identify the nitrogen atoms of pyridine and one of the two $\mathrm{N}$ atoms of ethylenediamine as acceptors of the hydrogen bond. The CLS are smaller than those previously observed in Nafion-H and sulfated zirconia (Johansson, M.; Klier, K. Topics Catal. 4 (1997) 99). An all-electron, non-relativistic DFT theory yields core-level orbital energies where shifts correlate well with the observed XPS CLS. As a result of this combined study, the propylsulfonic groups of the SBA-15 material are identified as weaker acids than those of Nafion- $\mathrm{H}$ and sulfated zirconia, albeit ones with high surface concentration and excellent ion-exchange capacity. Furthermore, SBA-15 derivatized by perfluoroalkyl sulfonic groups are predicted to be efficient catalysts for reactions requiring strong acid sites, herein dehydration of alcohols to olefins and hydration of olefins to alcohols.

Chapter IV. Dehydrocondensation of Alcohols to Form Ethers over Highly Ordered Mesoporous SBA-15 Catalyst. A well-ordered, propylsulfonic acid-derivatized mesoporous SBA-15 catalyst was examined for activity and selectivity in dehydrocondensation of methanol and isobutanol to form ethers, principally methylisobutylether (MIBE) and dimethylether (DME), and dehydration of isobutanol to olefins, at elevated temperatures and pressures. It was shown that the catalyst maintained activity for $>1600 \mathrm{~h}$, and the Brønsted acid sites corresponding to $1 \mathrm{meq} / \mathrm{g}$ of catalyst were stable under these reaction conditions until they were deliberately in situ poisoned by addition of pyridine. X-Ray photoelectron spectroscopy (XPS) revealed that the pyridine was selectively and strongly adsorbed on the sulfonic acid groups. Kinetic studies demonstrated that isobutene formation utilizes a vacant Brønsted acid site adjacent to the adsorbed isobutanol molecule, while MIBE and DME were again formed by surfacecatalyzed $\mathrm{S}_{\mathrm{N}} 2$ reactions that follow Langmuir-Hinshelwood kinetics involving competitive adsorption of the alcohols. The isobutene formation rate exhibited a distinct maximum as a function of the alcohol pressure. This kinetic behavior is similar to that observed with Nafion-H and other catalysts. Because of the high apparent activation energy of isobutene synthesis compared with the much lower apparent activation energies of the ethers, lower reaction temperature along with higher reactant pressures favor the formation of ethers over olefins.

Theoretical modeling of the reaction pathway located stationary points including the transition states (TS) with barrier energies for all reactions involved, and showed that for ether synthesis one alcohol was adsorbed on a sulfonic acid site (I) via a donor H-bond while the second alcohol was adsorbed on a proximal sulfonic acid site (II) via an acceptor H-bond. In the intermediate, methyl transfer from the adsorbed methanol to the isobutanol oxygen occurs to form MIBE. At the same time, isobutanol donates its proton to a sulfonic acid group (II) whose oxygen acts as a base, and the methanol $\mathrm{OH}$ group accepts a proton from a sulfonic acid group (I) and is split off as water. To balance the surface charge, the original 
proton on sulfonic acid group (II) is transferred to sulfonic acid group (I), and MIBE is desorbed. The flexibility of the TS involving the concerted movement of all three protons is essential for the connectivity of the TS with the reactants and products and the umbrella inversion of the methyl group during its transfer. The theory has thus not only yielded a picture that is fully consistent with observed isotope flows, $\mathrm{sp}^{3}$ carbon inversion, and temperature/pressure dependent selectivity, but also revealed unprecedented detail of the concerted proton transfer and the role of acid-base interactions in this dual-site catalysis.

Chapter V. Synthesis of Ethers from Alcohols over a High Acidity, Defective SBA-15 Catalyst. A highly defective SBA with proton concentration of $1.35 \mathrm{meq} / \mathrm{g}$ has been synthesized, and this material exhibited approximately a 2-fold increase in activity over highly ordered SBA-15 for coupling methanol/isobutanol $(\mathrm{MeOH} / \mathrm{i}-\mathrm{BuOH})$ to form methylisobutylether (MIBE). In addition, this material is active in dehydrocondensation of isopropanol (i-PrOH) to form diisopropylether (DIPE), dehydration of i-PrOH to propene (PE), and coupling of $\mathrm{i}-\mathrm{PrOH}$ with $\mathrm{MeOH}$ to form methylisopropylether (MIPE). It is noted that DIPE is currently commercially manufactured from refinery propylene and has a higher degree of acceptability as an octane enhancer than MTBE because it has lower solubility in water, is chemically more similar to hydrocarbons, has a higher boiling points, and allows more light, high octane, cyclic alkanes to be blended into gasoline. It is also noted that MIPE can also be synthesized completely from carbons derived from natural gas. A strong reaction pressure dependence on the product selectivities was observed. Experimental activation barriers have been determined, and DFT calculations located all of the transition states (TS) involved with theoretical barriers agreeing with experimental values to within $2-4 \mathrm{kcal} / \mathrm{mol}$. The theory includes the determination of imaginary vibrational frequencies associated with the passage of the reacting groups through the TS and assessment of kinetic isotope effects (KIE) due to labeling of critical parts of the molecule or catalyst by deuterium.

Chapter VI. Ion Exchange, Core-Level Shifts, and Bond Strengths in Mesoporous Solid Acid SBA-15. Mesoporous SBA-15 containing a highly ordered, uniform pore structure of $7 \mathrm{~nm}$ diameter parallel pores up to $1500 \mathrm{~nm}$ long and a high concentration of $\equiv \mathrm{Si}\left(\mathrm{CH}_{2}\right)_{3} \mathrm{SO}_{3} \mathrm{H}$ functionalities (1.0 mequiv/g) accessible to ion exchange and adsorption of nitrogen bases has been investigated. High-resolution XPS was used to determine stoichiometric equivalences between the $-\mathrm{SO}_{3}{ }^{-}$groups and $\mathrm{K}^{+}, \mathrm{Co}^{2+}, \mathrm{Ni}^{2+}, \mathrm{Cu}^{2+}$ and $\mathrm{NH}_{4}{ }^{+}$cations exchanged for the $-\mathrm{SO}_{3} \mathrm{H}$ protons. XPS core-level shifts (CLS) of S2p photoemission to lower $\mathrm{BEs}$ identify the $-\mathrm{SO}_{3} \mathrm{H}$ groups as sites for cation exchange. The CLS of the cations move in the opposite direction to higher BEs, demonstrating the direct interaction of the cations with the sulfonic exchange sites. All-electron DFT calculations agree well with the observed XPS core level shifts. 


\section{Objective and Background of the Research}

Overall objective. This research focused on catalytic synthesis of unsymmetrical ethers as a part of a larger program involving oxygenated products in general, including alcohols, ethers, esters, carboxylic acids and their derivatives that link together environmentally compliant fuels, monomers and high-value chemicals. Earlier, we found that ethers with primary alkyl substituents such as methyl-isobutyl ether (MIBE) are cetane boosters. These ethers are also storage chemicals for olefins such as isobutene, and have the potential for conversion to reformate hydrocarbon gasoline. Our aim is for all carbons to be derived from natural gas and renewable resources (such as in the ethyl-isobutyl ether EIBE).

Methodology. Our research has determined by isotope experiments, chirality inversion, and product composition that the most efficient path to ethers from alcohols is a Brønsted acid-catalyzed $\mathrm{S}_{\mathrm{N}} 2$ pathway over heterogeneous catalysts possessing a high surface concentration of acid sites of moderate-to-high strength. Further, kinetic analyses and theoretical calculations are entirely consistent with the findings that the most efficient catalytic mechanism of alcohol coupling is a $\mathrm{S}_{\mathrm{N}} 2$ pathway involving competitive adsorption of reactants on proximal Brønsted acid sites. From a practical viewpoint, improvement of the ether yields from alcohol coupling is achieved by increasing the surface area of the catalysts and providing higher concentrations of proximal Brønsted acid sites on the surface.

In the research reported here, we investigated and employed new inorganic acids whose syntheses have been forged elsewhere as well as in this laboratory. Our design involved anchoring acid group precursors, e.g. glycol disulfate ester precursors, on inorganic oxides. In addition, we investigated the remarkable new class of mesoporous solid acids, including propylsulfonic acid-derivatized silicas. After synthesis, these materials have been well-characterized in terms of physical and chemical properties, as well as in regard to surface and bulk characteristics, and then the catalysts were tested in a wide range of pressures, flow rates, and compositional variations for activity and selectivity in the bifunctional coupling of alcohols to form ethers. 


\section{TECHNICAL REPORT}

\section{Chapter I. A Novel $(\mathrm{OH})_{3} \mathrm{ZrO}_{3} \mathrm{SO}-\mathrm{CH}_{2} \mathrm{CH}_{2}-\mathrm{OSO}_{3} \mathrm{Zr}(\mathrm{OH})_{3}$-Derived Catalyst for Ether Synthesis: Synthesis and Characterization of $\left[\mathrm{NaO}_{3} \mathrm{SO}-\mathrm{CH}_{2} \mathrm{CH}_{2}-\mathrm{OSO}_{3} \mathrm{Na}\right]$ and its Anchored Form, the Surface-Grafted Acid Groups on Zirconium Hydroxide}

A novel disodium 1,2-ethanediol bis(hydrogen sulfate) salt precursor-based zirconia catalyst was previously synthesized and tested for the coupling of methanol with isobutanol to form methylisobutylether (MIBE), and it was found that the catalyst had higher activity and selectivity for this reaction than typical sulfated zirconia catalysts $[1,2]$. During the current project, study of this catalyst continued, and it has now been characterized by high resolution X-ray photoelectron (XPS), near-infrared diffuse reflectance (NIR-DRS), ${ }^{1} \mathrm{H}$ nuclear magnetic resonance (NMR), and ${ }^{13} \mathrm{C}$ magic angle spinning (MAS) NMR spectroscopies to clarify the state of the catalyst during synthesis steps and to determine the dominant factors in producing the higher activity and selectivity. This involved determining the structure, composition, and chemical properties of the precursor and the synthesized solid acid catalyst [3].

\section{Introduction}

In recent years, there has been increasing interest in the development of solid acid materials [4-9]. Such materials have extensive applications and scientific value, e. g. tungstena-zirconia [7], sulfated-zirconia [9], and Nafion-H [10] with strong acid functionalities were employed as catalytic materials for coupling alcohols to unsymmetrical ethers $[4,11,12]$. Our experimental results, kinetic analyses and theoretical calculations suggest that the mechanism of the ether syntheses from alcohols is a dual site $\mathrm{S}_{\mathrm{N}} 2$ reaction pathway involving competitive adsorption of reactants on surface Brønsted acid sites [1,4,1114]. For this purpose, sulfate deposition on metal oxide was carried out using a traditional impregnation method [5,7,9]. Although this technique has been successful, the concentration of surface acid groups was low (e.g. $12-17 \%$ of surface sulfate coverage), as determined by N1s XPS of conjugate pyridine base titrated to the acid groups $[15,16]$.

The catalytic effects in the coupling of alcohols involves the dispersion of surface acid species, contributions of the surface hydroxyl groups, and acid-base/electron-transfer interactions between the support and grafted species [1,4,11-13]. However, design and successful preparation of solid catalysts with close dual acid functionalities has not been demonstrated by others until our recent communication [1]. In this regard, our research focused on the design and synthesis of $\left[\mathrm{NaO}_{3} \mathrm{SO}-\mathrm{CH}_{2} \mathrm{CH}_{2}-\mathrm{OSO}_{3} \mathrm{Na}\right]$, a compound possessing double sulfate groups coordinated to an ethanediol $\left(-\mathrm{OCH}_{2} \mathrm{CH}_{2} \mathrm{O}-\right)$ bridge, anchoring of the $\left[-\mathrm{O}_{3} \mathrm{SOCH}_{2} \mathrm{CH}_{2} \mathrm{O}_{3} \mathrm{SO}-\right]^{2-}$ group on zirconium hydroxide, and subsequent decomposition to the surface-grafted acid groups on the supports. The structure, composition and chemical properties of the precursor and the synthetic solid acid materials were determined using nearinfrared diffuse reflectance spectroscopy (NIR-DRS), high-resolution X-ray photoelectron spectroscopy (HR-XPS), ${ }^{1} \mathrm{H}$ NMR and ${ }^{13} \mathrm{C}$ solid state MAS NMR spectroscopies, MMFF 
(Merck Molecular Force Field) [17] simulation, BET surface area measurement [18] and solid acid-titration technique $[9,19]$.

\section{Experimental Section}

\subsection{Sample Preparation.}

2.1.1. Precursor. A 11.9 g portion of $\mathrm{HCON}\left(\mathrm{CH}_{3}\right)_{2} \cdot \mathrm{SO}_{3}$ complex (DMF. $\mathrm{SO}_{3}$, Aldrich N,N-dimethylformamide) and $75 \mathrm{~mL} \mathrm{CCl}_{4}$ (Aldrich, HPLC grade) were placed in a $\mathrm{N}_{2}$-purged, round-bottom flask equipped with a magnetic stir bar. Ethylene glycol ( $\left.2.0 \mathrm{~mL}\right)$ (Aldrich, anhydrous) was then added dropwise by syringe under stirring over $20 \mathrm{~min}$ at room temperature. A clear insoluble oil formed, and the mixture was stirred under $\mathrm{N}_{2}$ for an additional $2 \mathrm{hr}$. After allowing the oil to settle, the $\mathrm{CCl}_{4}$ was decanted and discarded. Water $(50 \mathrm{~mL})$ was added to the oil, followed immediately by $\sim 7 \mathrm{~g}$ aqueous $\mathrm{NaOH}(50 \mathrm{wt} \%)$ until the solution $\mathrm{pH}$ reached to $\sim 9-10$. Ethanol $(100-150 \mathrm{~mL})$ was added, and the mixture was evaporated using a rotary evaporator to obtain a white solid. The solid was dissolved in $\sim 100$ $\mathrm{mL} \mathrm{H}_{2} \mathrm{O}$, and enough ethanol was added to begin precipitation. About $1 \mathrm{~g}$ of a white solid was collected by filtration and discarded. The filtrate was evaporated to dryness, redissolved in $\sim 30 \mathrm{~mL} \mathrm{H}_{2} \mathrm{O}$, and the product was precipitated by adding $\sim 50 \mathrm{~mL}$ ethanol. The white micocrystalline solid was isolated by filtration and dried in vacuum. The resulting product is denoted as precursor.

2.1.2. The Anchored Precursor. R-H resin ( $50 \mathrm{mmol}$ Rexyn 101, $7.7 \mathrm{meq} / \mathrm{g}$, Fisher) was cation-exchanged with $70 \mathrm{mmol}, 75 \mathrm{~mL}\left(\mathrm{NH}_{4}\right)_{2} \mathrm{SO}_{4}$ (Aldrich, $99.99 \%$ purity) solution over a catex column, to obtain a $\mathrm{NH}_{4}{ }^{+}$form of the resin. The $\mathrm{R}_{-} \mathrm{NH}_{4}(5.0 \mathrm{mmol})$ resin was then cation-exchanged with $1.88 \mathrm{mmol}(9.4 \mathrm{mM}, 200 \mathrm{~mL})$ of the synthesized precursor, to yield an aqueous solution containing the ammonium form of the precursor. Zirconium hydroxide (13.5 mmol, Aldrich, 97\% purity) was immersed into the solution of the ammonium precursor $(9.4 \mathrm{mM}, 200 \mathrm{~mL})$ with stirring. The mixed solution was equilibrated for $2 \mathrm{hr}$ under stirring at room temperature, filtered, washed free of $\mathrm{NH}_{4}{ }^{+}$ions with copious amounts of deionized $\mathrm{H}_{2} \mathrm{O}$, and dried in ambient air. The resulting white sample is a precursor anchored on the 'host' $\mathrm{Zr}(\mathrm{OH})_{4}$ matrix, which is denoted as anchored precursor.

2.1.3. The Surface-Grafted Acid Groups. The anchored precursor was calcined at $500^{\circ} \mathrm{C}$ for $3 \mathrm{hr}$ to produce surface-grafted acid groups on the zirconia support. From the resulting proton concentration, which was equivalent to the sulfur concentration, the calcination removed the $-\mathrm{CH}_{2} \mathrm{CH}_{2}-$ bridging species, envisaged as ejection of acetylene.

\subsection{Characterization of Samples.}

2.2.1. Near-Infrared Diffuse Reflectance Spectroscopy (NIR-DRS). NIR-DR spectra were recorded using a Varian Cary 5E UV-vis-NIR spectrophotometer with diffuse reflectance attachment with an integration sphere. The powder samples were mounted in a quartz cell with a Suprasil window and measured in the NIR region of 1000-2300 nm at room temperature with 50-120 co-added scans at $2 \mathrm{~cm}^{-1}$ resolution. A Halon white 
reflectance standard was used to obtain the baseline. The spectra were evaluated by the Schuster-Kubelka-Munk (SKM) function [20] that gives the ratio of the absorption (K) to the scattering (S) coefficients as

$$
\mathrm{K} / \mathrm{S}=\left(1-R_{\infty}\right)^{2} / 2 R_{\infty}
$$

where $R_{\infty}$ is the ratio of the intensities of light reflected from the sample and the standard.

2.2.2. High Resolution $X$-ray Photoelectron Spectroscopy. HR-XPS measurements were carried out using the Scienta ESCA-300 photoelectron spectrometer at Lehigh University [21]. This instrument utilizes a water-cooled rotating $\mathrm{Al} \mathrm{K} \alpha$ anode to generate an unpolarized $7.6 \mathrm{~kW}$ X-ray flux $(h v=1486.8 \mathrm{eV})$, which is monochromatized by seven toroidally bent quartz crystals. Both survey and high-resolution scans of the samples were performed at $5 \times 10^{-9}$ Torr in the analysis chamber. The Zr3d, S2p, O1s, C1s, Na1s and N1s spectral regions were recorded with $150 \mathrm{eV}$ pass energy, an incremental step size of $0.05 \mathrm{eV}$, and a $0.8 \mathrm{~mm}$ slit width. Because the samples were non-conducting, a hot filament electron gun set at $1.3 \mathrm{eV}$ was employed during the measurements to supply electrons for charge compensation and to improve the resolution [21].

2.2.3. Quantitative Analysis of HR-XPS Data. Dreiling [22a], Vedage et al. [23] and Himelfarb [22b] have developed a model based on exponential attenuation of the photoelectron intensity to study the surface overlayers in powders. The peak areas in the XPS spectra were obtained by curve-fitting using the Scienta program [15]. The sensitivity factors were determined by extensive calibration based on a modified photoionization cross sections [24]. A quantitative analysis of the surface atomic ratios of $\mathrm{S} / \mathrm{C}$ and $\mathrm{S} / \mathrm{Na}$ in the precursor was conducted in terms of the peak areas and the sensitivity factors $[15,16]$. The surface atomic ratio of $\mathrm{S} / \mathrm{Zr}\left(\mathrm{X}_{\mathrm{s}} / \mathrm{X}_{\mathrm{zr}}\right)$ in the anchored precursor was determined using Equation $2[15,16,22]$

$$
\left(\mathrm{X}_{\mathrm{s}} / \mathrm{X}_{\mathrm{Zr}}\right)_{\text {surface }}=\left(\mathrm{I}_{\mathrm{s}} \mathrm{g} \lambda_{\mathrm{Zr}} / \mathrm{I}_{\mathrm{Zr}} \mathrm{t}_{\mathrm{Zr}}{ }^{0}\right) /\left[\left(\sigma_{\mathrm{s}} \mathrm{E}_{\mathrm{Zr}} / \sigma_{\mathrm{Zr}} \mathrm{E}_{\mathrm{s}}\right)+\left(\mathrm{t}_{\mathrm{s}}{ }^{0} \mathrm{I}_{\mathrm{s}} / \mathrm{t}_{\mathrm{Zr}} \mathrm{I}_{\mathrm{Zr}}\right)\right] \text {, }
$$

where $\mathrm{g}$ is the escape angular factor, 0.75 [23], I is the measured photoelectron intensity, $\mathrm{t}_{\mathrm{s}}{ }^{\circ}$ is a sulfate ion size in the overlayer, $0.488 \mathrm{~nm}$ [25], and $\mathrm{t}_{\mathrm{Zr}}{ }^{\circ}$ is a monolayer thickness in bulk zirconium hydroxide, 0.182 [16]. The $\mathrm{S}$ and $\mathrm{Zr}$ photoelectron cross sections, $\sigma_{\mathrm{s}}$ and $\sigma_{\mathrm{Zr}}$, are 7.04 and 1.679 , respectively $[15,16]$, and $S 2 s$ and $\mathrm{Zr} 3 \mathrm{~d}$ kinetic energies, $\mathrm{E}_{\mathrm{s}}$ and $\mathrm{E}_{\mathrm{zr}}$, are 1316.7 and $1303.4 \mathrm{eV}$, respectively $[15,16]$. The escape depth, $\lambda_{\mathrm{Zr}}$, of photoelectrons of kinetic energy $\mathrm{E}_{\mathrm{Zr}}$ was calculated to be equal to $1.315 \mathrm{~nm}$ using Chang's empirical relationship [26],

$$
\lambda_{\mathrm{Zr}}=0.2 \mathrm{E}_{\mathrm{Zr}}^{1 / 2} \mathrm{t}_{\mathrm{Zr}}{ }^{\circ} .
$$

2.2.4. ${ }^{1} \mathrm{H}$ NMR and ${ }^{13} \mathrm{C}$ Solid State MAS NMR Spectroscopies. Solution state ${ }^{1} \mathrm{H}$ NMR spectra of the samples were recorded at $400 \mathrm{MHz}$ using standard library pulse sequences and $\mathrm{D}_{2} \mathrm{O}$ solution. ${ }^{13} \mathrm{C}$ solid state MAS NMR spectra were recorded with a GN300 spectrometer operating at $75.47 \mathrm{MHz}$. A DOTY Scientific double-tuned $7 \mathrm{~mm}$ double air bearing probe allowed spinning frequencies up to $5 \mathrm{kHz}$. Samples were loaded in ambient 
conditions with $25-50 \mathrm{mg}$ of $\mathrm{N}$-acetyl glycine as an internal standard. The measurements were carried out at room temperature using $3.5 \mu$ s pulse lengths (one-pulse experiments), 3.0 $\mathrm{kHz}$ spinning speed and a $60 \mathrm{~s}$ empirically determined relaxation delay. Conventional onepulse and single contact cross-polarization experiments were employed with proton decoupling during data acquisition.

2.2.5. Determination of Surface Area and Acid Exchange Capacities. The surface area of the samples was measured with a Gemini 2360 Surface Area Analyzer using the BET method [18]. The acid exchange capacities of the sample were determined using a solid acidtitration technique $[9,16,19]$. In a typical experiment, $0.05 \mathrm{~g}$ of solid sample was added to $\mathrm{NaCl}$ aqueous solution $(2 \mathrm{M}, 15 \mathrm{~mL}$ ). The resulting suspension was allowed to equilibrate and thereafter titrated potentiometrically by drop-wise addition of $0.01 \mathrm{M} \mathrm{NaOH}$ aqueous solution.

\section{Results and Discussion}

\section{1. ${ }^{1} \mathrm{H}$ NMR and ${ }^{13} \mathrm{C}$ Solid State MAS NMR Characterization of the Precursor and the Anchored Precursor.}

3.1.1. ${ }^{1} \boldsymbol{H}$ NMR Studies of the Precursor. The ${ }^{1} \mathrm{H}$ NMR spectrum of the synthetic precursor in $\mathrm{D}_{2} \mathrm{O}$ solution shows two peaks at 4.85 and $4.35 \mathrm{ppm}$, and two groups of narrow peaks centered at 4.19 and $3.90 \mathrm{ppm}$ (shown in [3]). The strong ${ }^{1} \mathrm{H}$ resonance signal at 4.35 ppm is assigned to the $\left[\mathrm{NaO}_{3} \mathrm{SO}-\mathrm{CH}_{2} \mathrm{CH}_{2}-\mathrm{OSO}_{3} \mathrm{Na}\right.$ ] ethyl species [27], while another ${ }^{1} \mathrm{H}$ signal at $4.85 \mathrm{ppm}$ is that of $\mathrm{HDO}$. A small amount of ${ }^{1} \mathrm{H}$ signal intensity of $\left[\mathrm{NaO}_{3} \mathrm{SO}\right.$ $\mathrm{CH}_{2} \mathrm{CH}_{2}-\mathrm{OSO}_{3} \mathrm{Na}$ ] and $\mathrm{HDO}$ species appears in the spinning sidebands. The lower intensity ${ }^{1} \mathrm{H}$ signals around 4.19 and $3.90 \mathrm{ppm}$ are attributed to a mono-sulfate species such as $\left[\mathrm{HOCH}_{2} \mathrm{CH}_{2} \mathrm{OSO}_{3} \mathrm{Na}\right]$ [27]. The ${ }^{1} \mathrm{H}$ intensities confirm that $\left[\mathrm{NaO}_{3} \mathrm{SO}-\mathrm{CH}_{2} \mathrm{CH}_{2}-\mathrm{OSO}_{3} \mathrm{Na}\right]$ was $96 \%$ of the organic compounds present in the precursor.

3.1.2. ${ }^{13}$ C MAS NMR Studies of the Precursor and the Anchored Precursor. The ${ }^{13} \mathrm{C}$ solid state MAS NMR spectrum of the precursor showed a high intensity narrow peak at $67.54 \mathrm{ppm}$, which is very close to the ${ }^{13} \mathrm{C}$ signal of $\mathrm{C}_{\alpha}$ in tetrahydrofuran $\left(\mathrm{C}_{4} \mathrm{H}_{8} \mathrm{O}\right)$ at $68 \mathrm{ppm}$ [27]. The single ${ }^{13} \mathrm{C}$ resonance signal indicates an equivalent chemical environment of the two adjacent carbons in the $-\mathrm{CH}_{2} \mathrm{CH}_{2}-$ group. Thus, the ${ }^{13} \mathrm{C}$ MAS NMR signal at $67.54 \mathrm{ppm}$ is assigned to the $\mu_{2}-\mathrm{CH}_{2} \mathrm{CH}_{2}-$ group of the precursor.

The anchored precursor yields a ${ }^{13} \mathrm{C}$ MAS NMR signal at $65.78 \mathrm{ppm}$, which is analogous to that of the precursor. This suggests that the $\mu_{2}-\mathrm{CH}_{2} \mathrm{CH}_{2}-$ group remained intact in the anchored precursor. However, the ${ }^{13} \mathrm{C}$ resonance peak of the anchored precursor gave a lower intensity and a small upfield shift $(67.54 \rightarrow 65.78 \mathrm{ppm}$, see figure in [3]), in comparison with that of the sodium precursor salt, $\left[\mathrm{NaO}_{3} \mathrm{SO}-\mathrm{CH}_{2} \mathrm{CH}_{2}-\mathrm{OSO}_{3} \mathrm{Na}\right]$. The lower intensity arising from the anchored precursor is expected due to the dilution effect upon bonding to the support. This is consistent with inference that the chemical environment around the $\mu_{2}-\mathrm{CH}_{2} \mathrm{CH}_{2}-$ group has changed upon anchoring. 


\subsection{NIR-DRS Characterization of the Precursor and the Anchored Precursor, and MMFF Simulation of the $\mathbf{C}-\mathbf{H}$ Vibrations.}

The NIR-DRS spectrum showed four NIR-DR C-H bands of the precursor at 5611, 5692,5845 and $6012 \mathrm{~cm}^{-1}$, while the anchored precursor exhibited other four $\mathrm{C}-\mathrm{H}$ peaks at 5622, 5717, 5829 and $5995 \mathrm{~cm}^{-1}$. Using the identifications assigned by ${ }^{1} \mathrm{H} \mathrm{NMR}$ and ${ }^{13} \mathrm{C}$ MAS NMR, these peaks were ascribed to the $\mathrm{C}-\mathrm{H}$ overtone and combination bands of the $\mu_{2}-\mathrm{CH}_{2} \mathrm{CH}_{2}-$ group [3]. To confirm further the assignment of the observed $\mathrm{C}-\mathrm{H}$ bands, fundamental vibrational frequencies of the $\left[\mathrm{NaO}_{3} \mathrm{SO}-\mathrm{CH}_{2}-\mathrm{CH}_{2}-\mathrm{OSO}_{3} \mathrm{Na}\right]$ were calculated using the MMFF94 package [17]. The bridging $\mu_{2}-\mathrm{CH}_{2} \mathrm{CH}_{2}-$ ligand is expected to yield four fundamental stretching frequencies in the $\mathrm{C}-\mathrm{H}$ region as listed in Table $1, v_{1}$ at $2913 \mathrm{~cm}^{-1}$ $(\mathrm{S}+\mathrm{S}), v_{2}$ at $2921 \mathrm{~cm}^{-1}(\mathrm{~S}-\mathrm{S}), v_{3}$ at $2992 \mathrm{~cm}^{-1}(\mathrm{~A}+\mathrm{A})$, and $v_{4}$ at $2993 \mathrm{~cm}^{-1}$ (A-A). The S and A symbols in parentheses denote the symmetric and antisymmetric modes of separate $\mathrm{CH}_{2}$ moieties, while the + and - signs represent in-phase and out-of-phase coupling of vibrations of the two $\mathrm{CH}_{2}$ moieties in the $\mu_{2}-\mathrm{CH}_{2} \mathrm{CH}_{2}-$ link. Approximating the $\mu_{2}-\mathrm{CH}_{2} \mathrm{CH}_{2}-$ bridge symmetry as $C_{2 v}$, these four vibrations correspond to $A_{1}\left(v_{1}\right), B_{1}\left(v_{2}\right), B_{2}\left(v_{3}\right)$ and $A_{2}\left(v_{4}\right)$ modes.

These four fundamental vibrations can combine into three overtone and combination band regions in the NIR spectrum. The region of interest of the combination bands and assignments are shown in Table 1, i. e. $5834\left(v_{1}+v_{2}\right), 5905\left(v_{1}+v_{3}\right), 5906\left(v_{1}+v_{4}\right), 5913$ $\left(v_{2}+v_{3}\right), 5914\left(v_{2}+v_{4}\right)$ and $5985\left(v_{3}+v_{4}\right) \mathrm{cm}^{-1}$. Based on the simulated combination models of the $\mathrm{C}-\mathrm{H}$ stretching vibrations in the $\mu_{2}-\mathrm{CH}_{2} \mathrm{CH}_{2}$ group of the $\left[\mathrm{NaO}_{3} \mathrm{SO}_{-} \mathrm{CH}_{2}-\right.$ $\mathrm{CH}_{2}-\mathrm{OSO}_{3} \mathrm{Na}$ ] (Table 1), the $5611 \mathrm{~cm}^{-1}$ band in spectrum A and the $5622 \mathrm{~cm}^{-1}$ band in spectrum B of Figure 3, are attributed to the $\left(v_{1}+v_{2}\right)$ of the $\mu_{2}-\mathrm{CH}_{2} \mathrm{CH}_{2}-$ group, while the $5692 \mathrm{~cm}^{-1}$ band in the precursor spectrum and $5717 \mathrm{~cm}^{-1}$ in the $\mathrm{Zr}(\mathrm{OH})_{4}$-anchored spectrum arise from an overlap of the $\left(v_{1}+v_{3}\right)$ and $\left(v_{1}+v_{4}\right)$ modes. The precursor $6012 \mathrm{~cm}^{-1}$ band and the $5995 \mathrm{~cm}^{-1}$ band in the anchored precursor are ascribed to the $\left(v_{3}+v_{4}\right)$ of the $\mu_{2}-\mathrm{CH}_{2} \mathrm{CH}_{2-}$ ligand, and the $5845 \mathrm{~cm}^{-1}$ band in the precursor spectrum and the $5829 \mathrm{~cm}^{-1}$ band in the spectrum of the anchored complex are assigned to another overlap band of the $\left(v_{2}+v_{3}\right)$ and $\left(v_{2}+v_{4}\right)$ modes (Table 1). The experimental NIR bands are also similar to those of ethylene glycol soaked into $\mathrm{MgO}\left(5679,5848,6333\right.$ and $6798 \mathrm{~cm}^{-1}$ in Table 1). Nevertheless, there are differences between the frequencies of the precursor and the MMFF94-simulated combination modes, which are mainly ascribed to the anharmonicities and strong coupling between the adjacent $\mathrm{CH}_{2}$ groups in the $\mu_{2}-\mathrm{CH}_{2} \mathrm{CH}_{2}-$ ligand. The analyses of ${ }^{1} \mathrm{H}$ and ${ }^{13} \mathrm{C}$ NMR, together with NIR-DR spectra and MMFF simulation, suggest the $-\mathrm{CH}_{2} \mathrm{CH}_{2}$ - ligand bridging two $-\mathrm{OSO}_{3}$ - groups in the precursor and an $\left[-\mathrm{O}_{3} \mathrm{SO}_{-} \mathrm{CH}_{2} \mathrm{CH}_{2} \mathrm{OSO}_{3}-\right]^{2-}$ group grafted onto the $\mathrm{Zr}(\mathrm{OH})_{4}$ surface in the anchored precursor. 
Table 1. The calculated and observed $\mathrm{C}-\mathrm{H}$ stretching frequencies of the $\mu_{2}-\mathrm{CH}_{2} \mathrm{CH}_{2}-$ group in the $\left[\mathrm{NaO}_{3} \mathrm{SO}-\mathrm{CH}_{2} \mathrm{CH}_{2}-\mathrm{OSO}_{3} \mathrm{Na}\right]$ molecule, the free precursor and the anchored precursor.

\begin{tabular}{|c|c|c|c|}
\hline $\begin{array}{l}\text { Model } \\
\text { or Sample }\end{array}$ & $\begin{array}{l}\text { Fundamental } \\
\text { Frequencies } \\
\left(\mathrm{cm}^{-1}\right)\end{array}$ & $\begin{array}{l}\text { Combination } \\
\text { Bands } \\
\left(\mathrm{cm}^{-1}\right)\end{array}$ & Assignment \\
\hline $\begin{array}{l}{\left[\mathrm{NaO}_{3} \mathrm{SO}-\mathrm{CH}_{2-}-\right.} \\
\left.\quad \mathrm{CH}_{2}-\mathrm{OSO}_{3} \mathrm{Na}\right]\end{array}$ & $\begin{array}{l}2913, v_{1}(\mathrm{~S}+\mathrm{S}) \\
2921, v_{2}(\mathrm{~S}-\mathrm{S}) \\
2992, v_{3}(\mathrm{~A}+\mathrm{A}) \\
2993, v_{4}(\mathrm{~A}-\mathrm{A})\end{array}$ & $\begin{array}{l}5834^{\mathrm{a}} \\
5905^{\mathrm{a}} \\
5906^{\mathrm{a}} \\
5913^{\mathrm{a}} \\
5914^{\mathrm{a}} \\
5985^{\mathrm{a}}\end{array}$ & $\begin{array}{l}\left(v_{1}+v_{2}\right) \\
\left(v_{1}+v_{3}\right) \\
\left(v_{1}+v_{4}\right) \\
\left(v_{2}+v_{3}\right) \\
\left(v_{2}+v_{4}\right) \\
\left(v_{3}+v_{4}\right)\end{array}$ \\
\hline precursor & & $\begin{array}{l}5611^{\mathrm{b}} \\
5692^{\mathrm{b}} \\
5845^{\mathrm{b}} \\
6012^{\mathrm{b}}\end{array}$ & $\begin{array}{l}\left(v_{1}+v_{2}\right) \\
\left(v_{1}+v_{3}\right),\left(v_{1}+v_{4}\right) \\
\left(v_{2}+v_{3}\right),\left(v_{2}+v_{4}\right) \\
\left(v_{3}+v_{4}\right)\end{array}$ \\
\hline anchored precursor & & $\begin{array}{l}5622^{\mathrm{b}} \\
5717^{\mathrm{b}} \\
5829^{\mathrm{b}} \\
5995^{\mathrm{b}}\end{array}$ & $\begin{array}{l}\left(v_{1}+v_{2}\right) \\
\left(v_{1}+v_{3}\right),\left(v_{1}+v_{4}\right) \\
\left(v_{2}+v_{3}\right),\left(v_{2}+v_{4}\right) \\
\left(v_{3}+v_{4}\right)\end{array}$ \\
\hline \multicolumn{2}{|c|}{ ethylene glycol soaked in $\mathrm{MgO}$} & $\begin{array}{l}5679^{\mathrm{b}} \\
5848^{\mathrm{b}} \\
6333^{\mathrm{b}} \\
6798^{\mathrm{b}}\end{array}$ & $\begin{array}{l}\left(v_{1}+v_{2}\right) \\
\left(v_{1}+v_{3}\right),\left(v_{1}+v_{4}\right) \\
\left(v_{2}+v_{3}\right),\left(v_{2}+v_{4}\right) \\
\left(v_{3}+v_{4}\right)\end{array}$ \\
\hline
\end{tabular}

${ }^{a}$ the calculated bands; ${ }^{b}$ the observed bands.

In addition, the NIR-DR spectrum of the precursor showed extremely narrow $\mathrm{H}_{2} \mathrm{O}$ overtone bands at $5100 \mathrm{~cm}^{-1}\left(v_{2}+v_{3}\right)[28]$ with $97 \mathrm{~cm}^{-1} \mathrm{FWHM}$ (full width at half maximum) and $7080 \mathrm{~cm}^{-1}\left(v_{1}+v_{3}\right)$ [28] with $147 \mathrm{~cm}^{-1}$ FWHM, indicating that crystal water was 
contained in the precursor $[28,29]$. The intensities of the overtone bands of crystal water greatly decreased on passing to the anchored precursor, indicating loss of the water of crystallization.

\subsection{HR-XPS Characterization of the Precursor and the Anchored Precursor.}

3.3.1. HR-XPS Analysis of the Precursor. HR-XPS analysis of the precursor was carried out in order to probe the surface composition. The $S 2 p_{3 / 2}$ binding energy at $168.8 \mathrm{eV}$ was used as an internal standard for all peak positions [16,21]. The XPS spectra are shown in [3], and the precursor showed the $S 2 p_{3 / 2}$ binding energy at $168.80 \mathrm{eV}$ and $\mathrm{S} 2 \mathrm{p}_{1 / 2}$ binding energy at $170.00 \mathrm{eV}$. The $\mathrm{C} 1 \mathrm{~s}$ binding energies for the precursor were observed at 284.97, 286.84 , and $288.73 \mathrm{eV}$, where $286.84 \mathrm{eV}$ corresponds to carbon in $\mathrm{a} \equiv \mathrm{C}-\mathrm{O}-$ bond [30]. The binding energies of other elements in the precursor are listed in Table 2. The O1s binding energies observed at 531.77 and $533.17 \mathrm{eV}$ suggest that the precursor contained two types of sulfur-oxygen bonds, namely, $\mathrm{S}=\mathrm{O}$ and $\mathrm{S}-\mathrm{O}$ bonds $[4,9,31]$. The Na1s binding energy was found at $1071.48 \mathrm{eV}$. The peak intensities and atomic ratios in the precursor are presented in Table 2. The $\mathrm{Na} / \mathrm{S} / \mathrm{C}$ ratio (where $\mathrm{C}$ is only the carbon from the $\equiv \mathrm{C}-\mathrm{O}-$ bond) was calculated to be 13.0/10.0/4.0. Assuming the precursor formula contains $\mathrm{x}\left[\mathrm{NaO}_{3} \mathrm{SO}\right.$ $\left.\mathrm{CH}_{2} \mathrm{CH}_{2}-\mathrm{OSO}_{3} \mathrm{Na}\right]$ and $\mathrm{y}\left[\mathrm{Na}_{2} \mathrm{SO}_{4}\right]$, the composition calculated from the $\mathrm{Na} / \mathrm{S} / \mathrm{C}$ ratio indicates that the initial precursor consisted of $40 \%\left[\mathrm{NaO}_{3} \mathrm{SO}-\mathrm{CH}_{2} \mathrm{CH}_{2}-\mathrm{OSO}_{3} \mathrm{Na}\right]$ and $60 \%$ $\left[\mathrm{Na}_{2} \mathrm{SO}_{4}\right]$ (Table 2). This information, together with the ${ }^{1} \mathrm{H}$ NMR, ${ }^{13} \mathrm{C}$ MAS NMR, and NIRDR spectra of the precursor, confirm the structure of the precursor as

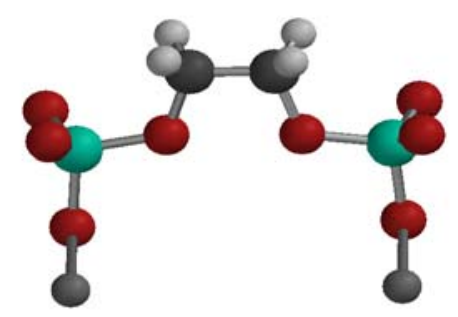

Atom color codes are follows: $C$, black; H, light-gray; $O$, red; S, blue-green; Na, gray. 
Table 2. XPS binding energies, peak intensities, and surface atomic ratios.

\section{A. Precursor}

\begin{tabular}{|c|c|c|c|c|}
\hline & B. E. $(\mathrm{eV})$ & Peak Intensity $^{\text {a }}$ & $\mathrm{S} / \mathrm{C}^{\underline{\mathrm{b}}}$ & $\mathrm{S} / \mathrm{Na}^{\underline{\mathrm{b}}}$ \\
\hline $\mathrm{S} 2 \mathrm{p}_{\text {total }}$ & & 2514 & $1.0: 0.3$ & $1.0: 1.0$ \\
\hline $\mathrm{S} 2 \mathrm{p}_{3 / 2}$ & 168.80 & 1695 & & \\
\hline$\underline{\mathrm{S} 2 \mathrm{p}_{1 / 2}}$ & 170.00 & 806 & & \\
\hline C $1 s_{\text {total }}$ & & 1596 & & \\
\hline $\mathrm{C} 1 \mathrm{~s}$ & 284.97 & 750 & & \\
\hline $\mathrm{C} 1 \mathrm{~s}$ & 286.84 & 687 & $1.0: 0.3$ & \\
\hline$\underline{\mathrm{C} 1 \mathrm{~s}}$ & 288.73 & 147 & & \\
\hline $\mathrm{O} 1 \mathrm{~s}_{\text {total }}$ & & 8185 & & \\
\hline $\mathrm{O} 1 \mathrm{~s}$ & ---- & & & \\
\hline $\mathrm{O} 1 \mathrm{~s}$ & 531.77 & 5964 & & \\
\hline$\underline{\mathrm{O} 1 \mathrm{~s}}$ & 533.17 & 2221 & & \\
\hline $\mathrm{Na} 1 \mathrm{~s}$ & 1071.48 & 2447 & & 1.0:1.0 \\
\hline $\mathrm{Zr} 3 \mathrm{~d}_{\text {total }}$ & ---- & & & \\
\hline $\operatorname{Zr} 3 \mathrm{~d}_{5 / 2}$ & ---- & & & \\
\hline$\underline{\mathrm{Zr} \mathrm{3}} \mathrm{d}_{3 / 2}$ & ---- & & & \\
\hline \multicolumn{5}{|c|}{$40 \%\left[\mathrm{NaOSO}_{3}-\mathrm{CH}_{2} \mathrm{CH}_{2}-\mathrm{OSO}_{3} \mathrm{Na}\right]+60 \% \mathrm{Na}_{2} \mathrm{SO}_{4}$} \\
\hline
\end{tabular}

B. Anchored Precursor

\begin{tabular}{|c|c|c|c|c|}
\hline & B. E. $(\mathrm{eV})$ & Peak Intensity $^{\mathrm{a}}$ & $\mathrm{S} / \mathrm{C}^{\underline{\mathrm{b}}}$ & $\mathrm{S} / \mathrm{Zr}^{\mathrm{b}}$ \\
\hline $\mathrm{S} 2 \mathrm{p}_{\text {total }}$ & & 301 & $1.0: 1.0$ & $0.70: 1.0$ \\
\hline $\mathrm{S} 2 \mathrm{p}_{3 / 2}$ & 168.80 & 224 & & \\
\hline$\underline{\mathrm{S} 2 \mathrm{p}_{1 / 2}}$ & 170.00 & 77 & & \\
\hline $\mathrm{C} 1 \mathrm{~s}_{\text {total }}$ & & 913 & & \\
\hline C 1s & 284.93 & 545 & & \\
\hline $\mathrm{C} 1 \mathrm{~s}$ & 286.80 & 248 & 1.0:1.0 & \\
\hline$\underline{\mathrm{C} 1 \mathrm{~s}}$ & 288.67 & 120 & & \\
\hline $\mathrm{O} 1 \mathrm{~s}_{\text {total }}$ & & 3601 & & \\
\hline $\mathrm{O} 1 \mathrm{~s}$ & 530.14 & 1496 & & \\
\hline $\mathrm{O} 1 \mathrm{~s}$ & 531.61 & 1474 & & \\
\hline$\underline{\mathrm{O} 1 \mathrm{~s}}$ & 532.72 & 631 & & \\
\hline $\mathrm{Na} \mathrm{1s}$ & ---- & & & \\
\hline$\overline{\mathrm{Zr} 3 \mathrm{~d}_{\text {total }}}$ & & 1623 & & $0.70: 1.0$ \\
\hline $\operatorname{Zr} 3 \mathrm{~d}_{5 / 2}$ & 182.49 & 974 & & \\
\hline$\underline{\mathrm{Zr} \mathrm{3}} \mathrm{d}_{3 / 2}$ & 184.91 & 656 & & \\
\hline
\end{tabular}


C. Surface-grafted Acid Groups

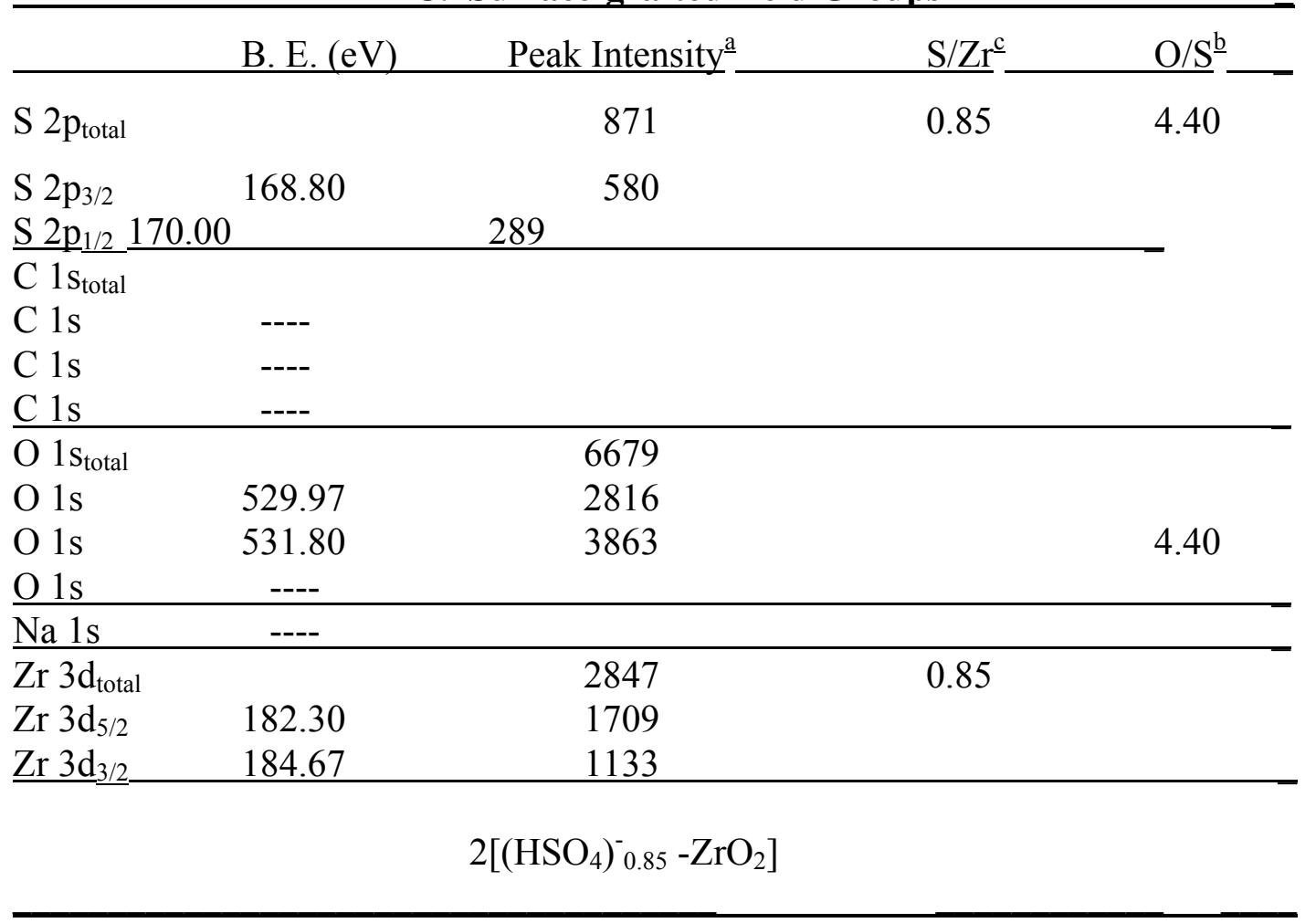

${ }^{\mathrm{a}}$ peak intensity $=$ peak area/sensitivity factor

${ }^{b}$ the peak intensity ratio

${ }^{\mathrm{c}} \mathrm{S} / \mathrm{Zr}$ ratio was determined using Equation 2

3.3.2. HR-XPS Analysis of the Anchored Precursor. For the anchored precursor, XPS of S2p, Zr3d, O1s, Na1s, N1s, and C1s were investigated, and the S2 $\mathrm{p}_{3 / 2}$ and S2 $\mathrm{p}_{1 / 2}$ binding energies were observed at 168.8 and $170.0 \mathrm{eV}$, respectively. The $\mathrm{C} 1 \mathrm{~s}$ binding energy was observed at $286.80 \mathrm{eV}$, corresponding to carbon of an oxygenate species. The observed binding energies, peak intensities and concentration of elements in the anchored precursor are listed in Table 2. A 1.0/1.0 of S/C (where $\mathrm{C}$ is only carbon of the $\equiv \mathrm{C}-\mathrm{O}-$ bond species) atomic ratio in the anchored precursor is consistent with the $\mathrm{S} / \mathrm{C}$ ratio in the $\left[\mathrm{NaO}_{3} \mathrm{SO}\right.$ $\mathrm{CH}_{2} \mathrm{CH}_{2}-\mathrm{OSO}_{3} \mathrm{Na}$ ] species of the precursor. Three O1s peaks are observed at 532.72, 531.61 and $530.14 \mathrm{eV}$ (Table 2). The lower O1s binding energy at $530.14 \mathrm{eV}$ is ascribed to the lattice oxygen of the zirconium hydroxide, while the higher O1s binding energies at 531.61 and $532.72 \mathrm{eV}$ correspond to the oxygens of the sulfate ester groups [6,9,15,16,31]. Furthermore, the $\mathrm{O} 1 \mathrm{~s}$ binding energy shifts in the $-\mathrm{OSO}_{3}-$ group between the precursor and the anchored precursor ( 531.77 to $531.61 \mathrm{eV}$ and 533.17 to $532.72 \mathrm{eV}$ ) were observed (Table 2). This implies an interaction between the $-\mathrm{OSO}_{3}-$ group and the zirconium. The $\mathrm{Zr3d}$ binding energies are observed at 182.49 and $184.91 \mathrm{eV}$ (Table 2). The surface atomic ratio of the sulfate-to-zirconium in the anchored precursor was determined from Equation 2 
to be 0.70/1.0, as shown in Table 2. The Na1s and N1s peaks were not found in the XPS spectrum, showing that the $\mathrm{Na}^{+}$and $\mathrm{NH}_{4}{ }^{+}$cations of the precursor were completely removed on passing to the anchored precursor. The stoichiometry of zirconium hydroxide anchoring of the precursor is represented by Equations 4 and 5 .

$$
\begin{aligned}
& {\left[\mathrm{NaO}_{3} \mathrm{SO}-\mathrm{CH}_{2} \mathrm{CH}_{2}-\mathrm{OSO}_{3} \mathrm{Na}\right]+2 \mathrm{NH}_{4}{ }^{+}-\mathrm{R} \rightarrow} \\
& {\left[\mathrm{NH}_{4} \mathrm{O}_{3} \mathrm{SO}-\mathrm{CH}_{2} \mathrm{CH}_{2}-\mathrm{OSO}_{3} \mathrm{NH}_{4}\right]+2 \mathrm{Na}^{+}-\mathrm{R}} \\
& {\left[\mathrm{NH}_{4} \mathrm{O}_{3} \mathrm{SO}-\mathrm{CH}_{2} \mathrm{CH}_{2}-\mathrm{OSO}_{3} \mathrm{NH}_{4}\right]+2 \mathrm{Zr}(\mathrm{OH})_{4} \rightarrow} \\
& {\left[(\mathrm{OH})_{3} \mathrm{ZrO}_{3} \mathrm{SO}-\mathrm{CH}_{2} \mathrm{CH}_{2}-\mathrm{OSO}_{3} \mathrm{Zr}(\mathrm{OH})_{3}\right]+2 \mathrm{NH}_{4} \mathrm{OH}}
\end{aligned}
$$

Based on the above analysis, the structure of the anchored precursor is proposed to be

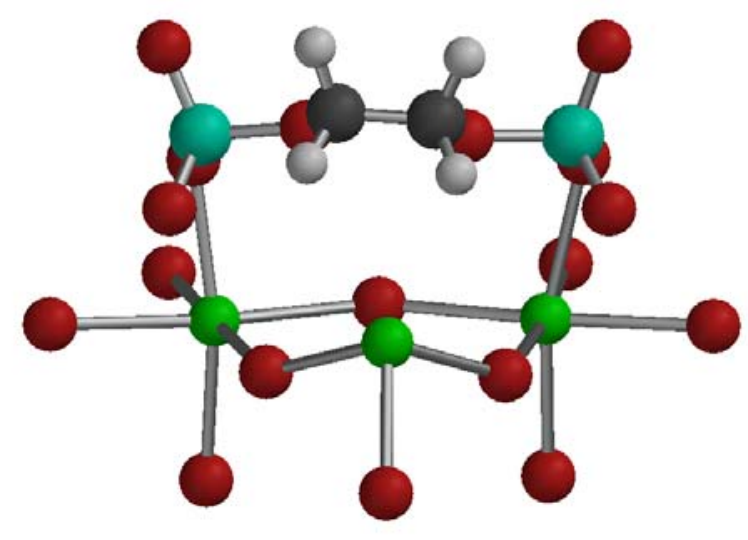

Atom color codes are as follows: $C$, black; $\mathrm{H}$, light-gray; $\mathrm{O}$, red; $\mathrm{S}$, blue-green, $\mathrm{Zr}$, green.

The anchored precursor was calcined at $500^{\circ} \mathrm{C}$ to remove the $\mu_{2}-\mathrm{CH}_{2} \mathrm{CH}_{2}-$ ligand, resulting in the formation of surface-grafted acid groups $2\left[\left(\mathrm{H}_{\mathrm{y}} \mathrm{SO}_{4}\right)^{-(2-\mathrm{y})}{ }_{\mathrm{x}}-\mathrm{ZrO}_{2}\right]$ on the zirconia support [1]. The so-functionalized zirconia exhibited $0.71 \mathrm{mmol} / \mathrm{g}$ surface sulfur concentration (based on the XPS analysis) and $0.70 \mathrm{meq} / \mathrm{g}$ acid exchange capacity, while the unpromoted $\mathrm{ZrO}_{2}$ support exhibited no proton exchange capacity under the same titration condition. The BET surface area was $97 \mathrm{~m}^{2} / \mathrm{g}$ for the calcined sample, and XPS quantitative determination of the sample yielded the ratios 0.85 for $\mathrm{S} / \mathrm{Zr}$ and $\sim 4.0$ for $\mathrm{O} / \mathrm{S}$, where $\mathrm{O}$ was only the oxygen from the hydrogen sulfonic group. The results suggest that the surfacegrafted acid groups correspond to the formula $2\left[\left(\mathrm{HSO}_{4}\right)^{-}{ }_{0.85}-\mathrm{ZrO}_{2}\right]$ on the surface. Such $2\left[\left(\mathrm{HSO}_{4}\right)_{0.85}^{-}-\mathrm{ZrO}_{2}\right]$ groups grafted on the zirconia surface possessed proximal acid sites favoring high activity and selective catalysis for the alcohols coupling to ethers [1]. 
A sulfated zirconia catalyst prepared by the usual method of impregnation of hydrous zirconium hydroxide [9], followed by calcination at $620^{\circ} \mathrm{C}$, yielded a surface area of $60 \mathrm{~m}^{2} / \mathrm{g}$ and exhibited surface acidity of $0.25,0.26$, and $0.29 \mathrm{mmol} / \mathrm{g}$, based on S/Zr XPS analysis, chemical analysis, and ion exchange titration, respectively [16]. These data indicate that all sulfur was on the surface of the catalyst and that every sulfate group was monoprotonated. The same impregnated catalyst calcined only to $500^{\circ} \mathrm{C}$ possessed a surface area of $72 \mathrm{~m}^{2} / \mathrm{g}$ and exhibited a concentration of surface acid sites of $0.31 \mathrm{mmol} / \mathrm{g}$, as determined by $\mathrm{N} 1 \mathrm{~s}$ XPS analysis of pyridine adsorbed at $150^{\circ} \mathrm{C}$ [16]. For these two catalysts, the concentrations correspond to $4.2-4.8 \mu \mathrm{mol}$ acid sites $/ \mathrm{m}^{2}$ of surface. The new $\left[\left(\mathrm{CH}_{2} \mathrm{OSO}_{3}-\mathrm{Zr}(\mathrm{OH})_{3}\right]_{2}\right.$-derived catalyst reported here was tested and compared with the impregnated catalyst calcined at $620^{\circ} \mathrm{C}$, and it was shown that the new catalyst exhibited a $78 \%$ higher space time yield of methylisobutylether (MIBE) formed by methanol/isobutanol coupling [1]. The new catalyst described here was prepared using the ethanediol bridge to form sulfate acid sites in proximity, and it possessed a surface concentration of acid sites of $7.2-7.3 \mu \mathrm{mol} / \mathrm{m}^{2}$, which is a $50-74 \%$ increase in acid site density over that observed for sulfate-impregnated catalysts. Thus, the increased number of surface acid sites achieved here yielded an improved catalyst for MIBE synthesis.

\section{Conclusions}

The results demonstrated the successful synthesis of the disodium 1,2-ethanediol, bis(hydrogen sulfate) compound and the anchored form on zirconium hydroxide. The HRXPS, NIR-DR, ${ }^{1} \mathrm{H}$ NMR and ${ }^{13} \mathrm{C}$ solid state MAS NMR spectra, as well as MMFF simulation, confirm the structure and composition of the samples. The surface-grafted acid groups derived from the anchored precursor showed a high concentration of Brønsted acid sites. This work illustrates a new method for preparing anchored Brønsted acid functionalities on supports, which have utility for surface reactions that proceed by dual acid site mechanism.

\section{References to Chapter I:}

1. Shen, J. G. C.; Kalantar, T. H.; Ma, Q.; Herman, R. G.; Klier, K., J. Chem. Soc., Chem. Commun. (2001) 653.

2. Klier, K.; Herman, R. G.; Kwon, H.-H.; Shen, J. G. C.; Ma, Q.; Hunsicker, R. A.; Butler, A. P.; Bollinger, S. J., Final Technical Report DE-FG26-98FT40113-F of "Catalysts for High Cetane Ethers as Diesel Fuels," 67 pp (Nov. 2002).

3. Shen, J. G. C.; Kalantar, T. H.; Herman, R. G.; Roberts, J. E.; Klier, K., Chem. Mater. 13 (2001) 4479. 
4. (a) Nunan, J.; Klier, K.; Herman, R. G., J. Chem. Soc., Chem. Commun., (1985) 676. (b) Nunan, J. G.; Klier, K.; Herman, R. G., J. Catal. 139 (1993) 406. (c) Feeley, O. C.; Sun, Q.; Herman, R. G.; Johansson, M.; Lietti, L.; Klier K., Catal. Lett. 35 (1995) 13.

5. (a) Olah, G. A.; Sutya Parkash, G. K.; Sommer, J. “Superacids,” John Wiley \& Sons, New York (1985); p 53. (b) Tanabe, K.; Misono, M.; Ono, Y.; Hattori, H. in "New Solid Acids and Bases," Eds.; Delmon, B.; Yates, J. T., Elsevier, Amsterdam (1989).

6. (a) Yamaguchi, T.; Jin, T.; Tanabe, K., J. Phys. Chem., 90 (1986) 3148. (b) Jin, T.; Yamaguchi, T.; Tanabe, K., J. Phys. Chem., 90 (1986) 4794.

7. (a) Scheithauer, M.; Grasselli, R. K.; Knözinger, H., Langmuir, 14 (1998) 3019. (b) Boyse, R. A.; Ko, E. I., J. Catal., 179 (1998) 100. (c) Barton, D. G.; Soled, S. L.; Meitzner, G. D.; Fuentes, G. A.; Iglesia, E., J. Catal., 181 (1999) 57.

8. (a) Margolese, D.; Melero, J. A.; Christiansen, S. C.; Chmelka, B. F.; Stucky, G. D., Chem. Mater., 12 (2000) 2448. (b) Ciesla, U.; Fröba, M.; Stucky, G. D.; Schüth, F., Chem. Mater., 11 (1999) 227.

9. (a) Hino, M.; Kobayashi, S.; Arata, K., J. Am. Chem. Soc., 101 (1979) 6439. (b) Hino, M.; Arata, K., J. Chem. Soc., Chem. Comm., (1980) 851.

10. (a) Olah, G. A.; Kaspi, J.; Bukala, J., J. Org. Chem., 42 (1977) 4187. (b) Kaspi, J.; Montgomery, D. D.; Olah, G. A., J. Org. Chem., 43 (1978) 3147.

11. Klier, K.; Kwon, H. H.; Herman, R. G.; Hunsicker, R. A.; Ma, Q.; Bollinger, S. J., in $12^{\text {th }}$ International Congress Catalysis, Eds., Corma, A.; Melo, F. V.; Mendioroz, A.; Fierro, F. L. S., Elsevier, Amsterdam (2000) p 3447.

12. (a) Klier, K.; Herman, R. G.; Johansson, M. A.; Feeley, O. C., Preprints, Div. Fuel. Chem. ACS, 37(1) (1992) 236. (b) Feeley, O. C.; Johansson, M. A.; Herman, R. G.; Klier, K., Preprints, Div. Fuel. Chem. ACS, 37(4) (1992) 343. (c) Herman, R. G.; Klier, K.; Feeley, O. C.; Johansson, M. A., Preprints, Div. Fuel. Chem. ACS, 39(2) (1994) 343.

13. Sun, Q.; Lietti, L.; Herman, R. G.; Klier, K., Preprints, Div. Fuel. Chem. ACS, 40(1) (1995) 138.

14. Streitweiser, A.; Heathcock, C. H., "Introduction to Organic Chemistry," $2^{\text {nd }}$ Ed., Macmillan, New York (1981) p162.

15. Johansson, M.; Klier, K., Topics Catal., 4 (1997) 99. 
16. Johansson, M., Ph.D. Dissertation, Lehigh University, Bethlehem, PA, USA (1995).

17. Merck Molecular Force Field Program (1994).

18. Brunauer, S.; Emmett, P. H.; Teller, E., J. Am. Chem. Soc., 60 (1938) 309.

19. Forni, L., Catal. Rev., 8 (1973) 65.

20. (a) The discussion of validity of the SKM theory is given in Kortüm, G., "Reflectance Spectroscopy," Springer-Verlag, New York (1969) pp 103-127, 170-216. (b) Klier, K., J. Opt. Soc. Amer., 62 (1972) 882.

21. Chaney, R. L.; Simmons, G. W., R\&D Magazine (1990) 83.

22. (a) Dreiling, M. J., Surf. Sci., 71 (1978) 231. (b) Himelfarb, P. B., Ph.D. Dissertation, Lehigh University, Bethlehem, PA, USA (1986).

23. Vedage, G. A.; Himelfarb, P. B.; Simmons, G. W.; Klier, K., ACS Symp. Ser., 279 (1985) 295.

24. Scofield, J. H., J. Electron Spectrosc. Relat. Phenom., 8 (1976) 129.

25. Huheey, J. E.; Keiter, E. A.; Keiter, R. L., "Inorganic Chemistry: Principles of Structure and Reactivity," $4^{\text {th }}$ ed., Harper Collins College Publ., New York (1993).

26. Chang, C. C., Surface Sci., 48 (1975) 9.

27. Kemp W. “NMR in Chemistry,” Macmillan Publ. Co., New York, (1988).

28. Herzberg, G, "Infrared and Raman Spectra," Van Nostrand Reinhold Co., New York (1945) p 281.

29. Klier, K.; Shen, J. H.; Zettlemoyer, A. C., J. Phys. Chem., 77 (1973) 1458.

30. Moulder, J. F.; Stickle, W. F.; Sobul, P. E.; Bomben, K. D., "Handbook of X-Ray Photoelectron Spectroscopy," Ed.; Chastain, J. Perkin-Elmer Corp. (1992).

31. (a) Morterra, C.; Cerrato, G.; Emanuel, C.; Bolis, V., J. Catal., 142 (1993) 349. (b) Morterra, C.; Cerrato, G.; Bolis, V., Catal. Today, 17 (1993) 505. 


\section{Chapter II. Sulfonic Acid-Functionalized Mesoporous Silica: Synthesis, Characterization, and Catalytic Reaction of Alcohol Coupling to Ethers}

The large number of zeolites now available provides for a variety of novel and selective catalytic reactions. However, complex cages and narrow channels in these zeolites can prevent the formation of branch-chain hydrocarbons/oxygenates from simpler molecules. For example, Sun et al. [1] reported alcohol coupling to form unsymmetrical ethers inside HZSM-5, where the cross coupling of ethanol and pentan-2-ol could not proceed either inside straight-type channels or elliptical-type channels but did proceed in the large space at the intersection of the channels. The result is consistent with inference that the narrow channels of ZSM-5 did not allow the ethanol to attack the pentan-2-ol adsorbed at internal Brønsted acid sites but only at the channel intersections, where the attack was from the rear end of the asymmetric carbon via an $\mathrm{S}_{\mathrm{N}} 2$ reaction pathway to yield a chirally inverted ether [1].

Thus, a large pore silica with internal strong acid species, high surface area, large void space, and thermal stability is expected to effectively catalyze ether formation. During the past decade, high surface mesoporous and relatively high thermal stabilities silica materials have been successfully synthesized [2-4]. These materials have recently been derived with Brønsted acid functionalities by covalent attachment of alkylsulfonic acid groups to the silica cavities [5]. To increase the concentration of the acid species, a direct synthesis method was used to synthesize periodic ordered sulfonic acid-functionalized mesoporous silica [4a]. This involves a one-step synthetic strategy based on the hydrolysis followed by co-condensation of tetraethoxysilane (TEOS) and 3-mercatopropyltrimethoxysilane (MPTMS) under the templating of Pluronic 123 copolymer and in situ oxidation of thiol groups by $\mathrm{H}_{2} \mathrm{O}_{2}$ in aqueous acidic solution. The synthesis technique has now been employed by us to form a solid acid catalyst that is selective in the formation of unsymmetrical ethers, i.e. the high cetane methylisobutylether, from alcohols at moderate temperatures and ambient pressure.

\section{Synthesis Technique}

A 4 g portion of Pluronic 123 (poly(ethylene glycol)-block-poly(propylene glycol)block-poly(ethylene glycol), $\mathrm{EO}_{20} \mathrm{PO}_{70} \mathrm{EO}_{20}, M_{\mathrm{av}}=5800$, Aldrich) was dissolved with stirring in $125 \mathrm{~g}$ of $1.9 \mathrm{M} \mathrm{HCl}$ solution at room temperature. After adding $32.8 \mathrm{mmol}$ TEOS $(99+\%$, Aldrich), the resultant solution was equilibrated for $3 \mathrm{hr}$ for pre-hydrolysis, and then 8.2 mmol MPTMS (95\%, Aldrich) and $73.8 \mathrm{mmol} \mathrm{H}_{2} \mathrm{O}_{2}(30 \mathrm{wt} \%$, Aldrich) were added to the solution. The resulting mixture was stirred at $313 \mathrm{~K}$ for $20 \mathrm{hr}$ and then transferred into a polypropylene bottle for aging an additional $24 \mathrm{hr}$ at $373 \mathrm{~K}$ under static conditions. The solid product was obtained by filtration and dried in ambient atmosphere overnight. The template was removed from the as-synthesized material by refluxing in ethanol for $24 \mathrm{hr}(1.5 \mathrm{~g}$ of assynthesized material per $400 \mathrm{~mL}$ of ethanol), filtering, washing with separate portions of water and ethanol, and drying at $333 \mathrm{~K}$, yielding the extracted sulfonic acid-functionalized SBA-15 material [4a]. 


\section{X-Ray Powder Diffraction}

The X-ray powder diffraction (XRD) pattern of the sample showed $\mathrm{d}_{100}=74 \AA$ and a small (200) peak, indicating that mesoporous silica with channels of $74 \AA$ diameter was synthesized, which has a two-dimensional $p 6 \mathrm{~mm}$ hexagonal symmetry with a well-ordered hexagonal array and one-dimensional channel structure [4]. The XRD data are in agreement with those reported by other authors for samples prepared under similar conditions [4a].

\section{High resolution X-ray photoelectron spectroscopy (HR-XPS)}

HR-XPS analyses of the extracted sulfonic acid-functionalized SBA-15 material were carried out at $5 \times 10^{-9}$ Torr using the Scienta ESCA-300 photoelectron spectrometer at Lehigh University [6]. The S2p, O1s, Si2p, Si2s, and C1s spectral regions were recorded with $150 \mathrm{eV}$ pass energy, an incremental step size of $0.05 \mathrm{eV}$ and a $0.8 \mathrm{~mm}$ slit width. The $\mathrm{S}_{2} \mathrm{p}_{3 / 2}$ binding energy (BE) at $168.8 \mathrm{eV}$ was used as an internal standard for all peak positions [6]. Resolution of the $S 2 p$ peaks indicated that two sulfur species were present: $S_{I}$ at $168.8 \mathrm{eV}\left(\mathrm{S} 2 \mathrm{p}_{3 / 2}\right) \mathrm{S}_{\mathrm{II}}$ at approximately $164.4 \mathrm{eV}$, as shown in Figure 1. The $\mathrm{S} 2 \mathrm{p}_{3 / 2}$ and $\mathrm{S} 2 \mathrm{p}_{1 / 2}$ components were not experimentally resolved.

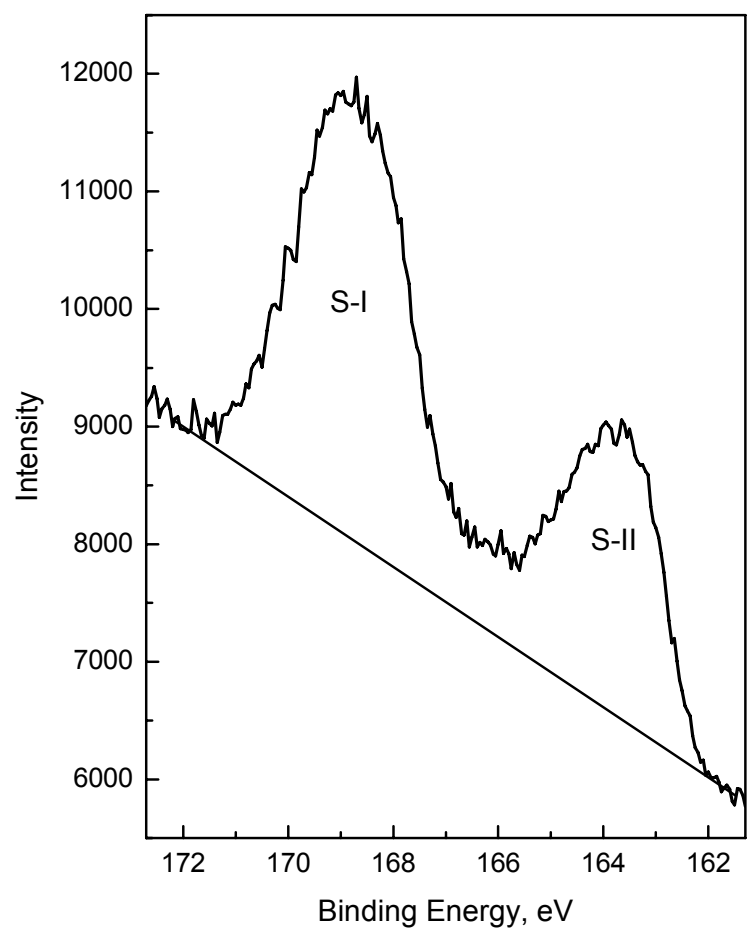

Figure 1. The S2p XPS spectrum of the extracted propanesulfonic acidderivatized SBA-15 catalyst. 
The higher S2p binding energy $\left(\mathrm{S}_{\mathrm{I}}\right)$ corresponds to oxidized sulfur in an anchored $\equiv \mathrm{Si}\left(\mathrm{CH}_{2}\right)_{3} \mathrm{SO}_{3} \mathrm{H}$ species ( $\equiv \mathrm{Si}$ represents $\mathrm{Si}$ bonded to three framework atoms), and the lower S2p binding energy $\left(\mathrm{S}_{\mathrm{II}}\right)$ is sulfur remaining in the original reduced thiol state, i.e. in unoxidized $\equiv \mathrm{Si}\left(\mathrm{CH}_{2}\right)_{3} \mathrm{SH}[7,8]$. The $\mathrm{C} 1 \mathrm{~s} \mathrm{BE}$ was observed at $284.27 \mathrm{eV}$. The $\mathrm{O} 1 \mathrm{~s} \mathrm{BE}$ was found at $532.08 \mathrm{eV}$, and $\mathrm{Si} 2 \mathrm{p} \mathrm{BE}$ at $102.75 \mathrm{eV}$ resulted from an overlap of $\mathrm{Si} 2 \mathrm{p}_{3 / 2}$ and $\mathrm{Si} 2 \mathrm{p}_{1 / 2}$ binding energies. The sulfur ratio between $\equiv \mathrm{Si}\left(\mathrm{CH}_{2}\right)_{3} \mathrm{SH}$ and $\equiv \mathrm{Si}\left(\mathrm{CH}_{2}\right)_{3} \mathrm{SO}_{3} \mathrm{H}$ species was calculated to be $0.5 / 1.0$, suggesting two-thirds of the initial $\equiv \mathrm{Si}\left(\mathrm{CH}_{2}\right)_{3} \mathrm{SH}$ groups (but not all) were oxidized to alkylsulfonic acid groups bonded onto the mesoporous silica. SBA-15 samples subsequently prepared in this research (discussed later in this report) were demonstrated to have all of the original thiol groups completely oxided to the sulfonic acid species.

\section{Surface Area and Surface Acid Concentration}

The extracted sulfonic acid-functionlized SBA-15 material had a BET surface area of $674 \mathrm{~m}^{2} / \mathrm{g}$. The solid acid-titration technique [4a,7c] was used to determine the acid exchange capacity as 1.64 meq $\mathrm{H}^{+} / \mathrm{g} \mathrm{SiO}_{2}$, while the unpromoted silica exhibited no acid exchange capacity using the same titration condition. Unlike in the base-synthesized MCM-41, after removing the surfactant by ethanol wash under reflux, the alkylsulfonic acid groups (R$\mathrm{SO}_{3} \mathrm{H}$ ) remained inside the mesoporous structure of this SBA material.

\section{Catalytic Testing}

The dehydrative coupling of methanol (99.8\%, anhydrous, Aldrich) with isobutanol (2-methyl-1-propanol, $99.9+\%$, Alfa) was investigated using $1 \mathrm{~g}$ of the extracted sulfonic acid-functionalized SBA-15 catalyst charged into a downflow 0.5-inch O.D. stainless steel tubular reactor; centering using $3 \mathrm{~mm}$ Pyrex beads. The catalytic reaction was performed in the temperature range of $388-523 \mathrm{~K}$, total pressure of $101.3-4.2 \times 10^{3} \mathrm{kPa}(1 \mathrm{~atm}=101.325$ $\mathrm{kPa}$ ) and $\mathrm{MeOH} / \mathrm{i}-\mathrm{BuOH}=1-2$ molar ratio with a carrier gas of $4.94 \% \mathrm{~N}_{2}$ diluted in $\mathrm{He}$ $[9,10]$. Steady state activities were reached within $2 \mathrm{hr}$ of the initial alcohol injection or after altering reaction variables such as temperature or pressure. The catalytic testing of the extracted sulfonic acid-functionalized SBA-15 under each condition was carried out for 8-12 $\mathrm{hr}$, wherein carbon and oxygen balances were within $\pm 0.2 \%$ and no deactivation was observed in long term tests of several hundred hours. The rate of product formation increased with increasing temperature, but the selectivity in favor of isobutene formation increased rapidly at higher temperature, as presented in Table 1 . The methyl isobutyl ether (MIBE) yields of $0.02 \mathrm{~mol} / \mathrm{kg}$ cat $/ \mathrm{hr}$ at $398 \mathrm{~K}$ represented an enhancement of $82-150 \%$ over the $\mathrm{SiO}_{2} / \mathrm{Al}_{2} \mathrm{O}_{3}$ and montmorillonite catalysts [10c,e]. The dimethyl ether (DME) yields of $0.009 \mathrm{~mol} / \mathrm{kg}$ cat $/ \mathrm{hr}$ increased $50 \%$ from $0.006 \mathrm{~mol} / \mathrm{kg}$ cat $/ \mathrm{hr}$ on $\mathrm{SO}_{4}{ }^{2-} / \mathrm{ZrO}_{2}, 29 \%$ from 0.007 $\mathrm{mol} / \mathrm{kg}$ cat $/ \mathrm{hr}$ on the $\mathrm{SiO}_{2} / \mathrm{Al}_{2} \mathrm{O}_{3}$ catalyst and $13 \%$ from $0.008 \mathrm{~mol} / \mathrm{kg}$ cat $/ \mathrm{hr}$ on the montmorillonite catalyst $[10 \mathrm{c}, \mathrm{e}]$. No dibutyl ethers were observed. 
Although the extracted sulfonic acid-functionalized SBA-15 material was superior over the inorganic solid acid catalysts in MIBE and DME formation, its catalytic activity was lower than polymeric acid catalysts, as shown in Table 1. However, with the present inorganic, high stability catalytic material, the ethers were formed at $100 \%$ selectivity below $400 \mathrm{~K}$, which was appreciably higher than observed over either the inorganic catalysts (30$67 \%$ selectivity to ethers) or the polymeric acid catalysts (66-79\% ether selectivity) as previously reported by us $[10,7 \mathrm{~b}]$. Further, it is noted that among the ether products, the extracted sulfonic acid-functionalized SBA-15 favored MIBE formation (70\% MIBE selectivity at $388 \mathrm{~K})$, whereas the Amberlyst-35 resin catalyst favored DME formation ( $79 \%$ DME selectivity at $388 \mathrm{~K}$ in Table 1 ).

The dehydration of the alcohol mixture $(\mathrm{MeOH} / \mathrm{i}-\mathrm{BuOH}=2 / 1)$ over the extracted sulfonic acid-functionalized SBA-15 was studied in a wide range of pressures at $388 \mathrm{~K}$. Dramatic increases of MIBE and DME yields were observed with the alcohol pressure. The MIBE product yielded a maximum selectivity of $78 \%$ at $80 \mathrm{kPa}$ alcohol partial pressure $\left(\mathrm{p}_{\mathrm{M}}\right.$ $=54 \mathrm{kPa}, \mathrm{p}_{\mathrm{B}}=26 \mathrm{kPa}$ ), and DME and MIBE yields approached a constant value above total alcohol partial pressure of about $300 \mathrm{kPa}$. The effect of pressure was found to be reversible, as observed for the other catalysts previously studied [10a,b], i. e. when alcohol pressure was decreased to its original value, MIBE and DME decreased to their original rates. 
Table 1. Product space time yields (mol/kg cat $/ \mathrm{hr}$ ) in the reaction of $\mathrm{MeOH} / \mathrm{i}-\mathrm{BuOH}(1: 1)$ with flow rates of $3.44 \mathrm{~mol} / \mathrm{kg}$ cat $/ \mathrm{hr}$ alcohols and $16 \mathrm{~mol} / \mathrm{kg}$ cat $/ \mathrm{hr}$ carrier gas at $101.3 \mathrm{kPa}$ total pressure of carrier gas and alcohols over the extracted sulfonic acid-functionalized SBA-15 material. Comparisons with other previously studied catalysts are shown.

\begin{tabular}{|c|c|c|c|c|c|c|}
\hline Temp/K & MIBE & DME & MTBE & Butenes $^{\underline{\mathrm{a}}}$ & $\begin{array}{c}\% \text { Ether } \\
\text { Selectivity }\end{array}$ & Catalyst \\
\hline 388 & 0.014 & 0.006 & $-\mathrm{-O}^{\mathrm{b}}$ & ---- & 100 & SBA \\
\hline 388 [7b] & 0.058 & 0.040 & ---- & 0.026 & 79 & Nafion-H \\
\hline $388[7 \mathrm{~b}, 10 \mathrm{e}]$ & 0.082 & 0.337 & 0.009 & 0.218 & 66 & Amberlyst-35 \\
\hline 398 & 0.020 & 0.009 & ---- & ---- & 100 & SBA \\
\hline 398 [10c] & 0.011 & 0.007 & 0.001 & 0.028 & 40 & $\mathrm{SiO}_{2} / \mathrm{Al}_{2} \mathrm{O}_{3}$ \\
\hline 398 [10c] & 0.008 & 0.008 & ---- & 0.008 & 67 & Montmorillonite \\
\hline $398[7 b, 10 c]$ & 0.020 & 0.006 & 0.003 & 0.067 & 30 & $\mathrm{ZrO}_{2} / \mathrm{SO}_{4}$ \\
\hline 423 & 0.023 & 0.013 & ---- & 0.053 & 40 & SBA \\
\hline 448 & 0.033 & 0.018 & ---- & 0.125 & 29 & SBA \\
\hline 473 & 0.041 & 0.026 & ---- & 0.198 & 25 & SBA \\
\hline 498 & 0.053 & 0.037 & ---- & 0.322 & 23 & SBA \\
\hline 523 & 0.074 & 0.061 & --- & 0.551 & 20 & SBA \\
\hline
\end{tabular}

$\bar{a}$ Butenes mainly consisted of isobutene, but also included $n$-butene, cis- and trans-2butene

b --- indicates "not observed"

The dehydration reactions are considered to occur to a greater or lesser extent within the catalyst mass, wherein the reactants, products and solvent are in equilibrium with the gas phase [11]. The kinetic analysis provides an indication that elevated pressure favored the ether-forming reaction in comparison with the dehydration of isobutanol to form butenes, which would result in a molar volume increase $[9,10]$. Figure 2 illustrates the rate of MIBE formation, $v_{\mathrm{MIBE}}(\boldsymbol{\square})$, DME formation, $v_{\mathrm{DME}}(\boldsymbol{\theta})$, and isobutene formation, $v_{\mathrm{IB}}(\boldsymbol{\Delta})$, in the reaction of $\mathrm{MeOH} / \mathrm{i}-\mathrm{BuOH}(2: 1 \mathrm{molar}$ ratio) with $15.6 \mathrm{~mol} / \mathrm{kg}$ cat $/ \mathrm{hr}$ alcohols and $186 \mathrm{~mol} / \mathrm{kg}$ cat $/ \mathrm{hr}$ carrier gas at $388 \mathrm{~K}$ as a function of isobutanol partial pressure, $\mathrm{P}_{\mathrm{i}-\mathrm{BuOH} \text {. The }}$ experimental data are indicated as individual points, and the full lines fitting the MIBE and DME data points were obtained using the Langmuir-Hinshelwood kinetic laws $[9,10] v_{\mathrm{MIBE}}=$ $\mathrm{k}_{4} \mathrm{~K}_{\mathrm{M}} \mathrm{p}_{\mathrm{M}} \mathrm{K}_{\mathrm{B}} \mathrm{p}_{\mathrm{B}} /\left(1+\mathrm{K}_{\mathrm{M}} \mathrm{p}_{\mathrm{M}}+\mathrm{K}_{\mathrm{B}} \mathrm{p}_{\mathrm{B}}\right)^{2}$ and $v_{\mathrm{DME}}=\mathrm{k}_{1} \mathrm{~K}_{\mathrm{M}}^{2} \mathrm{p}_{\mathrm{M}}{ }^{2} /\left(1+\mathrm{K}_{\mathrm{M}} \mathrm{p}_{\mathrm{M}}+\mathrm{K}_{\mathrm{B}} \mathrm{p}_{\mathrm{B}}\right)^{2}$, where $\mathrm{p}$ is the partial pressure of methanol (M) or isobutanol (B). Here, $\mathrm{k}_{1}$ and $\mathrm{k}_{4}$ are the kinetic constants for DME and MIBE formation, and $\mathrm{K}_{\mathrm{M}}$ and $\mathrm{K}_{\mathrm{B}}$ denote the adsorption equilibrium constants for methanol and isobutanol. The kinetic laws were derived on the basis of the reactions occurring on dual surface acid sites of the catalyst [10]. Such sites are realized in the SBAbased material by the n-propyl- $\alpha$-sulfonic acid groups anchored on the silica walls by the $\gamma$ carbon. In the present experiment, the ratio of partial pressures of methanol and isobutanol 
was kept at a constant value $\mathrm{p}_{\mathrm{M}} / \mathrm{p}_{\mathrm{B}}=2$ at the entry of the reactor bed while changing the total pressure as a kinetic variable. This partial pressure ratio prevailed in the entire reaction zone within the range of conversions studied. A further constraint used in the kinetic analysis was that the values of adsorption equilibrium constants $\mathrm{K}_{\mathrm{M}}$ and $\mathrm{K}_{\mathrm{B}}$ must be identical for both the DME and MIBE rates of formation. Non-linear fitting of the observed data was performed using the above rate equations for DME and MIBE with weighting factors $0.02\left(\mathrm{v}_{\max }\right)^{2} / \mathrm{v}_{\mathrm{i}}$ for each i-th data point, based on an estimate of a $2 \%$ error associated with the highest rates. Values of $\mathrm{K}_{\mathrm{M}}=0.0092 \pm 0.001 \mathrm{kPa}^{-1}, \mathrm{~K}_{\mathrm{B}}=0.019 \pm 0.002 \mathrm{kPa}^{-1}, \mathrm{k}_{1}=0.59 \pm 0.01 \mathrm{~mol} / \mathrm{kg}$ cat $/ \mathrm{hr}$ and $\mathrm{k}_{4}=1.12 \pm 0.01 \mathrm{~mol} / \mathrm{kg}$ cat $/ \mathrm{hr}$ were obtained. The relative magnitudes of $\mathrm{K}_{\mathrm{B}}>\mathrm{K}_{\mathrm{M}}$ agreed with those previously observed with other catalysts $[9,10]$.

In addition, the rate of isobutene formation, represented in Figure 2 as $v_{\mathrm{IB}}(\boldsymbol{\Delta})$, was found to obey the kinetic law $v_{\mathrm{IB}}=\mathrm{k}_{3} \mathrm{~K}_{\mathrm{B}} \mathrm{p}_{\mathrm{B}} /\left(1+\mathrm{K}_{\mathrm{M}} \mathrm{p}_{\mathrm{M}}+\mathrm{K}_{\mathrm{B}} \mathrm{p}_{\mathrm{B}}\right)^{3}$, yielding $\mathrm{k}_{3}=1.79 \pm 0.02$ $\mathrm{mol} / \mathrm{kg}$ cat $/ \mathrm{hr}$ with the same values of $\mathrm{K}_{\mathrm{M}}$ and $\mathrm{K}_{\mathrm{B}}$ previously determined from the DME and MIBE data. Hence, the overall error in the kinetic constants was on the order of $\pm 2 \%$ and in the adsorption equilibrium constants, $\pm 11 \%$. Solid curves in Figure 2 represent the theoretical values with $\mathrm{K}_{\mathrm{M}}=0.0092 \mathrm{kPa}^{-1}, \mathrm{~K}_{\mathrm{B}}=0.019 \mathrm{kPa}^{-1}, \mathrm{k}_{1}=0.59 \mathrm{~mol} / \mathrm{kg}$ cat $/ \mathrm{hr}, \mathrm{k}_{3}=$ $1.79 \mathrm{~mol} / \mathrm{kg}$ cat $/ \mathrm{hr}$ and $\mathrm{k}_{4}=1.12 \mathrm{~mol} / \mathrm{kg}$ cat $/ \mathrm{hr}$ at $388 \mathrm{~K}$. These values, however, need a refinement as a larger set of data becomes available. Nevertheless, the main features of the kinetic observations strongly indicate that the present SBA-propylsulfonic acid catalyst performs in a similar fashion as all the inorganic and polymeric solid acid materials studied earlier $[9,10]$ : the selectivity to ethers increases with total pressure, isobutene formation is favored at low pressures, and MTBE is not observed while it is a minor product over other catalysts. The data for isobutene formation over the present SBA-based material show, however, a stronger retardation with isobutanol pressure than previously observed, e.g. with the Nafion-H catalyst [10b]. This feature gives rise to a higher selectivity to ethers over the SBA-propylsulfonic catalyst than on any other solid acid catalyst so far studied. In contrast, sulfated zirconia catalysts favors the formation of isobutene over MIBE and DME [10c]. Therefore, a large class of solid acid catalysts for dehydrocondensation and dehydration of methanol/isobutanol mixtures has been found to obey similar kinetic laws, while selectivity to MIBE, DME, (MTBE) and isobutene is controlled by the total pressure and subtle variations of the surface rate and adsorption equilibrium constants. 


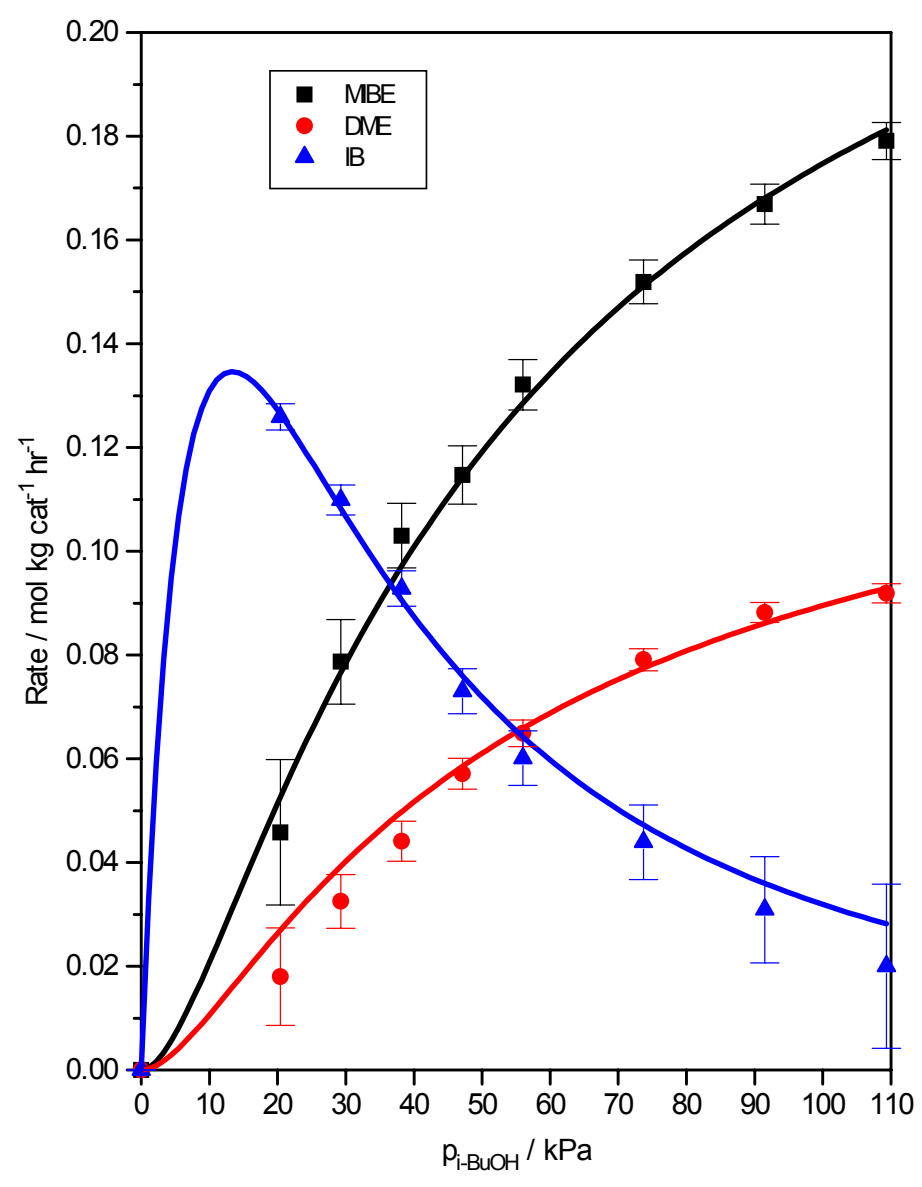

Figure 2. The rates of MIBE formation, $v_{\mathrm{MIBE}}(\mathbf{\square})$, DME formation, $v_{\mathrm{DME}}(\bullet)$, and isobutene (IB) formation, $v_{\mathrm{IB}}(\boldsymbol{\Delta})$, in the reaction of $\mathrm{MeOH} / \mathrm{i}-\mathrm{BuOH}(2: 1$ molar ratio) with flowrates of $15.6 \mathrm{~mol} / \mathrm{kg} \mathrm{cat} / \mathrm{hr}$ alcohols and $186 \mathrm{~mol} / \mathrm{kg} \mathrm{cat} / \mathrm{hr}$ carrier gas at $388 \mathrm{~K}$ as a function of isobutanol partial pressure, $\mathrm{P}_{\mathrm{i}-\mathrm{BuOH}}$, are given as data points. The fitted kinetic laws (cf. Text) are shown as the curves, giving DME kinetic constant, $\mathrm{k}_{1}=0.59 \mathrm{~mol} / \mathrm{kg}$ cat $/ \mathrm{hr}$; isobutene kinetic constant, $\mathrm{k}_{3}=1.79 \mathrm{~mol} / \mathrm{kg}$ cat $/ \mathrm{hr}$; MIBE kinetic constant, $\mathrm{k}_{4}=1.12 \mathrm{~mol} / \mathrm{kg}$ cat $/ \mathrm{hr}$; methanol adsorption equilibrium constant, $\mathrm{K}_{\mathrm{M}}=0.0092 \mathrm{kPa}^{-1}$; and isobutanol adsorption equilibrium constant $\mathrm{K}_{\mathrm{B}}=0.019 \mathrm{kPa}^{-1}$. Error bars, $0.02\left(\mathrm{v}_{\mathrm{i}, \max }\right)^{2} / \mathrm{v}_{\mathrm{i}}$, are based on an estimate of $2 \%$ error associated with the highest rate measured.

The experimental data also exhibited increasing isobutene yields with increasing temperature (Table 1). The isobutanol dehydration to isobutene competed with $\mathrm{MeOH} / \mathrm{i}$ $\mathrm{BuOH}$ coupling and $\mathrm{MeOH}$ dehydration in the reaction system. The enhancement of selectivity for isobutene from $0 \%$ at $398 \mathrm{~K}$ to $80 \%$ at $523 \mathrm{~K}$ is in agreement with earlier observations on a large number of solid acid catalysts. The temperature dependence of the rate of formation of the products in Table 1 is determined by a complex combination of the activation energies of the kinetic constants and adsorption enthalpies of the reactants. 
Nevertheless, the trends are such that the rates are increasing with temperature, the butenes more than the ethers, and MTBE, thermodynamically more stable than MIBE, is a very minor or not observed product. In Table 1, we also compare the rates of formation of MIBE, DME and IB over the present sulfonic acid-derivatized SBA-15 material and earlier studied inorganic and polymeric solid acid catalysts. A remarkable feature of the SBA catalyst is the superior selectivity for ethers at low synthesis temperatures $(<400 \mathrm{~K})$.

In summary, the results demonstrate that direct synthesis of sulfonic acidfunctionalized mesoporous silica material was successful, resulting in a catalyst possessing hexagonal mesostructure with $\sim 74 \AA$ pore size, acid exchange capacities of $1.6 \mathrm{meq} \mathrm{H}^{+} / \mathrm{g}$ of $\mathrm{SiO}_{2}$, surface area of $674 \mathrm{~m}^{2} / \mathrm{g}$, and excellent thermal stabilities. Such sulfonic acid groups bonded onto mesoporous silica effectively catalyzed the alcohol coupling reaction forming MIBE and DME at high pressure. The material exhibited high ether selectivities and higher catalytic activity for ether formation than other inorganic solid acid catalysts.

\section{References to Chapter II}

1. Sun, Q.; Herman, R. G.; Klier, K., J. Chem. Soc., Chem. Commun. (1995) 1849.

2. (a) Kresge, C. T.; Leonowicz, M. E.; Roth, W. J.; Vartuli, J. C.; Beck, J. S., Nature, 359 (1992) 710. (b) Beck, J. S.; Vartuli, J. C.; Roth, W. J.; Leonowicz, M. E.; Kresge, C. T.; Schmitt, K. D.; Chu, C. T. W.; Olson, D. H.; Sheppard, E. W.; McCullen, S. B.; Higgins, J. B.; Schlenker, J. L., J. Am. Chem. Soc., 114 (1992) 10834. (c) Yong, H.; Kuperman, A.; Coombs, N.; Mamiche-Afara, S.; Ozin, G. A., Nature, 379 (1996) 703.

3. (a) Huo, Q.; Leon, R.; Petroff, P. M.; Stucky, G. D., Science, 268 (1995) 1324. (b) Schacht, S.; Huo, Q.; Voigt-Martin, I. G.; Stucky, G. D.; SchÜth, F., Science, 273 (1996) 768. (c) Tanev, P. T.; Pinnavaia, T. J., Science, 267 (1995) 865. (d) Tanev, P. T.; Pinnavaia, T. J., Science, 271 (1996) 1267. (e) Attard, G. S.; Glyde, J. C.; Göltner, C. G., Nature, 378 (1995) 366.

4. (a) Margolese, D.; Melero, J. A.; Christiansen, S. C.; Chmelka, B. F.; Stucky, G. D., Chem. Mater., 12 (2000) 2448. (b) Zhao, D.; Huo, Q.; Feng, J.; Chmelka, B. F.; Stucky, G. D., J. Am. Chem. Soc., 120 (1998) 6024. (c) Zhao, D.; Feng, J.; Huo, Q.; Melosh, N.; Fredrickson, G. H.; Chmelka, B. F.; Stucky, G. D., Science, 279 (1998) 548.

5. (a) Van Rhijn, W. M.; De Vos, D. E.; Sels, B. F.; Bossaert, W. D.; Jacobs, P., J. Chem. Soc., Chem. Commun. (1998) 317. (b) Lim, M. H.; Blanford, C. F.; Stein, A., Chem. Mater., 10 (1998) 467.

6. Chaney, R. L.; Simmons, G. W., R\&D Magazine, 83(9) (1990) 1. 
7. (a) Johansson, M.; Klier, K., Topics Catal., 4 (1997) 99. (b) Johansson, M., PhD Dissertation, Lehigh University, Bethlehem, PA USA, (1995). (c) Shen, J. G. C.; Kalantar, T. H.; Herman, R. G.; Roberts, J. E.; Klier, K., Chem. Mater., 13 (2001) 4479.

8. Moulder, J. F.; Stickle, W. F.; Sobul, P. E.; Bomben, K. D., "Handbook of X-Ray Photoelectron Spectroscopy," Ed.; Chastain, J. Perkin-Elmer Corp.: Eden Prairie, MN (1992).

9. Shen, J. G. C.; Kalantar, T. H.; Ma, Q.; Herman, R. G.; Klier, K., J. Chem. Soc., Chem. Commun. (2001) 653.

10. (a) Nunan, J.; Klier, K.; Herman, R. G., J. Chem. Soc., Chem. Commun. (1985) 676. (b) Nunan, J. G.; Klier, K.; Herman, R. G., J. Catal., 139 (1993) 406. (c) Klier, K.; Herman, R. G.; Johansson, M. A.; Feeley, O. C., Preprints, Div. Fuel Chem. ACS, 37 (1992) 236. (d) Klier, K.; Kwon, H.-H.; Herman, R. G.; Hunsicker, R. A.; Ma, Q.; Bollinger, S. J., in “12 ${ }^{\text {th }}$ Intern. Congr. Catal.," Ed.: Corma, A.; Melo, F. V.; Mendioroz, A.; Fierro, F. L. S. Elsevier, Amsterdam, (2000) 3447. (e) Klier, K.; Herman, R. G., Final Technical Report to U.S. Department of Energy (DOE/FC/90044-F), (1994) 167 pp. (f) Lietti, L.; Sun, Q.; Herman, R. G. Klier, K., Catal. Today, 27 (1996) 151.

11. (a) Polanskii, N. G., Russ. Chem. Rev., 39 (1974) 244. (b) Helfferich, F., J. Am. Chem. Soc., 76 (1954) 5567. 


\section{Chapter III. Sorption of Nitrogen Bases and X-Ray Photoelectron Spectroscopy Study of Mesoporous Solid Acid SBA-15}

\section{Introduction}

SBA-15 is a high surface area mesoporous thermostable solid acid with high proton concentration associated with propylsulfonic groups anchored on silica [1,2]. We prepared this material following the one-step synthesis of Margolese et al. [1] and reported the dehydrocondensation of alcohols to unsymmetrical ethers catalyzed by this material [2]. This reaction requires high surface concentration of Brønsted acid sites, since the mechanism is a dual site process, as indicated by kinetic analysis of the catalytic reaction on previously studied solid acids [2-5]. The hydrogen ion concentrations found were $1.2-2.2 \mathrm{meq} / \mathrm{g}[1,6]$, $1.6 \mathrm{meq} / \mathrm{g}$ [2], and presently $1.0 \mathrm{meq} / \mathrm{g}$.

The mesoporous structure of SBA-15 is obtained by using an organic structuredirecting agent that can subsequently be removed from the highly ordered two-dimensional siliceous mesostructure. During the synthesis of SBA-15, mercaptopropyl groups are anchored onto the walls of the siliceous pores, and these groups are oxidized by $\mathrm{H}_{2} \mathrm{O}_{2}$ to form propylsulfonic acid moieties. In a previous synthesis of SBA-15, we showed by X-ray photoelectron spectroscopy (XPS) that only about $67 \%$ of the $\equiv \mathrm{Si}\left(\mathrm{CH}_{2}\right)_{3} \mathrm{SH}$ groups were oxidized to $\equiv \mathrm{Si}\left(\mathrm{CH}_{2}\right)_{3} \mathrm{SO}_{3} \mathrm{H}$ species, but the material still contained an appreciable concentration of Brønsted acid sites [2].

Goals of this research are to maximize the concentration of acid sites to facilitate the catalytic coupling of alcohols to form ethers and to determine the accessibility and strength of the acid groups. Anchoring of dual acid sites in molecular proximity was previously achieved by molecular design of a "double pincer" bis(hydrogen sulfate) ethylene glycol precursor on zirconium hydroxide to yield a sulfated zirconia [7] that exhibited higher activity [3] than a traditionally prepared sulfated zirconia catalyst. With the SBA-15 catalyst, the degree of oxidation of propylthiol groups to sulfonic acid moieties as well as the proximity and strength of the acid groups need to be assessed to provide input into optimizing these materials for acid-catalyzed reactions.

We have employed high resolution XPS to gain information in regard to the nature, strength, and concentration of acid sites on surfaces of solid catalysts. In particular, XPS can (a) identify the source of a proton donors and acceptors from core level shifts $[4,8]$, (b) distinguish between Brønsted and Lewis acid sites [4,8], (c) provide a quantitative assessment of specific surface species involved in acid-base interactions $[4,7,8]$, and (d) distinguish between metal ions in cation exchange sites and substitutional support framework locations [9]. The experimental results are supported and predicted by the theory of core levels, valence bands, and strength of base bonding to acid sites in optimized geometries.

In this chapter, we report on the properties of the SBA-15 with respect to the 
adsorption of pyridine and ethylene diamine, representing nitrogen bases, and the exchange of the $-\mathrm{SO}_{3} \mathrm{H}$ protons with ammonium cations. The XPS analysis of experimental core-level shifts (CLS) is accompanied by the theory of relative orbital energies in the surface acid-base complexes and ion-exchanged sulfonic groups.

\section{Experimental Methods}

\subsection{Synthesis.}

SBA-15 was synthesized by first dissolving $4 \mathrm{~g}$ of Pluronic 123 [poly(ethylene glycol)-block-poly(propylene glycol)-block-poly(ethylene glycol)], $\mathrm{EO}_{20} \mathrm{PO}_{70} \mathrm{EO}_{20}\left(\mathrm{M}_{\mathrm{n}}=\right.$ 5800 , Aldrich) in $125 \mathrm{~g}$ of $1.9 \mathrm{M} \mathrm{HCl}$. The mixture was then heated to $40^{\circ} \mathrm{C}$, at which point $32.8 \mathrm{mmol}$ of tetraethoxysilane (TEOS) (99+\% TEOS, Aldrich) were added. The mixture was then stirred and kept at $40^{\circ} \mathrm{C}$ for three $\mathrm{hr}$ during pre-hydrolysis. Next, $73.8 \mathrm{mmol}$ of hydrogen peroxide $\left(30 \% \mathrm{H}_{2} \mathrm{O}_{2}\right.$, Aldrich) and $8.2 \mathrm{mmol}$ of 3-mercaptopropyltrimethoxysilane (MPTMS) (95\% MPTMS, Aldrich) were added to the mixture, which was allowed to equilibrate at $40^{\circ} \mathrm{C}$ for $20 \mathrm{~h}$ with stirring.

After this oxidation period, the mixture was transferred to a closed polypropylene bottle for aging and placed in a furnace at $100^{\circ} \mathrm{C}$ for $24 \mathrm{hr}$. The white solid that had precipitated was filtered, air-dried at room temperature, weighed and subsequently refluxed in $95 \%$ ethanol for $24 \mathrm{~h}(400 \mathrm{~mL}$ of ethanol $/ 1.5 \mathrm{~g}$ of dried material) to extract any remaining Pluronic. After the ethanol reflux, the material was filtered, washed sequentially with distilled water and absolute ethanol, and finally dried in an oven at $60^{\circ} \mathrm{C}$.

\subsection{Characterization.}

High-resolution X-ray photoelectron spectroscopy (HR-XPS) was used to characterize the synthesized SBA-15. Electron microscopy (EM) was also used to determine the pore structure of SBA-15, the detailed description of which will be published elsewhere [10]. All XPS measurements were carried out using the Scienta ESCA-300 instrument at Lehigh University. Each sample was scanned initially with a brief survey from $0-1000 \mathrm{eV}$, followed by high-resolution scans of specific spectral regions including S2p, O1s, Si2p, C1s, and N1s orbitals. Also scanned were the $2 p$ spectral regions of metals whose ions were used in the ion-exchanged SBA-15 samples were.

The Scienta ESCA-300 instrument combines a high-power rotating anode X-ray source with monochromatization $\left(\mathrm{Al} \mathrm{K}_{\alpha}\right)$ and $300-\mathrm{mm}$ mean radius hemispherical electron energy analyzer (HMA) to offer high sensitivity and resolution at acceptable scan times $[8,11,12]$. Because SBA-15 is an insulating sample, a hot filament electron flood gun provides low energy electrons $(0-10 \mathrm{eV})$ during analysis to minimize positive charge buildup on the sample surface [11]. All samples were pressed in open atmosphere onto double-sided sticky tape, forming a wafer. Based on estimates made by Hunsicker et al. [9], XPS analysis of very porous materials of uniform composition provides a bulk analysis because of the large escape depths. 
Quantitative analysis was performed using the ESCA analysis software from Scienta. After integration, peak areas were converted to corresponding concentrations by dividing them by their respective "sensitivity factors." These factors are instrument specific, and they are effectively response factors specific to each orbital of each element, referenced to the sensitivity factor for the $1 \mathrm{~s}$ orbital of carbon $(\mathrm{C} 1 \mathrm{~s})$ being 1.0000 . The sensitivity factors used herein were 1.630 for $\mathrm{N} 1 \mathrm{~s}$ and 1.679 for $\mathrm{S} 2 \mathrm{p}_{3 / 2}$ and $\mathrm{S} 2 \mathrm{p}_{1 / 2}$ combined.

To determine the relative binding energies (BEs) of insulating samples [13a], a useful method is to reference the measured BE to an internal or external standard, thereby allowing the comparison of spectra. Here, all BE values are referenced to the Si2p BE being $103.5 \mathrm{eV}$. All BE values at peak maxima were obtained from fast Fourier transform (FFT) filter smoothing of the data.

In addition to the ESCA analysis, the multipoint Brunauer, Emmett, and Teller (BET) method [14] was used to measure the total surface area of the synthesized SBA-15, employing a Gemini 2360 V1.03 instrument for the procedure. A series of measurements was made wherein a given mass of sample was heated up to $120^{\circ} \mathrm{C}$ for $1-2 \mathrm{~h}$ under nitrogen gas flow, subsequently re-weighed, and the surface area re-determined. This procedure was repeated until there was no change in the mass of the sample, nor in the BET surface area. To determine its acid exchange capacity, a 50-mg portion of the SBA-15 material was dispersed into $10 \mathrm{~g}$ of $2 \mathrm{M} \mathrm{NaCl}_{(\mathrm{aq})}$, to which phenolphthalein was added as an indicator. The mixture was then titrated with $0.1 \mathrm{M} \mathrm{NaOH}_{(\mathrm{aq})}$. From the volume of titrant solution, the acid exchange capacity was determined in units of meq $\mathrm{H}^{+} / \mathrm{g}$ material.

X-Ray powder diffraction (XRD) was used to determine the pore size of the SBA-15 from the observed diffraction pattern using the low angle $2 \theta$ peak. XRD data was collected on a Siemens D5000 instrument in parallel beam geometry with $\mathrm{CuK} \alpha$ radiation and a $\theta-\theta$ goniometer. X-Ray optics included a Göbel mirror on the incident beam side with Soller slits and a $\mathrm{LiF}$ monochromator on the diffracted beam side. The diffraction pattern was utilized to assign the reflections of particular atomic planes that match a hexagonal lattice and to determine the unit cell dimension.

\subsection{Nitrogen Base Adsorption and Ammonium Exchange.}

The synthesized SBA-15 material was used in both the adsorption of nitrogen bases from hydrocarbon solution and ammonium exchange from $0.1 \mathrm{M}$ aqueous solution of ammonium chloride $\left(10 \mathrm{~mL}\right.$ of $\mathrm{NH}_{4} \mathrm{Cl}_{(\mathrm{aq})}$ over $0.1 \mathrm{~g}$ of SBA-15 for $1 \mathrm{~h}$ at $298 \mathrm{~K}$, filtered, washed with distilled water, and dried at $388 \mathrm{~K})$.

Adsorption of the nitrogen bases was carried out in refluxing solutions. After refluxing $300 \mathrm{mg}$ of SBA- 15 for four hours in a solution of $0.03 \mathrm{~mL}$ ethylene diamine (En) in $100 \mathrm{~mL}$ cyclohexane, a $50 \%$ molar excess of En relative to the proton concentration, the reaction mixture was cooled and filtered using Whatman No. 2 filter paper under a vacuum 
provided by an aspirator. The solid was washed several times with cyclohexane to ensure that all excess, unbound En was removed from the SBA-15 material. The mostly dry solid was then placed in a $383 \mathrm{~K}$ oven for $10 \mathrm{~min}$. The same procedure was also used to titrate the SBA-15 with the nitrogen base pyridine (Py) by refluxing $200 \mathrm{mg}$ of SBA- 15 for four $\mathrm{h}$ in a solution of $0.03 \mathrm{~mL}$ of anhydrous pyridine (Aldrich, $99.8 \%$ ) in $100 \mathrm{~mL}$ of cyclohexane, again a $50 \%$ molar excess of Py.

The XPS analysis of the N1s region of the nitrogen base and the S2p region of the sulfonic groups of the SBA sorbent included quantitative assay of the elements and CLS. The $\mathrm{C} 1 \mathrm{~s}$ analysis is also reported for total carbon assay and, together with $\mathrm{Si} 2 \mathrm{p}$, for referencing of the core level (CL) binding energies.

\section{Theoretical Methods}

The models adopted to represent the single and dual propylsulfonic acid sites anchored on the silica wall of the SBA-15 material are specified by the chemical formulas

and

$$
\text { HS- } \mathrm{CH}_{2} \cdot \mathrm{CH}_{2} \cdot \mathrm{CH}_{2}-\mathrm{Si}\left(\mathrm{H}_{2}\right)-\mathrm{O}-\mathrm{Si}\left(\mathrm{H}_{2}\right)-\mathrm{CH}_{2} \cdot \mathrm{CH}_{2} \cdot \mathrm{CH}_{2}-\mathrm{SO}_{3} \mathbf{H} \text { "single site" (I) }
$$

$$
\mathbf{H O}_{3} \mathrm{~S}-\mathrm{CH}_{2} \cdot \mathrm{CH}_{2} \cdot \mathrm{CH}_{2}-\mathrm{Si}\left(\mathrm{H}_{2}\right)-\mathrm{O}-\mathrm{Si}\left(\mathrm{H}_{2}\right)-\mathrm{CH}_{2} \cdot \mathrm{CH}_{2} \cdot \mathrm{CH}_{2}-\mathrm{SO}_{3} \mathbf{H} \text { "dual site" (II) }
$$

The highlighted $-\mathrm{SO}_{3} \mathrm{H}$ groups are the active sites and the $-\mathrm{SH}$ groups are inert to both ion exchange and nitrogen base adsorption, as shown by all calculations. The $-\mathrm{SO}_{3} \mathrm{H}$ groups are hydrogen donors for bonding with neighboring sulfonic groups, with nitrogen bases, and are proton-exchange and cation-exchange sites. When there is a hydrogen-donating group in the vicinity, the lone electron pairs of doubly bonded oxygen atom of the $\mathrm{O}=\mathrm{S}(\mathrm{O}) \mathrm{OH}$ group will act as a hydrogen bond acceptor. To simulate the rigidity of the silica wall, the seven atoms of the -Si-O-Si- backbone capped by four hydrogen atoms were kept frozen in all geometry optimizations in which all other atoms in the bare sites (I) and (II), as well as their complexes with neutral molecules or ions, were allowed to move.

The density functional theoretical (DFT) calculations [15] were performed at an allelectron, generalized gradient approximation (GGA) at a non-relativistic level using the Becke-Perdew functional [16,17] and the double-numerical basis set of Delley [18], similarly as in our earlier work on models of acid sites in fluorocarbon sulfonic acids, sulfated zirconia (SZ), tungstena-zirconia (WZ), and transition states for dehydrocondensation of alcohols to ethers $[4,19,20]$. These calculations yield total energies of the reactants, sorption bonding energies, and optimized geometries. In addition, the calculated orbital Kohn-Sham (KS) energies afford a comparison of chemical CLS with those observed in XPS. Because of the presently employed non-relativistic level of calculation, the core-level spin-orbit split states $\mathrm{S} 2 \mathrm{p}_{3 / 2}$ and $\mathrm{S} 2 \mathrm{p}_{1 / 2}$ are represented by the KS energies disregarding the spin-orbit interactions, i.e. as $\mathrm{S} 2 \mathrm{p}$. This approximation is sufficient for the correlations revealed in this work because the experimental XPS $2 p$ levels are incompletely resolved. On the contrary, the N1s and C1s 
levels are not spin-orbit split in experiment or theory. The final state energies involving core-hole states have not been calculated, assuming that, although the final states contribute to absolute photoemission energies quite significantly, they will have little influence on relative positions of the core levels between similar molecular species in the presently studied closed-shell molecules [21].

That the present theoretical approach is sufficient for interpretation and prediction of CLS is supported by the agreement between the previously observed experimental difference of the $\mathrm{S} 2 \mathrm{p}$ CLS in the $-\mathrm{SH}$ and $-\mathrm{SO}_{3} \mathrm{H}$ moieties, reported as $5.15 \mathrm{eV}$ [2], and the presently calculated difference between the corresponding KS S2p orbitals, $5.27 \mathrm{eV}$. In addition, the present theory correctly accounts for the simultaneous shift of N1s core levels of the nitrogen bases to higher $\mathrm{BEs}$ and $\mathrm{S} 2 \mathrm{p}$ levels of the $-\mathrm{SO}_{3} \mathrm{H}$ groups to lower $\mathrm{BEs}$ upon the formation of the $-\mathrm{SO}_{3} \mathrm{H} \ldots \mathrm{N}$-base complex [8]. Higher level, fully relativistic calculations involving both the initial and the final states are feasible and appear necessary for the interpretation of CLS in metal alloys [22], and have also been employed in the theory of CLS which establishes the correlational relationship between the total energies and the KS orbital energies in zeolites [21]. However, the present correlation between theoretical orbital energies and experimental BEs indicates that the relative core-level chemical shifts in insulators are qualitatively and semi-quantitatively accounted for by the initial KS orbital energies.

\section{Results}

\subsection{Experimental Results.}

The synthetic route employed in the present work gave rise to mesoporous silica SBA15. The BET surface area was found to be $551 \mathrm{~m}^{2} / \mathrm{g}$, and the sodium hydroxide titration of the material gave an acid exchange capacity of $1.00 \mathrm{meq} \mathrm{H}^{+} / \mathrm{g}$. XRD analysis yields a wellresolved pattern of one prominent peak at a small $2 \theta$ value and two weak peaks at slightly larger $2 \theta$ values. The peaks can be indexed to a hexagonal lattice, where the d-spacings correspond to a large hexagonal unit cell dimension and hexagonal close-packed parallel pores $[1,2,6,23-26]$. The XRD pattern here gave a hexagonal unit cell dimension $\left(\mathrm{a}_{0}=\right.$ $2 \mathrm{~d}(100) / \sqrt{ } 3)$ of $14.5 \mathrm{~nm}$ with spacings $\mathrm{d}(100)=12.6 \mathrm{~nm}, \mathrm{~d}(110)=7.3 \mathrm{~nm}$, and $\mathrm{d}(200)=6.3$ $\mathrm{nm}$. Knowing the proton concentration of $1.00 \mathrm{meq} / \mathrm{g}$, the surface area of $551 \mathrm{~m}^{2} / \mathrm{g}$, and having calculated the silicon surface concentration to be $8.22 \mathrm{Si}$ atom $/ \mathrm{nm}^{2}$ previously [27], one can calculate the molar equivalence of protons per silicon atom. This value is found to be 0.133 , equivalent to $7.52 \mathrm{Si}$ atoms per proton.

HR-XPS analysis of each sample was carried out and each spectrum was shifted to the reference BE of Si2p $=103.5 \mathrm{eV}$. XPS of the material showed a single S2p peak at 169.25 $\mathrm{eV}$ with a full width at half maximum (FWHM) of $2.63 \mathrm{eV}$ and a C1s peak at $285.00 \mathrm{eV}$ with a FWHM of $2.43 \mathrm{eV}$. Dividing the $\mathrm{C} 1 \mathrm{~s}$ concentration percentage by that of the $\mathrm{S} 2 \mathrm{p}$ gave a carbon to sulfur ratio $(\mathrm{C} / \mathrm{S})$ of 2.9. Figures 1 and 2 show the $\mathrm{S} 2 \mathrm{p}$ and $\mathrm{C} 1 \mathrm{~s}$ regions of the pure SBA-15, respectively. 
XPS results from the adsorbed nitrogen bases are summarized in Table 1. For the ethylene diamine adsorbed on SBA-15 (En-SBA), two N1s peaks of equal intensity separated by $2.05 \mathrm{eV}$ were observed. There is only one S2p peak, at $168.15 \mathrm{eV}$, with a FWHM of 2.01 $\mathrm{eV}$. The ratio of areas of the $\mathrm{S} 2 \mathrm{p}$ and N1s peaks (i.e. the area of both nitrogen peaks combined) is 1.0. The $\mathrm{C} 1 \mathrm{~s}$ peak was observed at $285.15 \mathrm{eV}$ and has a large shoulder to higher BEs, at approximately $286.45 \mathrm{eV}$. The FWHM of the C1s peak is $2.56 \mathrm{eV}$.

Table 1. Stoichiometric Equivalences, Binding Energies ${ }^{\mathrm{a}}$, Peak Widths, and Chemical Shifts for the SBA-15 Material with Adsorbed Nitrogen Bases.

\begin{tabular}{ccccccc}
\hline \multirow{2}{*}{ Species } & \multirow{2}{*}{ S/N Ratio } & \multicolumn{3}{c}{$\mathrm{S} 2 \mathrm{p}$} & \multicolumn{3}{c}{$\mathrm{N} 1 \mathrm{~s}$} & \multirow{2}{*}{$\Delta \mathrm{BE}(\mathrm{eV})^{\mathrm{b}}$} \\
\cline { 3 - 7 } & & $\mathrm{BE}(\mathrm{eV})$ & $\mathrm{FWHM}(\mathrm{eV})$ & $\mathrm{BE}(\mathrm{eV})$ & $\mathrm{FWHM}(\mathrm{eV})$ & \\
\hline \multirow{2}{*}{ En-SBA } & 1.0 & 168.15 & 2.01 & 399.80 & - & 231.65 \\
Py-SBA & 2.5 & 168.45 & 2.41 & 402.85 & - & 233.70 \\
& & 169.30 & 2.85 & & 1.87 & 233.70 \\
$\mathrm{NH}_{4}$-SBA & \multirow{2}{*}{3.5} & 168.60 & 2.85 & & 233.30 \\
\hline SBA & - & 169.25 & 2.63 & - & - & - \\
\hline
\end{tabular}

${ }^{a}$ All BEs referenced to Si2 $p=103.5 \mathrm{eV}$.

${ }^{\mathrm{b}}$ This is the separation of the N1s peak from the S2p peak for the given sample, i.e. N1s - S2p.

The pyridine adsorbed on SBA-15 (Py-SBA) was found to have a $\mathrm{S} / \mathrm{N}$ ratio of 2.5 , with only one N1s peak observed. The N1s peak is at $402.15 \mathrm{eV}$, and it has FWHM of $1.87 \mathrm{eV}$, with a slight tail to the lower BE side. The S2p peak for the py-SBA has a BE of $168.45 \mathrm{eV}$ and a FWHM of $2.41 \mathrm{eV}$. The C1s peak was found to be at $285.25 \mathrm{eV}$, with a FWHM of $2.46 \mathrm{eV}$. The S2p, C1s, and N1s regions of the SBA-15 material after the sorption of nitrogen bases are shown in Figures 1, 2, and 3, respectively.

The ammonium-exchanged $\left(\mathrm{NH}_{4}-\mathrm{SBA}\right)$ material yielded $\mathrm{S} / \mathrm{N}=3.5, \mathrm{C} / \mathrm{N}=8.95$ and $\mathrm{C} / \mathrm{S}=2.55$, respectively. The single N1s peak has a BE of $402.60 \mathrm{eV}$ with FWHM of 2.45. The maximum of the $\mathrm{S} 2 \mathrm{p}$ peak is at $169.30 \mathrm{eV}$, but there is a second, overlapping peak on the lower BE side at $168.60 \mathrm{eV}$ with FWHM of $2.85 \mathrm{eV}$ entailing both S2p peaks. The C1s is at $285.20 \mathrm{eV}$ with FWHM of $1.84 \mathrm{eV}$. 


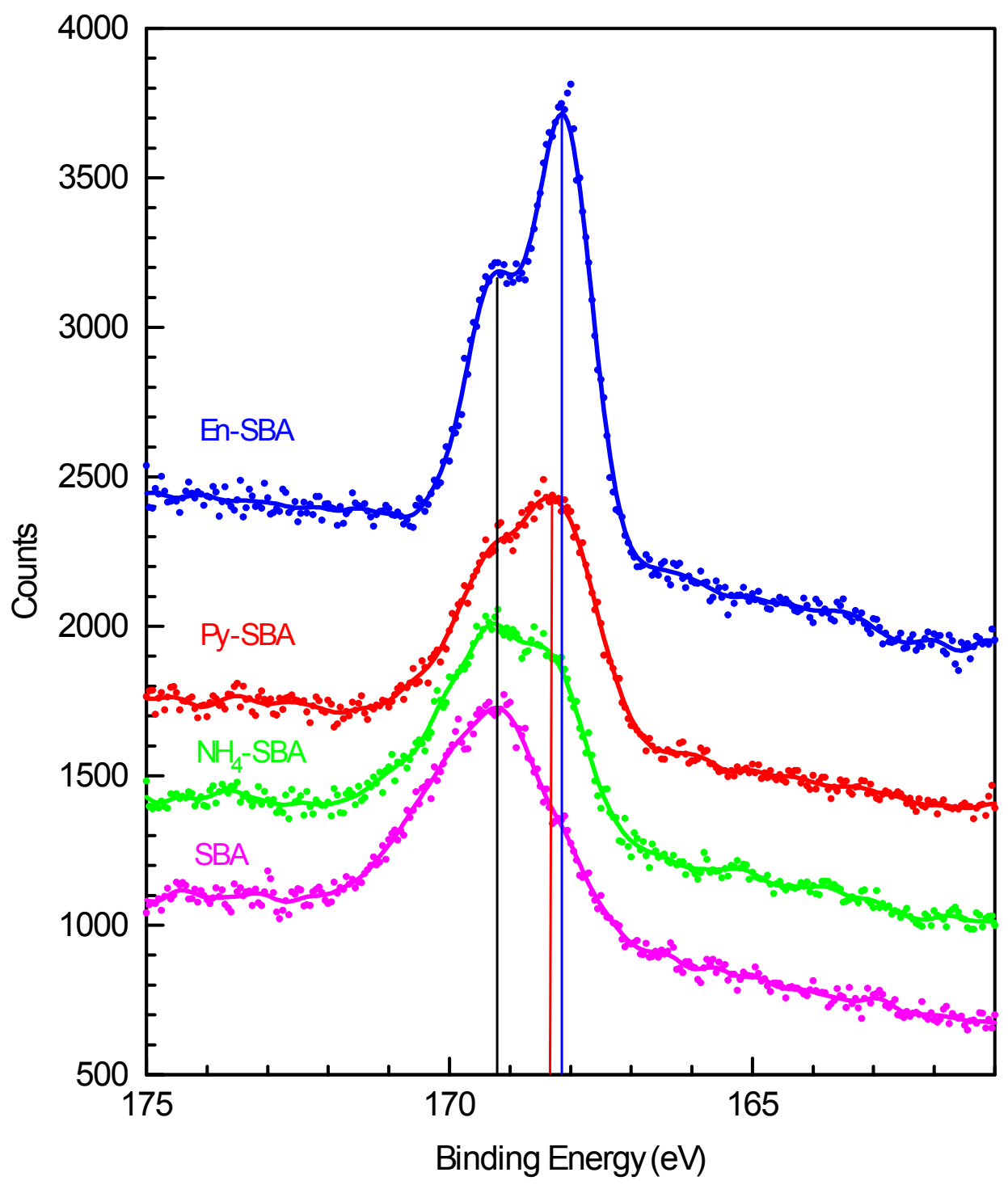

Figure 1. S2p regions of SBA-15 Material with Adsorbed Nitrogen Bases. Data are color coded and stacked additively. FFT filter smoothed line plots are shown with data points. 


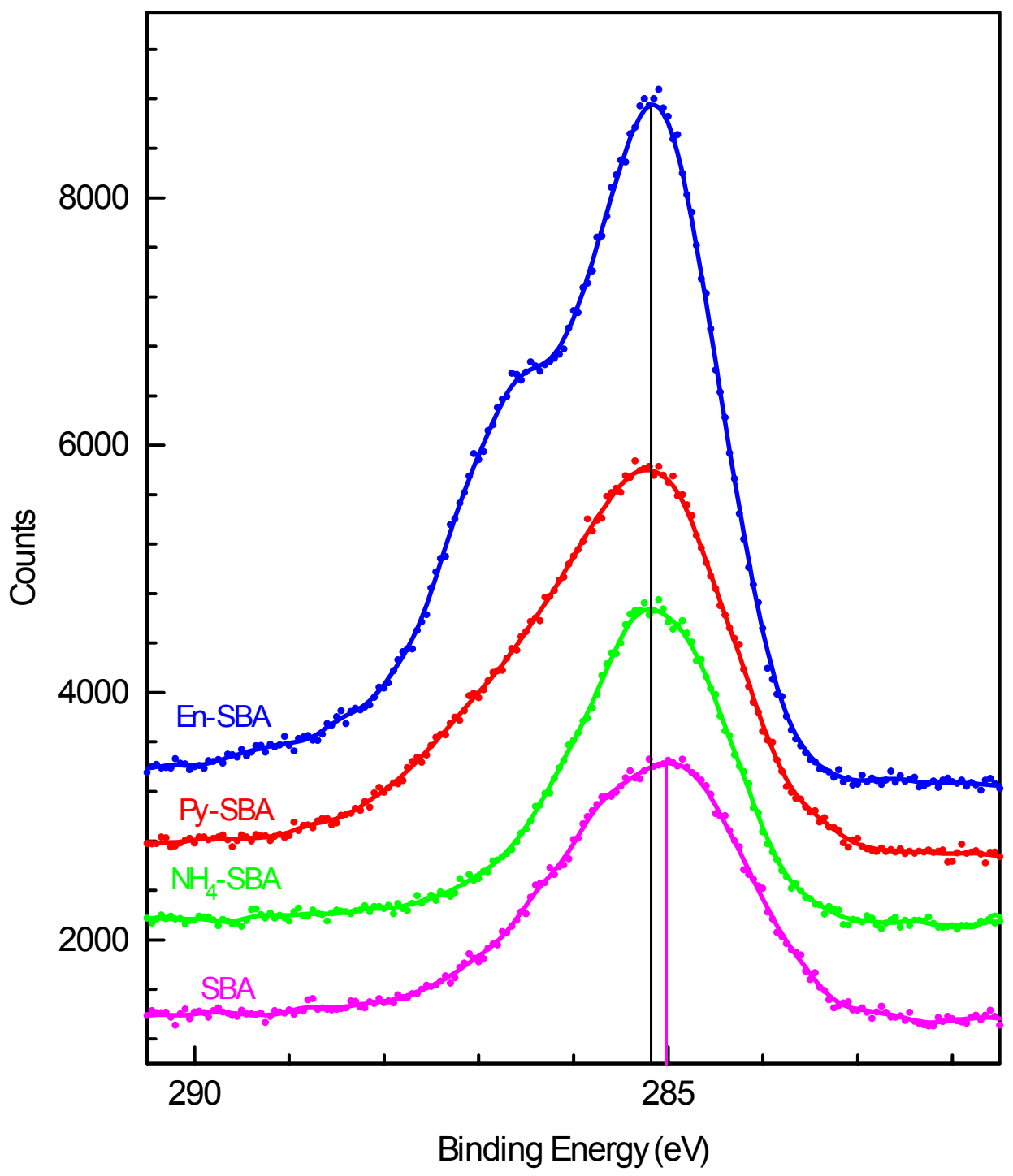

Figure 2. C1s regions of SBA-15 Material with Adsorbed Nitrogen Bases. Data are color coded and stacked additively. FFT filter smoothed line plots are shown with data points. The main peak of En-SBA is emission from the propyl-sulfonic groups and the shoulder at higher $\mathrm{BE}$ are the carbons of ethylene diamine. 


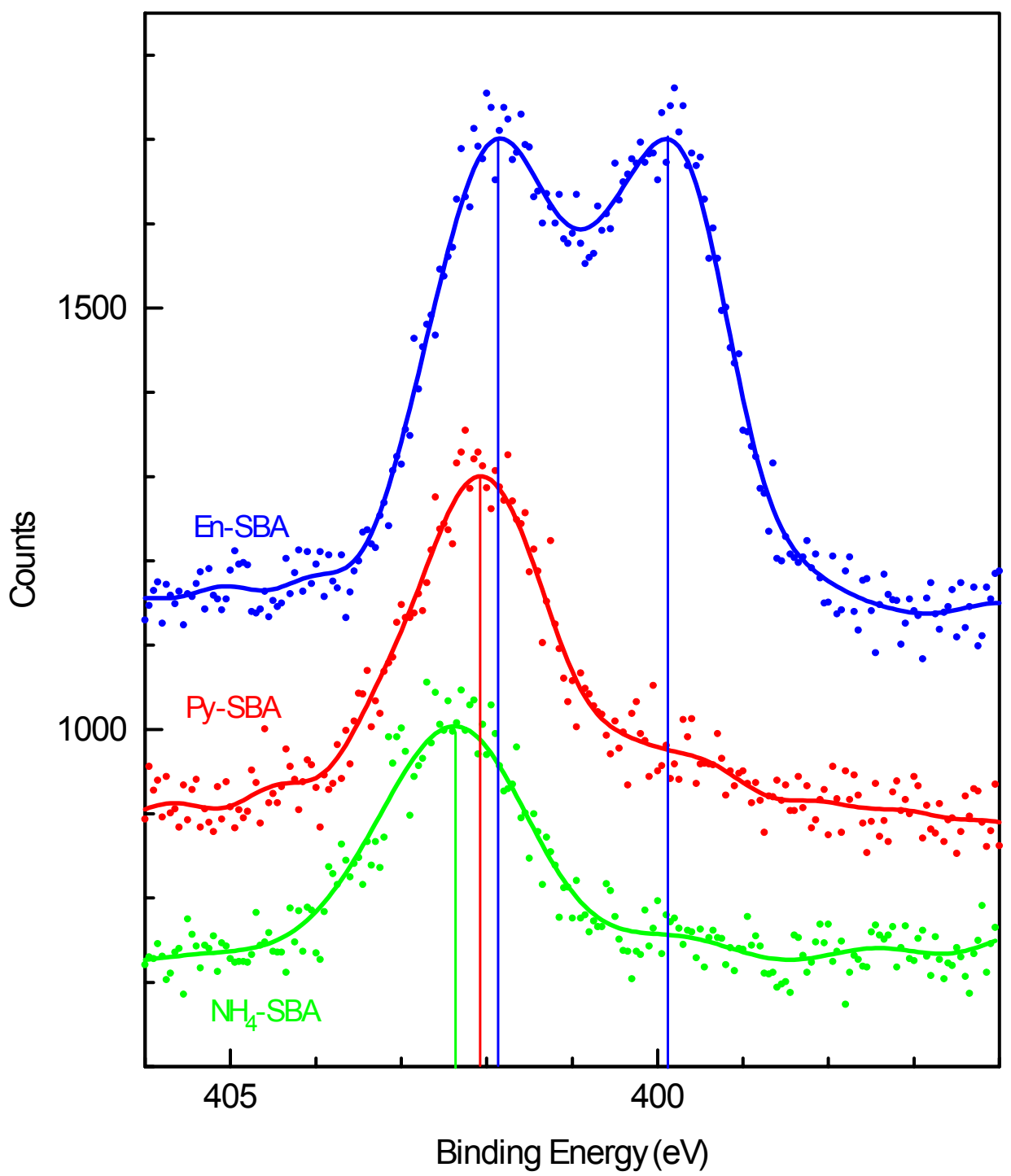

Figure 3. N1s regions of SBA-15 Material with Adsorbed Nitrogen Bases. Data are color coded and stacked additively. FFT filter smoothed line plots are shown with data points.

\subsection{Theoretical Results.}

4.2.1. Models for SBA. The optimized geometries of the bare single-site (I) and dualsite (II) assemblies shown in Figure 4 reveal a significant hydrogen donor-acceptor bonding between the neighboring $-\mathrm{SO}_{3} \mathrm{H}$ groups of the proximal sites (II), while such a hydrogen bonding is absent in the single site moiety (I). 


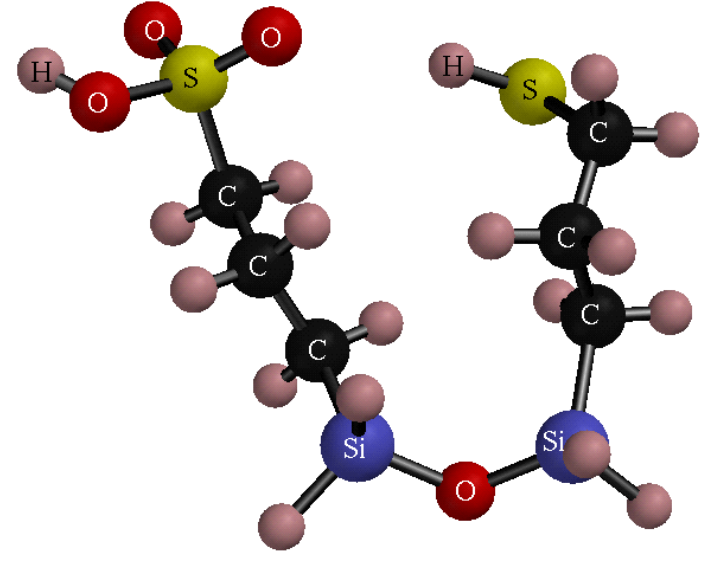

Single site

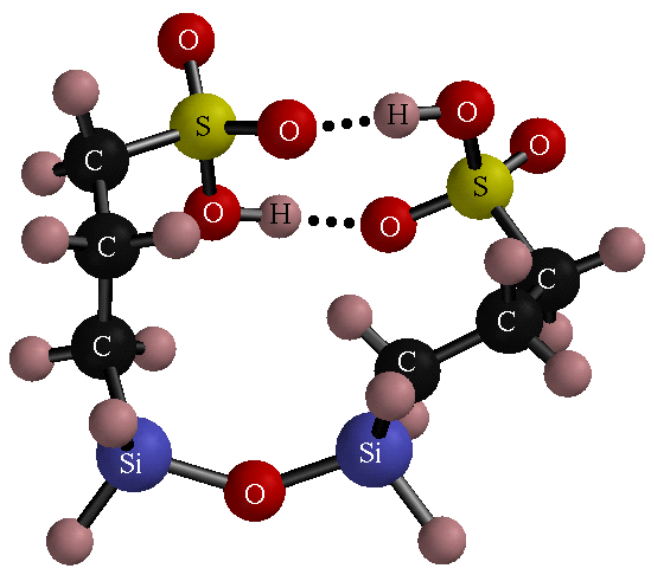

Dual site

Figure 4. Optimized models for the propylsulfonic pendant groups in the SBA material: single site [formula (I)] and dual site [formula (II)]. The thiol group in the single site is inert and the distance $-\mathrm{SH} . . \mathrm{O}=\mathrm{S}$ is $0.25 \mathrm{~nm}$. The dotted lines in the dual site mark a weak double hydrogen bonding with distances $\mathrm{OH} . . \mathrm{O}=\mathrm{S}$ equal to $0.16 \mathrm{~nm}$.

The complexes with adsorbed En, Py, and ammonia shown in Figure 5 reveal a stronger hydrogen bond between the $-\mathrm{SO}_{3} \mathrm{H}$ group and the nitrogen base in which, however, the proton of the sulfonic group is not completely transferred to the nitrogen to form an "ammonium ion". The sorption energies of the three nitrogen bases were calculated for both the single sites depicted in Figure 5 and the dual sites, as summarized in Table 2. The adsorption energy on dual sites is substantially smaller than that on the single sites due to repulsive interactions between the adsorbates in molecular proximity.

The calculated KS orbital energies for the various complexes studied on sites (I) and (II) are summarized in Table 3 and Figure 6. For the sake of comparison with experiment in section 4.1, only the S2p and N1s orbital energies are listed, although of course all the coreand valence-levels have been calculated. 


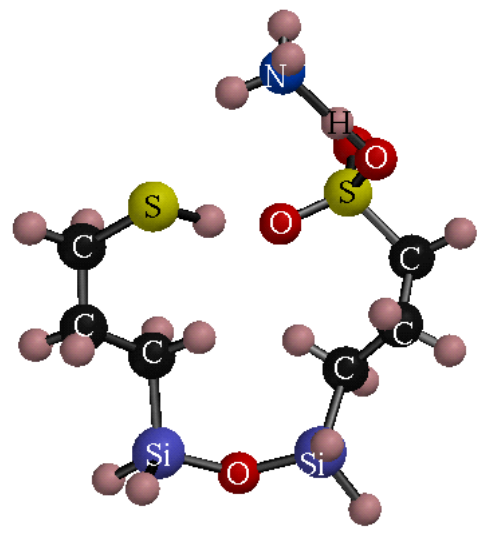

(a)

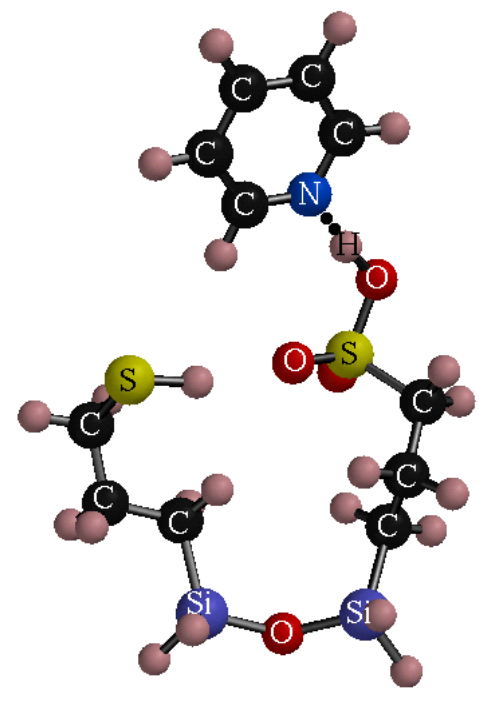

(b)

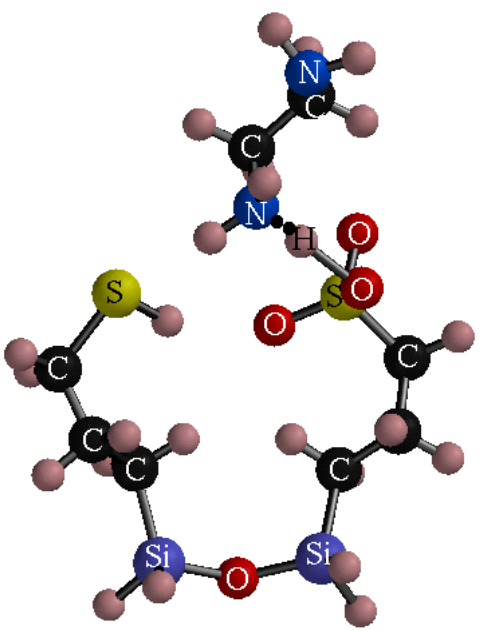

(c)

Figure 5. Single site complexes with nitrogen bases: (a) ammonia, (b) pyridine, (c) ethylene diamine. The hydrogen bonding distances $-\mathrm{O}_{2} \mathrm{SO} \ldots \mathrm{H} \ldots \mathrm{N}$ are, in $\mathrm{nm},(\mathrm{a}) 0.108(\mathrm{O} \ldots \mathrm{H})$ and $0.152(\mathrm{H} \ldots \mathrm{N}),(\mathrm{b}) 0.110(\mathrm{O} \ldots \mathrm{H})$ and $0.148(\mathrm{H} \ldots \mathrm{N})$, and $(\mathrm{c}) 0.153(\mathrm{O} \ldots \mathrm{H})$ and 0.111 $(\mathrm{H} \ldots \mathrm{N})$. All the $-\mathrm{SH}$ groups are inert to the nitrogen base adsorption and far enough from the $\mathrm{SO}_{3} \mathrm{H}$ sites, $0.21-0.22 \mathrm{~nm}$, indicating an extremely weak, if any, hydrogen bonding $\mathrm{SH} \ldots \mathrm{O}=\mathrm{SO}_{2} \mathrm{H}$.

Table 2. Adsorption Energies of Nitrogen Bases on Propylsulfonic Acid Sites. Energies are given in $\mathrm{kJ} / \mathrm{mol}$ of adsorbate.

\begin{tabular}{ccccc}
\hline $\begin{array}{c}\text { Adsorbed } \\
\text { Molecule }\end{array}$ & $\mathrm{NH}_{3}$ & Pyridine & $\begin{array}{c}\text { Ethylene } \\
\text { Diamine }\end{array}$ & $\begin{array}{c}\text { Ethylene } \\
\text { Diamine } \\
\text { Bridging Sites }\end{array}$ \\
\hline Single site $^{\mathrm{a}}$ & -75.3 & -54.4 & -96.2 & --- \\
Dual site $^{\mathrm{b}}$ & -46.0 & -33.5 & -33.5 & -83.7 \\
\hline
\end{tabular}

${ }^{\mathrm{a}} \mathrm{M... \textrm {HO } _ { 3 } \mathrm { S } ( \mathrm { CH } _ { 2 } ) _ { 3 } \text { -Si-O-Si- } ( \mathrm { CH } _ { 2 } ) _ { 3 } \mathrm { SH } . \mathrm { M } \text { is the adsorbed molecule. Si atoms are capped by } 2} \mathrm{H}$ atoms each

${ }^{\mathrm{b}} \mathrm{M} \ldots \mathrm{HO}_{3} \mathrm{~S}\left(\mathrm{CH}_{2}\right)_{3}$-Si-O-Si- $\left(\mathrm{CH}_{2}\right)_{3} \mathrm{SO}_{3} \mathrm{H} \ldots \mathrm{M}$. When $\mathrm{M}$ is ethylenediamine (En), column 4 shows adsorption energy per En with each $-\mathrm{SO}_{3} \mathrm{H}$ bonding one En molecule, and column 5 shows adsorption energy per En with one En molecule bridging the two $-\mathrm{SO}_{3} \mathrm{H}$ sites 
Table 3. The Kohn-Sham Orbital Energies of Propylsulfonic Acid Sites with Nitrogen Bases. All Energies are in $\mathrm{eV}$.

The single site is modeled as $\mathrm{HO}_{3} \mathrm{~S}\left(\mathrm{CH}_{2}\right)_{3}-\mathrm{Si}-\mathrm{O}-\mathrm{Si}-\left(\mathrm{CH}_{2}\right)_{3} \mathrm{SH}$. The sulfur of the sulfonic group is denoted $\mathrm{S} 1$ and that in the thiol group as $\mathrm{S} 2$. Each $\mathrm{S} 2 \mathrm{p}$ level $\mathrm{BE}(\mathrm{S} 2 \mathrm{p})$ is averaged over the $2 \mathrm{p}_{\mathrm{x}}, 2 \mathrm{p}_{\mathrm{y}}$,

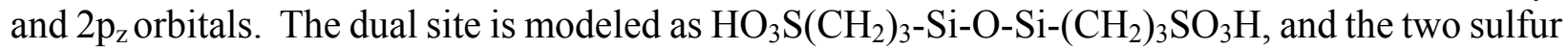
atoms, S1 and S2, have S2p average levels as above. The spread of the $2 p$ orbitals due to their structural non-equivalence is shown in Figure 6 . The Si atoms are capped by $2 \mathrm{H}$ atoms each. The adsorbed molecules, whose N1s orbital energies are given as $\mathrm{BE}(\mathrm{N} 1 \mathrm{~s})$, are ethylene diamine (En) with two non-equivalent nitrogens, pyridine (Py), and ammonia $\left(\mathrm{NH}_{3}\right)$. Single and dual sites exchanged with the $\mathrm{NH}_{4}{ }^{+}$ions are obtained by replacing the protons of one or two $-\mathrm{SO}_{3} \mathrm{H}$ groups. Adsorbed ammonia is equivalent to $-\mathrm{SO}_{3} \mathrm{NH}_{4}$. The orbital energy chemical shifts for the "bare sites" (rows 1-3), adsorbed complexes (rows 4-15), and ion-exchanged species (rows 16-19) are represented as $\Delta(\mathrm{S} 2 \mathrm{p})$ referenced to the average $\mathrm{S} 2 \mathrm{p}$ energy of the $-\mathrm{SO}_{3} \mathrm{H}$ group in the single-site model (row 1, column 4) and $\Delta(\mathrm{N} 1 \mathrm{~s}$ ) referenced to the N1s energy in free ammonia (row 20, column 5). The levels of calculation and geometry optimization are described in text.

\begin{tabular}{lcccc}
\hline \multicolumn{1}{c}{ Site } & $B E(S 2 p)$ & $B E(N 1 s)$ & $\Delta(S 2 p)$ & $\Delta(N 1 s)$ \\
\hline SingleSite.S1 & -160.10 & - & 0.00 & - \\
SingleSite.S2 & -154.83 & - & 5.27 & - \\
DualSite.S2 & -160.29 & - & -0.19 & - \\
SingleSite.En.S1 & -158.31 & -383.19 & 1.79 & -2.72 \\
SingleSite.En.S2 & -154.87 & -381.64 & 5.23 & -1.17 \\
DualSite.En.S1 & -159.78 & -382.76 & 0.32 & -2.29 \\
DualSite.En.S2 & -158.97 & -382.07 & 1.13 & -1.60 \\
SingleSite.Py.S1 & -159.25 & -382.48 & 0.85 & -2.01 \\
SingleSite.Py.S2 & -154.60 & - & 5.50 & - \\
DualSite.Py.S1 & -159.32 & -382.80 & 0.78 & -2.33 \\
DualSite.Py.S2 & -159.47 & - & 0.63 & - \\
DualSite.2En.S1.N1 & -159.02 & -382.92 & 1.08 & -2.45 \\
DualSite.2En.S1.N2 & -159.02 & -381.46 & 1.08 & -0.99 \\
DualSite.2En.S2.N1 & -159.61 & -382.24 & 0.49 & -1.77 \\
DualSite.2En.S2.N2 & -159.61 & -380.62 & 0.49 & -0.15 \\
SingleSite.NH3.S1 & -159.37 & -382.11 & 0.73 & -1.64 \\
SingleSite.NH3.S2 & -154.87 & - & 5.23 & - \\
DualSite.2NH3.S1 & -159.60 & -382.46 & 0.50 & -1.99 \\
DualSite.2NH3.S2 & -158.53 & -381.96 & 1.57 & -1.49 \\
NH3 & - & -380.47 & - & 0.00 \\
En.N1 & - & -380.57 & - & -0.10 \\
En.N2 & - & -380.52 & - & -0.05 \\
Py & - & -381.03 & - & -0.56 \\
\hline
\end{tabular}




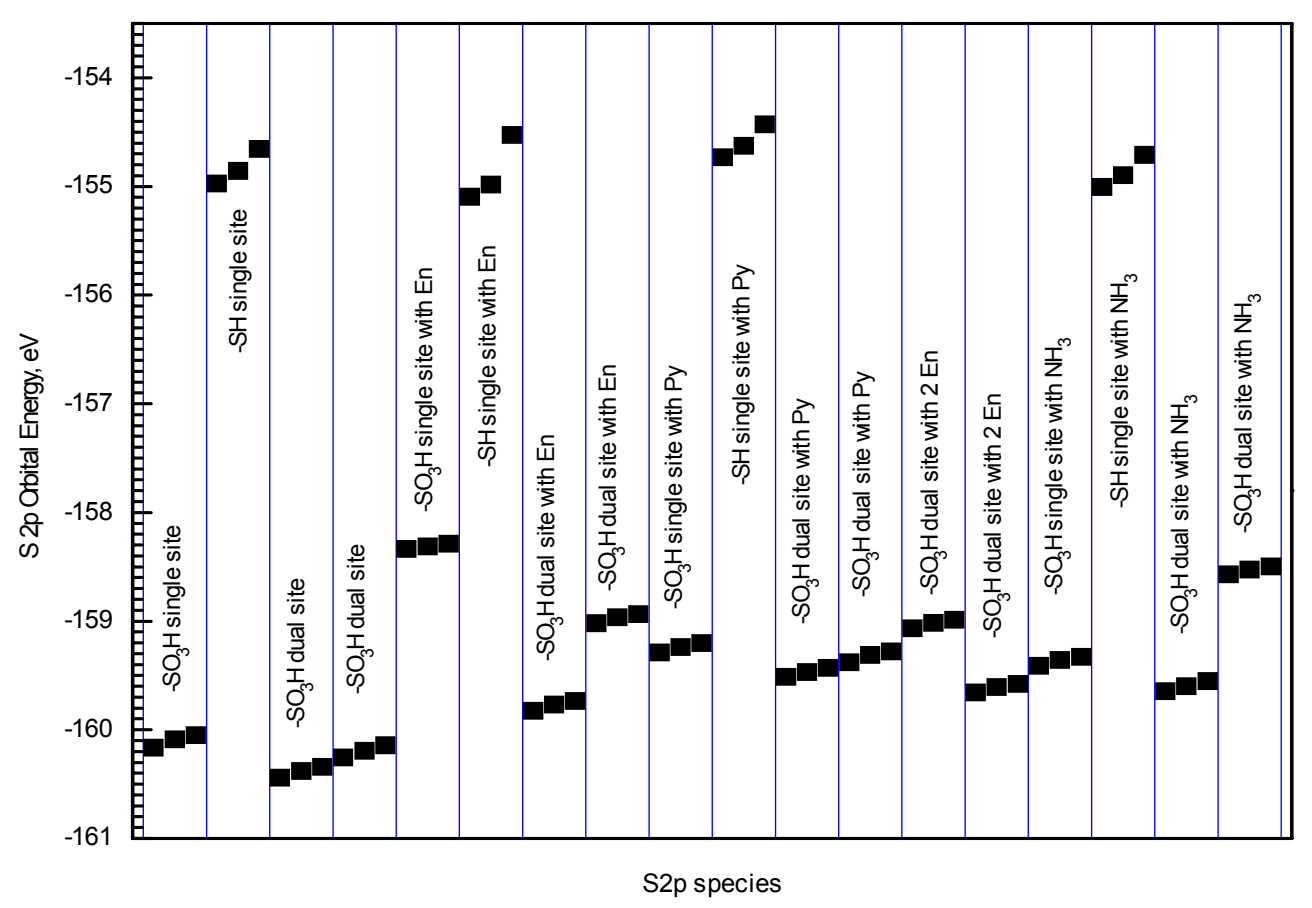

Figure 6. S2p orbital energies (DFT/BP/DN**) in the single and dual sites and their complexes with nitrogen bases. Each sulfur atom-containing species has three S2p levels associated with the $2 \mathrm{p}_{\mathrm{x}}, 2 \mathrm{p}_{\mathrm{y}}$, and $2 \mathrm{p}_{\mathrm{z}}$ orbitals.

4.2.2. Models for Hydrocarbon- vs Fluorocarbon-Sulfonic Acids. Models in which the alkyl chain carrying the $-\mathrm{SO}_{3} \mathrm{H}$ functionality is modified by halogen substitution are useful for understanding, control and design of acid catalysts. Substitution of fluorine for hydrogen in the alkyl-sulfonic group affects the acid strength of the $-\mathrm{SO}_{3} \mathrm{H}$ goups as well as the XPS CLS, as exemplified by calculations summarized in Table 4. 
Table 4. Adsorption Energies of Pyridine, $E_{a d s}$, and Theoretical N1s, S2s and S2p CoreLevel Shifts in Molecular Adducts of Pyridine with Ethyl-Sulfonic Acid and PerfluoroethylSulfonic Acid. All energies are in $\mathrm{eV}$ except $\mathrm{E}_{\mathrm{ads}}$ in $\mathrm{kJ} / \mathrm{mol}$.

\begin{tabular}{|c|c|c|c|c|c|c|c|c|}
\hline $\begin{array}{l}\text { Molecule or } \\
\text { Adduct }^{\mathrm{a}}\end{array}$ & $\begin{array}{c}\text { Total } \\
\text { DFT } \\
\text { Energy }\end{array}$ & $\begin{array}{c}E_{\text {ads }} \\
\mathrm{kJ} / \mathrm{mol}\end{array}$ & $\begin{array}{l}\text { N1s } \\
\text { orbital } \\
\text { energy }\end{array}$ & $\begin{array}{c}\text { S2s } \\
\text { orbital } \\
\text { energy }\end{array}$ & $\begin{array}{c}\text { S2p } \\
\text { orbital } \\
\text { energy b }\end{array}$ & $\Delta \mathrm{N} 1 \mathrm{~s}^{\mathrm{c}}$ & $\Delta \mathrm{S} 2 \mathrm{~s}$ & $\Delta \mathbf{S} 2 \mathbf{p}$ \\
\hline Pyridine & -6755.87 & & -381.03 & -- & -- & 0.00 & & \\
\hline $\mathrm{EtSO}_{3} \mathrm{H}$ & -19146.05 & & -- & -213.73 & -159.87 & -- & & \\
\hline $\operatorname{Et}\left(\mathrm{F}_{5}\right) \mathrm{SO}_{3} \mathrm{H}$ & -32648.74 & & -- & -214.77 & -160.90 & -- & & \\
\hline $\mathrm{Py}-\mathrm{EtSO}_{3} \mathrm{H}$ & -25902.44 & -50.6 & -382.23 & -212.76 & -158.90 & -1.20 & $0.97^{\mathrm{d}}$ & $0.97^{\mathrm{d}}$ \\
\hline $\begin{array}{l}\mathrm{Py}- \\
\mathrm{Et}\left(\mathrm{F}_{5}\right) \mathrm{SO}_{3} \mathrm{H}\end{array}$ & -39405.43 & -78.7 & -383.88 & -212.92 & -159.06 & -2.84 & $1.85^{\mathrm{e}}$ & $1.84^{\mathrm{e}}$ \\
\hline
\end{tabular}

${ }^{a} \mathrm{EtSO}_{3} \mathrm{H}$ : Ethylsulfonic acid; $\mathrm{Et}\left(\mathrm{F}_{5}\right) \mathrm{SO}_{3} \mathrm{H}$ : Perfluoroethylsulfonic acid; $\mathrm{Py}-\mathrm{EtSO}_{3} \mathrm{H}$ : Complex shown in Figure 7(a); $\mathrm{Py}-\mathrm{Et}\left(\mathrm{F}_{5}\right) \mathrm{SO}_{3} \mathrm{H}$ : Complex shown in Figure 7(b).

${ }^{\mathrm{b}}$ Average of $\mathrm{S} 2 \mathrm{p}_{\mathrm{x}}, \mathrm{S} 2 \mathrm{p}_{\mathrm{y}}$ and $\mathrm{S} 2 \mathrm{p}_{\mathrm{z}}$

${ }^{\mathrm{c}} \mathrm{N} 1 \mathrm{~s}$ core-level shift from free pyridine

${ }^{\mathrm{d}}$ Core-level shift from $\mathrm{EtSO}_{3} \mathrm{H}$

${ }^{\mathrm{e}}$ Core-level shift from $\mathrm{Et}\left(\mathrm{F}_{5}\right) \mathrm{SO}_{3} \mathrm{H}$

The sorption energies and CLS are accompanied by a pronounced proton shift from the $-\mathrm{SO}_{3} \mathrm{H}$ group to the nitrogen base induced by the presence of the backbone fluorine, as shown in Figure 7. 


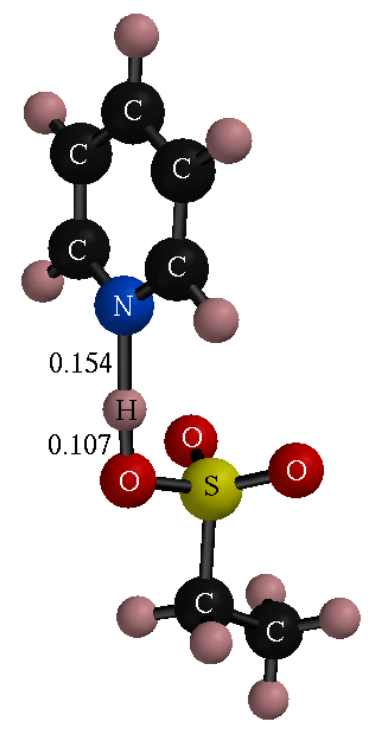

(a)

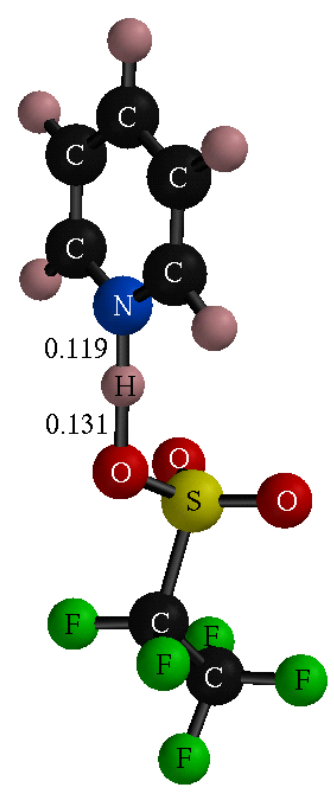

(b)

Figure 7. Pyridine complexes with (a) ethyl-sulfonic acid and (b) perfluoroethyl-sulfonic acid showing differences in the proton transfer from the $-\mathrm{SO}_{3} \mathrm{H}$ functionality to the nitrogen atom of pyridine due to substitution of aliphatic hydrogen by fluorine in the ethyl group. Calculations at the DFT/BP/DN** level with fully optimized geometries. The $\mathrm{O}-\mathrm{H}$ and $\mathrm{N}-\mathrm{H}$ distances are in $\mathrm{nm}$.

4.2.3. General Pattern of Nitrogen CLS - a Comparison with Experiment. Nitrogen CLS have been used for characterization of organic compounds with heterocyclic, amine, amide, nitrile, and nitro organic compounds. The application of XPS to the diagnostics of solid acid-base interactions is reinforced by a theoretical treatment, at the present level, of a large database of organic polymeric materials accumulated by Beamson and Briggs [13b]. Correlation between experiment and theory of reference compounds justifies the extension of the theory into a predictive realm of subtle effects of molecular environment and weak interactions examined in the previous sections. We therefore provide such a correlation using the calculated orbital energies rather than those previously employing effective atomic charges calculated by semi-empirical methods [8,28], later refined for polarizabilities and other molecular parameters of conjugated $\pi$-systems [29] which, however, did not produce satisfactory or predictive results [8]. Even though the Beamson-Briggs database entails polymers, it is evident from the data that segments and pendant groups can be modeled by capped molecular units.

The results based on a comparison of the calculated orbital energies and XPS binding energies are presented in detail in Appendix 1: Supporting Information given at the end of this chapter, and they are summarized herein as follows: 
(a) The experimental N1s BEs of the 22 nitrogen-containing polymers listed in the Beamson-Briggs database span a range of $\approx 10 \mathrm{eV}$ and are given with a precision to $0.01 \mathrm{eV}$;

(b) The calculated orbital energies $\mathrm{E}(\mathrm{N} 1 \mathrm{~s})$ in the nitrogen-containing segments defined in Table $\mathrm{S} 1$, rounded off to $0.01 \mathrm{eV}$, span the same range and correlate linearly with the experimental data as $\left[-\mathrm{E}(\mathrm{N} 1 \mathrm{~s})=(0.999 \pm 0.0003) * \mathrm{BE}(\mathrm{N} 1 \mathrm{~s})_{\text {corr. }} \approx 18.20\right] \mathrm{eV}$ (Table S2 and Figure S1).

(c) Experimental reference levels for aliphatic carbon $\mathrm{BE}(\mathrm{C} 1 \mathrm{~s})=285.0 \mathrm{eV}[13 \mathrm{~b}]$ were refined based on calculations of $\mathrm{C} 1 \mathrm{~s}$ orbital energies which yield somewhat different values for different polymer segments. This procedure yielded adjusted $\mathrm{BE}(\mathrm{N} 1 \mathrm{~s})_{\text {corr }}$ as defined and listed in Table S2 and used in the correlation (b) above.

As a result, the correlation between the calculated N1s orbital energies and experimental BEs provides a strong support for the use of XPS in conjunction with theory for a quantitative assessment of energies and structural changes resulting from interactions with molecular environment, including weak hydrogen bonding.

\section{Discussion}

The pendant propyl-sulfonic groups of the SBA material are identified as hydrogendonor sites in the $-\left(\mathrm{CH}_{2}\right)_{3} \mathrm{SO}_{3} \mathrm{H} \ldots \mathrm{N}$-base sorption complexes by the $\mathrm{S} 2 \mathrm{p}$ and $\mathrm{N} 1 \mathrm{~s}$ core-level shifts in opposite directions. The precursor mercaptopropyl groups, which are present in incompletely oxidized SBA, are inert. Ethylene diamine adsorption takes place with one nitrogen-down and the second nitrogen free, indicating that the propyl-sulfonic groups are separated beyond the span of accessibility to both nitrogens. Bonding of the conjugate bases in SBA is weaker than in Nafion-H, a fluorocarbon sulfonic acid, and sulfated zirconia (SZ). The N1s CLS of the SBA-bound nitrogen bases are substantially smaller than in Nafion-H and $\mathrm{SZ}$ and calculated adsorption energies are $55 \%$ smaller for pyridine bonded to propylsulfonic groups than to perfluoropropyl-sulfonic moieties. An all-electron theory accounts for the chemical CLS of both the S2p levels in the hydrogen-donor $-\mathrm{SO}_{3} \mathrm{H}$ and the N1s levels of the conjugate bases. The theory is validated by a linear correlation with experimental CLS of a polymer database presented in the Appendix: Supporting Information. A detailed analysis referring to specific results of section 4 is given below.

\subsection{Pure SBA-15.}

The presence of a single S2p peak in the experimental spectrum (Figure 1) indicates one oxidation state of sulfur, and its BE of $169.25 \mathrm{eV}$ confirms that it is the sulfur of the propylsulfonic acid group generated by the complete oxidation of the precursor mercaptopropyl groups. The peak width of $2.63 \mathrm{eV}$ suggests a degree of heterogeneity among the sulfonic acid groups. The $\mathrm{C} / \mathrm{S}$ ratio of 2.9 is close to the theoretically predicted 3.0 for the $-\left(\mathrm{CH}_{2}\right)_{3} \mathrm{SO}_{3} \mathrm{H}$ species. This ratio demonstrates that all the excess Pluronic 123 was removed in the ethanol reflux, as a higher ratio would be observed otherwise.

Two theoretical models were employed. The "single site" model includes one $-\mathrm{SO}_{3} \mathrm{H}$ 
and one $-\mathrm{SH}$ group, with the S2p levels separated by $5.27 \mathrm{eV}$ (Table 3), in excellent agreement with the experimental difference of $5.15 \mathrm{eV}$ found previously in a partially oxidized SBA material [2]. The second, "dual site" model involves two $-\mathrm{SO}_{3} \mathrm{H}$ groups in a sufficient proximity to interact. The $-\mathrm{SO}_{3} \mathrm{H}$ groups have only slightly different theoretical S2p energies in the single and the dual sites (to within $\pm 0.1 \mathrm{eV}$, cf. Table 3 and Figure 6), however, even though the latter are tied together by weak hydrogen bonds (Figure 6). The S2p levels are therefore an adequate reference for CLS upon nitrogen base adsorption discussed in section 5.2 below.

\subsection{Sorption of Nitrogen Bases.}

Adsorption of pyridine, a weak base, is widely used for the diagnostics of strong acid sites. In the case of Brønsted acid functionalities, interaction with pyridine may range from weak hydrogen bonding to a complete proton transfer to form a pair between the pyridinium cation and conjugate anion. The N1s XPS core levels in pyridine reflect this type of bonding by shifts to higher BEs, up to $3.6 \mathrm{eV}$ (from the N1s BE of gaseous pyridine) in case of strong protonic acids [8]. Simultaneously, atoms in the proton donor groups undergo CLS in the opposite direction to lower BEs. This was documented for the $-\mathrm{SO}_{3} \mathrm{H}$ functionalities in Nafion- $\mathrm{H}$ and the $-\mathrm{OSO}_{3} \mathrm{H}$ acid groups in $\mathrm{SZ}$ in our earlier work [8]. Even though adsorption of pyridine on the presently studied SBA-15 material was incomplete, with N/S ratio of 0.4 (Table 1), the CLS of the pyridine N1s of $2.35 \mathrm{eV}$ (from the N1s BE of the "free" nitrogen of En adsorbed on SBA-15) to higher BEs and the S2p CLS of $0.80 \mathrm{eV}$ (from the S2p of the bare SBA) to lower BEs observed (cf. Table 1) are consistent with the previous results [8] for pyridine adsorption on all oxysulfur-based Brønsted acid sites.

Theoretical results for the KS orbital energies, where more negative theoretical orbital energies correspond to higher experimental BEs, fully support this trend, yielding N1s CLS on the order of -1.5 to $-1.8 \mathrm{eV}$. We note that the free nitrogen of ethylenediamine has theoretical N1s level close to that of ammonia, cf. Table 3, cols. 3 and 5, rows 20-22. The calculated N1s of free pyridine is by $0.56 \mathrm{eV}$ lower, cf. Table 3, and that of the polymers $\mathrm{P} 4 \mathrm{VP}$ and P2VP with pendant pyridine groups by $0.3 \mathrm{eV}$ lower, cf. Table S2 of Appendix 1: Supporting Information. These theoretical results indicate that the N1s reference levels are uncertain to within 0.3-0.6 eV. However, the observed N1s CLS exceed this value and are accounted by the theory within this error margin. The S2p CLS are in the opposite direction of $+0.8 \mathrm{eV}$ to $+0.9 \mathrm{eV}$ for the two models (cf. Table 3), indicating again that the $-\mathrm{SO}_{3} \mathrm{H}$ groups are adsorption centers. The optimized geometry in Figure $5 \mathrm{~b}$ confirms this but shows that proton transfer from the $-\mathrm{SO}_{3} \mathrm{H}$ groups to pyridine is far from complete. The calculated adsorption energies are $-54.4 \mathrm{~kJ} / \mathrm{mol}$ for single sites and $-33.5 \mathrm{~kJ} / \mathrm{mol}$ of pyridine for dual sites (Table 2), indicating a relatively weak acidity of the sulfonic acid functionalities in SBA-15 compared to Nafion- $\mathrm{H}$, a fluorocarbon sulfonic acid. The pronounced effect of the fluorine substitution for hydrogen on the aliphatic chain carrying the $-\mathrm{SO}_{3} \mathrm{H}$ group is exemplified by the calculated sorption energies, structures and CLS of pyridine adducts with ethylsulfonic acid and perfluoroethylsulfonic acid (Table 4, Figure 7): adsorption energies are by $55 \%$ higher, the acidic proton is shifted by 0.3 Angstrom toward the nitrogen atom, 
and N1s CLS is by $1.64 \mathrm{eV}$ larger in the fluoro-derivative.

Ethylenediamine forms an adduct En-SBA which shows N1s CLS similar to Py-SBA to higher $\mathrm{BEs}$ for one of its two $\mathrm{N}$ atoms by $2.05 \mathrm{eV}$ (from the "free" nitrogen of the adsorbed En), and S2p CLS to lower BEs by $1.10 \mathrm{eV}$ from the S2p BE of the bare site (Table 1). The theoretical models yield the N1s CLS of $-1.55 \mathrm{eV}$ and $-0.7 \mathrm{eV}$ for the single and dual sites, and S2p CLS of +1.79 and $+0.8 \mathrm{eV}$ for the two sites. The theory thus supports single site adsorption of ethylene diamine with one nitrogen atom adsorbed and the second free, better than the dual site model. The optimized geometry in Figure $5 \mathrm{c}$ shows that proton transfer from the $-\mathrm{SO}_{3} \mathrm{H}$ groups to ethylene diamine is more pronounced than in the pyridine case. The calculated adsorption energy on single sites is $-96.2 \mathrm{~kJ} / \mathrm{mol}$ (cf. Table 2), consistent with stronger basicity of ethylene diamine than that of pyridine. The model with ethylene diamine bridging two $-\mathrm{SO}_{3} \mathrm{H}$ groups (Table 2, col. 5) is discarded because the N1s CLS of the two bonded $\mathrm{N}$ atoms would be much smaller than observed.

The ammonium-exchanged $\mathrm{NH}_{4}$-SBA material has been prepared from aqueous solution of $\mathrm{NH}_{4} \mathrm{Cl}$ rather than by adsorption of $\mathrm{NH}_{3}$. The resulting dry form of the ammonium ion-exchanged material, $-\mathrm{SO}_{3} \mathrm{NH}_{4}$, is equivalent to adsorbed ammonia on the protonated sulfonic groups, $-\mathrm{SO}_{3} \mathrm{H}$... $\mathrm{NH}_{3}$. The quantitation of the XPS spectrum indicates an incomplete exchange wherein slightly less than $30 \%$ of the $-\mathrm{SO}_{3} \mathrm{H}$ protons were replaced by ammonium ions, based on the experimental N/S ratio 0.29 (Table 1). The S2p levels at $169.30 \mathrm{eV}$ of the bare $-\mathrm{SO}_{3} \mathrm{H}$ site and the shoulder at $168.60 \mathrm{eV}$ of the occupied $-\mathrm{SO}_{3} \mathrm{NH}_{4}$ site show a CLS of $0.7 \mathrm{eV}$, in an excellent agreement with theory that yields the S2p CLS of $0.73 \mathrm{eV}$ for the single-site $-\mathrm{SO}_{3} \mathrm{H} . . . \mathrm{NH}_{3}$ (Table 3, column 4, row 16).

The SBA-15 material has been previously shown to be a catalyst for dehydrocondensation of alcohols to ethers, in particular with a 2/1 molar ratio of methanol to isobutanol to the methylisobutyl ether (MIBE), in excess to dimethyl ether (DME) from methanol and to isobutene (IB) from isobutanol. ${ }^{2}$ The rates over this material are in the midrange of polymeric and inorganic solid acids [2,5,30], but the selectivity toward the unsymmetrical MIBE is high and comparable only to that over Nafion-H [31]. One beneficial feature of the inorganic SBA is the presence of large non-swelling pores, in contrast to Nafion with swelling pores of undefined size. The present results show that further improvements of the SBA material for acid-catalyzed reaction are possible, specifically by derivatizing the silica inner surfaces by fluorocarbon sulfonic pendant groups for increased acid strength, and increasing the surface concentration of the acid functionalities for reactions that require molecular proximity of dual sites, as indicated by the kinetic behavior [2]. 


\section{Conclusions}

The mesoporous SBA-15 material affords chemical versatility due to large pores and flexible pendant proton-exchanging $-\mathrm{SO}_{3} \mathrm{H}$ functionalities. There are some differences among individual preparations in terms of pore size, concentration of ion exchanging sites, completeness of oxidation of the precursor thiol groups, and successful removal of the organic templating agent $[1,2,6]$. The control of these properties and design of synthetic strategy for specific applications requires a thorough characterization, which is augmented by XPS and theory.

The present study shows that all of the organic templating agent can be removed and that the sulfur moieties can be fully oxidized to accessible $\equiv \mathrm{Si}-\left(\mathrm{CH}_{2}\right)_{3} \mathrm{SO}_{3} \mathrm{H}$ groups which exchange their protons with ammonium ions and adsorb nitrogen bases as proton-donor Brønsted acids. The $-\mathrm{SO}_{3} \mathrm{H}$ sites, although their concentration is comparable to polymeric sulfonated polyelectrolytes, are sufficiently separated so as not to have to be abridged by a short bifunctional base such as ethylene diamine. XPS has identified the proton donors through the S2p core-level shifts to lower BEs and the proton acceptors through the N1s core-level shifts of the adsorbed base to higher BEs.

The theory of core level shifts based on calculations of orbital energies has proven to be in excellent agreement with experiment, and in addition affords energies and optimized geometries of sorption adducts, including that of partial hydrogen transfer between the surface acid and the adsorbed base. The theory also has a predictive value in that one can calculate models of structurally and chemically different pendant groups that enable the control of acid strength and reaction pathways catalyzed by this mesoporous material.

\section{References to Chapter III}

1. Margolese, D.; Melero, J. A.; Christiansen, S. C.; Chmelka, B. F.; Stucky, G. D., Chem. Mater. 12 (2000) 2448.

2. Shen, J. G. C.; Herman, R. G.; Klier, K., J. Phys. Chem. 106 (2002) 9975.

3. Shen, J. G. C.; Kalantar, T. H.; Ma, Q.; Herman, R. G.; Klier, K., J. Chem. Soc., Chem. Commun. (2001) 653.

4. Klier, K.; Kwon, H.-H.; Herman, R. G.; Hunsicker, R. A.; Ma, Q.; Bollinger, S. J., in Studies in Surface Science and Catalysis, $130 \mathrm{D}\left(12^{\text {th }}\right.$ Intern. Congr. Catal., 2000, Pt. D), A. Corma, F. V. Melo, S. Mendioroz, J. L. G. Fierro (Eds.), Elsevier, Amsterdam (2000) p. 3447. 
5. Klier, K.; Sun, Q.; Feeley, O. C.; Johanson, M.; Herman, R. G., in Studies in Surface Science and Catalysis, 101A (1 $1^{\text {th }}$ Intern. Congr. Catal. - 40th Ann., 1996, Pt. A), J. W. Hightower, W. N. Delgass, E. Iglesia, A. T. Bell (Eds.), Elsevier, Amsterdam (1996) p. 601.

6. Melero, J. A.; Stucky, G. D.; van Grieken, R.; Morales, G., J. Mat. Chem. 12 (2002) 1664.

7. Shen, J. G. C.; Kalantar, T. H.; Herman, R. G.; Roberts, J. E.; Klier, K., Chem. Mater. 13 (2001) 4479.

8. Johansson, M.; Klier, K., Topics Catal. 4 (1997) 99.

9. Hunsicker, R. A.; Klier, K.; Gaffney, T. S.; Kirner, J. G., Chem. Mater. 14 (2002) 4807.

10. Klier, K. et al., to be published.

11. Gelius, U.; Wannberg, B.; Baltzer, P.; Fellner-Feldegg, H.; Carlsson, G.; Johansson, C.G.; Larsson, J.; Münger, P.; Vegerfors, G., J. Electron Spectrosc. Relat. Phenom. 52 (1990) 747.

12. Chaney, R. L.; Simmons, G. W., R\&D Magazine 83(9) (1990) 1.

13. (a) Briggs, D.; Seah, M. P., "Practical Surface Analysis by Auger and X-ray Photoelectron Spectroscopy," Wiley, Chichester (1983); (b) Beamson, G.; Briggs, D., "High Resolution XPS of Organic Polymers: The Scienta ESCA300 Database," Wiley, Chichester (1992).

14. Brunauer, S.; Emmet, P. H.; Teller, E., J. Am. Chem. Soc. 60 (1938) 309.

15. SPARTAN, ver. 3.1, Wavefunction, Inc., Irvine, CA, USA.

16. Becke, A. D., Phys. Rev. A 38 (1988) 3098.

17. Perdew, J. P., Phys. Rev. B 33 (1986) 8822.

18. The $\mathrm{DN}^{* *}$ basis set uses polarization functions for hydrogen, is equivalent in performance to Gaussian 6-31G**, and its construction follows that in Delley, B. J. Chem. Phys. 92 (1990) 508 (Wavefunction, Inc., private communication).

19. Ma, Q.; Klier, K.; Herman, R.G., In $74^{\text {th }}$ ACS Colloid and Surface Science Symposium, Lehigh University, Bethlehem, PA (2000) Abstract p 196. 
20. Klier, K. Topics Catal. 18 (2002) 141.

21. Klier, K., to be published.

22. Methfessel, M.; Fiorentini, V.; Oppo, S., Phys. Rev. B 61 (2000) 5229.

23. Zhao, D.; Feng, J.; Huo, Q.; Melosh, N.; Frederickson, G. H.; Chmelka, B. F.; Stucky, G. D., Science 279 (1998) 548.

24. Luan, Z.; Hartmann, M.; Zhao, D.; Zhou, W.; Kevan, L., Chem. Mater. 11 (1999) 1621.

25. Morey, M. S.; O'Brien, S.; Schwarz, S.; Stucky, G. D., Chem. Mater. 12 (2000) 898.

26. Van Grieken, R.; Calleja, G.; Stucky, G. D.; Melero, J. A.; Garcia, R. A.; Iglesias, J., Langmuir 19 (2003) 3966.

27. A theoretical investigation of a silica model slab with hexagonal unit cell containing three layers of $\mathrm{SiO}_{2}$ with the silicon layer sandwiched by two layers of oxygen resembling the (111) surface of $\beta$-cristobalite - was determined to have in-plane unit cell parameters $\mathrm{a}=\mathrm{b}=0.53 \mathrm{~nm}$, with angle $\angle(\mathrm{a}, \mathrm{b})=120^{\circ}$ (Ma, Q.; Klier, K.; Cheng, H.; Mitchell, J. W.; Hayes, K. S., J. Phys. Chem. B 104 (2000) 10618). With two silicon atoms per unit cell and a planar unit cell area of $(0.53 \mathrm{~nm})^{2} \sin \left(120^{\circ}\right)=0.243 \mathrm{~nm}^{2}$, the silicon surface concentration is calculated to be $8.22 \mathrm{Si}$ atom $/ \mathrm{nm}^{2}$.

28. Nordberg, R.; Albridge, R. G.; Bergmark, T.; Ericson, U.; Hedman, J.; Nordling, C.; Siebahn, K.; Lindberg, B. J., Arkiv Kemi. 28 (1968) 257.

29. Gasteiger, J.; Hutchings, M. J., J. Chem. Soc. Perkin Trans. 2 (1984) 559.

30. Klier, K.; Beretta, A.; Sun, Q.; Feeley, O. C.; Herman, R. G., Catal. Today 36 (1997) 3.

31. Nunan, J. G.; Klier, K.; Herman, R. G., J. Catal. 139 (1993) 406. 


\section{Appendix 1. Supporting Information Sorption of Nitrogen Bases and XPS Study of Mesoporous Solid Acid SBA-15}

In Table S1, each of the nitrogen-containing polymers is represented by its acronym, full name and segment formula, while the corresponding molecular model is the segment formula with capping groups. The geometry of each molecular model was fully optimized at the $\mathrm{DFT} / \mathrm{BP} / \mathrm{DN}^{* *}$ level, and the optimized geometries are available as coordinate files from the authors.

The experimental binding energies (BEs) of nitrogen-containing polymers and the presently calculated theoretical KS core levels of the model capped segments are presented in Table S2. The KS orbital energies of the capping groups, marked red in Table S1, were excluded from calculations presented in Table S2. Thus, only the inner segments marked black in Table S1, which are common to the polymers from the XPS database and the theoretical models, are being compared and rectified in Table S2.

Table S1. Nitrogen-Containing Polymers and Molecular Models for Calculations of N1s Core Level Chemical Shifts

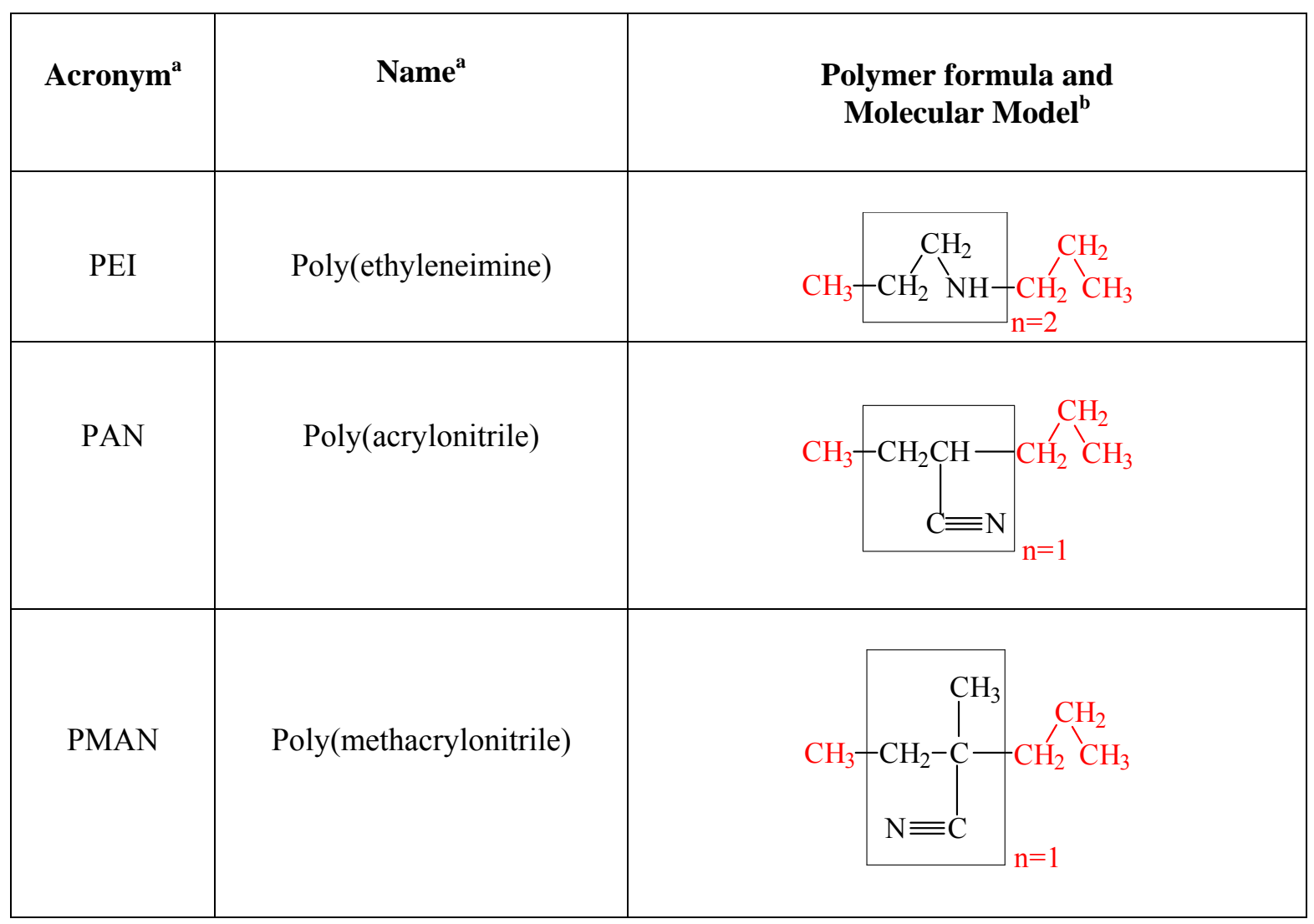




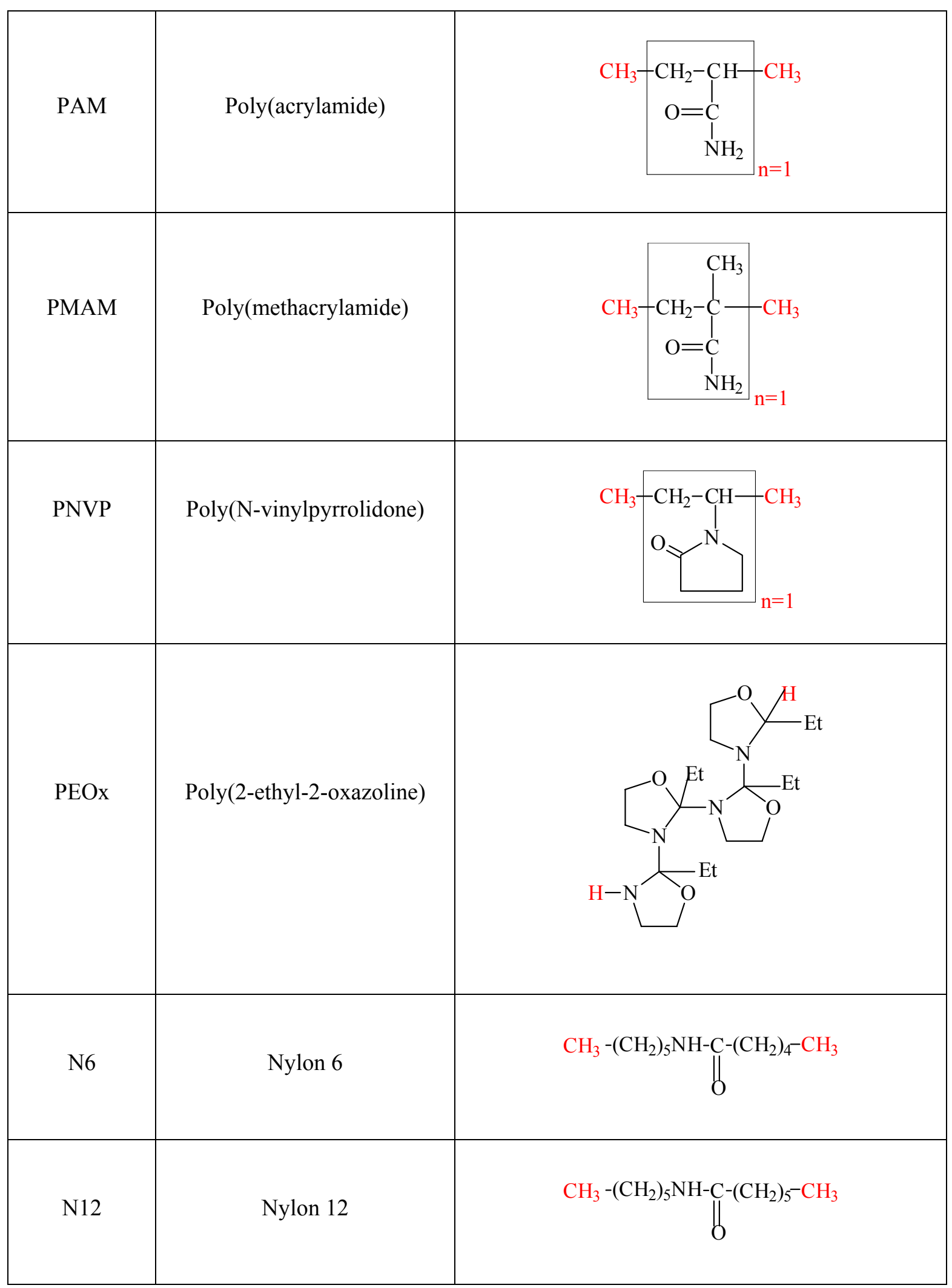




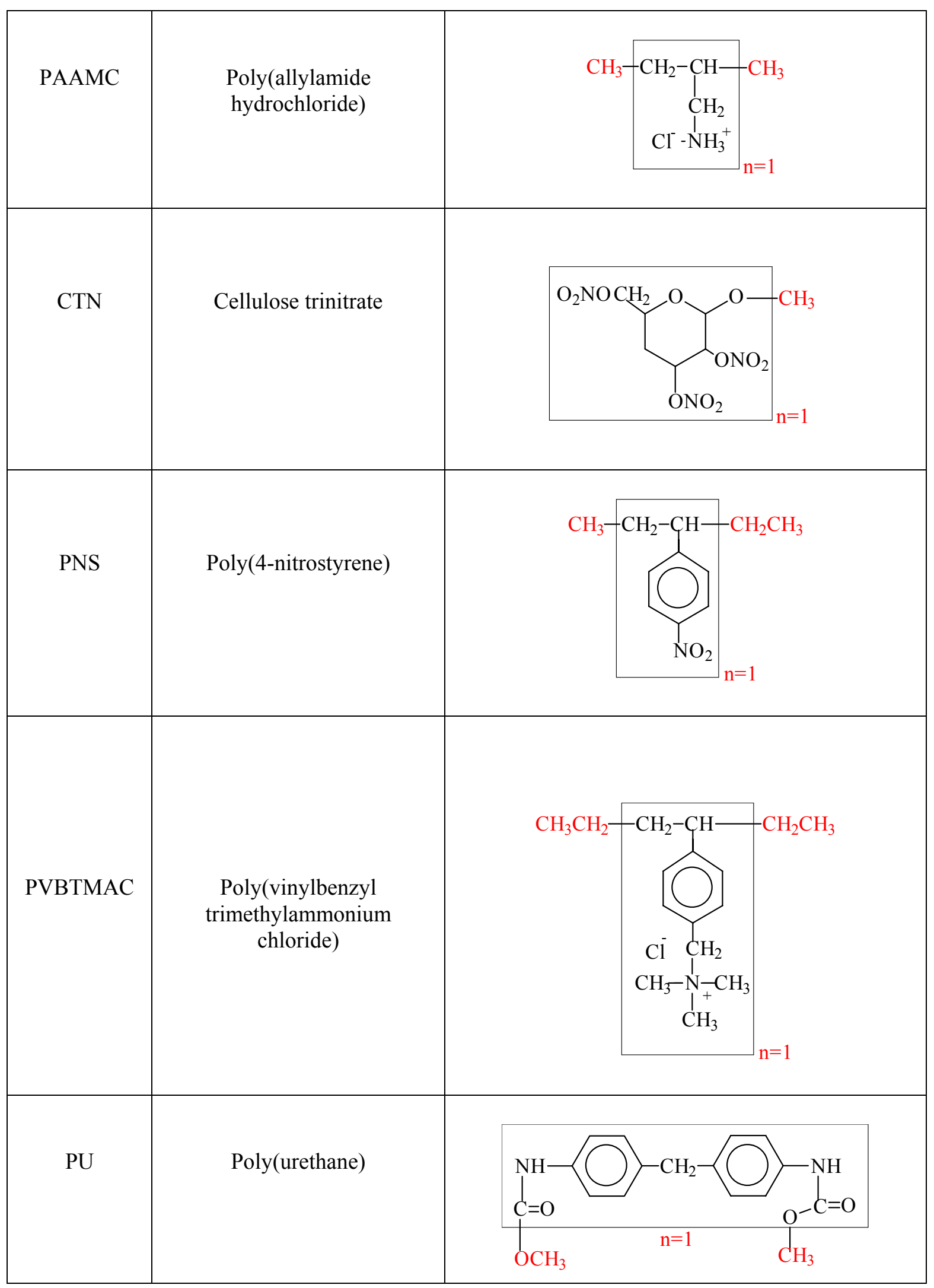




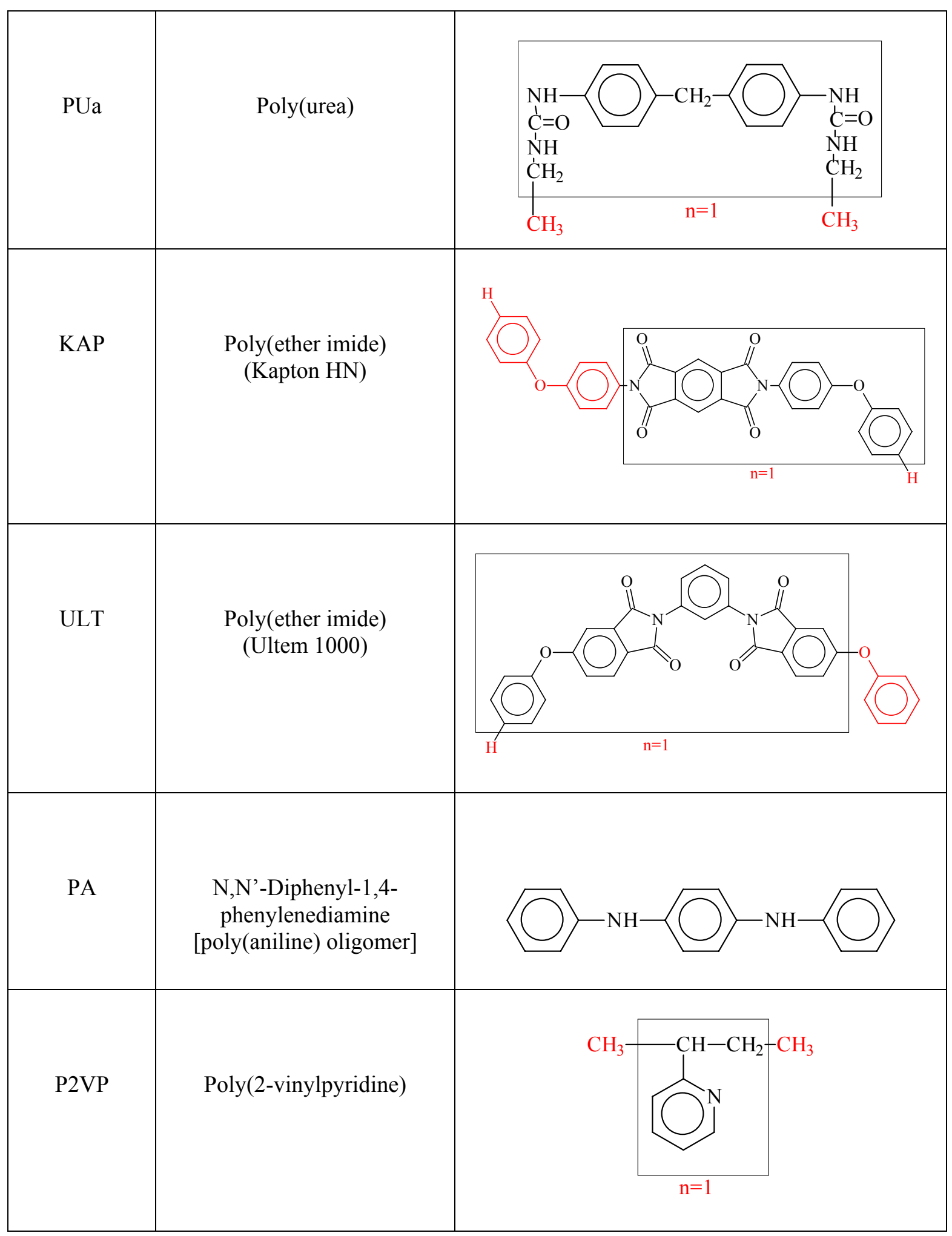




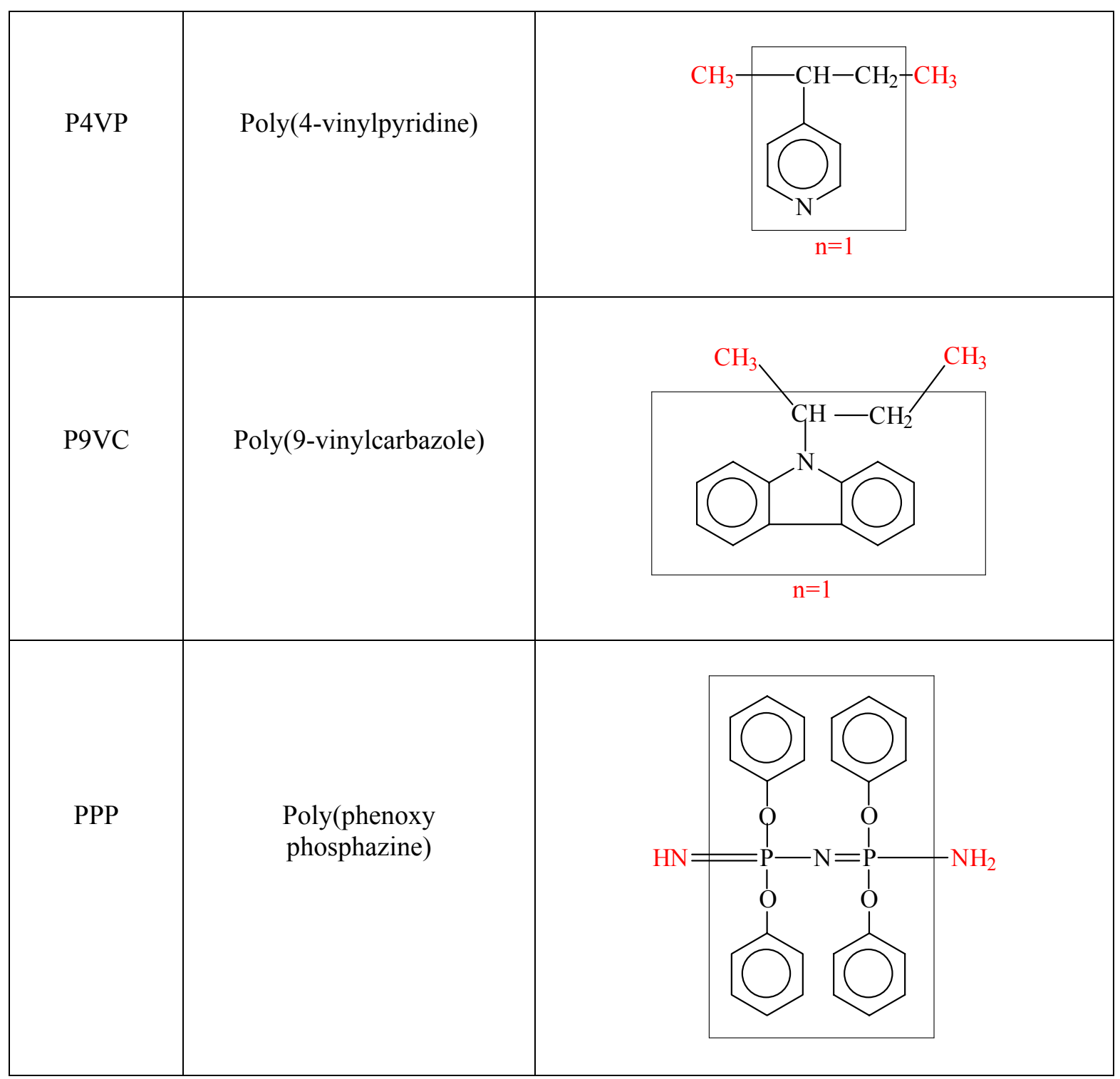

${ }^{a}$ Names of polymers are as in Beamson, G.; Briggs, D. "High Resolution XPS of Organic Polymers: The Scienta ESCA300 Database,” Wiley \& Sons, Chichester 1992, ISBN 0471935921.

${ }^{\mathrm{b}}$ Segments of polymers are represented in black letters. The capping groups and multiplicities of the segments in the molecular models are marked red. 
Table S2. N1s and C1s Experimental Binding Energies and Theoretical Core-Levels of Nitrogen-Containing Polymers and Corresponding Molecular Models (eV).

\begin{tabular}{|c|c|c|c|c|c|c|c|c|}
\hline No. & Polymer & $\begin{array}{l}\text { N1s- } \\
\text { expt }\end{array}$ & $\begin{array}{l}\text { N1s- } \\
\text { expt, } \\
\text { rectified }\end{array}$ & $\begin{array}{c}\text { C1s- } \\
\text { expt, } \\
\text { lowest }\end{array}$ & $\begin{array}{l}\text { C1s- } \\
\text { theor, } \\
\text { lowest }\end{array}$ & $\begin{array}{c}7 \\
\text { Theor. } \\
\text { shift from } \\
\text { aliphatic } \\
\text { C1s of } \\
\text { Nylon } 6\end{array}$ & $\begin{array}{c}\text { C1s- } \\
\text { expt, } \\
\text { rectified }\end{array}$ & $\begin{array}{l}\text { N1s- } \\
\text { theor }\end{array}$ \\
\hline 1 & PEI & 399.07 & 399.62 & 285.56 & 269.94 & 0.55 & 286.11 & 380.56 \\
\hline 2 & PAN & 399.57 & 400.00 & 285.48 & 269.82 & 0.43 & 285.91 & 381.00 \\
\hline 3 & PMAN & 399.57 & 399.79 & 285.00 & 269.61 & 0.22 & 285.22 & 380.96 \\
\hline 4 & PAM & 399.83 & 400.15 & 285.00 & 269.71 & 0.32 & 285.32 & 381.66 \\
\hline 5 & PMAM & 399.96 & 400.19 & 285.00 & 269.61 & 0.23 & 285.23 & 381.63 \\
\hline 6 & PNVP & 399.88 & 400.11 & 285.00 & 269.61 & 0.23 & 285.23 & 381.70 \\
\hline 7 & PEOx & 399.87 & 399.62 & 285.00 & 269.14 & -0.25 & 284.75 & 380.96 \\
\hline 8 & N6 & 399.77 & 399.77 & 285.00 & 269.39 & 0.00 & 285.00 & 381.61 \\
\hline 9 & $\mathrm{~N} 12$ & 399.84 & 399.77 & 285.00 & 269.32 & -0.07 & 284.93 & 381.70 \\
\hline 10 & PAAMC & 401.46 & 401.92 & 285.00 & 269.85 & 0.46 & 285.46 & 382.43 \\
\hline 11 & CTN & 408.15 & 409.40 & 287.13 & 270.86 & 1.25 & 288.56 & 389.09 \\
\hline 12 & PNS & 405.45 & 405.93 & 284.49 & 269.87 & 0.48 & 284.97 & 387.06 \\
\hline 13 & PVBTMAC & 402.14 & 402.48 & 284.47 & 269.73 & 0.34 & 284.81 & 384.97 \\
\hline 14 & PU & 400.32 & 400.60 & 284.64 & 269.67 & 0.28 & 284.92 & 382.32 \\
\hline 15 & PUa & 399.89 & 400.38 & 284.58 & 269.88 & 0.49 & 285.07 & 381.97 \\
\hline 16 & KAP & 400.60 & 401.26 & 284.70 & 270.05 & 0.66 & 285.36 & 383.07 \\
\hline 17 & ULT & 400.40 & 400.80 & 284.72 & 269.79 & 0.40 & 285.12 & 382.67 \\
\hline 18 & PA & 399.92 & 400.14 & 284.70 & 269.61 & 0.22 & 284.92 & 382.05 \\
\hline 19 & P2VP & 399.30 & 399.45 & 285.00 & 269.54 & 0.15 & 285.15 & 380.83 \\
\hline 20 & P4VP & 399.34 & 399.58 & 285.00 & 269.63 & 0.24 & 285.24 & 380.84 \\
\hline 21 & P9VC & 400.22 & 400.30 & 284.67 & 269.47 & 0.08 & 284.75 & 382.22 \\
\hline 22 & PPP & 397.93 & 398.27 & 284.70 & 269.73 & 0.34 & 285.04 & 380.19 \\
\hline
\end{tabular}

Col. 1: Number of the polymer or model compound

Col. 2: Name of the polymer

Col. 3: N1s-expt $=$ Experimental XPS BE (eV) from Beamson and Briggs, see Ref. in Table S1.

Col. 4: N1s-expt, rectified $=$ N1s-expt $($ Col. 3) + Theoretical shift from aliphatic C1s of Nylon 6 (Col. 7)

Col. 5: $\mathrm{C} 1 \mathrm{~s}$-expt, lowest $=$ Lowest experimental $\mathrm{C} 1 \mathrm{~s} \mathrm{BE}(\mathrm{eV})$ in the respective nitrogen-containing polymer from Beamson and Briggs

Col. 6: C1s-theor, lowest: Lowest theoretical C1s core-level energy $(\mathrm{eV})$ in the respective nitrogencontaining model compound

Col. 7: Theoretical shift from aliphatic $\mathrm{C} 1 \mathrm{~s}$ of Nylon $6=\mathrm{C} 1$ s-theor, lowest (Col. 6) for the given polymer C1s-theor, lowest for Nylon 6 (row 8 in Col. 6)

Col. 8: $\mathrm{C} 1 \mathrm{~s}$-expt, rectified $=\mathrm{C} 1 \mathrm{~s}$-expt, lowest $(\mathrm{Col}$. 5) - Theoretical shift from aliphatic C1s of Nylon 6 (Col. 7)

Col. 9: Theoretical N1s core-level energy $(\mathrm{eV})$ in the model compound 
In the Beamson-Briggs experimental database, the XPS core-level binding energies are referenced to a selected C1s energy, which is set at a certain value such as $285.0 \mathrm{eV}$ for aliphatic carbon, as exemplified in Column 5, Rows 3-10 and 19-20 of Table S2. The carbon atoms are not equivalent, however, and calculations show a spread of some $0.2 \mathrm{eV}$ around an average value for the aliphatic carbons in the different molecules, as in Column 6 . Thus we refined the reference values in the following manner: we calculated the difference between the lowest $\mathrm{C} 1 \mathrm{~s}$ core-level energy in a given model molecule and the $\mathrm{C} 1 \mathrm{~s}$ core-level in the $\mathrm{CH}_{2}$ groups of the model for Nylon 6 (Col. 7, Theoretical shift from aliphatic C1s of Nylon 6), and then added these shift values to each experimental C1s BE (Col. 8, C1s-expt, rectified) and N1s BE (Col. 4, N1s expt, rectified). The theoretically calculated N1s corelevel energies (Col. 9) are then plotted against the rectified experimental N1s BEs of Column 4 in Figure S1.

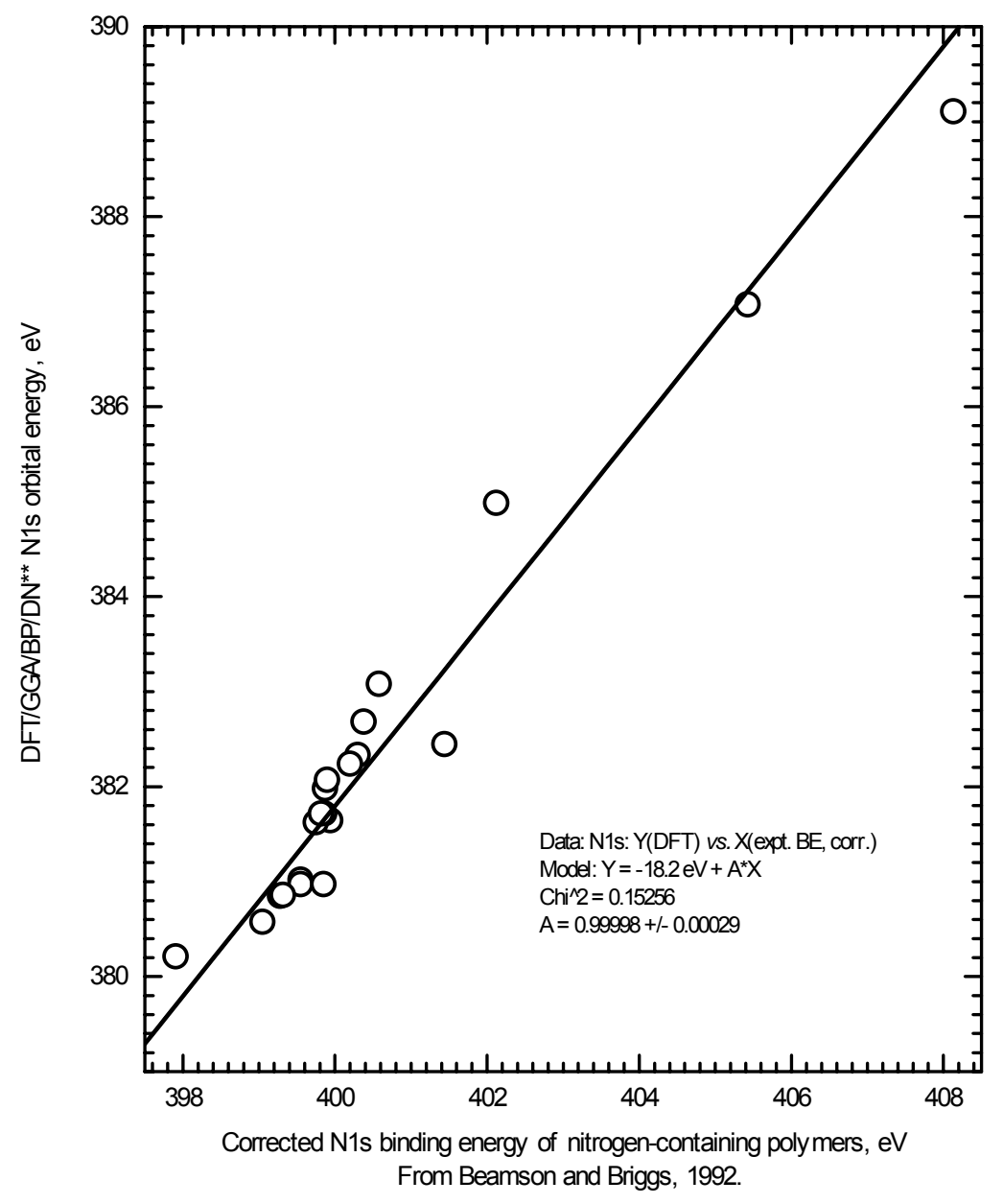

Figure S1. Correlation between the DFT N1s orbital energies (negative of the Kohn-Sham core-level energies) and the experimental N1s BEs of nitrogencontaining polymers. Identification of the models for polymer segments and data from Table S1. 


\section{Chapter IV. Dehydrocondensation of Alcohols to Form Ethers over Highly Ordered Mesoporous SBA-15 Catalyst}

\section{Introduction}

There is considerable interest in efficient conversions of natural gas and coal to highvalue chemicals and to high energy, high purity liquid fuels. The conversion of natural gas and coal to $\mathrm{H}_{2} / \mathrm{CO}$ synthesis gas, with $\mathrm{H}_{2} / \mathrm{CO}$ typically in the ranges of 2-3 and $0.45-1.0$, respectively, are well-established processes [1-3], as is the conversion of synthesis gas to methanol [3-5]. Methanol can be catalytically converted directly to chemicals [6-9] and to a gasoline consisting of a mixture of isoparaffins/aromatics [6,10]. It has also been shown that synthesis gas can be directly converted to a mixture of methanol $(\mathrm{MeOH})$ and higher alcohols over heavy alkali base-promoted $\mathrm{Cu}$-based oxide catalysts, with isobutanol (i-BuOH) being the dominant higher alcohol [11-15].

Regarding conversion of alcohols to ethers, it was found in this laboratory that Nafion-H resins converted the $\mathrm{MeOH} / \mathrm{i}-\mathrm{BuOH}$ mixture to methylisobutylether (MIBE) by acid-catalyzed dehydrocondensation at low temperatures such as $359-389 \mathrm{~K}$ and ambient or moderate pressures [16,17], where the MIBE has a high cetane number of 53 [18]. Organic resins were more active for ether synthesis than the Nafion-H resins, but they were less selective and less thermally stable [12,20]. Alternatively, thermally stable inorganic catalysts such as sulfated zirconia and H-ZSM-5 could be used at high temperatures, e.g. 448K, to give high yields of isobutene (IB) from the alcohol mixture while forming much smaller amounts of the ethers [21]. Isotopic studies of the alcohol coupling reaction over Nafion- $\mathrm{H}$, Amberlyst-35, and H-ZSM-5 indicated that the reaction proceeded via a surface-catalyzed $\mathrm{S}_{\mathrm{N}} 2$ reaction with competition of the alcohols for the surface acid sites [22-24]. Ideally, a high-efficiency catalyst designed for the alcohol dehydration/coupling reactions would possess Brønsted acid functionalities in close proximity to one another on a thermally stable, high surface area support with low diffusion resistance to the reactants and products.

One approach taken by us was to design and synthesize a high-efficiency catalyst by anchoring $\left[-\mathrm{O}_{3} \mathrm{SOCH}_{2} \mathrm{CH}_{2} \mathrm{OSO}_{3}\right]^{2-}$ groups on $\mathrm{Zr}(\mathrm{OH})_{4}$ followed by calcination at $773 \mathrm{~K}$ to remove the $\mu-\mathrm{CH}_{2} \mathrm{CH}_{2}$ - ligand bridge, yielding surface-grafted acid groups in close proximity to one another on zirconia [25]. The resultant catalyst had significantly enhanced activity and selectivity in producing MIBE from a MeOH/i-BuOH mixture [26]. However, this catalyst had a surface area of $97 \mathrm{~m}^{2} / \mathrm{g}$ and an acid-exchange capacity of $0.70 \mathrm{meq} \mathrm{H} / \mathrm{g} \mathrm{[25]}$. Higher surface area and acid concentration would be desirable for a high-efficiency ether synthesis catalyst, and mesoporous supports may yield an improved catalyst.

A family of mesoporous molecular sieves designated as M41S, with MCM-41 as a member, was reported in 1992 [27,28]. These materials exhibited high surface areas and a hexagonal arrangement of uniform parallel 15-100 $\AA$ diameter mesopores that adsorbed large amounts of benzene. More recently, a larger pore mesoporous silica, designated as SBA-15, 
with structural features similar to MCM-41 was synthesized [29,30]. SBA-15 is a wellordered hexagonal mesoporous silica structure that is synthesized under acidic reaction conditions using an amphiphilic block copolymer as a structure-directing agent [29,30]. This material has a larger unit cell parameter, a larger uniform pore size, a larger pore volume, and thicker silica walls than MCM-41 synthesized by using conventional low-molecular weight cationic surfactants [30]. It has been reported that SBA-15 is much more hydrothermally stable than are the MCM-type materials [29,31].

Similar to the anchoring of 3-mercaptopropyltrimethoxysilane moieties on MCM and hexagonal mesoporous silicas [32-35], SBA-15 has been surface-derivatized with pendant propylthiol groups that can be subsequently or in situ oxidized by $\mathrm{H}_{2} \mathrm{O}_{2(\mathrm{aq})}$ to form propylsulfonic acid groups [31]. By X-ray photoelectron spectroscopy (XPS), we have shown that oxidation of the thiol $(-\mathrm{SH})$ groups to sulfonic acid $\left(-\mathrm{SO}_{3} \mathrm{H}\right)$ groups is not always complete and can be quantitatively analyzed from photoemissions of the two species [36,37]. The $-\mathrm{SO}_{3} \mathrm{H}$ groups on SBA-15 can be utilized for Brønsted acid-catalyzed synthesis reactions at vapor-solid interfaces, e.g. coupling of alcohols to form ethers [36], or liquid phase, e.g. esterification of fatty acids with methanol to form methyl esters [38] and synthesis of 2-ethoxytetrahydropyran from 3,4-dihydro-2H-pyran and ethanol [33].

In the present research, we investigate the catalytic properties and stability of a large pore SBA-15 catalyst, prepared in this laboratory and characterized by X-ray powder diffraction (XRD), X-ray photoelectron spectroscopy (XPS), BET surface area, and sorption of nitrogen bases [37], for the dehydrocondensation/dehydration of mixtures of alcohols to form ethers and olefins and probe the mechanistic pathway and reaction intermediates involved in these reactions. The advantages of large-pore silica-based materials are in applicability to reactions of large molecules and non-swelling properties.

\section{Experimental Procedures}

\subsection{Catalyst Synthesis.}

The SBA-15 catalyst was synthesized at $313 \mathrm{~K}$ from tetraethoxysilane (TEOS, Aldrich) and 3-mercaptopropyltrimethoxysilane (MPTMS, Aldrich) with Pluronic 123 $\mathrm{EO}_{20} \mathrm{PO}_{70} \mathrm{EO}_{20}$ triblock copolymer ( $\mathrm{MW}=5800$, Aldrich) as the templating agent using the one-step direct synthesis procedure of Margolese et al. [31] and as described previously [37]. Following prehydrolysis of TEOS and Pluronic 123, MPTMS and $\mathrm{H}_{2} \mathrm{O}_{2}(30 \%$, Aldrich) were added and the mixture was equilibrated for $20 \mathrm{~h}$. After further aging at $373 \mathrm{~K}$ for $24 \mathrm{~h}$, the white precipitate was filtered, air-dried at ambient temperature, and then refluxed in $95 \%$ ethanol for $24 \mathrm{~h}$ ( $200 \mathrm{ml}$ of ethanol/1.5 g of dried solid) to extract any remaining Pluronic

template. The material was then filtered, washed sequentially with distilled water and absolute ethanol, and dried in an oven at $333 \mathrm{~K}$.

\subsection{Determination of Activity and Selectivity.}

The activity and selectivity of the SBA-15 catalyst was determined for the dehydration 
and coupling of alcohols using methanol/isobutanol $(\mathrm{MeOH} / \mathrm{i}-\mathrm{BuOH})=1 / 1$ and $2 / 1$ molar ratio mixtures fed into nitrogen carrier gas using an ISCO high pressure pump. The catalyst $(0.40 \mathrm{~g})$ was diluted with $8 \mathrm{ml} 3 \mathrm{~mm}$ Pyrex beads, and the bed was held in place in the reactor with additional beads below and above the bed. The reactor consisted of a downflow 0.75 -inch O.D. (0.120-inch wall thickness) 316 stainless steel reactor containing an axial thermocouple well for monitoring the catalyst temperature. The catalyst was first purged with a flow of $\mathrm{N}_{2}$ at ambient pressure $(1 \mathrm{~atm}=0 \mathrm{psig}=101.3 \mathrm{kPa})$ that was monitored and controlled by a Porter mass flowmeter. After heating the catalyst bed to above $373 \mathrm{~K}$, the alcohol mixture was injected into the $\mathrm{N}_{2}$ stream at the top of the reactor in a preheated mixing zone before entering the vertical reactor contained in a three-zone furnace. For testing with $\mathrm{MeOH} / \mathrm{i}-\mathrm{BuOH}=1 / 1$, the reactant flow was $\mathrm{MeOH} / \mathrm{i}-\mathrm{BuOH} / \mathrm{N}_{2}=1.72 / 1.72 / 16 \mathrm{~mol} / \mathrm{kg}$ catal $/ \mathrm{hr}$ with gas hourly space velocity $(\mathrm{GHSV}) \approx 475 \mathrm{l} / \mathrm{kg}$ catal $/ \mathrm{hr}$, and the temperature sequence utilized was $382,388,394,398,403,408,391,385,379$, and $375 \mathrm{~K}$. For testing with $\mathrm{MeOH} / \mathrm{i}-\mathrm{BuOH}=2 / 1$, the reactant flow was $\mathrm{MeOH} / \mathrm{i}-\mathrm{BuOH} / \mathrm{N}_{2}=10.4 / 5.2 / 184 \mathrm{~mol} / \mathrm{kg}$ catal $/ \mathrm{hr}$ with GHSV $\approx 48701 / \mathrm{kg}$ catal $/ \mathrm{hr}$, and the temperature dependence was determined in the sequence $389,393,399,404,409,414,418,406,396,386$, and $401 \mathrm{~K}$. The reactor pressure in the range of 0.1-4.6 MPa was controlled by an in-line Mity-Mite back-pressure regulator located between the reactor and the gas chromatograph. The back-pressure regulator and all exit lines were heated to $423-443 \mathrm{~K}$.

Analysis of the reactants and products was carried out by on-line gas chromatography (GC) using a CP-SIL 5CB WCOT dimethylpolysiloxane column (30 $\mathrm{m} \times 0.25 \mathrm{~mm}$ ID) in a Hewlett-Packard (HP) Model 5890 Series II GC. The GC was coupled with a HP Model 3396 Series II integrator/controller unit that was interfaced with an automated heated, in-line Valco sampling valve. The thermal response factors (TRFs) of the analyzed compounds were calibrated, and the following values were used: nitrogen (42), water (33), methanol $(\mathrm{MeOH}, 50)$, isobutanol (i-BuOH, 125), dimethylether (DME, 75), methylisobutylether (MIBE, 125), methyltertiarybutylether (MTBE, 125) isobutene (IB, 93), n-butenes (97), diisobutylether (DIBE, 220), and tertiarybutylisobutylether (TBIBE, 220). Data points presented here are generally averages of 3-10 GC analyses obtained under steady-state conditions that were usually maintained for 6-24 hr.

\subsection{Kinetic Modelling.}

Kinetic analyses of the data were carried out based on Langmuir-Hinshelwood model involving competitive adsorption of the alcohols on the reactive acid centers of the catalyst. As pointed out earlier [22-24], this is a simplified approach that nevertheless successfully describes the competitive nature of the reactions occurring on the catalyst surface. This kinetic treatment was described previously [17], and the rate laws used here for the formation of the products are the following:

$$
\begin{aligned}
& \mathrm{r}_{\mathrm{DME}}=\mathrm{k}_{1} \mathrm{~K}_{\mathrm{M}}^{2} \mathrm{p}_{\mathrm{M}}^{2} /\left(1+\mathrm{K}_{\mathrm{M}} \mathrm{p}_{\mathrm{M}}+\mathrm{K}_{\mathrm{B}} \mathrm{p}_{\mathrm{B}}\right)^{2} \\
& \mathrm{r}_{\mathrm{IB}}=\mathrm{k}_{3} \mathrm{~K}_{\mathrm{B}} \mathrm{p}_{\mathrm{B}} /\left(1+\mathrm{K}_{\mathrm{M}} \mathrm{p}_{\mathrm{M}}+\mathrm{K}_{\mathrm{B}} \mathrm{p}_{\mathrm{B}}\right)^{2} \\
& \mathrm{r}_{\mathrm{MIBE}}=\mathrm{k}_{4} \mathrm{~K}_{\mathrm{M}} \mathrm{p}_{\mathrm{M}} \mathrm{K}_{\mathrm{B}} \mathrm{p}_{\mathrm{B}} /\left(1+\mathrm{K}_{\mathrm{M}} \mathrm{p}_{\mathrm{M}}+\mathrm{K}_{\mathrm{B}} \mathrm{p}_{\mathrm{B}}\right)^{2}
\end{aligned}
$$


In these expressions, $\mathrm{k}_{1}, \mathrm{k}_{3}$, and $\mathrm{k}_{4}$ are the kinetic rate constants for DME, IB, and MIBE synthesis via Equations 4-6, respectively, and $\mathrm{K}_{\mathrm{M}}$ and $\mathrm{K}_{\mathrm{B}}$ are the adsorption equilibrium constants for methanol and isobutanol, respectively, while $\mathrm{p}_{\mathrm{M}}$ and $\mathrm{p}_{\mathrm{B}}$ are the partial pressures of alcohol reactants.

$$
\begin{aligned}
& 2 \mathrm{CH}_{3} \mathrm{OH} \rightarrow \mathrm{CH}_{3} \mathrm{OCH}_{3}+\mathrm{H}_{2} \mathrm{O} \\
& \left(\mathrm{CH}_{3}\right)_{2} \mathrm{CHCH}{ }_{2} \mathrm{OH} \rightarrow\left(\mathrm{CH}_{3}\right)_{2} \mathrm{C}=\mathrm{CH}_{2} \\
& \left(\mathrm{CH}_{3}\right)_{2} \mathrm{CHCH}_{2} \mathrm{OH}+\mathrm{CH}_{3} \mathrm{OH} \rightarrow\left(\mathrm{CH}_{3}\right)_{2} \mathrm{CHCH}_{2} \mathrm{OCH}_{3}+\mathrm{H}_{2} \mathrm{O}
\end{aligned}
$$

\subsection{Surface Analysis.}

High resolution X-ray photoelectron spectroscopy (XPS) analysis was carried out using the Scienta ESCA-300 instrument, as described in detail elsewhere [37]. Based on estimates by Hunsicker et al. [39], XPS analysis of very porous materials of uniform composition provides a bulk analysis because of the large escape depths. All binding energy (BE) values reported herein are referenced to the Si2p BE of $103.5 \mathrm{eV}$.

The BET surface area [40] was determined by $\mathrm{N}_{2}$ adsorption at $77 \mathrm{~K}$ in the relative pressure range $\left(\mathrm{P} / \mathrm{P}_{\mathrm{o}}\right)$ of 0.05 to 0.30 using a Micromeritics Gemini $2360 \mathrm{~V} 1.03$ instrument. An adsorption isotherm was also obtained, and the total pore volume was estimated from the amount of $\mathrm{N}_{2}$ adsorbed at $\mathrm{P} / \mathrm{P}_{\mathrm{o}}=0.975$. Before the measurements, the SBA-15 sample was purged in flowing $\mathrm{N}_{2}$ in the sample tube at $473 \mathrm{~K}$ for $2 \mathrm{hr}$. The mesopore size distribution was calculated on the basis of the adsorption branch of the $\mathrm{N}_{2}$ isotherm using the Barrett, Joyner, and Halenda (BJH) method [29,30,41-45].

To determine the accessible acidity of the catalyst (meq/g), a $50 \mathrm{mg}$ portion, after drying at $200^{\circ} \mathrm{C}$ in flowing $\mathrm{N}_{2}$ for $1 \mathrm{hr}$, was equilibrated in $15 \mathrm{ml} 2.0 \mathrm{M} \mathrm{NaCl}_{(\mathrm{aq})}$ at ambient temperature. Phenolphthalein was then added, and the titration of the mixture with $0.01 \mathrm{M}$ $\mathrm{NaOH}_{(\mathrm{aq})}$ was also followed potentiometrically.

\subsection{Electron Microscopy and X-Ray Powder Diffraction.}

Brightfield TEM images were obtained on a JEOL 2000FX microscope at the Center for Advanced Materials and Nanotechnology at Lehigh University. Samples were prepared by dispersing a small amount of SBA powder in $10 \mathrm{ml}$ of ethanol and sonicating the dispersion in an ultrasonic bath. A drop of the dispersion was placed on a holey carbon grid for examination in the TEM at $200 \mathrm{Kv}$ after evaporation of the ethanol. X-Ray powder diffraction (XRD) was used to monitor crystallinity and interlayer spacings for the hexagonal SBA-15 using the low angle $2 \theta$ peaks. The XRD data were collected on a Siemens D5000 instrument with $\mathrm{CuK} \alpha$ radiation as described previously [37]. 


\subsection{Computational Modelling and Analysis.}

The sulfonic acid catalyzed reactions of ethers from alcohols were first examined theoretically via DFT/GGA/DN** calculations based on the Nafion-type prototype system $2 \mathrm{CF}_{3} \mathrm{SO}_{3} \mathrm{H}+\mathrm{CH}_{3} \mathrm{OH}+\left(\mathrm{CH}_{3}\right)_{2} \mathrm{CHCH}_{2} \mathrm{OH}$ [46]. This investigation has now been extended to the much larger model of mesoporous silica derivatized with pendant propylsulfonic acid functionalities. The model for the dual site consisted of two propylsulfonic groups anchored on two silicon atoms capped by two hydrogen each and bridged by oxygen, of the composition $\mathrm{HO}_{3} \mathrm{~S}\left(\mathrm{CH}_{2}\right)_{3}-\mathrm{Si}\left(\mathrm{H}_{2}\right)-\mathrm{O}-\mathrm{Si}\left(\mathrm{H}_{2}\right)-\left(\mathrm{CH}_{2}\right)_{3} \mathrm{SO}_{3} \mathrm{H}$, abbreviated as $\mathrm{G}=(\mathrm{OH})_{2}$. The structural unit $-\left[\mathrm{Si}\left(\mathrm{H}_{2}\right)-\mathrm{O}-\mathrm{Si}\left(\mathrm{H}_{2}\right)\right]-$ was taken to represent the silica intraporous wall. The reaction models comprised adducts
(I) $\quad\left[\mathrm{G}=(\mathrm{OH})_{2}\right][2 \mathrm{MeOH}]$,
(II) $\quad\left[\mathrm{G}=(\mathrm{OH})_{2}\right][\mathrm{MeOMe}]\left[\mathrm{H}_{2} \mathrm{O}\right]$,
(III) $\left[\mathrm{G}=(\mathrm{OH})_{2}\right][\mathrm{MeOH}][\mathrm{i}-\mathrm{BuOH}]$,
(IV) $\left[\mathrm{G}=(\mathrm{OH})_{2}\right][\mathrm{i}-\mathrm{BuOMe}]\left[\mathrm{H}_{2} \mathrm{O}\right]$,
(V) $\left[\mathrm{G}=(\mathrm{OH})_{2}\right][\mathrm{i}-\mathrm{BuOH}]$, and
(VI) $\left[\mathrm{G}=(\mathrm{OH})_{2}\right]\left[\mathrm{i}-\mathrm{Bu}^{=}\right]\left[\mathrm{H}_{2} \mathrm{O}\right]$.

Reaction pathways (I) $\rightarrow($ II $),($ III $) \rightarrow(I V)$, and $(\mathbf{V}) \rightarrow($ VI $)$ represent the synthesis of DME, MIBE, and dehydration of $\mathrm{i}-\mathrm{BuOH}$ to isobutene $\mathrm{i}-\mathrm{Bu}^{=}$. The transition states (TS) on these three pathways were searched and located, in addition to pre- and post-reaction surface complexes.

The present calculations employed all-electron codes imbedded in the Titan software using the DFT $=$ Slater + Becke88 + PZ81 + Perdew86 method with the 6-31G** basis set [47]. The $6-31 \mathrm{G}^{* *}$ Gaussian basis set gave comparable relative energies to the earlier used double numerical basis set $\mathrm{DN}^{* *}$ [46], although the absolute energies were systematically higher with the 6-31G** set than with the $\mathrm{DN}^{* *}$ set. Geometry optimization for each of the adducts (I) - (VI) involved a "frozen wall" unit - $\left[\mathrm{Si}\left(\mathrm{H}_{2}\right)-\mathrm{O}-\mathrm{Si}\left(\mathrm{H}_{2}\right)\right]-$ and allowed all other atoms of these complexes to move to their equilibrium positions. The TS search looked for stationary saddle points on the paths (I) $\rightarrow($ II), (III) $\rightarrow($ IV), and (V) $\rightarrow$ (VI) and involved vibrational frequency analysis, including the calculation of the imaginary mode associated with saddle point crossings and group transfers from one adsorbed reactant to another. Such saddle points and imaginary frequencies were found for all three pathways. Those for the DME synthesis, (I) $\rightarrow$ (II), and the MIBE synthesis, (III) $\rightarrow$ (IV), were determined more easily, primarily due to successful TS calculations on earlier smaller models [46]. However, the search for the TS for the seemingly simpler dehydration of i-BuOH to i-Bu ${ }^{=}$and $\mathrm{H}_{2} \mathrm{O},(\mathbf{V})$ $\rightarrow(\mathrm{VI})$, has proven extraordinarily difficult, involved many initial guesses of the adsorbed conformations, many month-long computations on $2 \mathrm{GHz} / 2 \mathrm{~GB}$ machines, but eventually did succeed in locating the TS and unraveling a new indirect path for this dual-site catalyzed elimination reaction. 


\section{Results}

\subsection{Methanol/Isobutanol Reactions.}

3.1.1. Pressure Dependence with $\mathrm{MeOH} / \mathbf{i}-\mathrm{BuOH}=1 / 1$. After establishing $\mathrm{N}_{2}$ flow through the reactor at $101.3 \mathrm{kPa}(0 \mathrm{psig})$ total pressure, the SBA-15 catalyst was heated to $404 \mathrm{~K}$. Injection of the alcohol mixture was initiated so that the steady reactant flow rates were $3.44 \mathrm{~mol} / \mathrm{kg}$ catal $/ \mathrm{h}$ of alcohols and $16.0 \mathrm{~mol} / \mathrm{kg}$ catal $/ \mathrm{h}$ of carrier gas, giving a total gas hourly space velocity (GHSV) of about 4751 (STP)/kg catal $/ \mathrm{hr}$. After equilibration for $21 \mathrm{~h}$, the reactor pressure was sequentially increased. The observed product formation rates are shown in Figure 1. In addition to IB, MIBE, and DME, methyltertiarybutylether (MTBE), cis- and trans-2-butenes, diisobutylether (DIBE) and tertiarybutylisobutylether (TBIBE) were also observed as minor products. IB exhibited the highest selectivity at low pressures. As the pressure was increased, the formation and selectivity toward MIBE steadily increased, while the selectivity to DME increased more gradually and that to IB decreased.

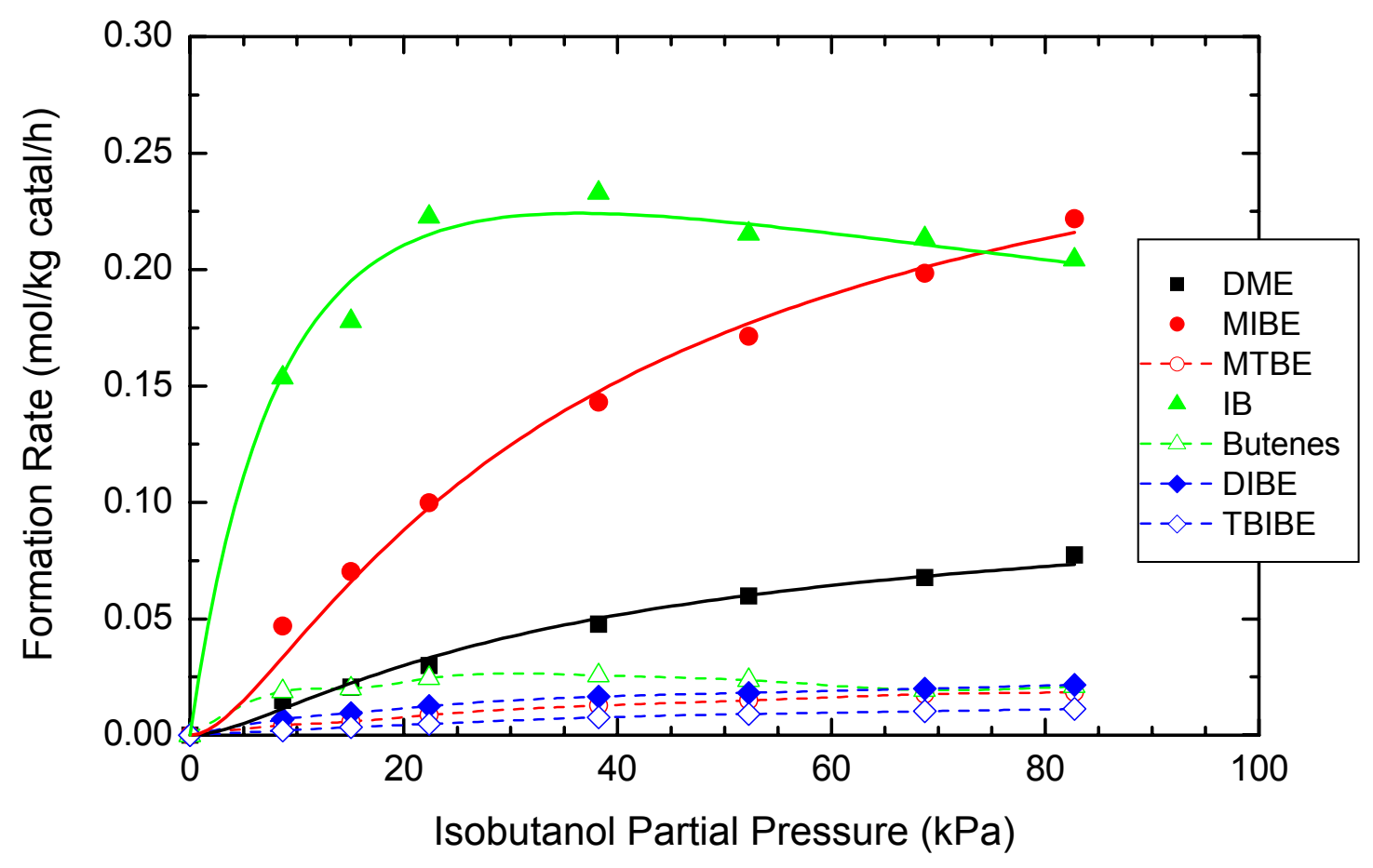

Figure 1. Rates of formation of dimethylether (DME), isobutene (IB), methyl isobutylether (MIBE), diisobutylether (DIBE), n-butenes (cis- and trans-2-butenes), methyl tertiarybutylether (MTBE), and tertiarybutylisobutylether (TBIBE) in the reaction of $\mathrm{MeOH} / \mathrm{i}-\mathrm{BuOH}$ (1/1 molar ratio) over the SBA-15 catalyst with flow rates of $3.44 \mathrm{~mol} / \mathrm{kg}$ catal $/ \mathrm{hr}$ alcohols and $16.0 \mathrm{~mol} / \mathrm{kg}$ catal $/ \mathrm{hr}$ of $\mathrm{N}_{2}$ at $404 \mathrm{~K}$ as a function of isobutanol partial pressure, $\mathrm{p}_{\mathrm{i}-\mathrm{BuOH}}$, are given as data points. The fitted kinetic laws (Equations 1-3, with the values of the kinetic parameters given in Section 4.1.1. in the Discussion) for IB, MIBE, and DME syntheses are shown as solid curves for those three products. 
3.1.2. Temperature Dependence with $\mathrm{MeOH} / \mathbf{i}-\mathrm{BuOH}=1 / 1$. The reactor was purged with an $\mathrm{N}_{2}$ flow at $101.3 \mathrm{kPa}$ and about $380 \mathrm{~K}$, and then alcohol injection ws initiated. The temperature dependence of the reactions involved was carried out as described in Section 2.2.

Arrhenius plots were used to determine the apparent activation energies of the products formed at $101.3 \mathrm{kPa}$. As shown in Figure 2, the plots were linear in the temperature range of $375-408 \mathrm{~K}$ that was employed here. In this temperature range, the conversions of methanol and isobutanol varied from 0.73 to $9.23 \%$ and from 0.91 to $23.30 \%$, respectively. Due to higher activation energy, IB became a dominant product at $>383 \mathrm{~K}$.

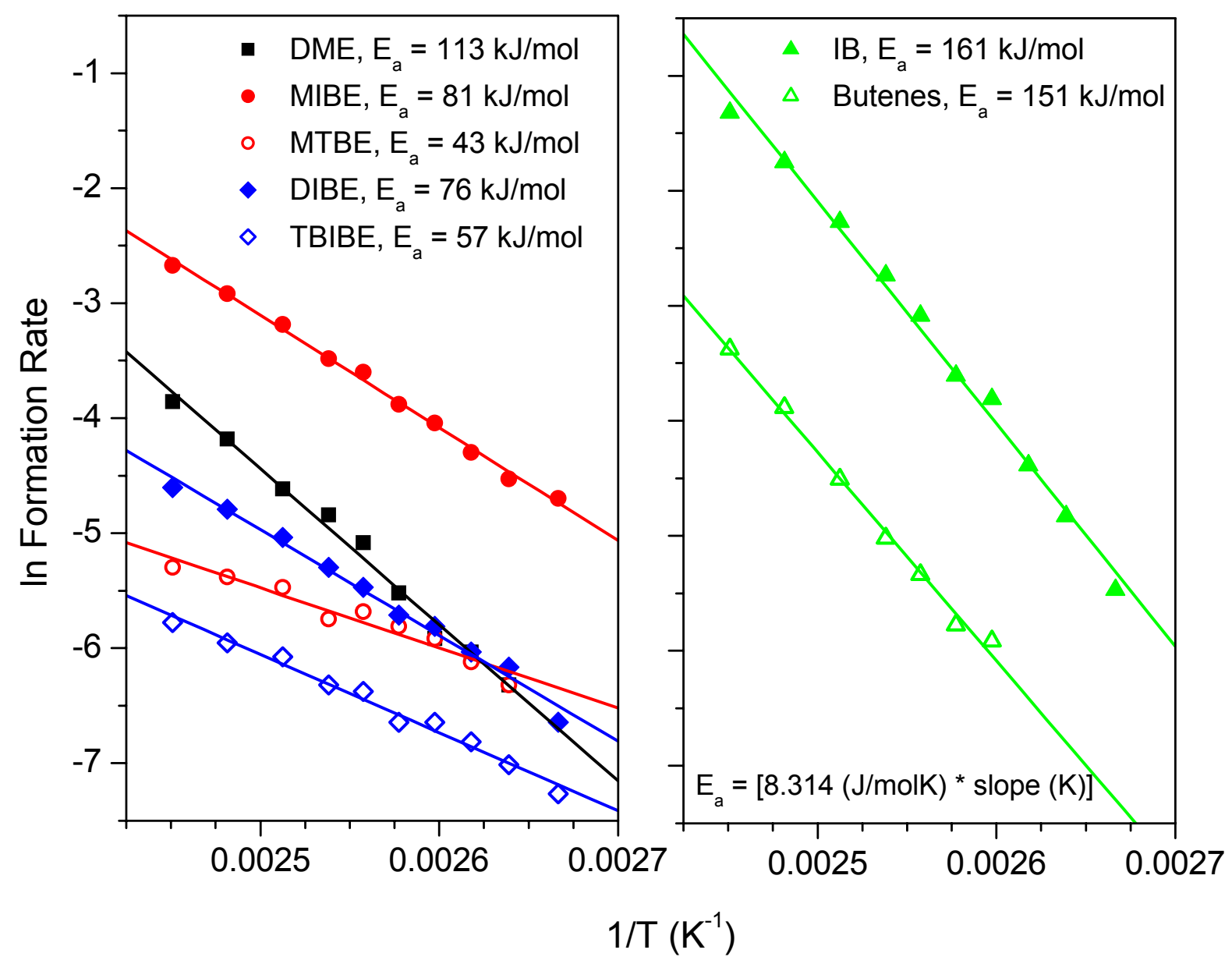

Figure 2. Arrhenius plots for determination of the apparent activation energies of the ethers (right) and olefins (left) formed over the SBA-15 catalyst from the $\mathrm{MeOH} / \mathrm{i}-\mathrm{BuOH}=1 / 1$ reactant mixture at $101.3 \mathrm{kPa}$. 
3.1.3. Pressure Dependence with $\mathrm{MeOH} / \mathbf{i}-\mathrm{BuOH}=2 / 1$. This reactant composition was investigated because it favors ether formation, and a higher flow rate was utilized for comparison with previous studies with other acid catalysts $[16,17,26,36]$. After heating the SBA-15 catalyst to $404 \mathrm{~K}$ in flowing $\mathrm{N}_{2}$ at $115 \mathrm{kPa}(2 \mathrm{psig}$ ) total pressure, injection of the alcohol mixture was initiated and the reactant flow rates were adjusted to $\mathrm{MeOH} / \mathrm{i}-\mathrm{BuOH} / \mathrm{N}_{2}$ $=12.3 / 6.2 / 184 \mathrm{~mol} / \mathrm{kg}$ catal $/ \mathrm{hr}$, corresponding to $\mathrm{GHSV}=4950 \mathrm{l} / \mathrm{kg}$ catal $/ \mathrm{hr}$. The total reactor pressure was then increased sequentially to $4.525 \mathrm{MPa}$ (642 psig), during which the partial pressures of both alcohols increased proportionally. The rates of formation of the DME, IB, and MIBE products are shown in Figure 3. The solid curves were obtained by fitting the data points using kinetic equations 1-3 of Section 2.3.

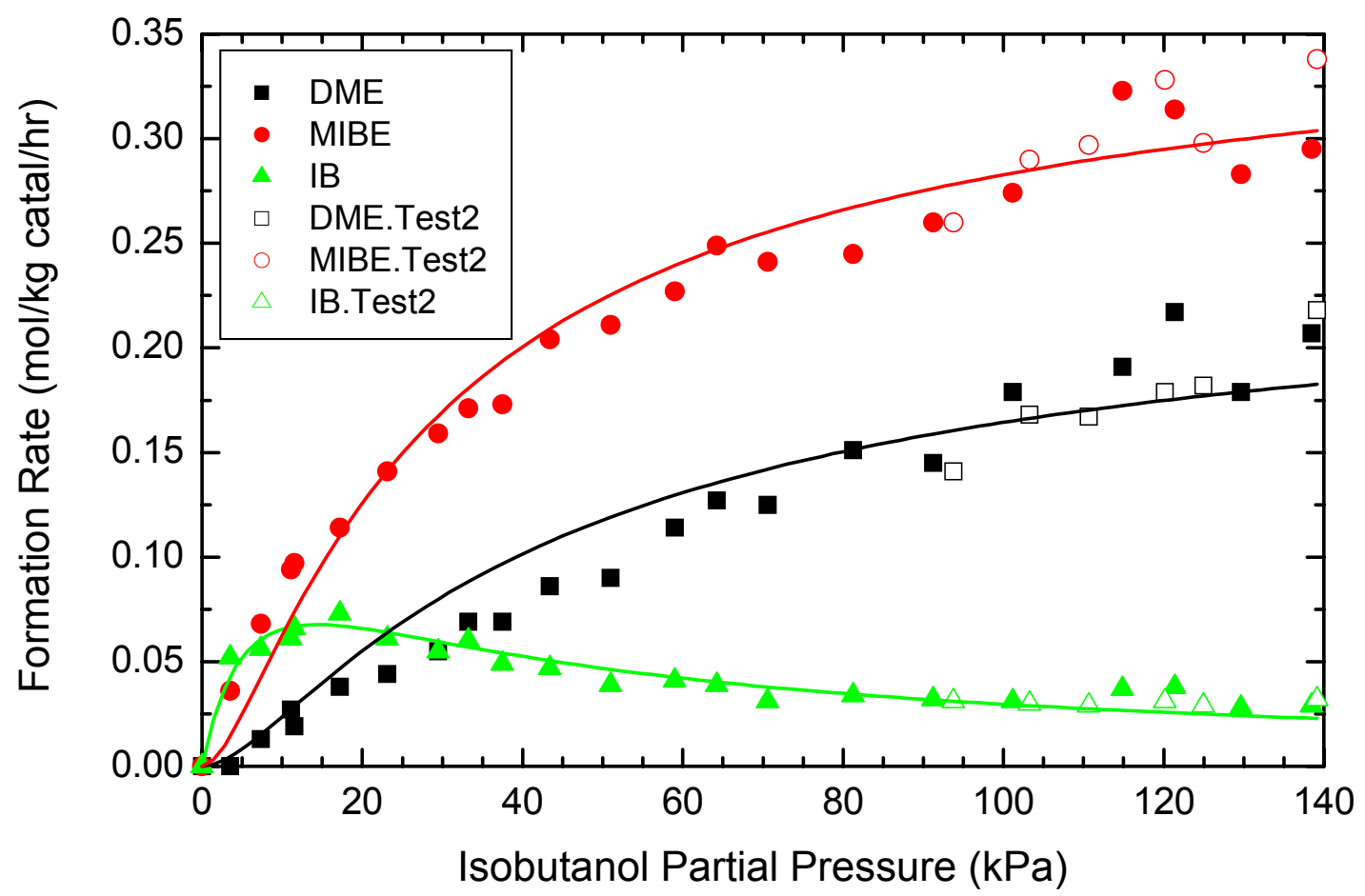

Figure 3. Rates of formation of DME, IB, and MIBE in the reaction of $\mathrm{MeOH} / \mathrm{i}-\mathrm{BuOH}(2 / 1$ molar ratio) over the SBA-15 catalyst with flow rates of $16.5 \mathrm{~mol} / \mathrm{kg}$ catal $/ \mathrm{hr}$ alcohols and $184 \mathrm{~mol} / \mathrm{kg}$ catal $/ \mathrm{h}$ of $\mathrm{N}_{2}$ at $404 \mathrm{~K}$ as a function of isobutanol partial pressure, $\mathrm{p}_{\mathrm{i}-\mathrm{BuOH}}$, are given as data points. The open symbols represent a second test sequence of the catalyst after the first test (closed symbols) was completed and the catalyst was purged with nitrogen at ambient pressure before repressurizing to the higher range of pressures. The fitted kinetic laws (Equations 1-3, with the kinetics parameters given in Section 4.1.2. in the Discussion) are shown as solid curves. 
3.1.4. Temperature Dependence with $\mathrm{MeOH} / \mathbf{i}-\mathrm{BuOH}=2 / 1$. The reactor pressure was adjusted to $2.17 \mathrm{MPa}$ and the temperature was initially set at $404 \mathrm{~K}$. Injection of the alcohol reactant mixture was initiated, and the temperature dependence of the catalytic behavior of the SBA-15 catalyst was determined. The formation rates of MIBE, DME, and IB increased with temperature, and MIBE remained the dominant product formed over the temperature range utilized. Only traces of MTBE, DIBE, and TBIBE were observed at this flow rate that was appreciably higher than that utilized for the $\mathrm{MeOH} / \mathrm{i}-\mathrm{BuOH}=1 / 1$ experiments. The DME selectivity decreased slightly with increasing temperature, while the MIBE selectivity decreased more significantly as that of IB increased. The Arrhenius plots of the rate data, given in Figure 4, showed that the apparent activation energy for isobutanol dehydration to form isobutene was more than twice as high as for the synthesis of the ethers under these reaction conditions.

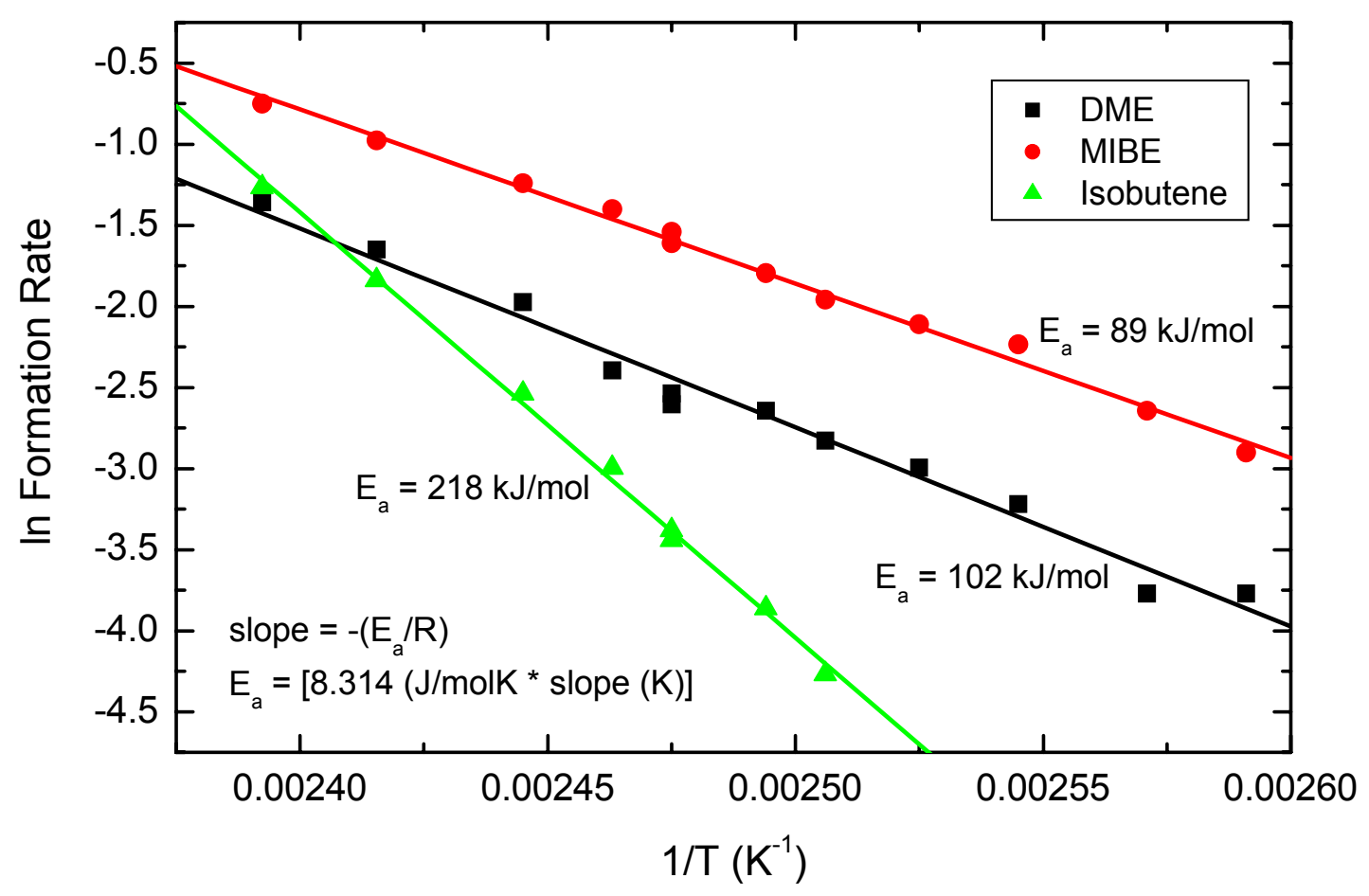

Figure 4. Arrhenius plots for the determination of the apparent activation energies of the products formed over the SBA- 15 catalyst from the $\mathrm{MeOH} / \mathrm{i}-\mathrm{BuOH}=2 / 1$ reactant mixture at 2.17 MPa.

\subsection{Catalyst Stability.}

During the determination of catalytic properties with alcohol mixtures, the catalyst was subjected to elevated temperature and pressure conditions for $1615 \mathrm{hr}$. In addition, it was purged with $\mathrm{N}_{2}$ alone at elevated temperatures and at either ambient pressure ( $297 \mathrm{hr}$ ) or elevated pressure $(291 \mathrm{hr})$ between experiments and when the alcohol mixture in the ISCO 
injection pump was being changed. With a reactant mixture of $\mathrm{MeOH} / \mathrm{i}-\mathrm{BuOH} / \mathrm{N}_{2}=$ $10.4 / 5.2 / 184 \mathrm{~mol} / \mathrm{kg}$ catal $/ \mathrm{hr}$ at $404 \mathrm{~K}$, the reaction pressure was increased to $2.17 \mathrm{MPa}$ and the reaction was allowed to run at steady state overnight. The results are shown in Table 1. After determining the activity of the catalyst under these conditions (a), pressure dependence experiments were conducted at pressures sequentially increasing to $4.39 \mathrm{MPa}$. The pressure was then reduced to $2.17 \mathrm{MPa}$ again to determine the steady state activity at the initial conditions (b). Continuous operation of the reactor was maintained for an additional $48 \mathrm{hr}$, and the results are shown in row (c), Table 1. Each of the product formation rates is an average of five to six analyses.

Table 1. Formation rates of products ( $\mathrm{mol} / \mathrm{kg}$ catal $/ \mathrm{h}$ ) as a function of time onstream at $404 \mathrm{~K}$ and $2.17 \mathrm{MPa}$ with $\mathrm{MeOH} / \mathrm{i}-\mathrm{BuOH} / \mathrm{N}_{2}=10.4 / 5.2 / 184 \mathrm{~mol} / \mathrm{kg}$ catal $/ \mathrm{hr}$.

\begin{tabular}{lllc}
\hline $\begin{array}{c}\text { Time On-Stream } \\
\text { (hr) }\end{array}$ & MIBE & DME & IB \\
\hline (a) $11.5-13.5$ & 0.200 & 0.078 & 0.030 \\
(b) $66.25-68.25$ & 0.200 & 0.079 & 0.034 \\
(c) $115.25-116.5$ & 0.214 & 0.074 & 0.032 \\
\hline
\end{tabular}

\subsection{Site Blocking by Pyridine.}

Our previous studies have utilized pyridine as a probe to determine the nature, strength and concentration of acid sites on surfaces of solid catalysts [25,37,46,48]. In particular, quantitative XPS data provide this information following adsorption of nitrogen bases on the acid sites. To determine whether pyridine in the reactant alcohol mixture retarded the synthesis of ethers by adsorption and site blocking, pyridine was added to the reactant stream. After purging the catalyst with $\mathrm{N}_{2}$ at $400 \mathrm{~K}$ and $375 \mathrm{kPa}$, the reactant alcohol injection was initiated, briefly with a $\mathrm{MeOH} / \mathrm{i}-\mathrm{BuOH}=1 / 1$ mixture that was followed by a mixture of $\mathrm{MeOH} / \mathrm{i}-\mathrm{BuOH} / \mathrm{Py}=2 / 1 / 0.2$. Figure 5 shows the resulting product formation rates, $\mathrm{MeOH} / \mathrm{i}-\mathrm{BuOH}$ molar ratio, and appearance of pyridine in the outlet stream, as determined by $\mathrm{GC}$ analyses as a function of time on stream.

After the pyridine poisoning experiment, reactant injection was terminated and the reactor was purged with $\mathrm{N}_{2}$ at $403 \mathrm{~K}$ and $375 \mathrm{kPa}$ for $65 \mathrm{hr}$. Injection of a MeOH/i-BuOH$/ \mathrm{N}_{2}$ $=10.4 / 5.2 / 184 \mathrm{~mol} / \mathrm{kg}$ catal $/ \mathrm{hr}$ reactant flow was then started. The inlet line between the pump and the $\mathrm{N}_{2}$ carrier gas line in the preheater section above the reactor contained some remaining $\mathrm{MeOH} / \mathrm{i}-\mathrm{BuOH} / \mathrm{Py}$ reactant mixture, but most of the pyridine had been purged from the system within $3 \mathrm{hr}$ on stream. However, there was still a trace of pyridine present in the chromatograms after $24 \mathrm{hr}$, and there was no evidence of products formed from the $\mathrm{MeOH} / \mathrm{i}-\mathrm{BuOH}$ reactant mixture. The reaction temperature was increased to $423 \mathrm{~K}$, and a 
small amount of MIBE was observed, amounting to $0.02-0.03 \mathrm{~mol} / \mathrm{kg}$ catal $/ \mathrm{hr}$ over the next $24 \mathrm{hr}$. No DME and IB formation was observed. The temperature was then increased to $473 \mathrm{~K}$, and after $3 \mathrm{hr}$ the steady state formation rates for MIBE, DME, and IB were approximately $0.220,0.070$, and $0.020 \mathrm{~mol} / \mathrm{kg}$ catal $/ \mathrm{hr}$, respectively. The temperature was decreased to $423 \mathrm{~K}$, and after $15 \mathrm{hr}$ the steady state synthesis rate of MIBE was 0.02-0.03 $\mathrm{mol} / \mathrm{kg}$ catal $/ \mathrm{hr}$. Again, no DME and IB were observed. Comparison of the activities of the catalyst at similar pressures before and after pyridine exposure is shown in Table 2. Alcohol coupling was still observed at the higher temperature and pressure after pyridine adsorption, but the initial activity was not fully recovered.

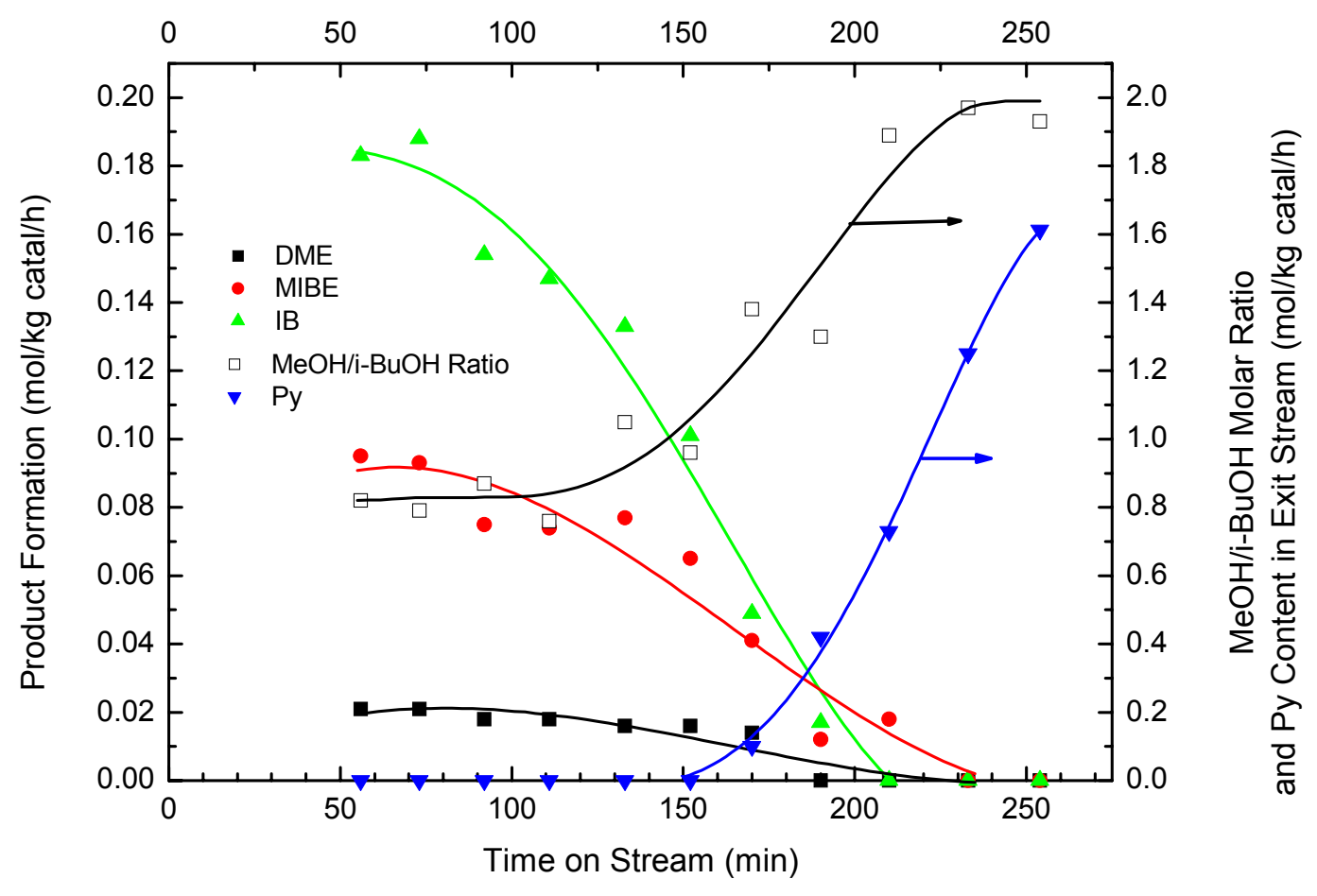

Figure 5. Deactivation of the SBA-15 catalyst at $404 \mathrm{~K}$ and $375 \mathrm{kPa}$ upon changing the reactant gas mixture from $\mathrm{MeOH} / \mathrm{i}-\mathrm{BuOH} / \mathrm{N}_{2}=7.4 / 7.4 / 184 \mathrm{~mol} / \mathrm{kg}$ catal $/ \mathrm{hr}$ to $\mathrm{MeOH} / \mathrm{i}$ $\mathrm{BuOH} / \mathrm{Py} / \mathrm{N}_{2}=10.4 / 5.2 / 1.04 / 183 \mathrm{~mol} / \mathrm{kg}$ catal $/ \mathrm{hr}$ with $\mathrm{GHSV}=48701 / \mathrm{kg} \mathrm{catal} / \mathrm{hr}$.

The alcohol injection was terminated and the reactor was purged with $\mathrm{N}_{2}$ at $403 \mathrm{~K}$ for $23 \mathrm{hr}$, first at $375 \mathrm{kPa}$ and then at $108 \mathrm{kPa}$. Injection of the $\mathrm{MeOH} / \mathrm{i}-\mathrm{BuOH}=2 / 1$ reactant was begun again at $403 \mathrm{~K}$ and $108 \mathrm{kPa}$, and the reactor pressure was gradually increased from $108 \mathrm{kPa}$ to $1080 \mathrm{kPa}$ over a period of $46 \mathrm{hr}$. No products were observed at the lower pressures, but at $1080 \mathrm{kPa}$ the sole product MIBE was observed $(0.016 \mathrm{~mol} / \mathrm{kg} \mathrm{catal} / \mathrm{hr})$. At this latter pressure, the temperature was increased to $423 \mathrm{~K}$ and steady state was maintained for $43 \mathrm{hr}$. Under these conditions, the formation rates of MIBE and DME were 0.044 and $0.008 \mathrm{~mol} / \mathrm{kg} \mathrm{catal} / \mathrm{hr}$, respectively, and no IB was observed (see Table 2). After terminating alcohol injection, the reactor was depressurized and cooled slowly while purging the catalyst 
with $\mathrm{N}_{2}$ over a period of $27 \mathrm{hr}$. The catalyst was then removed from the reactor under $\mathrm{N}_{2}$ for examination by other methods. The tested catalyst was an off-white light gray color compared with the white as-prepared catalyst.

Table 2. Comparison of the space time yields ( $\mathrm{mol} / \mathrm{kg}$ catal $/ \mathrm{hr}$ ) of the products before and after pyridine (Py) addition to the reactant stream consisting of $\mathrm{MeOH} / \mathrm{i}-\mathrm{BuOH} / \mathrm{N}_{2}=$ 10.4/5.2/183-184 mol/kg catal/hr. The entry (---) indicates Not Detected.

\begin{tabular}{ccccc}
\hline $\begin{array}{c}\text { Total Pressure } \\
(\mathrm{kPa})\end{array}$ & $\begin{array}{c}\text { Temperature } \\
(\mathrm{K})\end{array}$ & MIBE & DME & IB \\
\hline Before Py Addition & & & & \\
\hline 365 & 404 & 0.069 & 0.017 & 0.052 \\
1140 & 404 & 0.135 & 0.042 & 0.042 \\
& & & & \\
After Py Addition & & & & \\
\hline 375 & 403 & --- & --- & --- \\
& 423 & $0.02-0.03$ & --- & --- \\
1080 & 473 & 0.220 & 0.070 & 0.020 \\
& 403 & 0.016 & --- & --- \\
& 423 & 0.044 & 0.008 & --- \\
\hline
\end{tabular}

\subsection{XPS Analysis of SBA-15 After Testing.}

The tested and partially deactivated catalyst was analyzed by XPS. Both the survey and higher resolution $\mathrm{C} 1 \mathrm{~s}, \mathrm{~S} 2 \mathrm{p}, \mathrm{N} 1 \mathrm{~s}, \mathrm{O} 1 \mathrm{~s}$, and Si2p binding energy (BE) spectra were obtained. The O1s and $\mathrm{Si} 2 \mathrm{p}$ BE peaks were symmetrical, and the O1s peak was centered at $532.75 \mathrm{eV}$. The $\mathrm{C} 1 \mathrm{~s}$ spectrum showed a strong peak at $285.2 \mathrm{eV}$, with a higher BE shoulder that was resolved as a broad peak centered at $286.6 \mathrm{eV}$. The observed $\mathrm{C} / \mathrm{S}_{\text {(Total) }}$ ratio of 10.7 indicated excess carbon deposited on the used off-white gray catalyst. The S2p peak was broad and the $S 2 p_{1 / 2}$ and $S 2 p_{3 / 2}$ spin-orbit splitting was not evident in the spectrum, as noted in previous studies with SBA-15 [36,37]. The S2p peak asymmetry was fitted as two peaks with $\mathrm{BEs}$ of $\mathrm{S}(1)=169.1$ and $\mathrm{S}(2)=167.8 \mathrm{eV}$, with relative intensities corresponding to $72 \%$ and $28 \%$ of the total sulfur, respectively. These BEs indicate that both S species were present in a highly oxidized state [52]. An N1s peak was centered at $402.2 \mathrm{eV}$ with a slight tail to lower BEs. This peak position is consistent with a hydrogen-bonded pyridinium-type species but not with nitrate $[37,48-50]$ since the latter species is typically observed at higher 
binding energies of $407.6 \pm 0.5 \mathrm{eV}$. The overall $\mathrm{N} / \mathrm{S}_{\text {(Total) }}$ ratio was calculated from the XPS spectra to be $0.28 \pm 0.02$.

\subsection{Acidity and Textural Properties of the Tested Catalyst.}

Low angle XRD of the tested sample showed the same diffraction pattern as the assynthesized sample, shown in Figure 6 with $\mathrm{d}_{100} \approx 12 \mathrm{~nm}$ as given previously [37]. Titration of the tested catalyst with $\mathrm{Na}^{+}$showed that it contained $0.95 \mathrm{meq} \mathrm{H}^{+} / \mathrm{g}$ of catalyst. This value compares with the initial value of $1.00 \mathrm{meq} \mathrm{H}^{+} / \mathrm{g}$ of catalyst, indicating that all of the acidic protons, with or without adsorbed pyridine, were replaceable by the $\mathrm{Na}^{+}$. After outgassing at $473 \mathrm{~K}$, the BET surface area of the tested, partially poisoned SBA- 15 catalyst was $314 \mathrm{~m}^{2} / \mathrm{g}$, compared with the initial surface area of the fresh catalyst of $551 \mathrm{~m}^{2} / \mathrm{g}$. A complete $\mathrm{N}_{2}$ adsorption isotherm was then obtained, and it showed a sharp nitrogen uptake at a relative pressure of approximately 0.73 . The isotherm is typical of a Type IV isotherm, and the sharpness at a rather high relative pressure is indicative of a narrow mesopore size distribution. The pore size distribution plot showed a single mesopore structure present with a pore diameter of $7.7 \mathrm{~nm}$. Extending the plot down to $1.3 \mathrm{~nm}$ or to diameters larger than 18 $\mathrm{nm}$ yielded no additional features. The total pore volume was $0.60 \pm 0.02 \mathrm{~cm}^{3} / \mathrm{g}$, as determined from repeated isotherms.

Electron micrographs of the tested, partially poisoned SBA-15 catalyst exhibited the same structural features as the as-synthesized catalyst, shown in Figure 6. The micrographs showed that long-range order of the catalyst has been maintained. The pore center-to-pore center dimension of the mesopores measured from micrographs of multiple particles were $11.0 \pm 0.2 \mathrm{~nm}$.

\subsection{Quantum Mechanical Modeling of the Reaction Pathways for the Principal Reactions: (I) $\rightarrow$ (II) for DME, (III) $\rightarrow$ (IV) for MIBE, and (V) $\rightarrow$ (VI) for Dehydration of i-BuOH to IB.}

In this effort we employed all-electron computational analysis for calculations of the following properties: structures and total energies (a) of the reactants in the pre-reaction adsorbed complex, (b) of the products in the post-reaction adsorbed complex, (c) of the transition states (TS) at the saddle points; vibrational frequencies focusing on the imaginary mode and motion in the TS, and orbital energies including the core-levels that were previously shown to account for the XPS binding energy shifts observed in both the sorption sites and adsorbates upon the surface complex formation [37]. All the structures were optimized with the $-\left[\mathrm{Si}\left(\mathrm{H}_{2}\right)-\mathrm{O}-\mathrm{Si}\left(\mathrm{H}_{2}\right)\right]$ - "wall" frozen, as described in Section 2.6. The calculated total energies are summarized in Table 3. 

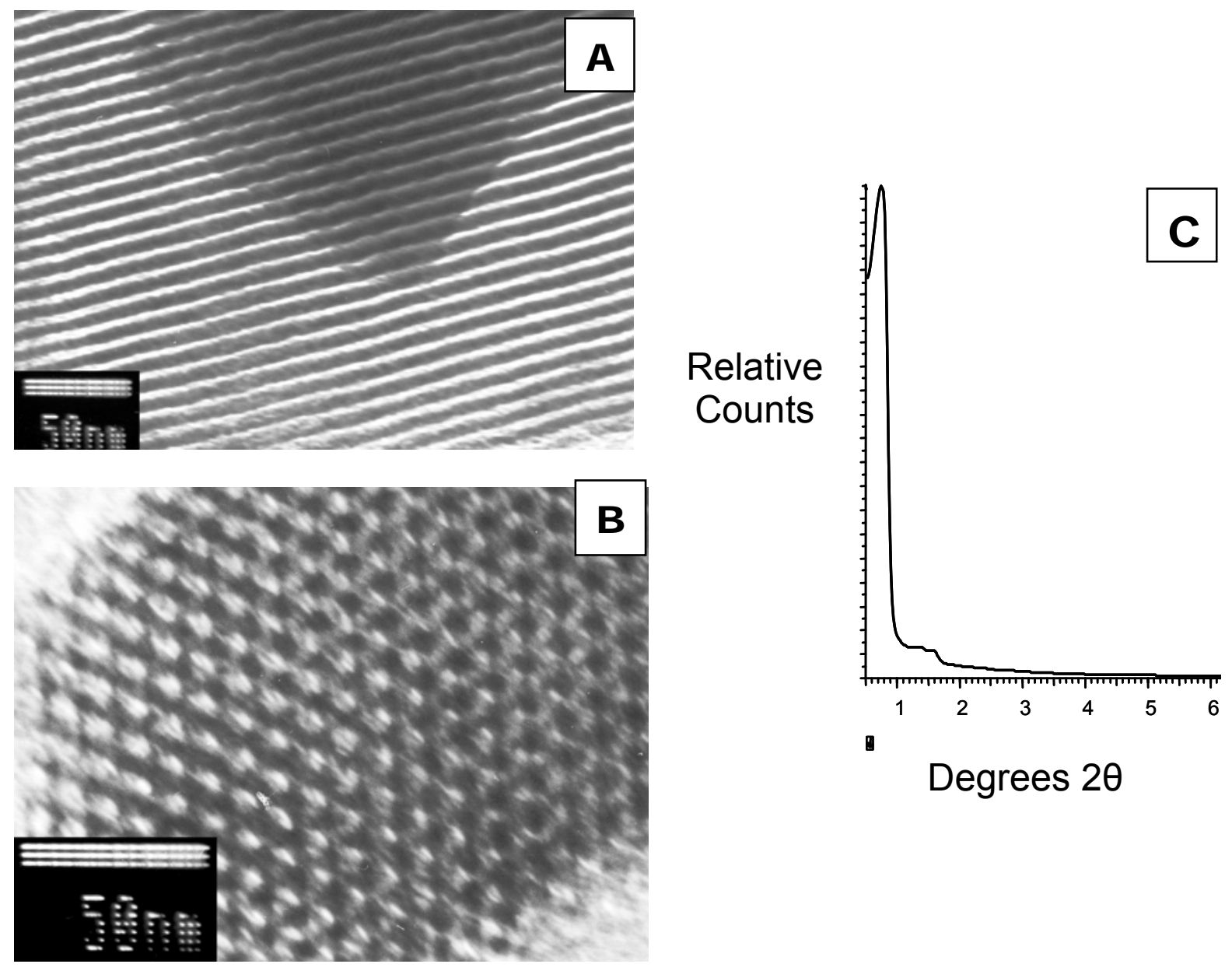

Degrees $2 \theta$

Figure 6. Transmission electron micrographs of the as-synthesized SBA-15 catalyst showing (A) the view perpendicular to the pore axes, (B) the close-packed hexagonal structure of parallel pores shown from the six-fold symmetry axis of view, and $(\mathrm{C})$ the small-angle XRD pattern. 
Table 3. Total energies of sorption complexes of reactants, products, and transition states for the dual-site catalyzed dehydrocondensation of methanol with $\mathrm{MeOH}$ to DME, of $\mathrm{MeOH}$ with i-BuOH to MIBE, and dehydration of $\mathrm{i}-\mathrm{BuOH}$ to IB. The models, calculation method, and optimization protocol are given in Section 2.6.

\begin{tabular}{|c|c|c|}
\hline Complex $^{\text {a }}$ & Energy (Hartree) & $\Delta \mathrm{E}(\mathbf{k J} / \mathbf{m o l})^{b}$ \\
\hline $\mathrm{G}=(\mathrm{OH})_{2}(\mathrm{MeOH})_{2}$ & -2372.97484 & \\
\hline $\mathrm{G}=(\mathrm{OH})_{2}(\mathrm{DME})\left(\mathrm{H}_{2} \mathrm{O}\right)$ & -2472.97577 & $-2.4^{\mathrm{c}}$ \\
\hline $\mathrm{G}=(\mathrm{OH})_{2}(\mathrm{MeOH})(\mathrm{i}-\mathrm{BuOH})$ & -2490.92086 & \\
\hline $\mathrm{G}=(\mathrm{OH})_{2}(\mathrm{MIBE})\left(\mathrm{H}_{2} \mathrm{O}\right)$ & -2490.92010 & $+2.0^{\mathrm{d}}$ \\
\hline $\mathrm{G}=(\mathrm{OH})_{2}(\mathrm{i}-\mathrm{BuOH})$ & -2375.19690 & \\
\hline $\mathrm{G}=(\mathrm{OH})_{2}\left(\mathrm{i}-\mathrm{Bu}^{=}\right)\left(\mathrm{H}_{2} \mathrm{O}\right)$ & -2375.18073 & $+42.4^{\mathrm{e}}$ \\
\hline TS-DME & -2372.94713 & $+72.7^{\mathrm{c}}$ \\
\hline TS-MIBE & -2490.88920 & $+83.1^{\mathrm{d}}$ \\
\hline TS-IB & -2375.14019 & $+148.8^{\mathrm{e}}$ \\
\hline \multicolumn{3}{|c|}{$\begin{array}{l}{ }^{\mathrm{a}} \mathrm{G}=(\mathrm{OH})_{2} \text { is the dual site } \mathrm{HO}_{3} \mathrm{~S}\left(\mathrm{CH}_{2}\right)_{3}-\mathrm{Si}\left(\mathrm{H}_{2}\right)-\mathrm{O}-\mathrm{Si}\left(\mathrm{H}_{2}\right)-\left(\mathrm{CH}_{2}\right)_{3} \mathrm{SO}_{3} \mathrm{H} \text {; TS-DME, TS- } \\
\mathrm{MIBE} \text { and TS-IB are transition states for DME, MIBE, and IB formation on the dual } \\
\text { site } \mathrm{G}=(\mathrm{OH})_{2} \text {. } \\
\text { b Energy difference of the products from the sorbed reactant complex: } \\
{ }^{\mathrm{c}} \mathrm{G}=(\mathrm{OH})_{2}(\mathrm{MeOH})_{2} \text {, } \\
{ }^{\mathrm{d}} \mathrm{G}=(\mathrm{OH})_{2}(\mathrm{MeOH})(\mathrm{i}-\mathrm{BuOH}) \text {, } \\
{ }^{\mathrm{e}} \mathrm{G}=(\mathrm{OH})_{2}(\mathrm{i}-\mathrm{BuOH})\end{array}$} \\
\hline
\end{tabular}

Here the difference between energies of the adsorbed products and reactants represents the thermodynamic driving force for the surface reaction, and the difference between energy of the TS and the reactants is the barrier on the potential energy surface for each of the processes (I) $\rightarrow$ (II) for DME, (III) $\rightarrow$ (IV) for MIBE, and (V) $\rightarrow$ (VI) for IB. Table 4 summarizes the imaginary vibrational frequencies found for each TS. Of these, the largest imaginary frequencies are associated with motions along the reaction pathway, i.e. of methyl group from $\mathrm{MeOH}$ to the second alcohol in the formation of ethers, and of the hydrogen of $\mathrm{C}-2$ of $\mathrm{i}-\mathrm{BuOH}$ to the surface sulfonic group. These "reaction modes" are boldfaced in Table 4 . The smaller imaginary frequencies involve mainly torsional oscillations of the "wall" unit and are irrelevant to the reaction path.

The paths for DME and MIBE are very similar, and are exemplified in Figure 7 by the process (I) $\rightarrow$ (II) for DME. The initial adsorption of DME on the sulfonic acid sites results in the formation of the $\mathrm{G}=(\mathrm{OH})_{2}(\mathrm{MeOH})_{2}$ complex, as shown in Figure 7, left, where distances are shown in $\AA$. The TS for the reaction pathway is shown in Figure 7, middle. 
The electron density isosurface in the TS, within 0.08 electrons/a.u. ${ }^{3}$, clearly indicates the bonds of the transferred methyl group with the $\mathrm{O}$ atoms of the two alcohols being symmetrically severed while the methyl group assumes a planar structure. The formed ether and water molecules leave the active sites as the transfers of two protons to different oxygens in the sulfonic groups are completed, as shown in Figure 7, right.

Table 4. Imaginary vibrational frequencies at the transition states for the formation of dimethylether (DME), methylisobutyl ether (MIBE), and dehydration to isobutene (IB). The models, calculation method and optimization protocol are given in Section 2.6.

\begin{tabular}{|c|c|c|}
\hline Complex ${ }^{a}$ & $\begin{array}{l}\text { Imaginary frequencies } \\
\qquad\left(\mathrm{cm}^{-1}\right)\end{array}$ & Character of Motion \\
\hline \multirow[t]{4}{*}{ TS-DME } & 394.43 & $\begin{array}{l}\text { methyl group transfer } \\
\text { with proton transfer }\end{array}$ \\
\hline & 86.03 & $\mathrm{CH}_{2}-\left(\mathrm{SiH}_{2}\right)-\mathrm{O}-$ rocking \\
\hline & 65.87 & $\mathrm{O}-\left(\mathrm{SiH}_{2}\right)-\mathrm{CH}_{2}$ rocking \\
\hline & 13.20 & delocalized mode \\
\hline \multirow[t]{5}{*}{ TS-MIBE } & 394.84 & $\begin{array}{l}\text { methyl group transfer } \\
\text { with proton transfer }\end{array}$ \\
\hline & 92.41 & $\mathrm{CH}_{2}-\left(\mathrm{SiH}_{2}\right)-\mathrm{O}-$ rocking \\
\hline & 64.20 & $\mathrm{O}-\left(\mathrm{SiH}_{2}\right)-\mathrm{CH}_{2}$ rocking \\
\hline & 30.28 & delocalized mode \\
\hline & 18.27 & delocalized mode \\
\hline \multirow[t]{5}{*}{ TS-IB } & 700.75 & $\begin{array}{l}\text { hydrogen transfer } \\
\mathrm{C} \leftrightarrow \mathrm{H} \leftrightarrow \mathrm{O}=\mathrm{S}\end{array}$ \\
\hline & 57.38 & $\mathrm{CH}_{2}-\left(\mathrm{SiH}_{2}\right)-\mathrm{O}-$ rocking \\
\hline & 40.31 & $\mathrm{O}-\left(\mathrm{SiH}_{2}\right)-\mathrm{CH}_{2}$ rocking \\
\hline & 21.54 & delocalized mode \\
\hline & 6.11 & delocalized mode \\
\hline
\end{tabular}

\footnotetext{
${ }^{\mathrm{a}}$ TS-DME, TS-MIBE, and TS-IB are the transition states for DME, MIBE and IB
} formation over the dual site $\mathrm{G}=(\mathrm{OH})_{2}$.

The path to MIBE is similar to that depicted for DME. The adsorption configuration of $\mathrm{MeOH}$ and $\mathrm{i}-\mathrm{BuOH}$ on the sulfonic acid centers to form the $\mathrm{G}=(\mathrm{OH})_{2}(\mathrm{MeOH})(\mathrm{i}-\mathrm{BuOH})$ complex is shown in Figure 8, left, with pertinent H-bond distances designated. The optimized TS for MIBE formation is shown in Figure 8, middle. Subsequently, the MIBE and $\mathrm{H}_{2} \mathrm{O}$ products form the weakly bonded post-reaction complex, Figure 8, right. 
The stationary points of the path (V) $\rightarrow$ (VI) for dehydration of i-BuOH to IB are shown in Figure 9. Figure 9, left, depicts adsorbed i-BuOH and Figure 9, middle, shows TS $\mathrm{G}=(\mathrm{OH})_{2}\left(\mathrm{i}-\mathrm{Bu}^{=}\right)\left(\mathrm{H}_{2} \mathrm{O}\right)$. The main motion of the TS imaginary mode for the dehydration to isobutene is indicated by the double-ended arrow, between the $\mathrm{C}-1$ carbon of $\mathrm{i}-\mathrm{BuOH}$ and an oxygen of one sulfonic group, while the water is already dissociated and "parked" on the second sulfonic group of the dual site. The product side in Figure 9, right, reveals weakly hydrogen-bonded water and "flown away" isobutene that is no longer bonded to any of the two sites.

The energies of adsorbed reactant couples, product molecules, and water given above are consistent with those of the individual adsorbed molecules, each on a single site $-\mathrm{SO}_{3} \mathrm{H}$ on the SBA model surface. The calculated adsorption energies are given in Table 5, with the addition of sorption energies of nitrogen bases that act as catalytic poisons for the reaction studied herein. Modeling of adsorption onto dual interacting surface sites follows the same trend in adsorption energies.

Table 5. The calculated adsorption energies of reactants, products, and poisons onto single site $-\mathrm{SO}_{3} \mathrm{H}$ with an adjacent non-interacting - $\mathrm{SH}$ group on the SBA-15 surface modeled as $\mathrm{HS}\left(\mathrm{CH}_{2}\right)_{3}-\mathrm{Si}(\mathrm{H})_{2}-\mathrm{O}-\mathrm{Si}(\mathrm{H})_{2}-\left(\mathrm{CH}_{2}\right)_{3} \mathbf{S O}_{3} \mathbf{H}$. Comparison is made with the adsorption energies calculated with a dual reactive site modeled as $\mathbf{H O}_{3} \mathbf{S}\left(\mathrm{CH}_{2}\right)_{3}-\mathrm{Si}(\mathrm{H})_{2}-\mathrm{O}-\mathrm{Si}(\mathrm{H})_{2}-\left(\mathrm{CH}_{2}\right)_{3} \mathbf{S O}_{3} \mathbf{H}$. To simulate the rigidity of the silica wall, the seven atoms of the $-\mathrm{Si}-\mathrm{O}-\mathrm{Si}-$ backbone capped by four hydrogen atoms were kept frozen in all geometry optimizations in which all other atoms were allowed to move.

\begin{tabular}{|c|c|c|}
\hline Adsorbate & $\begin{array}{c}\text { Single Site } \\
\text { Adsorption Energy } \\
(\mathrm{kJ} / \mathrm{mol})\end{array}$ & $\begin{array}{c}\text { Dual Site } \\
\text { Adsorption Energy } \\
(\mathrm{kJ} / \mathrm{mol})\end{array}$ \\
\hline $\mathrm{i}-\mathrm{BuOH}$ & -54.5 & -50.7 \\
\hline $\mathrm{MeOH}$ & -46.5 & -44.8 \\
\hline MIBE & -29.9 & -8.5 \\
\hline $\mathrm{H}_{2} \mathrm{O}$ & -22.2 & -17.6 \\
\hline DME & -26.5 & -8.9 \\
\hline IB & -7.4 & +33.3 \\
\hline Py & -55.3 & -34.3 \\
\hline $\mathrm{NH}_{3}$ & -74.6 & -79.7 \\
\hline $\mathrm{En}^{*}$ & -96.1 & $\begin{array}{l}-83.6 \\
\end{array}$ \\
\hline
\end{tabular}




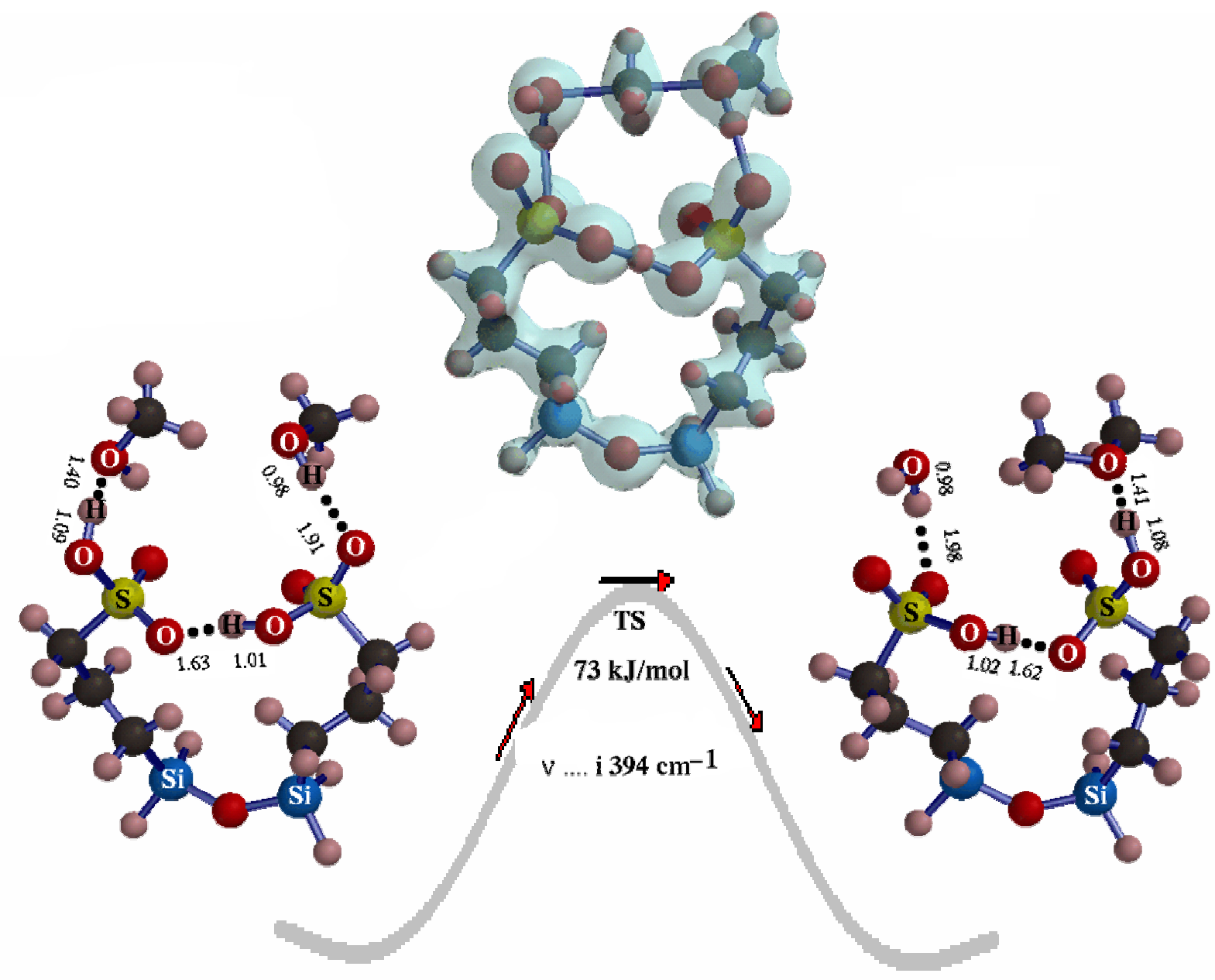

Figure 7. The optimized configuration (left) for the adsorption of two $\mathrm{MeOH}$ molecules on the dual sulfonic acid centers on the SBA-15 catalyst. The transition state for DME synthesis over SBA-15 is shown in the middle of the figure, where electron density is shown as a transparent isosurface to within 0.08 electrons/a.u. ${ }^{3}$. The optimized configuration of adsorbed DME and $\mathrm{H}_{2} \mathrm{O}$ product molecules on the dual sulfonic acid centers of the SBA-15 catalyst is shown on the right. Selected distances of importance to the adsorption and reaction are given in $\AA$. 

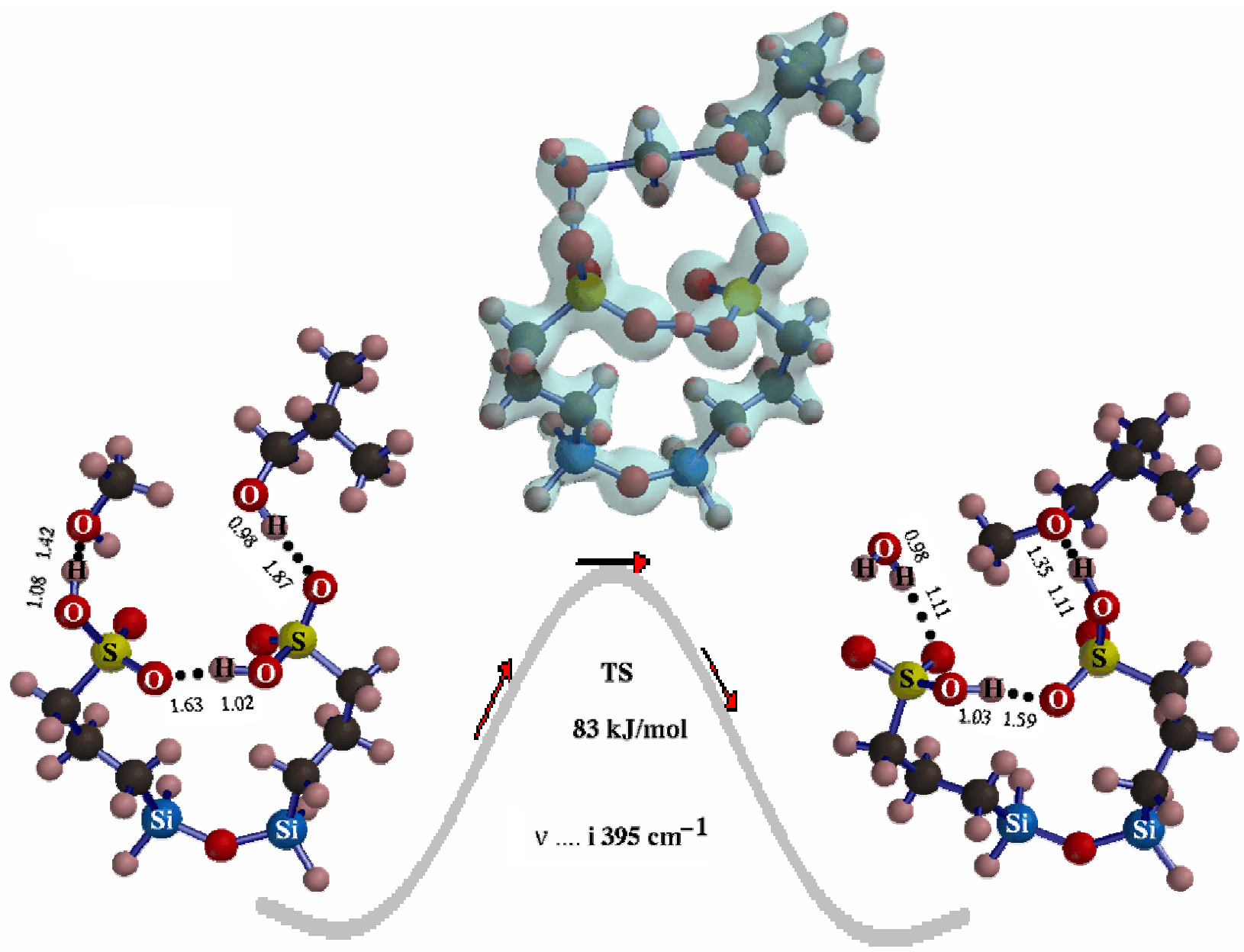

Figure 8. The optimized configuration, left, of adsorbed $\mathrm{MeOH}$ and i-BuOH molecules on the proximal sulfonic acid centers on the SBA-15 catalyst. The transition state for the reaction of $\mathrm{MeOH}$ with $\mathrm{i}-\mathrm{BuOH}$ to form MIBE over SBA-15 is shown in the middle, where electron density is shown as a transparent isosurface to within 0.08 electrons/a.u. ${ }^{3}$. The optimized configuration of adsorbed MIBE and $\mathrm{H}_{2} \mathrm{O}$ product molecules on proximal sulfonic acid centers of the SBA-15 catalyst is shown on the right. Selected distances of importance to the adsorption and reaction are given in $\AA$. 


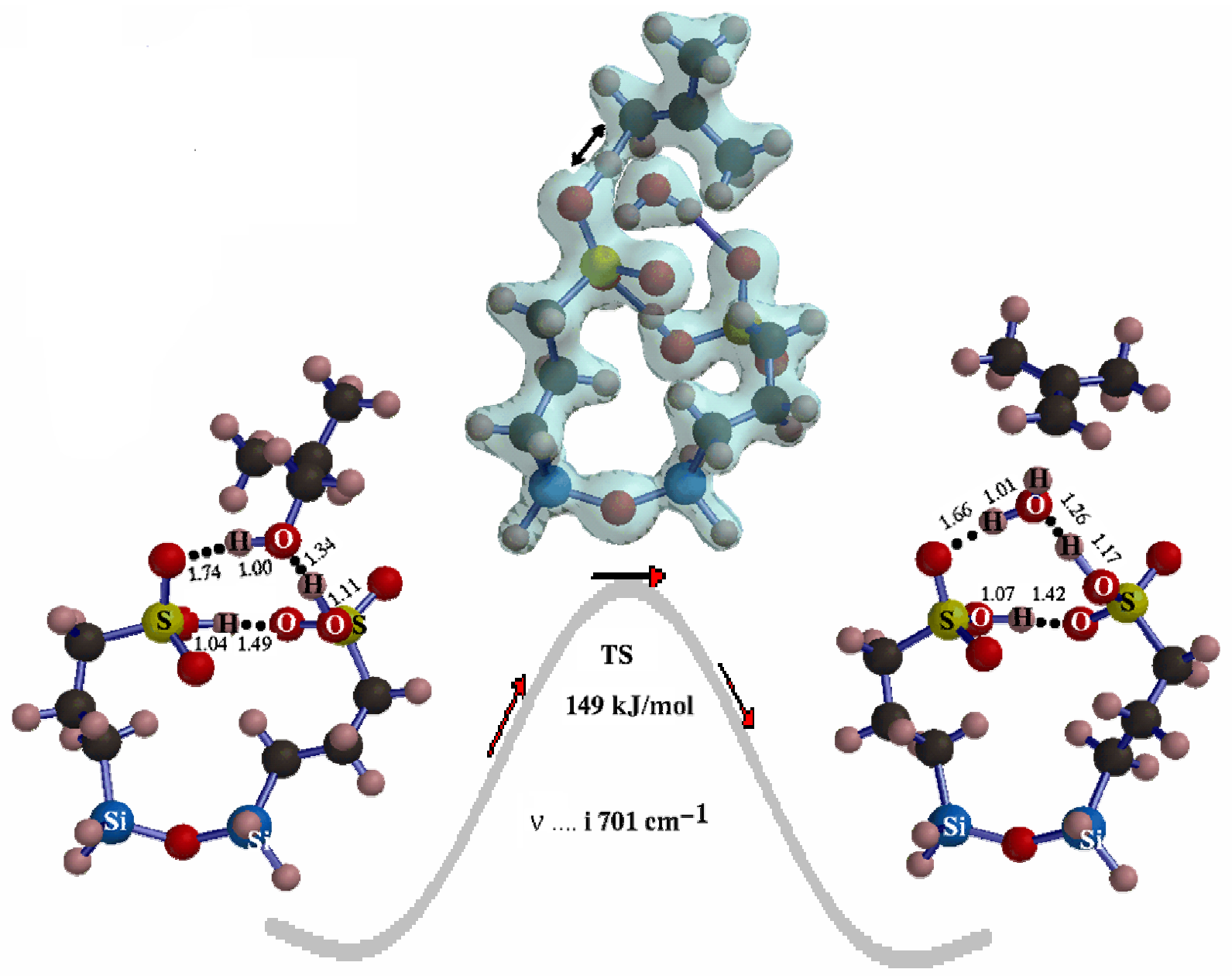

Figure 9. The optimized configuration, left, of an adsorbed i-BuOH molecule on a sulfonic acid center on the SBA-15 catalyst, also showing interaction with an adjacent unoccupied sulfonic acid group. The transition state for isobutanol dehydration over SBA-15 is shown in the middle of the figure, where electron density is shown as a transparent isosurface to within 0.08 electrons/a.u. ${ }^{3}$. The optimized configuration of the products of dehydration of isobutanol is shown on the right. Selected distances of importance to the adsorption and dehydration are given in $\AA$. 


\section{Discussion}

\subsection{Ethers from Alcohols.}

4.1.1. Ether Synthesis from $\mathrm{MeOH} / \mathrm{i}-\mathrm{BuOH}=1 / 1$ Reactants. As the reaction pressure was increased at $404 \mathrm{~K}$ with a constant flow rate of the $\mathrm{MeOH} / \mathrm{i}-\mathrm{BuOH}=1 / 1$ reactant mixture, the formation rates of the ethers steadily increased (Figure 1). In contrast, the rate of dehydration of isobutanol to form isobutene, as well as 2-butenes, increased sharply as the pressure was initially increased and then gradually declined with higher pressure to yield a broad maximum. The data points in Figure 1 were fitted with solid lines by using the kinetic laws represented by Equations 1-3. This yielded the values of $\mathrm{K}_{\mathrm{M}}=$ $0.015 \mathrm{kPa}^{-1}, \mathrm{~K}_{\mathrm{B}}=0.040 \mathrm{kPa}^{-1}, \mathrm{k}_{1}=1.47 \mathrm{~mol} / \mathrm{kg} \mathrm{catal} / \mathrm{hr}, \mathrm{k}_{3}=0.801 \mathrm{~mol} / \mathrm{kg}$ catal $/ \mathrm{hr}$, and $\mathrm{k}_{4}=$ $1.62 \mathrm{~mol} / \mathrm{kg}$ catal $/ \mathrm{hr}$ at $404 \mathrm{~K}$. The larger adsorption equilibrium constant for $\mathrm{i}-\mathrm{BuOH}$ relative to that for $\mathrm{MeOH}\left(\mathrm{K}_{\mathrm{B}} / \mathrm{K}_{\mathrm{M}}=2.67\right)$ indicates that $\mathrm{i}-\mathrm{BuOH}$ is more strongly held by the acid sites than the $\mathrm{MeOH}$ reactant and is consistent with the relative basicity of the two alcohols and the observations obtained with other catalysts [17,26,36,46,51]. This is also consistent with the calculated adsorption energies of the reactants (Table 5). The rate of IB formation passes through a maximum, consistent with Equation 3.

At ambient pressure $(101.3 \mathrm{kPa})$, the steady-state synthesis rate of all products increased as the reaction temperature was increased, and in particular the dehydration of isobutanol to form isobutene was greatly favored. This was accompanied by decreasing selectivities toward the formation of all of the ethers, especially MIBE. The apparent activation energies $\left(E_{a}\right)$, shown in Figure 2, demonstrated that the $E_{a}$ values for isobutene and the 2-butenes (150-160 kJ/mol range) were substantially higher than those for the ethers, with DME at $113 \mathrm{~kJ} / \mathrm{mol}$, MIBE and DIBE in the $75-80 \mathrm{~kJ} / \mathrm{mol}$ range, and MTBE and TBIBE in the $40-60 \mathrm{~kJ} / \mathrm{mol}$ range under these reaction conditions. This is also consistent with the high TS barrier calculated for the dehydration of i-BuOH to form IB (Table 3). Clearly, low temperatures favored ether synthesis.

4.1.2. Ether Synthesis from $\mathrm{MeOH} / \mathrm{i}-\mathrm{BuOH}=2 / 1$ Reactants. Increasing the $\mathrm{MeOH} / \mathrm{i}-\mathrm{BuOH}$ ratio to $2 / 1$ at $404 \mathrm{~K}$ significantly decreased the rate of dehydration of $\mathrm{i}$ $\mathrm{BuOH}$ to IB while enhancing the dehydrocondensation reactions to form MIBE and DME, as shown in Figure 3. MIBE was the dominant product formed, and only traces of MTBE, DIBE, and 2-butenes were observed. The solid lines in Figure 3 were obtained by using the kinetic laws represented by Equations 1-3 and maintaining the same values of $K_{M}$ and $K_{B}$ as determined with the $\mathrm{MeOH} / \mathrm{i}-\mathrm{BuOH}=1 / 1$ reaction test. This resulted in the values of $\mathrm{K}_{\mathrm{M}}=$ $0.015 \mathrm{kPa}^{-1}, \mathrm{~K}_{\mathrm{B}}=0.040 \mathrm{kPa}^{-1}, \mathrm{k}_{1}=1.13 \mathrm{~mol} / \mathrm{kg}$ catal $/ \mathrm{hr}, \mathrm{k}_{3}=0.474 \mathrm{~mol} / \mathrm{kg} \mathrm{catal} / \mathrm{hr}$, and $\mathrm{k}_{4}=$ $1.51 \mathrm{~mol} / \mathrm{kg}$ catal $/ \mathrm{hr}$ being obtained for this $\mathrm{MeOH} / \mathrm{i}-\mathrm{BuOH}=2 / 1$ experiment at $404 \mathrm{~K}$. Again, the kinetic rate constant for the MIBE synthesis reaction, $\mathrm{k}_{4}$, exhibited the largest value.

The experimental data in Figure 3 at an isobutanol partial pressure of $100 \mathrm{kPa}(300$ 
$\mathrm{kPa}$ total alcohol pressure; 3.27 MPa total pressure) correspond to the rate of formation of MIBE of about $25 \mathrm{~g} / \mathrm{kg}$ catal $/ \mathrm{hr}$ at $404 \mathrm{~K}$ with a selectivity of $60 \%$. At approximately these same reaction conditions with $\mathrm{MeOH} / \mathrm{i}-\mathrm{BuOH}=2 / 1$, but at $389 \mathrm{~K}$, a Nafion-H microsaddles catalyst exhibited a productivity of $27 \mathrm{~g} \mathrm{MIBE} / \mathrm{kg}$ catal $/ \mathrm{hr}$ with a selectivity of $66 \%[16,17]$. With the present SBA-15 catalyst, the selectivity to MIBE remained almost constant at about $60 \%$ at elevated reaction pressures, and this selectivity behavior is similar to that observed with the Nafion-H microsaddles catalyst $[16,17]$.

While maintaining the reaction pressure a $2.17 \mathrm{MPa}$, increasing reaction temperature with a $\mathrm{MeOH} / \mathrm{i}-\mathrm{BuOH} / \mathrm{N}_{2}=10.4 / 5.2 / 184 \mathrm{~mol} / \mathrm{kg}$ catal $/ \mathrm{hr}$ reactant stream resulted in increased rate of formation of all three products over the SBA-15 catalyst. Again, higher temperatures promoted the formation of IB to a larger degree than the ethers. In this case, the DME selectivity decreased only slightly (from $29.5 \%$ to $25.4 \%$ in the temperature range studied), while the MIBE selectivity decreased from $70.5 \%$ to $46.7 \%$ as the IB selectivity increased from zero to $27.9 \%$. The greater enhancement of the rate of formation of IB with increasing temperature is again reflected in the higher $\mathrm{E}_{\mathrm{a}}$ value of IB relative to the ethers, $218 \mathrm{~kJ} / \mathrm{mol}$ for IB compared with $102 \mathrm{~kJ} / \mathrm{mol}$ and $89 \mathrm{~kJ} / \mathrm{mol}$ for DME and MIBE, respectively (Figure 4). These apparent activation energies are in the same order as those observed with a Nafion-H microsaddles catalyst, with data obtained from Figure 6 of Ref [17], for product formation in the $389-430 \mathrm{~K}$ temperature range from a $\mathrm{MeOH} / \mathrm{i}-\mathrm{BuOH} / \mathrm{N}_{2}=$ $10.4 / 5.2 / 186 \mathrm{~mol} / \mathrm{kg}$ catal $/ \mathrm{hr}$ reactant stream at $7.58 \mathrm{MPa}$, i.e. for IB, DME, and MIBE the $\mathrm{E}_{\mathrm{a}}$ values were 222,75 , and $68 \mathrm{~kJ} / \mathrm{mol}$, respectively. In all cases with the different catalysts, the MIBE product exhibited the lowest apparent activation energy. If isobutene were the desired product, high $\mathrm{i}-\mathrm{BuOH} / \mathrm{MeOH}$ ratios and low reaction pressure, along with higher temperatures, should be utilized.

\subsection{Deactivation of the SBA-15 Catalyst by Pyridine.}

The catalyst was stable during testing, as demonstrated in Table 1. To probe blocking of the active Brønsted acid sites, exposure of the catalyst to the nitrogen-base pyridine (Py) in the reactant mixture was carried out at $404 \mathrm{~K}$ and $375 \mathrm{kPa}$. As the Py reached the catalyst, the rates of formation of all products decreased, as indicated in Figure 5. The decrease was initially most evident by loss of IB formation, while at the time no Py was detectable in the exit gas stream. This indicates that the Py was adsorbing onto the catalyst, particularly the unoccupied acid sites first, resulting in a delay in Py break-through in the exit gas and first preventing the dehydration of isobutanol to form IB. Further exposure of the catalyst to Py led to complete inhibition of the coupling reactions.

Purging the catalyst with $\mathrm{N}_{2}$ at the reaction temperature and pressure did not regenerate the catalyst. However, increasing the temperature or pressure did yield the expected products, but in much smaller yields than observed before the Py exposure (Table 2). In particular, the synthesis of IB was retarded. After the $473 \mathrm{~K}$ test, lowering the temperature to the original reaction condition did not lead to regeneration of the catalytic activity. Thus, the higher temperature did not regenerate the acid sites that were previously 
active at the lower temperatures. It is noted that not all active sites need to be blocked to inhibit dehydration of $\mathrm{i}-\mathrm{BuOH}$ and coupling reactions of $\mathrm{i}-\mathrm{BuOH}$ and $\mathrm{MeOH}$.

\subsection{XPS Analyses of the SBA-15 Catalyst.}

The initial SBA-15 material was completely devoid of residues of the Pluronic surfactant, and the $\mathrm{C} / \mathrm{S}$ ratio of 2.9 is near the stoichiometry of $-\left(\mathrm{CH}_{2}\right)_{3} \mathrm{SO}_{3} \mathrm{H}$ [37]. All the $\mathrm{S}$ was oxidized, and none was detectable as thiol groups. When Py was adsorbed, the S2p core level shift (CLS) was in the direction of lower BE, while the N1s of Py shifted to higher BE (402.2 eV vs $400.3 \mathrm{eV}$ for solid Py [52]). Details of such acid-base interactions and corresponding CLS calculations are given in our preceding paper [37]. In the present study, the S2p BE peak was resolved into two peaks, $\mathrm{S}(1)=169.1 \mathrm{eV}$ and $\mathrm{S}(2)=167.8 \mathrm{eV}$, with $\mathrm{S}(1)$ being nearly the same BE as for the S2p in SBA-15 prior to pyridine adsorption $(169.25$ $\mathrm{eV}$ [37]) and with $\mathrm{S}(2)$ being observed at lower BE. Quantitative resolution of the S2p spectrum into two $S 2 p$ peaks for the tested sample gave a $S(2) /(S(1)+S(2))$ ratio $=0.28$, which is the same ratio as observed for the $\mathrm{N} / \mathrm{S}_{\text {(Total) }}$ equivalence. Therefore, the Py is coordinated to $\mathrm{S}(2)$, and the $\mathrm{S}(2) \mathrm{S} 2 \mathrm{p}$ CLS of 1.3-1.45 eV to lower BE corresponds to the N1s CLS to higher BE by approximately $2 \mathrm{eV}$. These CLSs are consistent with direct interaction of the Py nitrogen base with a Brønsted acid functionality associated with the sulfonic $-\mathrm{SO}_{3} \mathrm{H}$ group, i.e. $\equiv \mathrm{Si}-\left(\mathrm{CH}_{2}\right)_{3} \mathrm{SO}_{3} \cdot{ }^{\cdot} \cdot \mathrm{H}^{\cdot} \cdot \mathrm{NC}_{5} \mathrm{H}_{5}$ and the proton donor group undergoes CLS in the opposite direction to that of the coordinating nitrogen base $[37,46,48]$.

\subsection{Textural Properties.}

Prolonged catalytic testing and partial Py poisoning of the SBA-15 catalyst resulted in a BET surface area of $314 \mathrm{~m}^{2} / \mathrm{g}$, a decrease from the initial surface area of the fresh catalyst of $551 \mathrm{~m}^{2} / \mathrm{g}$. The mesopore structure of the material was maintained, as shown by a narrow pore size distribution and by TEM micrographs of the tested catalyst showing long-range order of the one-dimensional tubular channels in the particles. Measurements yield a pore center-to-center distance (a) of $11.0 \pm 0.2 \mathrm{~nm}$, with the pore mouth diameters of 7.0-7.5 nm. Using the diameter of the mesopores determined by $\mathrm{N}_{2}$ adsorption $\left(\mathrm{d}_{\mathrm{p}}=7.7 \mathrm{~nm}\right)$ and the total pore volume $\left(\mathrm{V}_{\mathrm{p}}=0.60 \mathrm{~cm}^{3} / \mathrm{g}\right)$ determined from the adsorption isotherm, the specific surface area of mesopore structures is calculated by using the geometric relationship $\mathrm{S}_{\text {meso }}=(4 *$ $\left.V_{p}\right) / d_{p}$ [53] to be $312 \mathrm{~m}^{2} / g$. This is in agreement with the BET surface area of the tested catalyst, indicating no contribution to the surface area and total pore volume by micropores.

\subsection{Theory of Reactant Bonding, Pre-Reaction Complexes, Stationary Points on the Three Principal Reaction Pathways, and Reaction Mechanisms.}

The present theory not only yields adsorption and reaction patterns that are fully consistent with mechanisms based on earlier isotope studies, product composition, and the current experimental observations, but also affords predictions regarding catalyst design. We address the specific features as listed below: 
4.5.1. Single Adsorbates and Multiple Adsorbates. All the oxygen-containing species, alcohols, ethers and water, are bonded to the sulfonic groups O-down by an acceptor hydrogen bond following the order of bonding strengths, $\mathrm{i}-\mathrm{BuOH}>\mathrm{MeOH}>\mathrm{MIBE}>$ water $>$ DME (single site model in Table 5). Isobutene is very weakly bonded $(-7.4 \mathrm{~kJ} / \mathrm{mol}$ ) and this molecule is completely displaced when other oxygen-containing molecules, including the weakly bonded ethers and water $(-30$ to $-13 \mathrm{~kJ} / \mathrm{mol})$, are competing for the reaction site. Nitrogen bases are strongly bonded, as expected. Of those, pyridine is the weakest base but still is bonded more strongly than the oxygenated reactants and products. In all cases, the proton of the sulfonic acid group is not transferred to the oxygen or nitrogen of the adsorbate - only H-bonding of varying strengths is involved here, in contrast to the perfluoroalkylsulfonic acids that do transfer their protons to pyridine to form pyridinium $[37,48]$.

When two proximal sites are occupied by reactants or products, interactions result in changes of configurations that include donor hydrogen bonding of an - $\mathrm{OH}$ group of alcohol or water to an $\mathrm{O}=\mathrm{S}$ group of the sulfonic acid site. This is exemplified by the bonding of two methanol molecules to the proximal sites in Figure 7. Here the S-OH group of one sulfonic group acts as a "normal acid site" for one methanol while the $\mathrm{O}=\mathrm{S}$ group of the second sulfonic group acts as a basic site for the second methanol molecule. This situation repeats itself in simultaneous bonding of methanol and isobutanol as in Figure 8, and even with water hydrogen-down in the products of dehydrocondensations in Figures 7 and 8. In general terms, the acid functionality of one sulfonic site, when utilized as a hydrogen-donor site, changes the proximal site's function to one of a hydrogen-bond acceptor. In the dual site model, interaction via hydrogen-bonding lowers the adsorption energies of the products (Table 5), favoring their desorption from the catalyst surface compared to the single sites. In the case of the dual site adsorption of the reactants in particular, the H-bonding between the neighboring sites is not only an energy-determining feature but a structure-determining feature as well. This is evident from stretched $\mathrm{S}-\mathrm{O} \cdots \mathrm{H}$ and shortened $\mathrm{S}-\mathrm{OH} \cdots \mathrm{O}=\mathrm{S}$ distances in all dual site models in Figures 7-9.

4.5.2. Reaction Pathways. In all reactions studied, the overall TS barrier height and its connectivity with reactants and products is strongly influenced by the concerted motion of the "far away" atoms and flexibility of the entire dual-site ensemble with the H-bonded reactants. This is in complete agreement with conclusions drawn from simpler models for this class of reactions [54].

In the dehydrocondensation of alcohols to ethers, the results show convincingly that dissociation-reassociation of the C-O bond in the adsorbed methanol subject to "rear attack" onto its inverting methyl group is the dominant feature of the reaction pathway at the TS. In the TS complex, motions of all atoms associated with the TS imaginary modes occurs, in particular the "umbrella inversion" of the $\mathrm{CH}_{3}$ group in opposite phases of their vibrations,

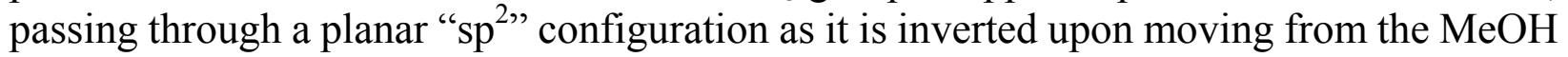
molecule to the oxygen end of the second alcohol to form DME (Figure 7) or MIBE (Figure 
8). At the same time, there is a cyclic transfer of three $\mathrm{H}$ atoms among the sulfonic acid groups and the two reacting alcohols that results in the release of water molecule formed from the oxygen originally in the $\mathrm{MeOH}$ molecule, consistent with selective rejection of ${ }^{18} \mathrm{O}$ from $\mathrm{Me}^{18} \mathrm{OH}$ in earlier observed MIBE synthesis [22-24]: the proton from the first sulfonic acid site attacks methanol, its methyl group is being transferred to the second alcohol whose proton is moving toward the base $\mathrm{O}=\mathrm{S}$ of the second sulfonic group, and the proton of the second sulfonic acid is moving to the first sulfonic group to render it electrically neutral. Examination of computed charges indicates that this proton transfer between neighboring sites minimizes charge imbalance in the TS. The theoretical barriers for the DME and the MIBE reactions are quite close (73 and $83 \mathrm{~kJ} / \mathrm{mol}$, respectively, Table 3), although their relative values are opposite to experimental apparent activation energies (see Figures 2 and 4). Both of these calculated barriers are, however, remarkably close to the experimental activation energies. The imaginary vibrational modes of the TS have nearly identical frequencies, within one wavenumber of $394 \mathrm{~cm}^{-1}$ (Table 4).

The mechanism for dehydration of isobutanol to isobutene and the associated reaction parameters are quite different: the E2 mechanism, previously proposed for this reaction based on kinetics [51], is operating here too, with the following features: the pre-reaction complex is $\mathrm{i}-\mathrm{BuOH}$ bonded O-down on one hydrogen-donor site (I), but also H-down to the other acceptor site (II) (Figure 9, left); then proton of site I attacks the $\mathrm{OH}$ group of the alcohol and water leaves to be "parked" on site I. The TS involves abstraction of $\mathrm{H}$ originally bonded to $\mathrm{C}-2$ which, however, has already traveled to $\mathrm{C}-1$. Its $700 \mathrm{~cm}^{-1}$ imaginary mode (Table 4) is indicated by an arrow in Figure 9, middle. The acceptor of this proton is the basic $\mathrm{O}=\mathrm{S}$ group of site II. The frequency of this mode that is associated with proton transfer is substantially higher than those associated with methyl transfer in the DME and MIBE forming reactions. The post-reaction complex is water bonded O-down to the proton of site I with the unbonded, planar isobutene released away. The theoretical barrier of $149 \mathrm{~kJ} / \mathrm{mol}$ is much higher than that for the DME and MIBE reactions (Table 3), is comparable to the experimental apparent activation energy determined at ambient pressure $(161 \mathrm{~kJ} / \mathrm{mol}$, Figure 2), but is lower than the $218 \mathrm{~kJ} / \mathrm{mol}$ obtained at higher pressure, under which the ether synthesis dominates the pre-reaction adsorption equilibria and blocks the sites for water release in isobutanol dehydration.

4.5.3. Poisoning by Pyridine. The theoretical adsorption energy of pyridine on a single acid site, $-55.3 \mathrm{~kJ} / \mathrm{mol}$, is comparable to that of isobutanol and substantially larger than that of any other reactant or product (Table 5). This has the consequence not only of blocking the sulfonic acid sites for adsorption and activation of methanol, the reactant for the ether formation, but also blocking the sites for water in the E2 dehydration of isobutanol. This is in agreement with experimental observation (Figure 5).

4.5.4. Relation to Kinetics. Even though that the present model is idealized, it successfully confirms the dual site $S_{\underline{N}} 2$ mechanism as the most efficient pathway for ethers and the E2 mechanism for dehydration of isobutanol. The dual site mechanism is consistent 
with kinetics in that increased pressure increases the DME and MIBE formation in a parallel fashion, but strongly suppresses the E2 reaction by adsorbed alcohols blocking the acceptor sites for water. The model holds generally, and the kinetic patterns are very similar for several classes of solid acids, including polymeric, derivatized inorganic oxides [16$24,26,36,46,51,54]$ and now the SBA material.

4.5.5. Some Theoretical Predictions for Catalyst Design. Apart from the generality of the reaction mechanism and the advantage of large pore spaces in the SBA material that allows extension of the present reaction types to large molecules, some theoretical predictions for catalyst design can be made: (1) because of the cyclic proton shuttling among the proximal catalyst sites accompanying the $\mathrm{S}_{\mathrm{N}} 2$ alkyl transfer, the most efficient catalysts for dehydrocondensation of alcohols to ethers will require large surface concentration of the acid sites, ideally one propylsulfonic group tethered to each surface Si atom; (2) dehydration of the higher alcohol can be promoted by low pressures that provide for empty acceptor sites for water, and will be suppressed at high pressures for the opposite reason - however, the proton capture from the TS will be facilitated by a stronger base than the present $\mathrm{O}=\mathrm{S}$ group; and (3) partial or total fluorination of the alkylsulfonic groups will increase the acid strength, or proton-donating ability, of one site, and cation-exchange of protons on the neighboring site will increase its proton-accepting ability. The background for testing the theory has been developed, in particular XPS core-level shifts were found a useful probe for the theoretically predicted effects of weakly and strongly hydrogen-bonded adsorbates [37].

\section{Conclusions}

SBA-15 is a stable mesoporous silica-based catalyst for synthesis of ethers from alcohols. The propylsulfonic acid groups anchored on the pore walls are robust and maintain their Brønsted acid functionality even after prolonged testing. However, these hydrocarbon sulfonic sites, even though weaker acids than fluorocarbon sulfonic groups, are easily poisoned by the presence of the nitrogen base pyridine in the reactant mixture. Full regeneration of the activity of the catalyst after deliberate poisoning was not successful under the mild reaction conditions utilized.

There is no direct pathway for MTBE formation from $\mathrm{MeOH}$ and i-BuOH reactants. The dominant reaction pathways are: (1) ether synthesis by $\mathrm{S}_{\mathrm{N}} 2$ rear-attack of one alcohol on a second alcohol molecule to yield MIBE and DME, and (2) dehydration of i-BuOH to yield IB via a carbenium-type intermediate in an E2-type pathway. Isobutene is only weakly adsorbed on the active sites of SBA-15, so little of this product reacts with $\mathrm{MeOH}$ to form MTBE via an indirect pathway before desorbing. Very small amounts of side products n-butenes, DIBE, and TBIBE were observed and are deemed insignificant for the kinetic and quantum mechanical modeling of the main pathways.

Selectivity for the products formed from the alcohols can be controlled by the following reaction conditions: 
1. At lower reaction pressures, $\mathrm{i}-\mathrm{BuOH}$ is preferentially adsorbed from $\mathrm{MeOH} / \mathrm{i}-\mathrm{BuOH}$ reactant mixtures on sulfonic acid groups, and with adjacent unoccupied sites, the initial dominant product is IB;

2. As the reaction pressure increased, adsorption of $\mathrm{MeOH}$ increased, and the productivity of the ethers increased at the expense of IB;

3. At lower reaction temperatures, ethers were the dominant products formed, consistent with the lower experimental apparent activation energies and calculated TS barriers along the reaction coordinate; and

4. As the reaction temperature increased, the product selectivity shifted toward IB, consistent with its high apparent activation energy and TS barrier.

For optimum synthesis of ethers, low reaction temperature and elevated pressures should be utilized with catalysts having a high concentration of Brønsted acid sites in close proximity to one another.

\section{References for Chapter IV}

1. "Kirk-Othmer Encyclopedia of Chemical Technology," Vol. 11, 3th Ed., John Wiley, New York (1980) pp 410-425.

2. Ridler, D. E.; Twigg, M. V., in: M. V. Twigg (Ed.), "Catalyst Handbook," $2^{\text {nd }}$ Ed., Wolfe Publ. Ltd., London (1989) p. 225.

3. LeBlanc, J. R.; Schneider III, R. V.; Strait, R. B., In W.-H. Cheng, H. H. Kung (Eds.), "Methanol Production and Use," Marcel Dekker, New York (1994) p. 51.

4. Bridger, G. W.; Spencer, M. S., In “Catalyst Handbook," $2^{\text {nd }}$ Ed., M. V. Twigg (Ed.), Wolfe Publ. Ltd., London (1989) p. 441.

5. Lee, S., "Methanol Synthesis Technology," CRC Press, Boca Raton, FL (1990).

6. Chang, C. D., “Hydrocarbons from Methanol,” Marcel Dekker, New York (1983).

7. "Catalytic Conversions of Synthesis Gas and Alcohols to Chemicals," R. G. Herman (Ed.), Plenum Press, New York, 1984.

8. Papp, H.; Baerns, M., In "New Trends in CO Activation," (Studies in Surface Science and Catalyst, Vol. 64), L. Guczi (Ed.), Elsevier, Amsterdam (1991) 430.

9. Kung, H. H.; Smith, K. J., In "Methanol Production and Use," W.-H. Cheng, H. H. Kung (Eds.), Marcel Dekker, New York (1994) p. 175. 
10. Chang, C. D., In "Methanol Production and Use," W.-H. Cheng, H. H. Kung (Eds.), Marcel Dekker, New York (1994) p. 133.

11. Smith, K.; Anderson, R. B., Canad. J. Chem. Eng. 61 (1983) 40.

12. Vedage, G. A.; Himelfarb, P.; Simmons, G. W.; Klier, K., Preprints, Div. Pet. Chem., ACS 28 (1983) 1261.

13. Nunan, J. G.; Bogdan, C. E.; Klier, K..; Smith, K. J.; Young, C.-W.; Herman, R. G., J. Catal. 116 (1989) 195.

14. Nunan, J. G.; Herman, R. G.; Klier, K., J. Catal. 116 (1989) 222.

15. Beretta, A.; Sun, Q.; Herman, R. G.; Klier, K., Ind. Eng. Chem. Res. 35 (1996) 1534.

16. Nunan, J.; Klier, K.; Herman, R. G., J. Chem. Soc., Chem. Commun. (1985) 676.

17. Nunan, J. G.;Klier, K.; Herman, R. G., J. Catal. 139 (1993) 406.

18. Herman, R. G.; Klier, K.; Feeley, O. C.; Johansson, M. A., Preprints, Div. Fuel Chem., ACS 39 (1994) 343.

19. Klier, K.; Herman, R. G.; Johansson, M. A.; Feeley, O. C., Preprints, Div. Fuel Chem., ACS 37 (1992) 236.

20. Herman, R. G.; Klier, K.; Feeley, O. C.; Johansson, M. A.; Sun, Q.; Lietti, L., Preprints, Div. Fuel Chem., ACS 39 (1994) 1141.

21. Feeley, O. C.; Johansson, M. A.; Herman, R. G.; Klier, K., Preprints, Div. Fuel Chem., ACS 37 (1992) 1817.

22. Sun, Q.; Herman, R. G.; Klier, K., J. Chem. Soc., Chem. Commun. (1995) 1849.

23. Feeley, O. C.; Sun. Q.; Herman, R. G.; Johansson, M.; Lietti, L.; Klier, K., Catal. Letters 35 (1995) 13.

24. Klier, K.; Sun, Q.; Feeley, O. C.; Johansson, M.; Herman, R. G., In $11^{\text {th }}$ Intern. Congr. Catal.-40 ${ }^{\text {th }}$ Ann., (Studies in Surface Science and Catalyst, Vol. 101), J. W. Hightower, W. N. Delgass, E. Iglesia, A. T. Bell (Eds.), Elsevier, Amsterdam (1996) 601.

25. Shen, J. G. C.; Kalantar, T. H.; Herman, R. G.; Roberts, J. E.; Klier, K., Chem. Mater. 13 (2001) 4479. 
26. Shen, J. G. C.; Kalantar, T. H.; Ma, Q.; Herman, R. G.; Klier, K., J. Chem. Soc., Chem.Commun. (2001) 653.

27. Kresge, C. T.; Leonowicz, M. E.; Roth, W. J.; Vartuli, J. C.; Beck, J. S., Nature 359 (1992) 710.

28. Beck, J. S.; Vartuli, J. C.; Roth, W. J.; Leonowicz, M. E.; Kresge, C. T.; Schmitt, K. D.; Chu, C. T.-W.; Olson, D. H.; Sheppard, E. W.; McCullen, S. B.; Higgins, J. B.; Schlenker, J.L., J. Am. Chem. Soc. 114 (1992) 10834.

29. Zhao, D.; Feng, J.; Huo, Q.; Melosh, N.; Fredrickson, G. H.; Chmelka, B. F.; Stucky, G. D., Science 279 (1998) 548.

30. Zhao, D.; Huo, Q.; Feng, J.; Chmelka, B. F.; Stucky, G. D., J. Am. Chem. Soc. 120 (1998) 6024.

31. Margolese, D.; Melero, J. A.; Christiansen, S. C.; Chmekla, B. F.; Stucky, G. D., Chem. Mater. 12 (2000) 2448.

32. Van Rhijn, W. M.; De Vos, D. E., Sels, B. F.; Bossaert, W. D.; Jacobs, P. A., J. Chem. Soc., Chem. Commun. (1998) 317.

33. Lim, M. H.; Blanford, C. F.; Stein, A., Chem. Mater. 10 (1998) 467.

34. Bossaert, W. D.; De Vos, D. E.; Van Rhijn, W. M.; Bullen, J.; Grobet, P. J.; Jacobs, P. A., J. Catal. 182 (1999) 156.

35. Díaz, I.; Mohino, F.; Pérez-Pariente, J.; Sastre, E., Appl. Catal. A: Gen. 205 (2001), 19.

36. Shen, J. G. C.; Herman, R. G.; Klier, K., J. Phys. Chem. B 106 (2002) 9975.

37. Smith, J. L.; Herman, R. G.; Terenna, C. R.; Galler, M. R.; Klier, K., J. Phys. Chem. A 108 (2004) 39.

38. Mbaraka, I. K.; Radu, D. R.; Lin, V. S.-Y.; Shanks, B.H., J. Catal. 219 (2003) 329.

39. Hunsicker, R. A.; Klier, K.; Gaffney, T. S.; Kirner, J. G., Chem. Mater. 14 (2002) 4807.

40. Brunauer, S.; Emmet, P. H.; Teller, E., J. Am. Chem. Soc. 60 (1938) 309.

41. Barrett, E. P.; Joyner, L. G.; Halenda, P. P., J. Am. Chem. Soc. 73 (1951) 373.

42. Gregg, S. J.; Sing, K. S. W., “Adsorption, Surface Area, and Porosity,” Academic Press, 
London (1967) pp. 160-172.

43. Kruk, M.; Jaroniec, M.; Ko, C. H.; Ryoo, R., Chem. Mater. 12 (2000) 1961.

44. Wang, Y.; Noguchi, M.; Takahashi, Y.; Ohtsuka, Y., Catal. Today 68 (2001) 3.

45. Zhang, W.-H.; Lu, J.; Han, B.; Li, M.; Xiu, J.; Ying, P.; Li, C., Chem. Mater. 14 (2002) 3413 .

46. Klier, K.; Kwon, H.-H.; Herman, R. G.; Hunsicker, R. A.; Ma, Q.; Bollinger, S. J., In $12^{\text {th }}$ Intern. Congr. Catal., (Studies in Surface Science and Catalysis, Vol. 130D), A. Corma, F. V. Melo, S. Mendioroz, J. L. G. Fierro (Eds.), Elsevier, Amsterdam (2000) 3447.

47. Specific functionals are: Becke88: Becke, A. D., Phys. Rev. A 38 (1988) 3098; PZ81: Perdew, J. P.; Zunger, A., Phys. Rev. B 23 (1981) 5048; Perdew 86: Perdew, J. P., Phys. Rev. B 33 (1986) 8822 and Phys. Rev. B 34 (1986) 7406 (erratum).

48. Johansson, M.; Klier, K., Topics Catal. 4 (1997) 99.

49. Moulder, J. F.; Stickle, W. F.; Sobul, P. E.; Bomben, K. D., in: J. Chastain, (Ed.), "Handbook of X-Ray Photoelectron Spectroscopy," Perkin-Elmer Corp., Eden Prairie, MN (1992).

50. Beamson, G.; Briggs, D., "High Resolution XPS of Organic Polymers: The Scienta ESCA300 Database," Wiley, Chichester (1992).

51. Lietti, L.; Sun, Q.; Herman, R. G.; Klier, K., Catal. Today 27 (1996) 151.

52. Suzuki, S.; Yamaguchi, Y.; Onishi, H.; Sasaki, T.; Jukui, K.; Iwasawa, Y., J. Chem. Soc., Faraday Trans. 94 (1998) 161.

53. Kruk, M.; Jaroniec, M.; Sayari, A., Langmuir 13 (1997) 6267.

54. Klier, K., Topics Catal. 18 (2002) 141. 


\section{Chapter V. Synthesis of Ethers from Alcohols over a High Acidity, Defective SBA-15 Catalyst}

\section{Introduction}

SBA materials, mesoporous silicas derivatized with propyl-sulfonic acid functionalities, were investigated for the coupling of methanol with isobutanol and 2propanol by means of reaction studies, theory of the reaction paths including transition states (TS), determination of proton concentration, TEM, and extensive characterization by quantitative XPS, including theoretical interpretation of core-level shifts. This investigation follows (a) reaction studies of dehydrocondensation of alcohols to unsymmetrical ethers on sulfonic acid resins [1], inorganic oxides [2], ZSM-5 [3], and hybrid material SBA-15 [4,5], (b) quantitative XPS for stoichiometric equivalences and bonding strength of nitrogen bases [6], and (c) theory $[5,6]$. We have shown that highly ordered SBA-15 is a very stable and active catalyst for coupling $\mathrm{MeOH} / \mathrm{i}-\mathrm{BuOH}$ to the high cetane MIBE [5]. The most efficient ether-forming mechanism was found to be a surface dual-site catalyzed $\mathrm{S}_{\mathrm{N}} 2$ pathway wherein the alkyl group of one alcohol inverts the orientation of its reacting $\mathrm{sp}^{3}$ carbon that results in chirality inversion in case of asymmetric alkyl [3]. There are also important olefin hydration reactions that lead to ethers via intermediacy of alcohols. Of these, hydration of propene forms not only 2-propanol, but also diisopropylether (DIPE), an octane booster considered for replacement of methyltertiarybutylether (MTBE) that is being discarded for environmental reasons [7]. Industrial DIPE synthesis generally involves liquid-phase reaction of propene with isopropanol. Proposed mechanisms for this etherification reaction have been summarized [7] into the following three types:

Type I - the least active mechanism occurring at high alcohol/olefin ratios via a carbocation intermediate,

Type II - the active reaction pathway occurring at intermediate alcohol/olefin ratios via intermediates, e.g. H-bonded i-PrOH, with greater stability, and

Type III - the most active pathway occurring at low alcohol/olefin ratios or at very low overall concentrations, e.g. where both reactant molecules are adsorbed from the gas phase.

In the present research, we investigate the catalytic properties and stability of a large pore, highly defective SBA catalyst, characterized by X-ray powder diffraction, X-ray photoelectron spectroscopy, and BET surface area, for the dehydrocondensation/ dehydration of mixtures of alcohols to form ethers and olefins and probe the mechanistic pathway and reaction intermediates involved in these reactions. The advantages of large-pore silica-based materials are in applicability to reactions of large molecules and the non-swelling properties. 


\section{Experimental}

\subsection{Catalyst Synthesis, Characterization, and Determination of Activity and Selectivity.}

The SBA catalyst was synthesized at 313K from tetraethoxysilane (TEOS) and 3mercaptopropyltrimethoxysilane (MPTMS) with Pluronic $123 \mathrm{EO}_{20} \mathrm{PO}_{70} \mathrm{EO}_{20}$ triblock copolymer ( $\mathrm{MW}=5800$, Aldrich) as the templating agent using the one-step direct synthesis procedure of Margolese et al. [8] and as described previously [5,6]. Catalyst performance was determined in a flow system described earlier [5] at steady state. The reaction conditions are given in the Results and Discussion section.

The bright field transmission electron microscopy (TEM) and secondary electron images were obtained on a JEOL JSM 7401F instrument. Samples were prepared by dispersing a small amount of SBA powder in ethanol and sonicating the dispersion, and placing a drop of the dispersion on a holey carbon-coated $\mathrm{Cu}$ grid for examination after evaporation of the ethanol. X-Ray powder diffraction (XRD) was used to monitor crystallinity and interlayer spacings for the catalyst. The small angle XRD data were collected on a Siemens D5000 instrument with CuK $\alpha$ radiation as described previously [6]. High resolution X-ray photoelectron spectroscopy (XPS) analyses, recording the S2p, O1s, $\mathrm{Si} 2 \mathrm{p}, \mathrm{Si} 2 \mathrm{~s}$, and C1s spectral regions, were carried out with a Scienta ESCA-300 spectrometer [6]. The Si2p binding energy (BE) of $103.5 \mathrm{eV}$ was used as an internal standard for all peak positions.

\subsection{Computational Modelling and Analysis.}

The sulfonic acid catalyzed reactions of ethers from alcohols were first examined theoretically via DFT/GGA/DN** calculations based on the Nafion-type prototype system $2 \mathrm{CF}_{3} \mathrm{SO}_{3} \mathrm{H}+\mathrm{CH}_{3} \mathrm{OH}+\left(\mathrm{CH}_{3}\right)_{2} \mathrm{CHCH}_{2} \mathrm{OH}$ [9]. This investigation has been extended to the much larger model of mesoporous silica derivatized with pendant propylsulfonic acid functionalities. The model for the dual site consisted of two propylsulfonic groups anchored on two silicon atoms capped by two hydrogen each and bridged by oxygen, of the composition $\mathrm{HO}_{3} \mathrm{~S}\left(\mathrm{CH}_{2}\right)_{3}-\mathrm{Si}\left(\mathrm{H}_{2}\right)-\mathrm{O}-\mathrm{Si}\left(\mathrm{H}_{2}\right)-\left(\mathrm{CH}_{2}\right)_{3} \mathrm{SO}_{3} \mathrm{H}$, abbreviated as $\mathrm{G}=(\mathrm{OH})_{2}$. The structural unit $-\left[\mathrm{Si}\left(\mathrm{H}_{2}\right)-\mathrm{O}-\mathrm{Si}\left(\mathrm{H}_{2}\right)\right]-$ was taken to represent the silica intraporous wall. The reaction models comprised adducts
(I) $\left[\mathrm{G}=(\mathrm{OH})_{2}\right][2 \mathrm{MeOH}]$,
(II) $\quad\left[\mathrm{G}=(\mathrm{OH})_{2}\right][\mathrm{MeOMe}]\left[\mathrm{H}_{2} \mathrm{O}\right]$,
(VII) $\left[\mathrm{G}=(\mathrm{OH})_{2}\right][2 \mathrm{i}-\mathrm{PrOH}]$,
(III) $\left[\mathrm{G}=(\mathrm{OH})_{2}\right][\mathrm{MeOH}][\mathrm{i}-\mathrm{BuOH}]$,
(VIII) $\left[\mathrm{G}=(\mathrm{OH})_{2}\right][\mathrm{i}-\mathrm{PrOi}-\mathrm{Pr}]\left[\mathrm{H}_{2} \mathrm{O}\right]$,
(IV) $\left[\mathrm{G}=(\mathrm{OH})_{2}\right][\mathrm{i}-\mathrm{BuOMe}]\left[\mathrm{H}_{2} \mathrm{O}\right]$,
(IX) $\left[\mathrm{G}=(\mathrm{OH})_{2}\right][\mathrm{MeOH}][\mathrm{i}-\mathrm{PrOH}]$,
(V) $\left[\mathrm{G}=(\mathrm{OH})_{2}\right][\mathrm{i}-\mathrm{BuOH}]$,
(X) $\left[\mathrm{G}=(\mathrm{OH})_{2}\right][\mathrm{i}-\mathrm{PrOMe}]\left[\mathrm{H}_{2} \mathrm{O}\right]$,
(VI) $\left[\mathrm{G}=(\mathrm{OH})_{2}\right]\left[\mathrm{i}-\mathrm{Bu}^{=}\right]\left[\mathrm{H}_{2} \mathrm{O}\right]$,
(XI) $\left[\mathrm{G}=(\mathrm{OH})_{2}\right][\mathrm{i}-\mathrm{PrOH}]$, and
(XII) $\left[\mathrm{G}=(\mathrm{OH})_{2}\right]\left[\mathrm{Pr}^{=}\right]\left[\mathrm{H}_{2} \mathrm{O}\right]$.

Reaction pathways $(\mathbf{I}) \rightarrow(\mathbf{I I}),(\mathbf{I I I}) \rightarrow(\mathbf{I V})$, and $(\mathbf{V}) \rightarrow(\mathbf{V I})$ represent the synthesis of DME, 
MIBE, and dehydration of $\mathrm{i}-\mathrm{BuOH}$ to isobutene $\mathrm{i}-\mathrm{Bu}^{=}$, while pathways (VII) $\rightarrow$ (VIII), (IX) $\rightarrow(\mathbf{X})$, and $(\mathbf{X I}) \rightarrow(\mathbf{X I I})$ represent the synthesis of DIPE, MIPE, and dehydration of i-PrOH to propene $\left(\mathrm{PE}=\mathrm{Pr}^{\overline{ }}\right)$. The transition states $(\mathrm{TS})$ on these three pathways were searched and located, in addition to the pre- and post-reaction surface complexes.

The present calculations employed all-electron codes implemented in the Titan software using the DFT $=$ Slater + Becke88 + PZ81 + Perdew86 method with the 6-31G** basis set [10]. The 6-31G** Gaussian basis set gave comparable relative energies to the earlier used double numerical basis set $\mathrm{DN}^{* *}$ [9], although the absolute energies were systematically higher with the $6-31 \mathrm{G}^{* *}$ set than with the $\mathrm{DN}^{* *}$ set. Geometry optimization for each of the adducts (I) - (XII) involved a "frozen wall" unit - $\left[\mathrm{Si}\left(\mathrm{H}_{2}\right)-\mathrm{O}-\mathrm{Si}\left(\mathrm{H}_{2}\right)\right]-$ and allowed all other atoms of these complexes to move to their equilibrium positions. The TS search looked for stationary saddle points on each of the reaction paths and involved vibrational frequency analysis, including the calculation of the imaginary mode associated with saddle point crossings and group transfers from one adsorbed reactant to another. Such saddle points and imaginary frequencies were found for all three pathways. Those for the DME synthesis, (I) $\rightarrow$ (II), and the MIBE synthesis, (III) $\rightarrow$ (IV), were determined more easily, primarily due to successful TS calculations on earlier smaller models [9]. For reactions (VII)-(XII) we have also calculated the kinetic isotope effects (KIE) on changes of the imaginary frequencies at the TS and enthalpy barriers due to deuterium substitutions for specific hydrogens of the reacting i-PrOH and the catalyst.

\section{Results and Discussion}

\subsection{Catalyst Properties.}

The dry, white SBA catalyst as prepared had all thiol groups oxidized to pendant propylsulfonic acid groups, as demonstrated by XPS with only a single S2p BE peak at 169 $\mathrm{eV}$. Aqueous titration yielded an acid exchange capacity of 1.35 mequiv $\mathrm{H}^{+} / \mathrm{g}$ of catalyst, compared with 1.0 mequiv $\mathrm{H}^{+} / \mathrm{g}$ observed for the highly ordered SBA-15 catalyst [5]. The BET surface area was $753 \mathrm{~m}^{2} / \mathrm{g}$. The small angle XRD pattern exhibited no distinguishable peaks down to $2 \theta=0.5^{\circ}$. However, the $\mathrm{N}_{2}$ adsorption isotherm exhibited an inflection at $\mathrm{P} / \mathrm{P}_{\mathrm{o}}$ of about 0.65 , and the pore size distribution analysis showed a broad pore diameter distribution centered in the range of 3-7 $\mathrm{nm}$.

TEM micrographs taken at magnifications of 100,000-300,000 of different groups of particles exhibited pore center-to-pore center dimension of the mesopores in the range of 8.5$15.5 \mathrm{~nm}$. Hence the open pore diameter was approximately equal to the pore wall thickness. Previously, it was observed that the pore center-to-pore center dimension of $\approx 11 \mathrm{~nm}$ of wellordered SBA-15 was much more uniform and yielded a very narrow size distribution of pores of 7.0-7.5 nm [5]. An example of the present defective SBA is shown in Figure 1. 


\subsection{Catalytic Activity, Selectivity, Primary and Secondary Products.}

3.2.1. Activity with $\mathrm{MeOH} / \mathbf{i}-\mathrm{BuOH}=2 / 1$ Reactant. The present catalyst exhibited high activity for the coupling and dehydration reactions with $\mathrm{MeOH} / \mathrm{i}-\mathrm{BuOH}$ at $2.17 \mathrm{MPa}$ and GHSV $=4900 \mathrm{l} / \mathrm{kg}$ catal $/ \mathrm{hr}$, e.g. at $386 \mathrm{~K}$ the space time yields (STY) of MIBE and DME were 0.1018 and $0.0473 \mathrm{~mol} / \mathrm{kg}$ catal $/ \mathrm{hr}$, respectively (with IB not detected). Increasing the temperature to $403 \mathrm{~K}$ increased the STYs of MIBE, DME, and IB to $0.3800,0.2462$, and $0.1209 \mathrm{~mol} / \mathrm{kg} \mathrm{catal} / \mathrm{hr}$, respectively. In comparison, the highly ordered SBA-15 catalyst at $386 \mathrm{~K}$ gave STYs of MIBE and DME of 0.055 and $0.023 \mathrm{~mol} / \mathrm{kg}$ catal $/ \mathrm{hr}$, respectively (no IB detected), while at 404K the MIBE, DME, and IB STYs were 0.200, 0.079, and 0.034 $\mathrm{mol} / \mathrm{kg}$ catal $/ \mathrm{h}$, respectively [5]. Thus, the defective SBA catalyst was almost twice as active as the highly ordered SBA- 15 catalyst. If one considers the $35 \%$ higher proton concentration and dual-site mechanism of the reaction, a crude estimate of the rate increase gives $1.35^{2}=$ 1.82 , almost doubled rate, consistent with the observation.

3.2.2. Pressure Dependence. As in all alcohol dehydrocondensations accompanied by dehydration of the $\mathrm{C}_{2}{ }^{+}$alcohol to an olefin, reaction pressure has a dramatic effect on the selectivity, which had been quantitatively described by competitive dual-site kinetics of the $\mathrm{S}_{\mathrm{N}} 2$ reaction for ethers and $\mathrm{E} 2$ reaction for olefins [1-5]. In the present work, reactant composition $\mathrm{MeOH} / \mathrm{i}-\mathrm{PrOH}=2 / 1$ was investigated. After heating the SBA catalyst to $387 \mathrm{~K}$ in flowing $\mathrm{N}_{2}$ at $2.17 \mathrm{MPa}$ total pressure, injection of the alcohol mixture was initiated and the reactant flow rates were adjusted to $\mathrm{MeOH} / \mathrm{i}-\mathrm{PrOH} / \mathrm{N}_{2}=10.4 / 5.2 / 184 \mathrm{~mol} / \mathrm{kg}$ catal $/ \mathrm{hr}$, corresponding to GHSV $\approx 49001 / \mathrm{kg}$ catal $/ \mathrm{h}$. The total reactor pressure was then decreased sequentially over a period of 10 days, during which the partial pressures of both alcohols decreased proportionally. The rates of formation of the products are shown in Figure 2, demonstrating again the strong suppression at high pressures of the E2 reaction for the olefin, here propene, due to blocking of the acceptor sites for the dehydration product - adsorbed water.

3.2.3. Contact Time Dependence. Contact time (or the reciprocal flow rate) dependence has been used (a) to determine the range of the differential reactor regime and (b) to identify the primary and secondary products. The contact time of the reaction with $\mathrm{MeOH} / \mathrm{i}-\mathrm{PrOH} / \mathrm{N}_{2}=2 / 1 / 35$ mixture was varied over the catalyst at 0.1 and $2.17 \mathrm{MPa}$ while maintaining a constant reactant ratio and the temperature at $387 \pm 1^{\circ} \mathrm{C}$. The reactant conversions are given in Table 1, and linear dependences of conversion on reciprocal flow rate were observed within the range employed. At both reaction pressures studied, short contact times favor the formation of ethers, while long residence times promote the formation of the olefin from i-PrOH. The graph of product selectivities, given in Figure 3 for 2.17 $\mathrm{MPa}$, indicates that MIPE, DIPE, and PE are formed as primary products from i-PrOH. Because DIPE is a primary product and propene (PE) a secondary product, the mechanistic implication is that DIPE is formed directly from two i-PrOH molecules, not as a reaction between $\mathrm{i}-\mathrm{PrOH}$ and propene. At higher contact times, the primary product MIPE decomposes to give rise to increased amount of the secondary PE. 


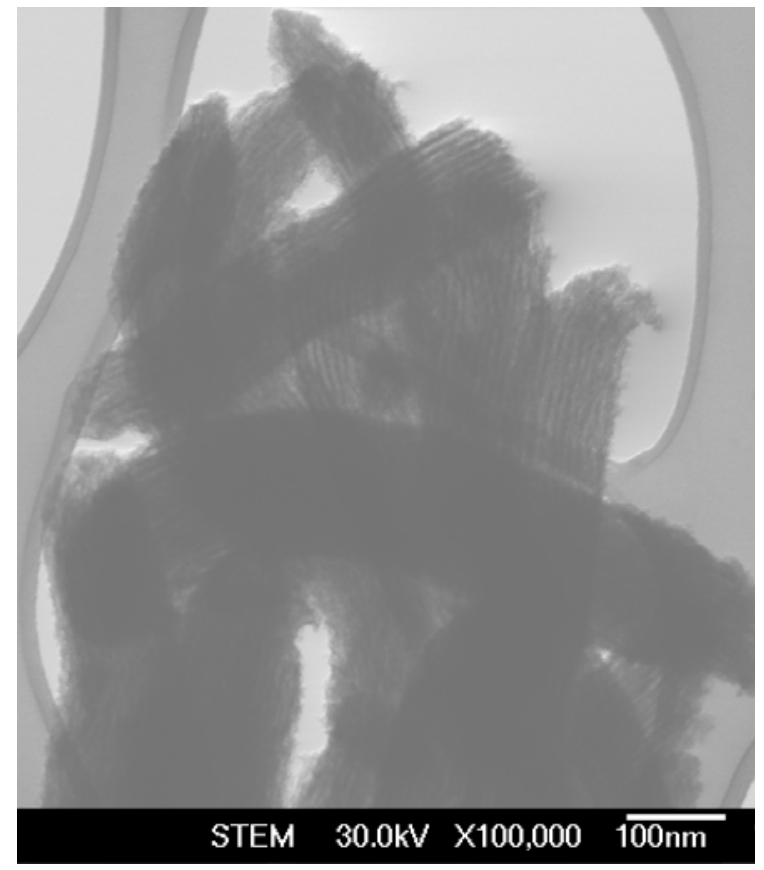

Figure 1. A cluster of defective SBA particles. These particles have pore diameters of about $10 \mathrm{~nm}$, and the particles tend to be $500-1000 \mathrm{~nm}$ in length, appreciably shorter than particles of wellordered SBA-15 [5].

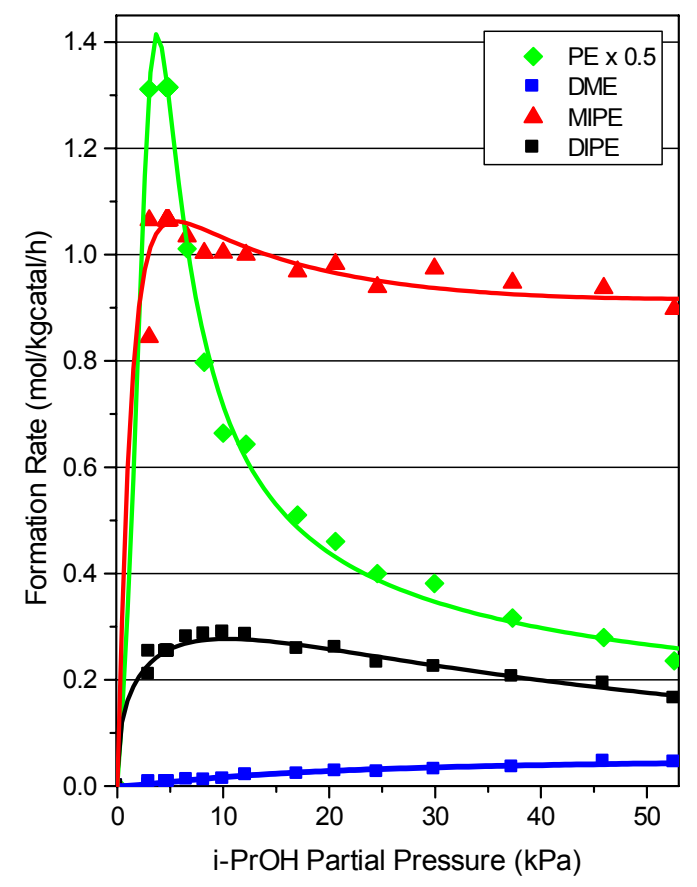

Figure 2. Rates of formation of PE, DME, MIPE, and DIPE in the reaction of $\mathrm{MeOH} / \mathrm{i}-\mathrm{PrOH}(2 / 1$ molar ratio) over the SBA catalyst at $387 \mathrm{~K}$ as a function of $i-$ $\mathrm{PrOH}$ partial pressure.

Table 1. Conversion of $\mathrm{MeOH}$ and $\mathrm{i}-\mathrm{PrOH}$ as a function of $\mathrm{GHSV}$ at $387^{\circ} \mathrm{C}$ over SBA catalyst.

\begin{tabular}{ccccc}
\hline GHSV & \multicolumn{2}{c}{ Conversion at $0.1 \mathrm{MPa}$} & \multicolumn{2}{c}{ Conversion at $2.17 \mathrm{MPa}$} \\
$(1 / \mathrm{kg} \mathrm{catal} / \mathrm{h})$ & $\mathrm{MeOH}$ & $\mathrm{i}-\mathrm{PrOH}$ & $\mathrm{MeOH}$ & i-PrOH \\
\hline 2450 & - & - & 18.53 & 55.86 \\
4900 & 8.24 & 71.18 & 11.21 & 30.38 \\
7350 & 5.84 & 43.35 & 8.18 & 22.19 \\
9800 & 5.23 & 38.80 & 7.31 & 20.31 \\
12250 & 4.03 & 25.15 & - & - \\
14700 & 4.03 & 25.58 & 5.47 & 14.82 \\
\hline
\end{tabular}




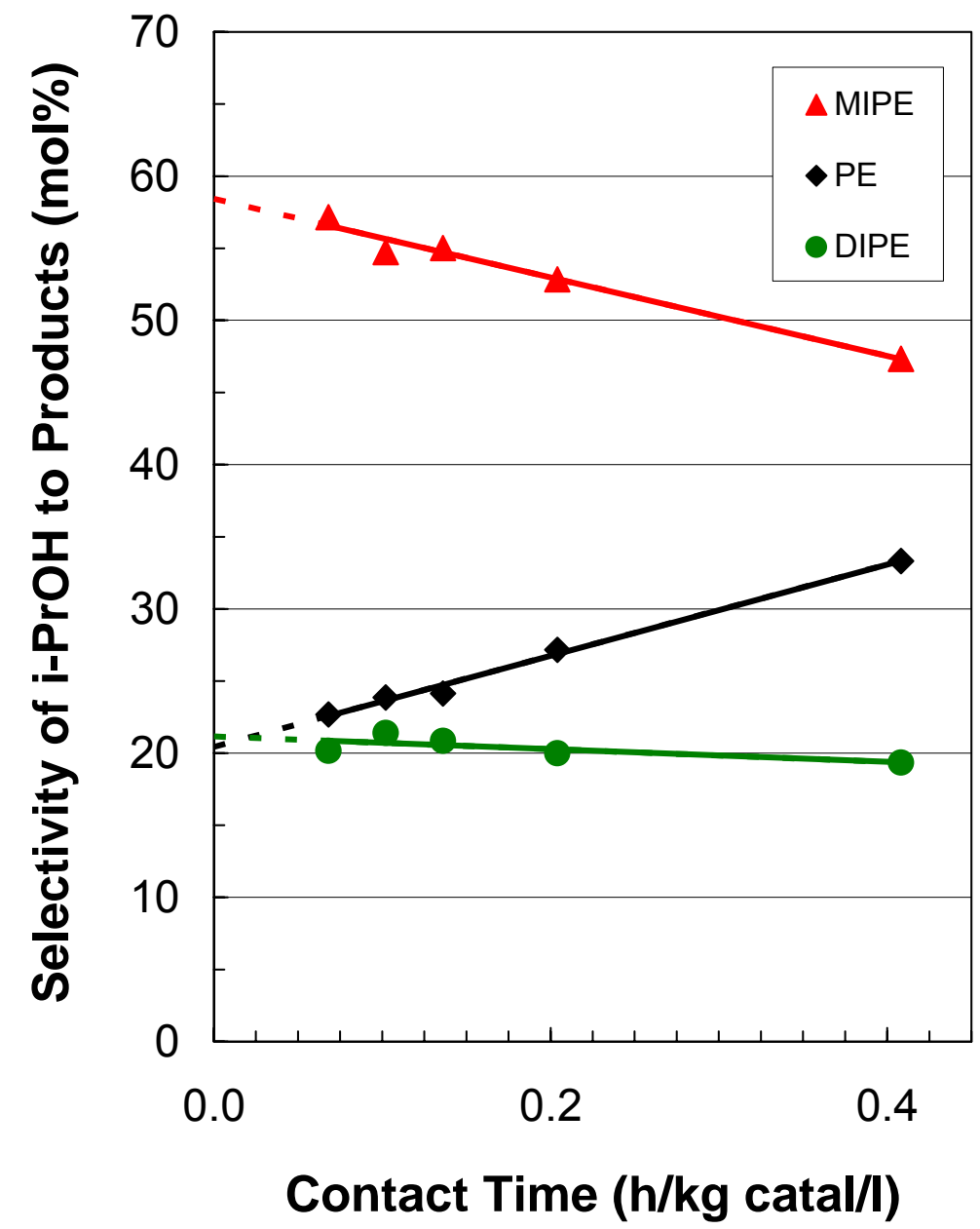

Figure 3. Selectivity of i-PrOH conversion to the MIPE, PE, and DIPE products formed from $\mathrm{MeOH} / \mathrm{i}-\mathrm{PrOH}=2 / 1$ as a function of contact time at $114^{\circ} \mathrm{C}$ and $2.17 \mathrm{MPa}$.

The DME selectivity decreased slightly with increasing temperature, while the MIBE selectivity decreased more significantly as that of IB increased. Arrhenius plots of the rate data showed that the apparent activation energy for i-PrOH dehydration to form the olefin PE was approximately twice as high as for the synthesis of the ethers under these reaction conditions (Table 2). Under these conditions, the lowest activation energy was for the formation of DIPE, where its formation would be greatly enhanced if the $\mathrm{MeOH}$ concentration, and $\mathrm{MeOH} / \mathrm{i}-\mathrm{PrOH}$ reactant ratio, were reduced.

\subsection{Modeling and Analysis of the Catalytic Chemistry.}

The activation barriers have been calculated for the reaction pathways in these systems, and DFT calculations located all the TS involved, except for the TS for i-PrOH + 
PE coupling that could not be located. For alcohol dehydration to form olefins, adsorption on the acid site is via the alcohol oxygen. The theory includes the determination of imaginary vibrational frequencies associated with the passage of the reacting groups through the TS and assessment of isotope effects due to labeling of the critical part of the molecule by deuterium. These results are summarized in Table 2.

Table 2. Activities, barriers, isotope effects, and frequencies of $\mathrm{MeOH}+\mathrm{i}-\mathrm{BuOH}$ and $\mathrm{MeOH}+\mathrm{i}-\mathrm{PrOH}$ reactions.

\begin{tabular}{|c|c|c|c|c|c|}
\hline Reaction & Product & $\begin{array}{c}\mathrm{E}_{\mathrm{a}}(\mathrm{expt}), \\
\mathrm{kJ} / \mathrm{mol}\end{array}$ & $\begin{array}{c}\mathrm{E}_{\mathrm{a}} \text { (theor), } \\
\mathrm{kJ} / \mathrm{mol}\end{array}$ & $\begin{array}{c}\text { Kinetic } \\
\text { isotope effect }^{\mathrm{a}}\end{array}$ & $\begin{array}{l}\operatorname{Im}(v) \\
\text { at } \mathrm{TS}, \mathrm{cm}^{-1}\end{array}$ \\
\hline $\begin{array}{r}\mathrm{MeOH}+ \\
\text { i-BuOH }\end{array}$ & MIBE & 89 [5] & 83.1 & $\begin{array}{c}0.999 \\
\left(\mathrm{CH}_{3} \rightarrow \mathrm{CD}_{3}\right)\end{array}$ & $\begin{array}{c}394.8 \\
(394.6)\end{array}$ \\
\hline $\begin{array}{c}\mathrm{MeOH}+ \\
\mathrm{MeOH}\end{array}$ & DME & $\begin{array}{c}102[5] \\
88.3 \pm 12.3^{\mathrm{b}}\end{array}$ & 72.7 & $\begin{array}{c}0.999 \\
\left(\mathrm{CH}_{3} \rightarrow \mathrm{CD}_{3}\right)\end{array}$ & $\begin{array}{c}394.4 \\
(394.3)\end{array}$ \\
\hline i-BuOH & IB & 218 [5] & 148.8 & $\begin{array}{c}0.782 \\
(H \rightarrow D)\end{array}$ & $\begin{array}{c}700.8 \\
(548.3)\end{array}$ \\
\hline $\begin{array}{c}\mathrm{MeOH}+ \\
\mathrm{i}-\mathrm{PrOH}\end{array}$ & MIPE & $71.9 \pm 5.7$ & 65.5 & $\begin{array}{c}0.999 \\
\left(\mathrm{CH}_{3} \rightarrow \mathrm{CD}_{3}\right)\end{array}$ & $\begin{array}{c}387.4 \\
(387.1)\end{array}$ \\
\hline $\begin{array}{c}\mathrm{i}-\mathrm{PrOH}+ \\
\text { i-PrOH }\end{array}$ & DIPE & $67.2 \pm 7.2$ & 95.4 & See Table 3 & See Table 3 \\
\hline i-PrOH & $\mathrm{PE}$ & $143.8 \pm 9.9$ & 137.1 & $\begin{array}{c}0.879 \\
(H \rightarrow D)\end{array}$ & $\begin{array}{c}487.4 \\
(428.3)\end{array}$ \\
\hline
\end{tabular}

${ }^{a}$ From the ratio of vibrational frequencies of deuterated and protonated transfer group in parentheses

${ }^{b}$ From the $\mathrm{MeOH}+\mathrm{i}-\mathrm{PrOH}$ experiment

The agreement between theory and experiment is satisfactory, particularly in showing high barriers for the olefin formation compared to those for the unsymmetrical ethers (by 66$129 \mathrm{~kJ} / \mathrm{mol}$ for isobutene from isobutanol and $71-72 \mathrm{~kJ} / \mathrm{mol}$ for propene from isopropanol). Furthermore, the relatively low barrier for DIPE $(67 \mathrm{~kJ} / \mathrm{mol}$ expt and $95 \mathrm{~kJ} / \mathrm{mol}$ theor), together with this ether being a primary product, indicates a new mechanism for the direct dehydrocondensation of two i-PrOH molecules.

Therefore, a new path toward DIPE has been explored in addition to the mechanisms I-III proposed in the literature [7], which involves the dual-site $\mathrm{S}_{\mathrm{N}} 2$ direct coupling of two i$\mathrm{PrOH}$ molecules. The theoretical activation barrier of $95 \mathrm{~kJ} / \mathrm{mol}$ is higher than the experimental effective activation energy of $67 \mathrm{~kJ} / \mathrm{mol}$, but it is low enough to enable the mechanism that is depicted in Figure 4. 

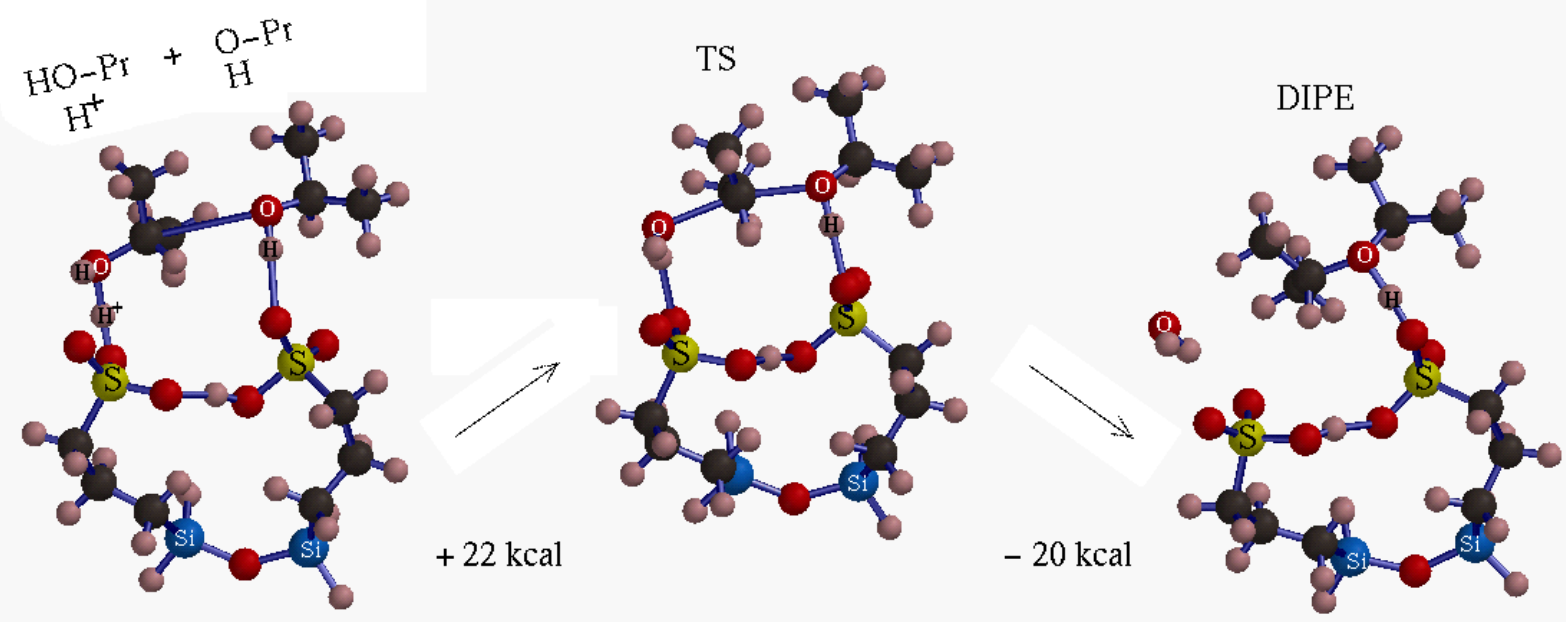

Figure 4. The optimized configuration of two adsorbed i-PrOH molecules (left), along with the reaction transition state (TS) in the middle and the adsorbed products DIPE and $\mathrm{H}_{2} \mathrm{O}$ on the right.

Computational modeling has also been carried out to predict the kinetic isotope effects (KIE) on DIPE synthesis upon substitution of designated hydrogens by deuterium atoms. The calculated KIEs gleaned from Table 3 yield the following simple predictions, all for the reaction temperature $387 \mathrm{~K}$ : (i) perdeuteration of the isopropyl groups results in negligibly small KIE for the reaction to DIPE. This relates to the $\mathrm{S}_{\mathrm{N}} 2$ mechanism in which the TS involves concerted breaking of one $\mathrm{O}-\mathrm{C}$ bond in the reactant alcohol and making of a $\mathrm{C}-\mathrm{O}$ bond in the ether DIPE; (ii) perdeuteration of the catalyst's protons results in $c a .8 \%$ negative KIE for DIPE; (iii) perdeuteration of the catalyst's and the alcohol's OH groups results in ca. $16 \%$ negative KIE for DIPE; (iv) deuteration of the secondary $\mathrm{CH}$ group in i-PrOH results in ca. $77 \%$ negative KIE for dehydration to propene, and (v) perdeuteration of the isopropyl group results in $81 \%$ negative KIE for dehydration to propene, by far the largest KIE. As result, selectivity to propene with respect to DIPE is expected to drop by a factor of 4 upon deuterium substitution of the secondary $\mathrm{CH}$ and of 5 upon perdeuteration of the propyl group in the reacting i-PrOH. The origin of the KIEs (iv) and (v) stems primarily from the zeropoint vibrational energy differences between the $\left(\mathrm{CH}_{3}\right)_{2} \mathrm{CHOH}$ and $\left(\mathrm{CH}_{3}\right)_{2} \mathrm{CDOH}$ or $\left(\mathrm{CD}_{3}\right)_{2} \mathrm{CHOH}$ and $\left(\mathrm{CD}_{3}\right)_{2} \mathrm{CDOH}$ species, respectively. These larger KIEs are observable and would constitute additional evidence for the nature of the dual site TS in both the etherforming and dehydration acid-catalyzed reactions. 
Table 3. Kinetic isotope effects in the dual SBA-acid site catalyzed $\mathrm{S}_{\mathrm{N}} 2$ reaction 2 i-PrOH $\rightarrow$ DIPE $+\mathrm{H}_{2} \mathrm{O}$ and dehydration of i-PrOH to propene.

\begin{tabular}{|c|c|c|c|c|c|c|c|c|}
\hline Reaction & Product & $\begin{array}{c}\mathrm{E}_{\mathrm{a}}(\operatorname{expt}) \\
\mathrm{kJ} / \mathrm{mol}\end{array}$ & $\begin{array}{c}{ }^{\mathrm{a}} \mathrm{E}_{\mathrm{a}}(\text { theor }) \\
\mathrm{kJ} / \mathrm{mol}\end{array}$ & $\begin{array}{c}\operatorname{Im}(v) \\
\text { at TS, } \\
\mathrm{cm}^{-1}\end{array}$ & $\begin{array}{c}{ }^{\mathrm{b}} \Delta \mathrm{H}^{\ddagger}, \\
\mathrm{kJ} / \mathrm{mol} \\
\text { at } \\
387 \mathrm{~K}\end{array}$ & $\begin{array}{l}{ }^{c} \text { Kinetic } \\
\text { isotope } \\
\text { effect - } \\
\text { frequenc } \\
\text { y }\end{array}$ & $\begin{array}{c}{ }^{\mathrm{d}} \text { Kinetic } \\
\text { isotope } \\
\text { effect - } \\
\text { enthalp } \\
\text { y }\end{array}$ & $\begin{array}{l}{ }^{\mathrm{e}} \text { Kinetic } \\
\text { isotope } \\
\text { effect - } \\
\text { overall }\end{array}$ \\
\hline $\begin{array}{l}\mathrm{i}-\mathrm{PrOH}+ \\
\mathrm{i}-\mathrm{PrOH}+ \\
2\left(\mathrm{SO}_{3} \mathrm{H}\right)\end{array}$ & DIPE & $67.2 \pm 7.2$ & 95.4 & 311.5 & 0.000 & 1.000 & 1.000 & 1.000 \\
\hline $\begin{array}{l}\mathrm{i}-\mathrm{PrOH}+ \\
\mathrm{i}-\mathrm{PrOD}+ \\
2\left(\mathrm{SO}_{3} \mathrm{H}\right)\end{array}$ & DIPE & $67.2 \pm 7.2$ & 95.4 & 310.7 & -0.025 & 0.997 & 1.008 & 1.005 \\
\hline $\begin{array}{l}\mathrm{i}-\mathrm{PrOH}+ \\
\mathrm{i}-\mathrm{PrOH}+ \\
2\left(\mathrm{SO}_{3} \mathrm{D}\right)\end{array}$ & DIPE & $67.2 \pm 7.2$ & 95.4 & 308.5 & 0.238 & 0.990 & 0.929 & 0.919 \\
\hline $\begin{array}{l}\mathrm{i}-\mathrm{PrOD}+ \\
\mathrm{i}-\mathrm{PrOD}+ \\
2\left(\mathrm{SO}_{3} \mathrm{D}\right)\end{array}$ & DIPE & $67.2 \pm 7.2$ & 95.4 & 305.5 & 0.506 & 0.981 & 0.854 & 0.838 \\
\hline $\begin{array}{l}\mathrm{i}-\mathrm{d} 7- \\
\mathrm{PrOH}+ \\
\mathrm{i}-\mathrm{d} 7- \\
\mathrm{PrOH}+ \\
2\left(\mathrm{SO}_{3} \mathrm{H}\right)\end{array}$ & DIPE & $67.2 \pm 7.2$ & 95.4 & 302.2 & -0.154 & 0.970 & 1.049 & 1.017 \\
\hline $\begin{array}{l}\mathrm{i}-\mathrm{PrOH}+ \\
2\left(\mathrm{SO}_{3} \mathrm{H}\right)\end{array}$ & $\begin{array}{l}\text { Propene } \\
+ \text { water }\end{array}$ & $143.8 \pm 9.9$ & 137.1 & 487.4 & 0.000 & 1.000 & 1.000 & 1.000 \\
\hline $\begin{array}{l}\text { i-CD- } \\
\mathrm{PrOH}+ \\
2\left(\mathrm{SO}_{3} \mathrm{H}\right)\end{array}$ & $\begin{array}{l}\text { Propene } \\
+ \text { water }\end{array}$ & $143.8 \pm 9.9$ & 137.1 & 428.3 & 4.372 & 0.879 & 0.257 & 0.226 \\
\hline $\begin{array}{l}\mathrm{i}-\mathrm{d} 7- \\
\mathrm{PrOH}+ \\
2\left(\mathrm{SO}_{3} \mathrm{H}\right)\end{array}$ & $\begin{array}{l}\text { Propene } \\
+ \text { water }\end{array}$ & $143.8 \pm 9.9$ & 137.1 & 409.4 & 4.707 & 0.840 & 0.232 & 0.194 \\
\hline
\end{tabular}

${ }^{a}$ Internal energy difference between the TS and GS of reactants adsorbed on the dual sulfonic sites, calculated by the all-electron DFT method (cf. 2.4 Computational Modeling and Analysis). An example of TS structure is in Figure 5.

${ }^{\mathrm{b}}$ Vibrational enthalpy difference between the TS and GS calculated from vibrational frequencies as $H=\Sigma_{\mathrm{i}}\left(\mathrm{h} v_{\mathrm{i}} / 2\right)\left[1+\exp \left(-\mathrm{h} v_{\mathrm{i}} / \mathrm{kT}\right] /\left[1-\exp \left(-\mathrm{h} v_{\mathrm{i}} / \mathrm{kT}\right)\right]\right.$, where $\Delta \mathrm{H}^{\ddagger}=[\mathrm{H}(\mathrm{TS})-\mathrm{H}(\mathrm{GS})](\mathrm{D}$-substituted) [H(TS)- H(GS)](unsubstituted).

${ }^{\mathrm{c}} \operatorname{Im}(v)(\mathrm{D}$-substituted TS)/Im(v)(unsubstituted TS).

${ }^{\mathrm{d}} \operatorname{Exp}\left(-\Delta \mathrm{H}^{\ddagger} / \mathrm{kT}\right)$, where $\Delta \mathrm{H}^{\ddagger}$ is from column 6 .

${ }^{\mathrm{e}}$ Product of the Kinetic Isotope Effects from frequencies and enthalpies, columns 7 and 8. 


\section{References for Chapter V}

1. Nunan, J.; Klier, K.; Herman, R. G., J. Chem. Soc., Chem. Commun. (1985) 676 and J. Catal., 139 (1993) 406. Feeley, O. C.; Sun, Q.; Herman, R. G.; Johansson, M.; Lietti, L.; Klier, K., Catal. Letters 35 (1995) 13. Lietti, L.; Sun, Q.; Herman, R. G.; Klier, K., Catal Today 27 (1996) 151.

2. Klier, K.; Kwon, H.-H.; Herman, R.G;. Hunsicker, R. A.; Ma, Q.; Bollinger, S. J., Stud. Surf. Sci. Catal. 130 (2000) 3447. Shen, J. G. C.; Kalantar, T. H.; Ma, Q.; Herman, R. G.; Klier, K., J. Chem. Soc., Chem. Commun. (2001) 653. Shen, J. G. C.; Kalantar, T. H.; Herman, R. G.; Roberts, J. E.; Klier, K., Chem. Mater. 13 (2001) 4479.

3. Sun, Q.; Herman, R. G.; Klier, K., J. Chem. Soc., Chem. Commun. (1995) 1849.

4. Shen, J. G. C.; Herman, R. G.; Klier, K., J. Phys. Chem. B 106 (2002) 9975.

5. Herman, R. G.; Khouri, F. H.; Klier, K.; Higgins, J. B.; Galler, M.R.; Terenna,C. R., J. Catal. 228 (2004) 347.

6. Smith, J. L.; Herman, R. G.; Terenna, C. R.; Galler, M. R.; Klier, K., J. Phys.Chem. A $108(2004) 39$.

7. Heese, F. P.; Dry, M. E.; Möller, K. P., Catal. Today 49 (1999) 32 and In $12^{\text {th }}$ Int. Congr. Catal., (Studies in Surface Science and Catalysis, Vol. 130D) (2000) 259.

8. Margolese, D.; Melero, J. A.; Christiansen, S. C.; Chmelka, B. F.; Stucky, G. D., Chem. Mater. 12 (2000) 2448.

9. Klier, K.; Kwon, H.-H.; Herman, R.G.; Hunsicker, R. A.; Ma, Q.; Bollinger, S. J., In $12^{\text {th }}$ Int. Congr. Catal., (Studies in Surface Science and Catalysis, Vol. 130D) (2000) 3447.

10. Specific functionals are: Becke88: Becke, A. D., Phys. Rev. A 38 (1988) 3098; PZ81: Perdew, J. P.; Zunger, A., Phys. Rev. B 23 (1981) 5048; Perdew 86: Perdew, J. P., Phys. Rev. B 33 (1986) 8822 and Phys. Rev. B 34 (1986) 7406 (erratum). 


\section{Chapter VI. Ion Exchange, Core-Level Shifts, and Bond Strengths in Mesoporous Solid Acid SBA-15}

\section{Introduction}

As previously discussed, SBA-15 is a high surface area mesoporous thermostable solid acid with high proton concentration associated with propylsulfonic groups anchored on the silica walls of the porous structure [1,2]. We investigated the dehydrocondensation of alcohols to unsymmetrical ethers catalyzed by this material [2], which requires a high surface concentration of the $-\mathrm{SO}_{3} \mathrm{H}$ sites since the mechanism is a dual site process, as indicated by kinetic analysis [2-5].

We have employed high resolution X-ray photoelectron spectroscopy (HR-XPS) to gain information in regard to the nature, strength, and concentration of acid sites on surfaces of solid catalysts. In particular, XPS can (a) identify the source of proton donors and acceptors from core level shifts [4,6,7], (b) distinguish between Brønsted and Lewis acid sites [4,7], (c) provide a quantitative analysis of specific surface species involved in acid-base interactions [4,6-8], and (d) distinguish between metal ions in cationic exchange sites and substitutional support framework locations [9].

Even though XPS probes a region within the escape depth of the photoelectrons, it provides compositional data close to those of the bulk in materials with large void volume and uniform elemental composition. This has been documented for framework and cationexchanged zinc faujasite (dry density $\sim 1.4 \mathrm{~g} / \mathrm{ml}$ ), where XPS and bulk chemical analyses and stoichiometric equivalences agreed to within relative 15\% [9], using sensitivity factors that include ionizations cross sections and instrumental response. The present SBA material has a comparable density $(1.3-1.5 \mathrm{~g} / \mathrm{ml})$ and hence similar escape depth. More detailed analysis of elemental distributions and local structures can be obtained by angle-resolved XPS of flat specimens, but in powder materials with many orientations of the particles, only average data can be obtained by XPS, as in chemical analysis [10] and most spectroscopies. The experimental results are supported by the theory of core level shifts, valence bands, and strength of base bonding to acid sites in optimized geometry.

Using the highly uniform propylsulfonic acid-derivatized SBA-15, we have shown that the catalyst was stable for $>1600 \mathrm{~h}$ of testing at elevated temperatures and pressures for the dehydrocondensation of methanol and isobutanol to form methylisobutylether (MIBE) and dimethylether (DME) [11]. The acid sites could be capped in situ with a nitrogen base to inhibit the acid-catalyzed reaction. It is now of interest to investigate the incorporation of metal cations into SBA-15 that could function as centers for other catalytic reactions. In this paper, the properties of the SBA-15 catalyst are reported with respect to the exchange of the $-\mathrm{SO}_{3} \mathrm{H}$ protons with $\mathrm{NH}_{4}^{+}, \mathrm{K}^{+}, \mathrm{Co}^{2+}, \mathrm{Ni}^{2+}$, and $\mathrm{Cu}^{2+}$ cations. The XPS analysis of experimental core-level shifts (CLS) is accompanied by the theory of orbital energies in the 
surface acid-base complexes and ion-exchanged sulfonic groups.

\section{Experimental Methods}

The SBA-15 material was synthesized as described previously [6,11]. Ion exchange was performed by stirring $100 \mathrm{mg}$ of SBA- 15 in $10 \mathrm{~mL}$ of a $0.1 \mathrm{M}$ aqueous solution of the salt of a given cation for one hour at room temperature. After stirring, the reaction mixture was then vacuum filtered and washed several times with distilled water, dried in an oven at $115^{\circ} \mathrm{C}$ for $10 \mathrm{~min}$, and transferred into a vial for storage. The various cations exchanged for the sulfonic protons came from the following compounds used to make their respective $0.1 \mathrm{M}$ aqueous solutions: $\mathrm{KNO}_{3}, \mathrm{Co}\left(\mathrm{NO}_{3}\right)_{2} \cdot 6 \mathrm{H}_{2} 0, \mathrm{Ni}\left(\mathrm{NO}_{3}\right)_{2} \cdot 6 \mathrm{H}_{2} \mathrm{O}, \mathrm{Cu}\left(\mathrm{NO}_{3}\right)_{2} \cdot 2.5 \mathrm{H}_{2} \mathrm{O}$, and $\mathrm{NH}_{4} \mathrm{Cl}$. High-resolution XPS and transmission electron microscopy (TEM) were used to characterize the SBA-15 material as described earlier [6,11]. All XPS core level binding energies (BE) are referenced to the Si2p BE being $103.5 \mathrm{eV}$. Quantitative XPS analysis was performed using the ESCA analysis software from Scienta by dividing the core level peak areas by their respective "sensitivity factors": $\mathrm{N} 1 \mathrm{~s}, 1.630 ; \mathrm{K} 2 \mathrm{p}, 3.970$ (combined $2 \mathrm{p}_{3 / 2}$ and $2 \mathrm{p}_{1 / 2}$ region); $\mathrm{Co} 2 \mathrm{p}_{3 / 2}, 12.620 ; \mathrm{Ni} 2 \mathrm{p}_{3 / 2}, 14.610 ; \mathrm{Cu} 2 \mathrm{p}_{3 / 2}, 16.730 ; \mathrm{S} 2 \mathrm{p}, 1.679$ (combined 2 $\mathrm{p}_{3 / 2}$ and $2 \mathrm{p}_{1 / 2}$ region). Surface areas and XRD patterns were obtained as described elsewhere [6,11].

\section{Theoretical Method}

The models adopted to represent the single and dual propylsulfonic acid sites anchored on the silica wall of the SBA-15 material are specified by the chemical formulas

$$
\begin{array}{ll}
\mathrm{HS}-\mathrm{CH}_{2} \cdot \mathrm{CH}_{2} \cdot \mathrm{CH}_{2}-\mathrm{Si}\left(\mathrm{H}_{2}\right)-\mathrm{O}-\mathrm{Si}\left(\mathrm{H}_{2}\right)-\mathrm{CH}_{2} \cdot \mathrm{CH}_{2} \cdot \mathrm{CH}_{2}-\mathbf{S O}_{3} \boldsymbol{H} & \text { "single site" (I) } \\
\mathbf{H O} \boldsymbol{O}_{3} \boldsymbol{S}-\mathrm{CH}_{2} \cdot \mathrm{CH}_{2} \cdot \mathrm{CH}_{2}-\mathrm{Si}\left(\mathrm{H}_{2}\right)-\mathrm{O}-\mathrm{Si}\left(\mathrm{H}_{2}\right)-\mathrm{CH}_{2} \cdot \mathrm{CH}_{2} \cdot \mathrm{CH}_{2}-\mathbf{S O}_{3} \boldsymbol{H} & \text { "dual site" (II). }
\end{array}
$$

The highlighted $-\mathrm{SO}_{3} \mathrm{H}$ groups are the active sites and the $-\mathrm{SH}$ groups are inert to both ion exchange and nitrogen base adsorption, as shown by all calculations and experiment. The $\mathrm{SO}_{3} \mathrm{H}$ groups are hydrogen donors for bonding with neighboring sulfonic groups, with nitrogen bases, and are proton- and cation-exchange sites. To simulate the rigidity of the silica wall, the seven atoms of the -Si-O-Si- backbone capped by four hydrogen atoms at $\mathrm{Si}$ were kept frozen in all geometry optimizations in which all other atoms in the bare sites (I) and (II), as well as their complexes with neutral molecules or ions, were allowed to move.

The density functional theoretical (DFT) calculations [12] were performed at an allelectron, non-relativistic generalized gradient approximation (GGA) using the Becke-Perdew functional $[13,14]$ and the double-numerical basis set of Delley [15], similarly as in our earlier work on models of acid sites in fluorocarbon sulfonic acids, sulfated zirconia (SZ), tungstena-zirconia (WZ), and transition states for dehydrocondensation of alcohols to ethers $[4,16,17]$. These calculations yield total energies of the reactants, sorption bonding energies, and optimized geometries. In addition, the calculated orbital Kohn-Sham (KS) energies afford a comparison of chemical CLS with those observed in XPS. Because of the presently 
employed non-relativistic level of calculation, the core-level spin-orbit split states such as $\mathrm{S} 2 \mathrm{p}_{3 / 2}, \mathrm{~S} 2 \mathrm{p}_{1 / 2}, \mathrm{~K} 2 \mathrm{p}_{3 / 2}$, or K2 $\mathrm{p}_{1 / 2}$ are represented by the KS energies disregarding the spin-orbit interactions, i.e. as S2p and K2p. This approximation is sufficient for the correlations revealed in this work because the experimental XPS $2 p$ levels are also incompletely resolved. On the contrary, the N1s and C1s levels are not spin-orbit split in experiment or theory. The final state energies involving core-hole states have not been calculated, assuming that, although the final states contribute to absolute photoemission energies quite significantly, they will have little influence on relative positions of the core levels between similar molecular species in the presently studied closed-shell molecules.

That the present theoretical approach is sufficient for interpretation and prediction of CLS is supported by the agreement between the experimentally observed difference of the $\mathrm{S} 2 \mathrm{p}$ CLS in the $-\mathrm{SH}$ and $\mathrm{SO}_{3} \mathrm{H}$ moieties, $5.15 \mathrm{eV}$, and the presently calculated difference between the corresponding KS S2p orbitals, $5.27 \mathrm{eV}[2,6]$. In addition, the present theory correctly accounts for the simultaneous shift of N1s core levels of the nitrogen bases [6] to higher BEs and $\mathrm{S} 2 \mathrm{p}$ levels of the $-\mathrm{SO}_{3} \mathrm{H}$ groups to lower BEs upon the formation of the $\mathrm{SO}_{3} \mathrm{H}$...Nitrogen base complex [7].

\section{Results and Discussion}

\subsection{Experimental}

The synthetic route employed in the present work gave rise to a highly ordered mesoporous silica SBA- 15 with surface area of $551 \mathrm{~m}^{2} / \mathrm{g}$ and an acid exchange capacity with $\mathrm{NaCl} / \mathrm{NaOH}$ of $1.00 \mathrm{meq} \mathrm{H}^{+} / \mathrm{g}$ material. In Figure 1, a TEM micrograph is shown as an inset to the cartoon of this mesoporous material.

XRD analysis yielded a well-resolved diffraction pattern consistent with a hexagonal unit cell dimension $\left(a_{0}=2 d(100) / \sqrt{3}\right)$ of $14 \mathrm{~nm}$ with spacings $\mathrm{d}(100)=12 \mathrm{~nm}, \mathrm{~d}(110)=7$ $\mathrm{nm}$, and $\mathrm{d}(200)=6 \mathrm{~nm}$. Knowing the proton concentration of $1.00 \mathrm{meq} / \mathrm{g}$, the surface area of $551 \mathrm{~m}^{2} / \mathrm{g}$, and having calculated the silicon surface concentration to be $8.22 \mathrm{Si}$ atom $/ \mathrm{nm}^{2}$ previously [6], the molar equivalence of protons per surface silicon atom was found to be 0.133 , equivalent to 1.1 protons $/ \mathrm{nm}^{2}$. The BET surface area of the K-SBA- 15 was $490 \mathrm{~m}^{2} / \mathrm{g}$

and the total pore volume $0.62 \mathrm{~cm}^{3} / \mathrm{g}$. The sorption isotherm was of Type IV, and the rapid uptake of adsorbed nitrogen at a relative pressure $\mathrm{P} / \mathrm{Po} \sim 0.7$ indicated a narrow mesopore size distribution. The pore size distribution obtained by using the Barrett, Joyner, and Halenda method [18-20] exhibited a narrow, sharp mesopore diameter of $7.1 \mathrm{~nm}$. 


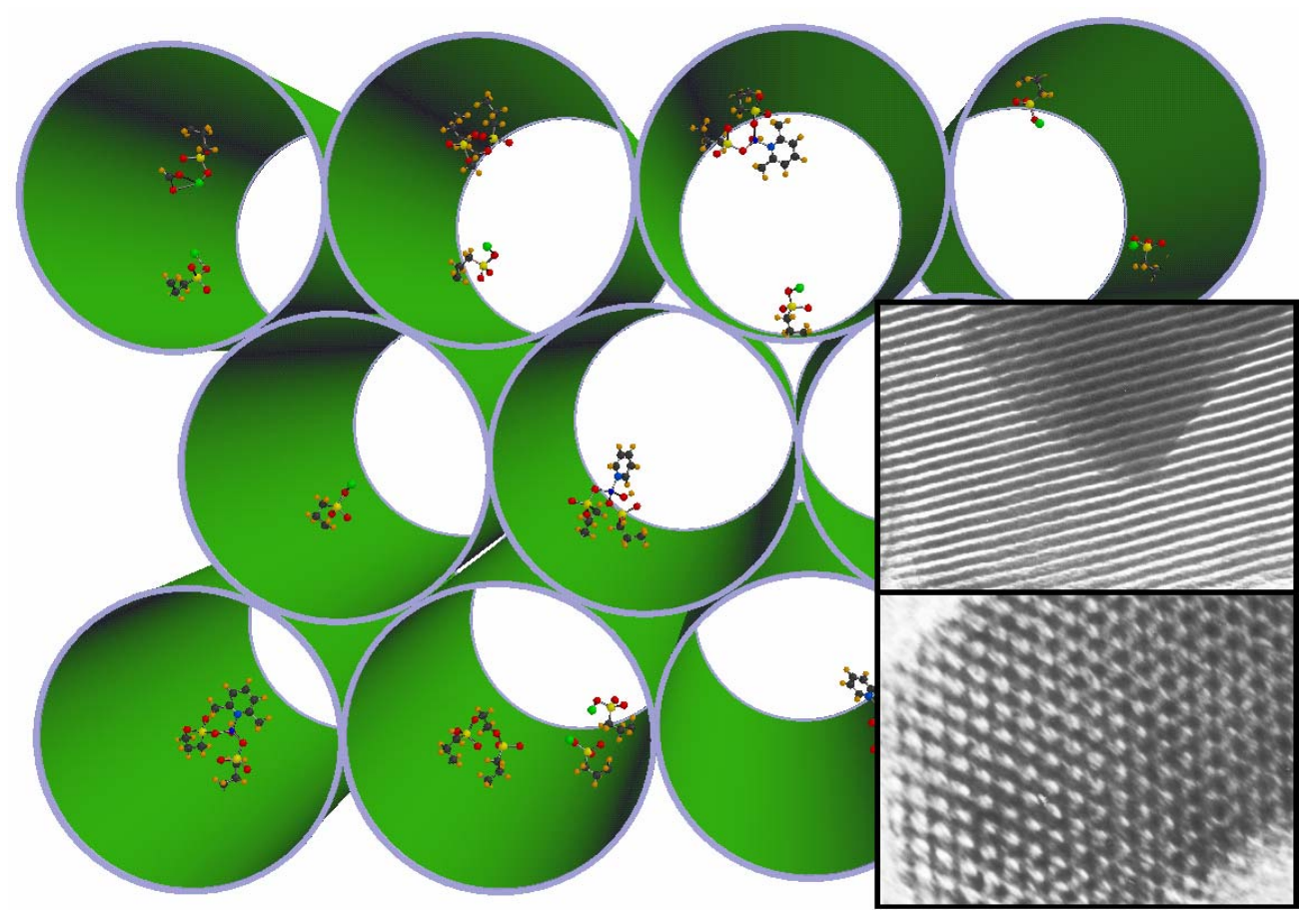

Figure 1. A cartoon of the potentially multifunctional SBA material with a TEM inset of a side (upper) and top (lower) view of the structure. Pore-to-pore distance is $14 \mathrm{~nm}$.

The XPS of the bare SBA-15 showed a single S2p peak at $169.25 \mathrm{eV}$ with full-width at half maximum $(\mathrm{FWHM})=2.63 \mathrm{eV}$ and a C1s peak at $285.00 \mathrm{eV}$ with a FWHM of 2.43 $\mathrm{eV}$, yielding a carbon to sulfur ratio $(\mathrm{C} / \mathrm{S})$ of 2.9 , close to theoretical composition of the pendant $-\left(\mathrm{CH}_{2}\right)_{3} \mathrm{SO}_{3} \mathrm{H}$ groups, $\mathrm{C} / \mathrm{S}=3.0$, free of any residual pluronic template. We previously showed that the thiol $\mathrm{S} 2 \mathrm{p}$ peak was located at a $\mathrm{BE} \approx 164 \mathrm{eV}$, while the sulfonic acid $\mathrm{S} 2 \mathrm{p}$ photoemission peak was at $\mathrm{BE} \approx 169 \mathrm{EV}[2]$. In the present preparation, only the sulfonic S2p peak at $169 \mathrm{eV}$ was observed, indicating complete oxidation of the thiol groups to sulfonic acid sites during the synthetic procedure.

XPS results from the ion-exchanged materials are shown in Table 1 . The $\mathrm{S} / \mathrm{K}$ ratio in the potassium-exchanged SBA-15 (K-SBA) was found to be 1.0 , the $\mathrm{C} / \mathrm{K}$ ratio 3.1 , and the $\mathrm{C} / \mathrm{S}$ ratio 3.0. The $\mathrm{K} 2 \mathrm{p}_{3 / 2}$ and $\mathrm{K} 2 \mathrm{p}_{1 / 2}$ peaks were found to have $\mathrm{BEs}$ of $293.75 \mathrm{eV}$ and 296.45 $\mathrm{eV}$, respectively. The $\mathrm{C} 1 \mathrm{~s}$ peak at $285.15 \mathrm{eV}$ had a tail to the higher $\mathrm{BE}$ side of the peak and a FWHM of $1.84 \mathrm{eV}$. As shown in Table 1, the S2p BE was $168.35 \mathrm{eV}$, a $0.90-\mathrm{eV}$ shift to lower BE from the S2p BE of pure SBA-15, and it has a FWHM of $2.35 \mathrm{eV}$. The cobalt(II)exchanged SBA-15 (Co-SBA), nickel(II)-exchanged SBA-15 (Ni-SBA), and copper(II)exchanged SBA-15 (Cu-SBA) materials exhibited similar properties. The Co2 $\mathrm{p}_{3 / 2}, \mathrm{Ni} 2 \mathrm{p}_{3 / 2}$, and $\mathrm{Cu} 2 \mathrm{p}_{3 / 2}$ peaks had BEs of 782.45, 875.70, and $933.55 \mathrm{eV}$, respectively. The $\mathrm{C} 1 \mathrm{~s}$ peaks were at $285.20 \pm 0.15 \mathrm{eV}$ with $\mathrm{FWHM}$ of $2.40 \pm 0.15 \mathrm{eV}$. For comparison, the $\mathrm{S} / \mathrm{N}$ ratio of the ammonium-exchanged SBA-15 $\left(\mathbf{N H}_{4^{-}} \mathbf{S B A}\right)$ was 3.5. A maximum of the $\mathrm{S} 2 \mathrm{p}$ peak was at $169.30 \mathrm{eV}$, but there was a second, overlapping peak on the lower BE side at $168.60 \mathrm{eV}-$ an 
S2p peak with a FWHM of $2.85 \mathrm{eV}$. The single N1s peak had a BE of $402.60 \mathrm{eV}$, with a FWHM of 2.45. The $\mathrm{C} 1 \mathrm{~s}$ was at $285.20 \mathrm{eV}$ with FWHM of $1.84 \mathrm{eV}$.

Table 1. XPS Stoichiometric Equivalences, Binding Energies, ${ }^{a}$ Peak Widths, and Chemical Shifts for the Ion-Exchanged SBA-15 Materials.

\begin{tabular}{|c|c|c|c|c|}
\hline \multirow{2}{*}{$\begin{array}{c}\text { Ion Exchanged } \\
\text { Species (X-SBA) }\end{array}$} & \multirow{2}{*}{ X/S Ratio } & \multicolumn{2}{|c|}{$\mathrm{S} 2 \mathrm{p}$} & \multirow{2}{*}{$\Delta \mathrm{BE}(\mathrm{eV})^{\mathrm{c}}$} \\
\hline & & $\mathrm{BE}(\mathrm{eV})$ & FWHM (eV) & \\
\hline K-SBA & 1.0 & 168.35 & 2.35 & 0.90 \\
\hline Co-SBA & 0.36 & 168.90 & 2.48 & 0.35 \\
\hline Ni-SBA & 0.29 & 169.10 & 2.85 & 0.15 \\
\hline $\mathrm{Cu}-\mathrm{SBA}$ & 0.29 & $168.90,169.35$ & 2.91 & $0.35,-0.10$ \\
\hline $\mathrm{NH}_{4}-\mathrm{SBA}$ & 0.29 & $168.60,169.30$ & 2.85 & $0.65,-0.05$ \\
\hline H-SBA & $1.0^{\mathrm{b}}$ & 169.25 & 2.63 & 0.00 \\
\hline
\end{tabular}

\subsection{Theoretical}

The optimized geometries of the bare single-site (I) and dual-site (II) assemblies revealed a weak but significant hydrogen donor-acceptor bonding between the neighboring $\mathrm{SO}_{3} \mathrm{H}$ groups of the proximal sites (II), with distances $\mathrm{SOH}^{\cdots} \mathrm{O}=\mathrm{S}$ of $0.16 \mathrm{~nm}$, while such a hydrogen bonding was absent in the single site moiety $(\mathrm{I})$, with a long $\mathrm{SOH}^{\cdots} \mathrm{O}=\mathrm{S}$ distance of $0.25 \mathrm{~nm}$ [6]. It is noted that the $-\mathrm{SO}_{3} \mathrm{H}$ groups have only slightly different theoretical $\mathrm{S} 2 \mathrm{p}$ energies in the single and the dual bare sites (Table 2), even though the latter are tied together by weak hydrogen bonds.

The model complex of ammonia with the single acid site revealed a stronger hydrogen bond between the $-\mathrm{SO}_{3} \mathrm{H}$ group and the nitrogen base in which, however, the proton of the sulfonic group was not completely transferred to the nitrogen to form an "ammonium ion". The optimized hydrogen bonding distances $-\mathrm{O}_{2} \mathrm{SO}^{\cdots} \mathrm{H}^{\cdots} \mathrm{NH}_{3}$ were $(\mathrm{O} \cdots \mathrm{H})=0.108 \mathrm{~nm}$ and $\left(\mathrm{H}^{\cdots \cdots} \mathrm{NH}_{3}\right)=0.152 \mathrm{~nm}[6]$. To simulate the ion-exchanged materials, optimized geometries of the single- and dual-site assemblies wherein protons of the $-\mathrm{SO}_{3} \mathrm{H}$ groups are replaced with potassium cations $\mathrm{K}^{+}$are shown in Figure 2 . The $\mathrm{K}^{+}$ions tend to be coordinated to more than one oxygen atom, as indicated by the K-O distances in Figure 2. 


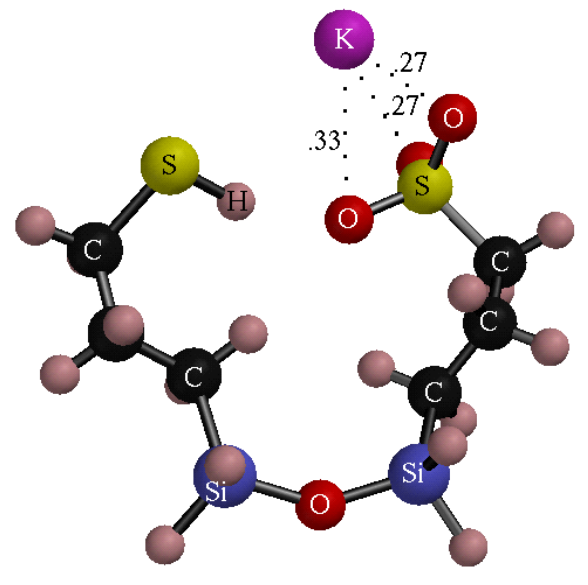

(a)

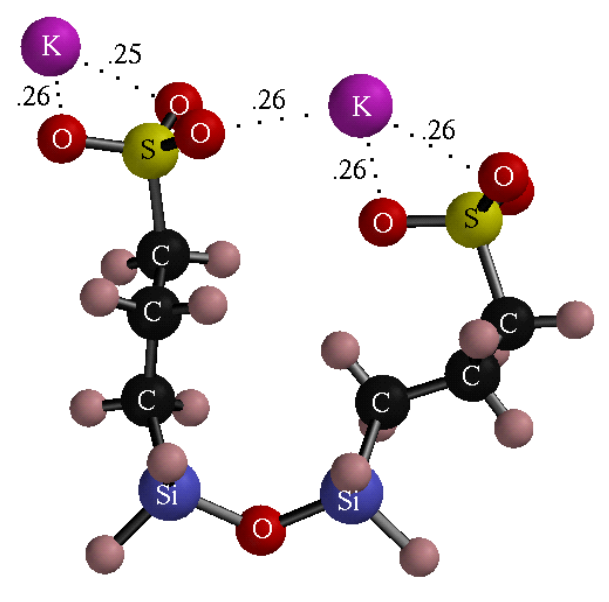

(b)

Figure 2. Models for potassium exchanged SBA material: (a) Single site with proton of the propylsulfonic group replaced by $\mathrm{K}^{+}$, (b) Dual site with protons of two neighboring propylsulfonic groups replaced by $\mathrm{K}^{+}$. Distances between the $\mathrm{K}^{+}$ions and nearest oxygens of the $-\mathrm{SO}_{3}{ }^{-}$counterions in $\mathrm{nm}$ show the multiple coordination of potassium, the nonequivalence of the two $\mathrm{K}^{+}$ions on the dual site, and the electrostatic repulsion between the two potassium cations on the dual site, as well as 'tying-up' of the proximal $-\mathrm{SO}_{3}{ }^{-}$groups of the dual site by one of the $\mathrm{K}^{+}$ions.

The calculated KS orbital energies for the ion exchange complexes on sites (I) and (II) are summarized in Table 2 and Figure 3. For comparison with experiment, only the S2p and N1s orbital energies are listed, although all the core- and valence levels have been calculated. For the $\mathrm{K}^{+}$-exchanged material, however, the calculated $\mathrm{K} 2 \mathrm{p}$ levels are also shown.

The state of hydration of all the cations, $\mathrm{K}^{+}, \mathrm{Co}^{2+}, \mathrm{Ni}^{2+}$, and $\mathrm{Cu}^{2+}$, and the protons in the present XPS analysis was unknown. For this reason, we have examined the effects of coordinated water on the CLS. In Figure 4, we show the results of calculations of the S2p CLS for $0,2,4$, and 6 water molecules coordinated to these cations. Obviously, the theory yields much greater detail than experiment, and therefore average S2p CLS are given.

The K-SBA was the only material in which $100 \%$ of the $-\mathrm{SO}_{3} \mathrm{H}$ protons were exchanged, as determined by XPS. The shift of $0.90 \mathrm{eV}$ in the experimental S2p BE, shown in Table 1, is to be compared with the theoretical orbital energy shift of $1.69 \mathrm{eV}$ for the single site and 1.20 or 2.53 for the dual site $-\mathrm{SO}_{3} \mathrm{~K}$ species (Table 2). The theoretical orbital energy shifts and experimental CLS have the same sign, although the latter are smaller by 0.3-1.6 $\mathrm{eV}$. The experimental $\mathrm{S} 2 \mathrm{p}$ line width of approximately $2.5 \mathrm{eV}$ still indicates some heterogeneity of the stoichiometric $-\mathrm{SO}_{3} \mathrm{~K}$ species, although the $\mathrm{K} 2 \mathrm{p}$ line is quite narrow and suggests that the $\mathrm{K}^{+}-\mathrm{K}^{+}$repulsion is small due to the separation of the cation-exchange sites - a repulsion interaction which is overestimated in the dual site model (Figure 3 and Table 2). 
Table 2. The KS orbital energies of $-\mathrm{SO}_{3} \mathrm{H}$ sites with exchanged ions.

\begin{tabular}{|c|c|c|c|c|c|}
\hline Site $^{a}$ & $\mathrm{BE}(\mathrm{S} 2 \mathrm{p})$ & $\mathrm{BE}(\mathrm{K} 2 \mathrm{p})$ & $\mathrm{BE}(\mathrm{N} 1 \mathrm{~s})$ & $\Delta(\mathrm{S} 2 \mathrm{p})$ & $\Delta(\mathrm{N} 1 \mathrm{~s})$ \\
\hline SingleSite. $\mathrm{SO}_{3} \mathrm{H}$ & -160.10 & -- & -- & 0.00 & -- \\
\hline SingleSite.SH & -154.83 & -- & -- & 5.27 & -- \\
\hline DualSite. $\mathrm{SO}_{3} \mathrm{H}$ & -160.29 & -- & -- & -0.19 & -- \\
\hline SingleSite. $\mathrm{K} \mathrm{SO}_{3} \mathrm{H}$ & -158.41 & -280.33 & -- & 1.69 & -- \\
\hline SingleSite.K.SH & -154.47 & -- & -- & 5.63 & -- \\
\hline DualSite. $\mathrm{K} . \mathrm{SO}_{3} \mathrm{H}$ & -157.57 & -280.62 & -- & 2.53 & -- \\
\hline DualSite. $\mathrm{K} . \mathrm{SO}_{3} \mathrm{H}$ & -158.90 & -278.73 & -- & 1.20 & -- \\
\hline SingleSite. $\mathrm{NH}_{3} \cdot \mathrm{SO}_{3} \mathrm{H}$ & -159.37 & & -382.11 & 0.73 & -1.64 \\
\hline SingleSite. $\mathrm{NH}_{3} . \mathrm{SH}$ & -154.87 & & -- & 5.23 & -- \\
\hline DualSite. $\mathrm{NH}_{3} \cdot \mathrm{SO}_{3} \mathrm{H}$ & -159.60 & & -382.46 & 0.50 & -1.99 \\
\hline DualSite. $\mathrm{NH}_{3} . \mathrm{SO}_{3} \mathrm{H}$ & -158.53 & & -381.96 & 1.57 & -1.49 \\
\hline
\end{tabular}

${ }^{a}$ The single site is modeled as $\mathbf{H O}_{3} \mathbf{S}\left(\mathrm{CH}_{2}\right)_{3}$ - $\mathrm{Si}$-O-Si- $\left(\mathrm{CH}_{2}\right)_{3} \mathrm{SH}$ and the dual as $\mathbf{H O}_{3} \mathbf{S}\left(\mathrm{CH}_{2}\right)_{3}$-Si-O$\mathrm{Si}-\left(\mathrm{CH}_{2}\right)_{3} \mathrm{SO}_{3} \mathbf{H}$. Each $\mathrm{BE}(\mathrm{S} 2 \mathrm{p})$ is averaged over the $2 \mathrm{p}_{\mathrm{x}}, 2 \mathrm{p}_{\mathrm{y}}$, and $2 \mathrm{p}_{\mathrm{z}}$ orbitals. The spread of the $2 \mathrm{p}$ orbitals due to their structural non-equivalence is shown in Fig. 3. The Si atoms are capped by $2 \mathrm{H}$ atoms each. Single and dual sites exchanged with the $\mathrm{K}^{+}$ions are obtained by replacing the protons of one or two $-\mathrm{SO}_{3} \mathrm{H}$ groups. The K2p levels of potassium are averaged the same way as the $\mathrm{S} 2 \mathrm{p}$ levels. The orbital energy chemical shifts for the "bare sites" (rows 1-3) and $\mathrm{K}^{+}$ion-exchanged species (rows 4-7) are represented as $\Delta(\mathrm{S} 2 \mathrm{p})$ referenced to the average S2p energy of the $-\mathrm{SO}_{3} \mathrm{H}$ group in the single-site model (row 1, column 5).

The XPS spectrum of $\mathrm{NH}_{4}-\mathrm{SBA}$ indicates an incomplete exchange wherein slightly less than $30 \%$ of $-\mathrm{SO}_{3} \mathrm{H}$ protons were replaced by $\mathrm{NH}_{4}{ }^{+}$, based on experimental $\mathrm{N} / \mathrm{S}=0.28$. From Table 1, the S2p peak maximum was observed at $169.30 \mathrm{eV}$, slightly higher than that of pure SBA, while there is a definite shoulder to lower BE, located at $168.60 \mathrm{eV}$. This is a broad S2p peak, indicating two distinct sulfur species: those of sulfonic acid groups exchanged with $\mathrm{NH}_{4}{ }^{+}$and the majority of bare acid sites. This observation is supported by theory: the $\mathrm{S} 2 \mathrm{p} \mathrm{CLS}$ in the $\mathrm{NH}_{4}-\mathrm{SBA}$ are represented by those in the optimized geometry of $\mathrm{NH}_{3}$ adsorbed on a single site, $-\mathrm{SO}_{3} \mathrm{HNH}_{3}$, from the bare $-\mathrm{SO}_{3} \mathrm{H}$ site (Table 2, column 5, rows 8 and 1).

Ion exchange with $\mathrm{Co}$ (II), $\mathrm{Ni}$ (II), and $\mathrm{Cu}$ (II) was incomplete (Table 1). A complete exchange of the divalent cations with the sulfonic protons would give $\mathrm{Me}(\mathrm{II}) / \mathrm{S}=0.5$, hence the SBA-15 sulfonic groups exchanged $72 \%\left(\mathrm{Co}^{2+}\right), 58 \%\left(\mathrm{Ni}^{2+}\right)$, and $58 \%\left(\mathrm{Cu}^{2+}\right)$ with the divalent metals under the ambient conditions employed. The S2p CLS were to lower BEs (Table 1), consistent with the theoretical treatment in Figure 4. 


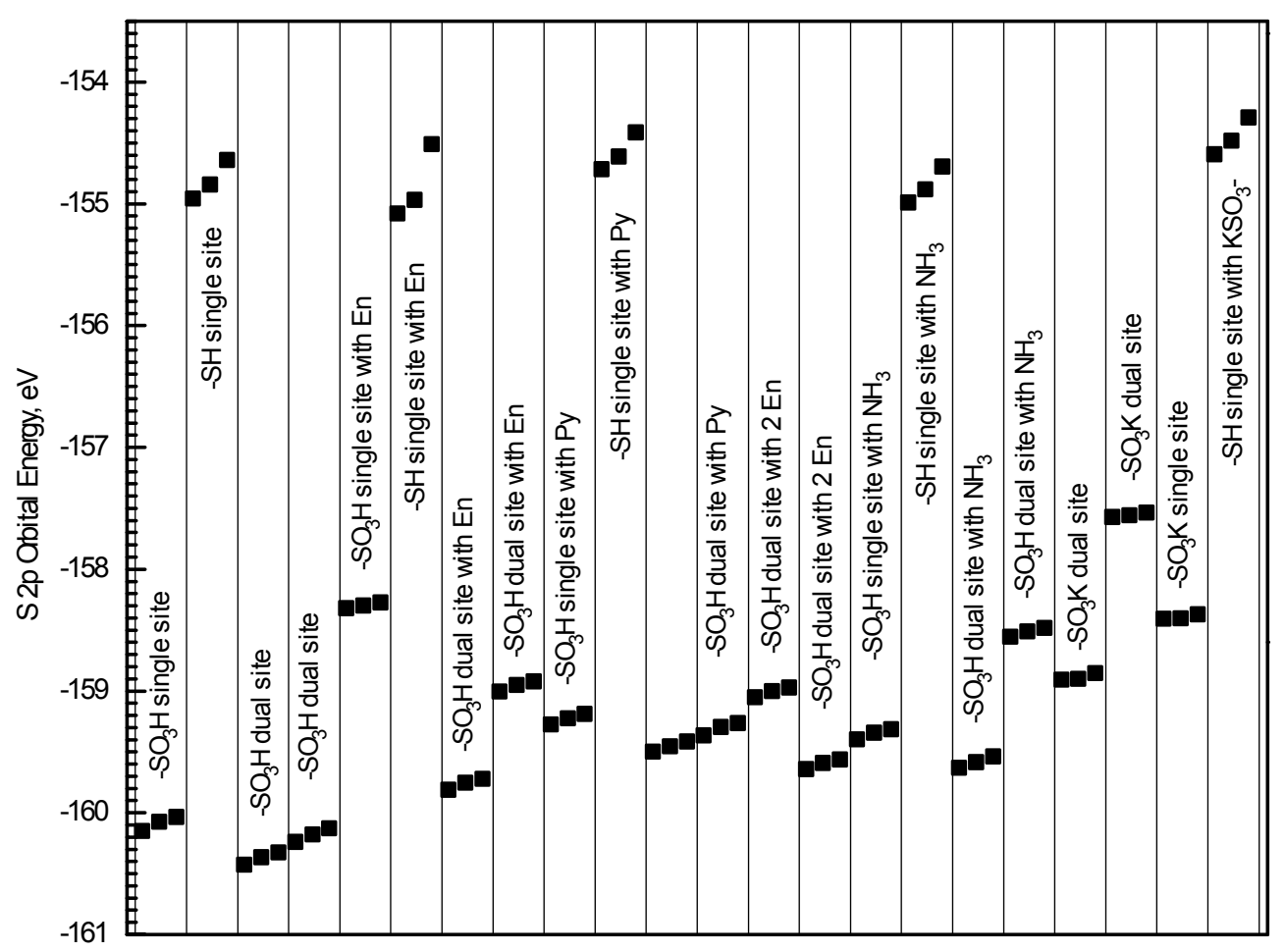

Figure 3. S2p orbital energies (DFT/GGA/BP/DN**) in the single and dual sites and protons exchanged with $\mathrm{K}^{+}$and binding as $-\mathrm{SO}_{3} \mathrm{H} \ldots \mathrm{NH}_{3}$. Each sulfur-containing species has three $S 2 p$ levels associated with the $2 p_{x}, 2 p_{y}$, and $2 p_{z}$ orbitals. Interactions with other nitrogen bases, ethylenediamine (En) and pyridine (Py) are shown for comparison.

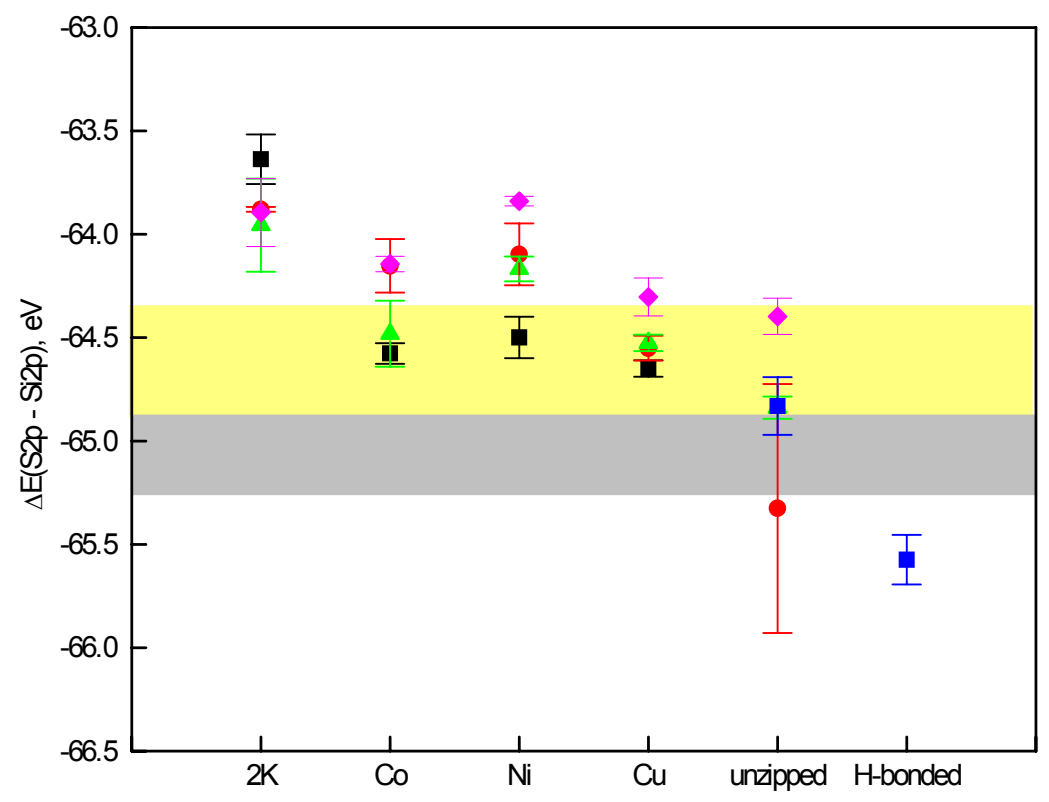

Figure 4. Average S2p core level shifts (CLS) referenced to Si2p. Number of hydration water molecules: $\boldsymbol{\square} 0, \boldsymbol{\Delta} 2,4, \bullet 6$. 


\section{Conclusions}

The mesoporous SBA-15 material affords chemical versatility due to large pores and flexible pendant proton-exchanging $-\mathrm{SO}_{3} \mathrm{H}$ functionalities. There are some differences among individual preparations in terms of pore size, concentration of ion exchanging sites, completeness of oxidation of the precursor thiol groups, and successful removal of the organic templating agent $[1,2,6,21]$. The control of these properties and design of synthetic strategy for specific applications requires a thorough characterization, which includes XPS and theory. The present study shows that all of the organic templating agent can be removed and that the sulfur moieties can be fully oxidized to accessible $\equiv \mathrm{Si}-\left(\mathrm{CH}_{2}\right)_{3} \mathrm{SO}_{3} \mathrm{H}$ groups that exchange their protons with univalent and divalent cations. XPS has identified the proton exchange sites through the S2p core-level shifts to lower BEs.

All-electron calculations (DFT/BP/DN** including non-relativistic core-levels) of the ion-exchanged complexes with the $\mathrm{HO}_{3} \mathrm{~S}\left(\mathrm{CH}_{2}\right)_{3}$ - $\mathrm{Si}-\mathrm{O}-\mathrm{Si}-\left(\mathrm{CH}_{2}\right)_{3} \mathrm{SO}_{3} \mathrm{H}$ model cluster yielded optimized geometries and the theoretical S2p orbital energy shifts in the same direction as the observed XPS binding energy shifts. Theoretical analysis of the effects of the state of hydration in the exchanged cations as $\mathrm{Me}\left[\mathrm{H}_{2} \mathrm{O}\right]_{\mathrm{n}}, \mathrm{n}=0,2,4,6$, on the CLS revealed that the low-coordinated ions were bonded more strongly to the $-\mathrm{SO}_{3}{ }^{-}$groups than to coordination $\mathrm{H}_{2} \mathrm{O}$, and $\mathrm{K}^{+}$was very weakly hydrated compared to the divalent transition ions.

The combination of theory with XPS thus permitted the linking together of the XPS CLS with energy parameters such as the bonding strength of the partially hydrated cations to single and dual sites of the pendant ion-exchanging groups in the mesoporous material, as shown earlier for oxides [8] and alkyl-sulfonic polymeric resins [7].

\section{References for Chapter VI}

1. Margolese, D.; Melero, J. A.; Christiansen, S. C.; Chmelka, B. F.; Stucky, G. D., Chem. Mater. 12 (2000) 2448.

2. Shen, J. G. C.; Herman, R. G.; Klier, K., J. Phys. Chem. B, 106 (2002) 9975.

3. Shen, J. G. C.; Kalantar, T. H.; Ma, Q.; Herman, R. G.; Klier, K., J. Chem. Soc., Chem. Commun. (2001) 653.

4. Klier, K.; Kwon, H.-H.; Herman, R.G.; Hunsicker, R. A.; Ma, Q.; Bollinger, J. S., In $12^{\text {th }}$ Intern. Congr. Catal., (Studies in Surface Science and Catalysis, 2000, Pt. D), 130D (2000) 3447.

5. Klier, K.; Sun, Q.; Feeley, O. C.; Johansson, M.; Herman, R. G., In $11^{\text {th }}$ Intern. Congr. Catal. - 40th Ann., (Studies in Surface Science and Catalysis, 1996, Pt. A), 101A (1996) 601. 
6. Smith, J. L.; Herman, R. G.; Terenna, C. R.; Galler, M. R.; Klier, K., J. Phys. Chem. A $108(2004) 39$.

7. Johansson, M.; Klier, K., Topics Catal. 4 (1997) 99.

8. Shen, J. G. C.; Kalantar, T. H.; Herman, R. G.; Roberts, J. E.; Klier, K., Chem. Mater. 13 (2001) 4479.

9. Hunsicker, R.A.; Klier, K.; Gaffney, T. S.; Kirner, J. G., Chem. Mater. 14 (2002) 4807.

10. Breck, D. W., “Zeolite Molecular Sieves: Structure, Chemistry, and Use,” Wiley, NY (1974) p. 389.

11. Herman, R. G.; Khouri, F. H.; Klier, K.; Higgins, J. B.; Galler, M. R.; Terenna, C. R., J. Catal. 228 (2004) 347.

12. SPARTAN, ver. 3.1, Wavefunction, Inc., Irvine, CA, USA.

13. Becke, A. D., Phys. Rev. A 38 (1988) 3098.

14. Perdew, J. P., Phys. Rev. B 33 (1986) 8822.

15. The $\mathrm{DN}^{* *}$ basis set uses polarization functions for hydrogen, is equivalent in performance to Gaussian 6-31G**, and its construction follows that in Delley, B., $J$. Chem. Phys. 92 (1990) 508 (Wavefunction, Inc., private communication).

16. Ma, Q.; Klier, K.; Herman, R. G., In $74^{\text {th }}$ ACS Colloid and Surface Science Symposium, Lehigh University, Bethlehem, PA (2000) Abstract p 196.

17. Klier, K., Topics Catal. 18 (2002) 141.

18. Barrett, E. P., Joyner, L. G.; Halenda, P. P., J. Am. Chem. Soc. 73 (1951) 373.

19. Gregg S. J.; Sing, K. S. W., “Adsorption, Surface Area, and Porosity,” Academic Press, London (1967), pp 160-172.

20. Kruk, M;. Jaroniec, M.; Ko, C. H.; Ryoo, R., Chem. Mater. 12 (2000) 1961.

21. Melero, J. A.; Stucky, G. D.; van Grieken, R.; Morales, G., J. Mater. Chem. 12 (2002) 1664. 


\section{Publications in Journals Resulting to-date from this Research:}

"Ion Exchange, Core-Level Shifts, and Bond Strengths in Mesoporous Solid Acid SBA-15," J. L. Smith, R. G. Herman, and K. Klier, in "Molecular Sieves: From Basic Research to Industrial Applications" (Studies in Surface Science and Catalysis, Vol. 158A), ed. by J. Čejka, N. Žilková, and P. Nachtigall, Elsevier, Amsterdam, 797-804 (2005).

"SBA-Catalyzed Synthesis of Ethers from Alcohols," S. S. Hasan, R. G. Herman, and K. Klier, in "Molecular Sieves: From Basic Research to Industrial Applications" (Studies in Surface Science and Catalysis, Vol. 158B), ed. by J. Čejka, N. Žilková, and P. Nachtigall, Elsevier, Amsterdam, 1343-1350 (2005).

"Spectroscopic Studies of Zeolites and Mesoporous Materials," K. Klier, in "Zeolites and Ordered Mesoporous Materials: Progress and Prospects" (Studies in Surface Science and Catalysis, Vol. 158B), ed. by J. Čejka and H. van Bekkum, Elsevier, Amsterdam, 205-224 (2005).

"Dehydrocondensation of Alcohols to Form Ethers Over Mesoporous SBA-15 Catalyst," R. G. Herman, F. H. Khouri, K. Klier, J. B. Higgins, M. R. Galler, and C. R. Terenna, J. Catal. 228 (2004) 347-361.

"Sorption on Nitrogen Bases and XPS Study of Mesoporous Solid Acid SBA-15," J. L. Smith, R. G. Herman, C. R. Terenna, M. R. Galler, and K. Klier, J. Phys. Chem. A 108 (2004) 39-46.

"Sulfonic Acid-Functionalized Mesoporous Silica: Synthesis, Characterization, and Catalytic Reaction of Alcohol Coupling to Ethers," J. G. C. Shen, R. G. Herman, and K. Klier, J. Phys. Chem. B 106 (2002) 9975-9978.

"The Transition State in Heterogeneous Catalysis," K. Klier, Topics Catal. 18 (2002) 141156.

"Synthesis and Characterization of $\left[\mathrm{NaO}_{3} \mathrm{SOCH}_{2} \mathrm{CH}_{2} \mathrm{OSO}_{3} \mathrm{Na}\right]$ and its Anchored Form, the Surface-Grafted Acid Groups on Zirconium Hydroxide," J. G. C. Shen, T. H. Kalantar, R. G. Herman, J. E. Roberts, and K. Klier, Chem. Mater. 13 (2001) 4479-4485. 